\title{
Gas Phase Formation, Structure and Reactivity of Gold Cluster Ions
}

\author{
Athanasios Zavras, George N. Khairallah, and Richard A.J. O'Hair
}

\begin{abstract}
With the advent of electrospray ionisation (ESI) and matrix-assisted laser desorption ionisation (MALDI), mass spectrometry (MS) is now routinely used to establish the molecular formulae of gold nanoclusters (AuNCs). ESI-MS has been used to monitor the solution phase growth of AuNCs when gold salts are reduced in the presence of phosphine or thiolate ligands. Beyond this analytical role, over the past 2 decades MS-based methods have been employed to examine the fundamental properties and reactivities of AuNC ions. For example, ion mobility and spectroscopic measurements may be used to assign structures; thermochemical data provides important information on ligand binding energies; unimolecular chemistry can be explored; and ion-molecule reactions with various substrates can be used to probe catalysis by AuNC ions. MS can also be used to monitor and direct the synthesis of AuNC bulk material either by guiding solution phase synthesis conditions or by soft landing a beam of mass-selected (i.e. monodisperse) AuNC ions onto a surface. This review showcases all areas in which mass spectrometry has played a role in AuNC science.
\end{abstract}

Keywords Catalysis · Gas-phase reactions · Gold nanoclusters · Mass spectrometry · Spectroscopy $\cdot$ Synthesis

\section{Contents}

1 Introduction

1.1 Why Are Clusters Interesting?

1.2 Why Are Gold Clusters Interesting?

1.3 Definition of a Gold Cluster Ion

1.4 Scope of the Review

A. Zavras, G.N. Khairallah, and R.A.J. O'Hair (四)

School of Chemistry, University of Melbourne, Parkville, VIC 3010, Australia

e-mail: rohair@unimelb.edu.au 
2 MS-Based Analysis of Gold Nanoclusters Synthesised in the Condensed Phase

2.1 The Need for Net Charge to Allow for Analysis of Gold Nanoclusters via MS

2.2 Top-Down and Bottom-Up Approaches for the Synthesis of Gas-Phase Gold Nanoclusters

2.3 Thiolate Ligands

2.4 Phosphine Ligands

2.5 MS-Based Fragmentation Methods for the Production of Gas-Phase Gold Cluster Ions

2.6 Formation of Carbides, Hydroxides, Phosphides and Tellurides from Miscellaneous Top-Down Approaches

3 Tools for Determining Structures and Their Application to Gold Cluster Ions

3.1 MS-Based Fragmentation Methods

3.2 Ion Mobility

3.3 IR Spectroscopy

3.4 UV-Vis Spectroscopy

3.5 Trapped Ion Electron Diffraction

3.6 Photoelectron Spectroscopy

3.7 Thermochemistry

4 Reactivity of Gold Cluster Ions

4.1 Reactions of Bare Gold Cluster Ions: Overview

4.2 Ligated Gold Cluster Ions

4.3 Gold-Containing Bimetallic Cluster Ions

4.4 Catalysis by Gold Cluster Ions

5 From the Gas Phase to Materials

5.1 MS-Directed Synthesis of Gold Clusters

5.2 MS-Selected Deposition of Gold Cluster Ions

6 Conclusions

References

\section{Abbreviations}

2D Two-dimensional

3D Three-dimensional

AuNP Gold nanoparticle

BINAP $( \pm)$-2,2'-Bis(diphenylphosphino)-1,1'-binapthylene

BTBC Borane tert-butylamine complex

CID Collision-induced dissociation

$\mathrm{ClAuPPh}_{3} \quad$ Chlorotriphenylphosphinegold(I)

DFT Density functional theory

DLS Direct light scattering

DMA Differential mobility analysis

DMG $\quad N, N$-Dimethylglycine

DMSO Dimethylsulfoxide

dppe 1,2-Bis(diphenylphosphino)ethane

dppm Bis(diphenylphosphino)methane

dppp 1,3-Bis(diphenylphosphino)propane OR 1,5-Bis(diphenylphosphino) pentane

EA Electron affinity

EI Electron ionisation 


$\begin{array}{ll}\text { EID } & \text { Electron-induced dissociation } \\ \text { ESI } & \text { Electrospray ionisation } \\ \text { eV } & \text { Electron volt } \\ \text { FAB } & \text { Fast atom bombardment } \\ \text { FT } & \text { Fourier transform } \\ \text { ICP } & \text { Inductively coupled plasma } \\ \text { ICR } & \text { Ion cyclotron resonance } \\ \text { IMS } & \text { Ion mobility spectrometry } \\ \text { IR } & \text { Infrared } \\ \text { K } & \text { Kelvin } \\ \text { MALDI } & \text { Matrix-assisted laser desorption ionisation } \\ \text { MPC } & \text { Monolayer-protected cluster } \\ \text { MS } & \text { Mass spectrometry } \\ \text { MS } & \text { Tandem mass spectrometry } \\ \text { NC } & \text { Nanocluster } \\ \text { nm } & \text { Nanometre } \\ \text { NMR } & \text { Nuclear magnetic resonance } \\ \text { PD } & \text { Photodissociation } \\ \text { PES } & \text { Photoelectron spectroscopy } \\ \text { RRKM } & \text { Rice-Ramsperger-Kassel-Marcus } \\ \text { SAM } & \text { Self-assembled monolayer } \\ \text { SEC } & \text { Size exclusion chromatography } \\ \text { SIMS } & \text { Secondary ion mass spectrometry } \\ \text { SORI } & \text { Sustained off-resonance irradiation } \\ \text { THF } & \text { Tetrahydrofuran } \\ \text { TIED } & \text { Trapped ion electron diffraction } \\ \text { TOF } & \text { Time of flight } \\ \text { TS } & \text { Transition state } \\ \text { UV-Vis } & \text { Ultraviolet visible } \\ & \end{array}$

\section{Introduction}

\subsection{Why Are Clusters Interesting?}

As Castleman and Jena have previously noted [1], clusters are interesting since they (1) 'bridge phases as well as disciplines', including the studies of (a) the environment, materials science and biology [2] and (b) physics and chemistry [3] and (2) 'have come to symbolize a new embryonic form of matter that is intermediate between atoms and their bulk counterpart' [1]. For some time the motivation to study clusters was to model bulk behaviour by assuming that their properties vary smoothly as some power law until they reach the bulk limit. It has now become well appreciated that for certain cluster size regimes, the properties of materials can change in a highly non-monotonic fashion [3]. Thus the new motivation has 
become to control the size and shape of these cluster materials so that their properties can be controlled for novel material and catalytic applications.

\subsection{Why Are Gold Clusters Interesting?}

There are at least two reasons why there has been intense interest in gold clusters: (1) they serve as models for structure and bonding of cluster compounds [4-9], a topic further elaborated in [10] ("Theoretical studies on gold clusters and nanoparticles'). (2) Seminal work by Bond [11], Hutchings [12], Haruta [13] and others [14-16] in the 1970s and 1980s in the field of heterogeneous catalysis led to a paradigm shift by showing that gold, the noblest of all metals, can be turned into a highly active catalyst simply by reducing its dimensions to a few nanometres [13]. Examples of catalytic reactions that were discovered include hydrogenation of alkenes (Eq. (1)) [11], hydrochlorination of acetylene (Eq. (2)) [12] and oxidation of CO (Eq. (3)) [13]. Finally, it has been recognised for some time that homogenous catalysis may give rise to nanoparticles that maybe the actual catalysts [17]. Indeed a recent report by Corma et al. [18] has highlighted that such nanoclusters can be highly reactive catalysts for the ester-assisted addition of water to alkynes (Eq. (4)), with turnover numbers of ten million [19].

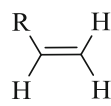

$\mathrm{H}-\mathrm{C} \equiv \mathrm{C}-\mathrm{H}$

$$
\mathrm{C}=\mathrm{O}
$$<smiles>[R]C(=O)Cl</smiles><smiles>C#CC(C)(C)O</smiles>

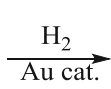<smiles>[R]C([2H])C</smiles>

$\underset{\mathrm{Au} \mathrm{cat}}{\stackrel{\mathrm{HCl}}{\longrightarrow}}$<smiles>C=CCl</smiles>

\subsection{Definition of a Gold Cluster Ion}

A diverse range of scientists have been involved in the study of clusters, which has given rise to a 'Tower of Babel' of other terms for clusters, including colloids, Q-particles, quantum dots, nanoparticles, grains, aerosols, hydrosols, dust, foam, non-covalent complexes, supramolecular complexes, protein assemblies, etc. Johnston [20] suggests that the earliest scientific reference to clusters may have been made by Robert Boyle in 1661, when he wrote of ' . . . minute masses or clusters ... as were not easily dissipable into such particles as compos'd them' [21]. Since then, the word 'cluster' has been commonly used by physicists, chemists and mass 
spectrometrists. Each group has their own definition of a cluster (The old IUPAC mass spectrometry definition of a cluster is as follows: An ion formed by the combination of more ions or atoms or molecules of a chemical species often in association with a second species: [22]), ${ }^{1,2}$ and these definitions can be further expanded to include the types of chemical bonding that 'holds the cluster together' [23]. The most recent recommended IUPAC definition of a cluster ion in mass spectrometry is an 'Ion formed by the combination via non-covalent forces of two or more atoms or molecules of one or more chemical species with an ion' [24], and thus this definition encompasses a wide range of ions formed from chemical and biological sources and also across all the types of bonding.

Further distinctions have been made in the literature based on size and other criteria:

1. An encyclopaedia article [25] has classified clusters as

(a) 'Microclusters having from 3 to 10-13 atoms. Concepts and methods of molecular physics are applicable';

(b) 'Small clusters have from 10 to 13 to about 100 atoms. Many different geometrical isomers exist for a given cluster size with almost the same energies. Molecular concepts lose their applicability';

(c) 'Large clusters have from 100 to 1,000 atoms. A gradual transition is observed to the properties of the solid state. Small nanoparticles and nanocrystals have at least 1,000 atoms. These bodies display some of the properties of the solids state'.

2. Kreibig and Vollmer have defined metal clusters by the number, $N$, of atoms per cluster as being:

(a) 'very small clusters' fall in the range $2<N \leq 20$;

(b) 'small clusters' are those where $20 \leq N \leq 500$;

(c) 'larger clusters' span a substantial range of sizes: $500 \leq N \leq 10^{7}$ [26].

3. Ott and Finke have made an important distinction between transition-metal nanoclusters and colloids: 'nanoclusters are expected to be smaller (1-10 nm)

\footnotetext{
${ }^{1}$ The IUPAP does not appear to have a formal definition of a cluster. Johnston [20] suggests the following 'physics' definition of clusters: I will take the term cluster to mean an aggregate of a countable number (2-10n, where $\mathrm{n}$ can be as high as 6 or 7 ) of particles (i.e. atoms or molecules). The constituent particles may be identical, leading to homo-atomic (or homo-molecular) clusters, $\mathrm{Aa}$, or they can be two or more different species - leading to hetero-atomic (hetero-molecular) clusters $\mathrm{AaBb}$.

${ }^{2}$ The IUPAC inorganic chemistry definition of cluster is as follows: A number of metal centres grouped close together which can have direct metal bonding interactions or interactions through a bridging ligand, but are not necessarily held together by these interactions. See IUPAC. Compendium of Chemical Terminology, 2nd ed. (the "Gold Book"). Compiled by A. D. McNaught and A. Wilkinson. Blackwell Scientific Publications, Oxford (1997). XML online corrected version: http://goldbook.iupac.org (2006) created by M. Nic, J. Jirat, B. Kosata; updates compiled by A. Jenkins. ISBN 0-9678550-9-8. doi:10.1351/goldbook.
} 
with near-monodisperse size distributions $(\leq 15 \%)$, while colloids are often $>10 \mathrm{~nm}$ with much broader size distributions' [27].

Since there are limits on many mass analysers used in mass spectrometry-based approaches to the study of gold cluster ions, in this chapter we take as our definition of a gold cluster ion:

A cluster containing 2 or more gold atoms and up to 1,000 atoms that has an ovall negative or positive charge. The cluster can be either a 'bare gold cluster' or a 'ligated gold cluster'.

\subsection{Scope of the Review}

There have been a number of general reviews on gas-phase cluster ions [28-32] as well as reviews on gold cluster ions [33, 34]. This review focuses on literature reports that utilise mass spectrometry (MS): (1) as a key analytical tool to examine the formation and reactions of gold clusters; (2) as basic methods to study the structure, properties and reactivity of gold cluster ions in the gas phase and (3) as a way of soft landing gold cluster ions onto surfaces to generate catalysts.

All mass spectrometers consist of: (1) an ionisation source to generate ions in or to transfer ions to the gas phase, (2) a mass analyser to separate ions according to their mass to charge ratio $(\mathrm{m} / \mathrm{z})$, (3) a detector to 'count' the number of ions at each $\mathrm{m} / \mathrm{z}$ value and (4) a data processor/recorder [35]. The development of matrixassisted laser desorption (MALDI) and electrospray ionisation (ESI) has revolutionised the analysis and study of inorganic and organometallic complexes and nanoclusters via mass spectrometry [36]. MALDI and ESI have been coupled to a range of mass analysers, and the resultant mass spectrometers are commonly used in the analysis of metal clusters. The mode of operation and the 'figures of merit' of the various types of mass analysers available are not discussed here - readers are referred to an excellent review [37].

There are many potential combinations of ionisation source and mass analyser that can be used for fundamental studies, but these are not discussed in any detail here. The most widely used mass spectrometers in gold cluster ion studies over the past decades have been ion cyclotron resonance (ICR) mass spectrometers (including their Fourier transform variants) [38-40], triple quadrupole mass spectrometers [41, 42], flowing afterglow reactors [43] and ion-trap mass spectrometers [44].

While computational chemistry plays a key role in supporting many experimental studies on the structure and reactivity of gold clusters, papers solely dealing with theoretical calculations are largely neglected except where they shed important insights into prior experimental work.

The structure and reactivity of neutral gold clusters have also been studied in the gas phase (see Sect. 3.3). Readers interested in this topic should also refer to recent work on the absorption of CO onto silver-doped gold clusters [45] and the oxidation 
of neutral gold carbonyl clusters by $\mathrm{O}_{2}$ and $\mathrm{N}_{2} \mathrm{O}$ [46] together with the reviews on neutral metal clusters by Knickelbein [47] and Shi and Bernstein [48].

Finally, while there are a growing number of reports on the use of gold nanoparticles as a co-additive in the analysis of low molecular weight compounds by laser desorption ionisation MS [49-53], these are not reviewed here.

\section{MS-Based Analysis of Gold Nanoclusters Synthesised in the Condensed Phase}

Historically, mass spectrometry-based analysis of gold cluster compounds has lagged behind other methods such as X-ray crystallography due to traditional ionisation methods such as electron ionisation or chemical ionisation being incompatible with compounds of low volatility. It appears that the first analytical studies of gold cluster compounds had to wait until the advent of fast atom bombardment (FAB) [54], which allowed transfer of gold cluster cations such as $\left[\mathrm{Au}_{6}\left(\mathrm{PPh}_{3}\right)_{6}\right]^{2+}$ to the gas phase [55].

\subsection{The Need for Net Charge to Allow for Analysis of Gold Nanoclusters via MS}

While MALDI-MS and ESI-MS have been a boon for the analysis of metal complexes and clusters, these ionisation methods are challenged by compounds that have no net charge. For inorganic and organometallic complexes, a number of strategies have been developed to overcome this limitation: (1) neutral metal halides can have a halide anion replaced with a neutral ligand such as pyridine, resulting in a MS detectable cationic complex [36]; (2) neutral ligands can be swapped for related fixed charge analogues [56]; (3) addition of acids or bases can allow protonation or deprotonation of coordinated ligands, thereby providing a positive or negative charge [36]; (4) oxidation to form a charged complex in which the metal centre is in a higher oxidation state [36]; (5) addition of a metal ion such as $\mathrm{Ag}^{+}$to form a coordination complex [36] and (6) carbonyl derivatisation of neutral metal carbonyls by alkoxides, azides and hydrides [36].

Gold NCs that have been synthesised in solution and then subjected to analysis via ESI or MALDI can be considered to have the following general formula given in Eq. (5):

$$
\left[\mathrm{Au}_{a}^{(0)} \mathrm{Au}_{b}^{(+1)} \mathrm{L}_{c} \mathrm{~A}_{d}^{(-1)}-n \mathrm{H}^{+}\right]^{z}
$$

where $\mathrm{L}$ is a neutral ligand such a phosphine or bisphosphine and $\mathrm{A}$ is an anionic ligand such as a thiolate or halide. 
a

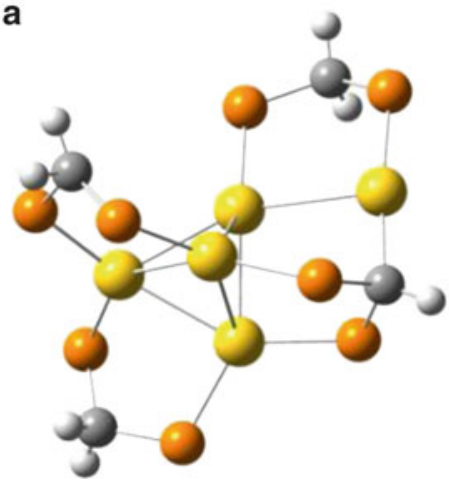

c

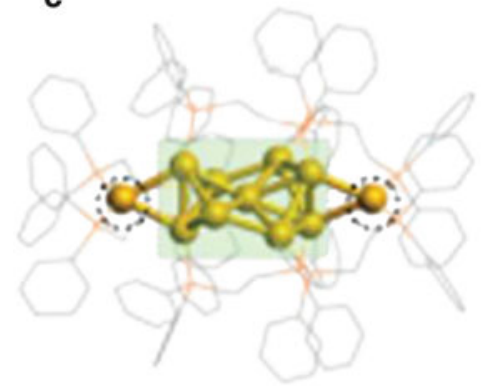

b

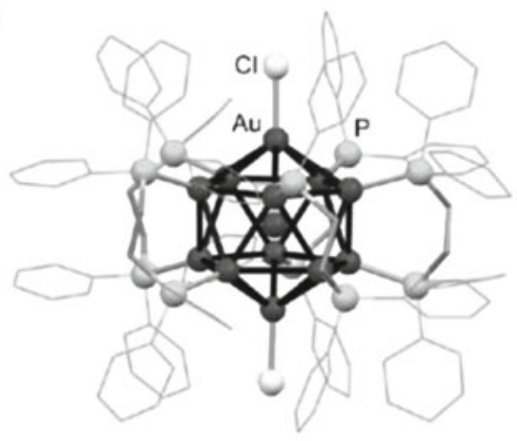

d

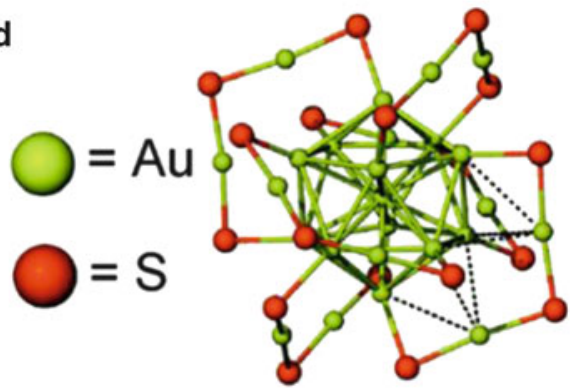

Fig. 1 Examples of charged AuNCs that fit the $\left[\mathrm{Au}^{(0)}{ }_{a} \mathrm{Au}^{(+1)}{ }_{b} \mathrm{~L}_{c} \mathrm{~A}^{(-1)}{ }_{d}-n \mathrm{H}^{+}\right]^{z}$ formulation and that have been analysed by both MS and X-ray crystallography: (a) $\left[\mathrm{Au}_{5}(\mathrm{dppm})_{4}-\mathrm{H}^{+}\right]^{2+}$ (where $a=2 ; b=3 ; c=4 ; n=1 ; z=+2)[57] ;(\mathbf{b})\left[\mathrm{Au}_{13}(\mathrm{dppe})_{5} \mathrm{Cl}_{2}\right]^{3+}($ where $a=8 ; b=5 ; c=5$; $d=2 ; z=+3$ ) [58]; (c) $\left[\mathrm{Au}_{11}(\mathrm{dppe})_{6}\right]^{3+}$ (where $a=8 ; b=3 ; c=6 ; z=+3$ ) [59] and (d) $\left[\mathrm{Au}_{25}\left(\mathrm{SCH}_{2} \mathrm{CH}_{2} \mathrm{Ph}\right)_{18}\right]^{+}$(where $a=6 ; b=19 ; d=18 ; z=+1$ ) [60]. Non-coordinating counter ions are omitted for clarity. Figures reproduced from (a) [57]; (b) [58]; (c) [59]; (d) [60]

Thus the net charge of the NC is given by Eq. (6):

$$
z=b(+1)+d(-1)-n
$$

Note that either L or A can be deprotonated to add a negative charge to the NC.

Figure 1 highlights some of the isolated charged AuNCs that have been structurally characterised by both X-ray crystallography and MS. The NC $\left[\mathrm{Au}_{5} \mathrm{~L}^{1}{ }_{4}-\mathrm{H}\right]^{2+}$ (Fig. 1a) is interesting as it possesses a tetrahedral gold core with an exopolyhedral $\mathrm{Au}\left(\mathrm{CH}\left(\mathrm{PPh}_{2}\right)_{2}\right)$ moiety formed via deprotonation of the dppm at the methylene carbon.

Some of the strategies listed above for the manipulation of inorganic and organometallic compounds that have no net charge have also been applied to AuNCs that have no net charge. Most examples are for AuNCs with thiolate ligands: (1) thiolate ligand possessing acidic protons can be further deprotonated, 
a

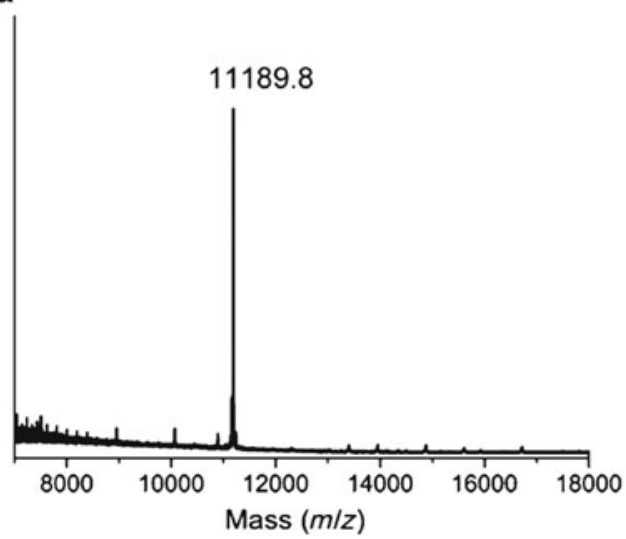

b

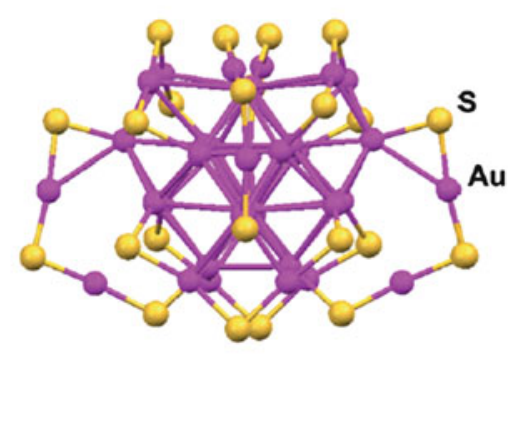

Fig. 2 Example of a neutral AuNC that has been analysed via MS: (a) ESI-MS Cs ${ }^{+}$adduct of $\mathrm{Au}_{36}(\mathrm{SPh}-\mathrm{Bu})_{34} ;\left(\right.$ b) crystal structure highlighting the $\mathrm{Au}_{36} \mathrm{~S}_{24}$ framework. Figure reproduced from [61]

as highlighted for glutathione ligands, which produce anionic NCs; (2) ESI-MS of caesium acetate-doped solutions of $\mathrm{Au}_{36}(\mathrm{SPh}-t \mathrm{Bu})_{24}$ give rise to cationic caesium adducts (Fig. 2a) [61].

The recent gold cluster literature can largely be divided into two classes based on the capping ligands used:

1. Thiolate ligands: these anionic ligands often produce neutral clusters that make them challenging to analyse via mass spectrometry. Nonetheless, there are quite a few examples of MALDI/MS and ESI-MS being used to examine their formation and size distributions. Since this area has been reviewed in 2010 [33], only subsequent work is briefly described below.

2. Phosphine ligands: these neutral ligands allow the ready identification of charged cationic gold nanoclusters via ESI-MS. Clusters capped by either monophosphines or bisphosphines (monodentate or bidentate phosphine ligands) have been studied. The latter exhibit interesting size-selectivity effects, as discussed in detail in the following sections.

\subsection{Top-Down and Bottom-Up Approaches for the Synthesis of Gas-Phase Gold Nanoclusters}

The techniques developed to study bare and ligated gold cluster ions in the gas phase fall into the same two categories, Fig. 3, as identified by Ott and Finke [27] for solution phase studies of clusters: 


\section{a Top-down}

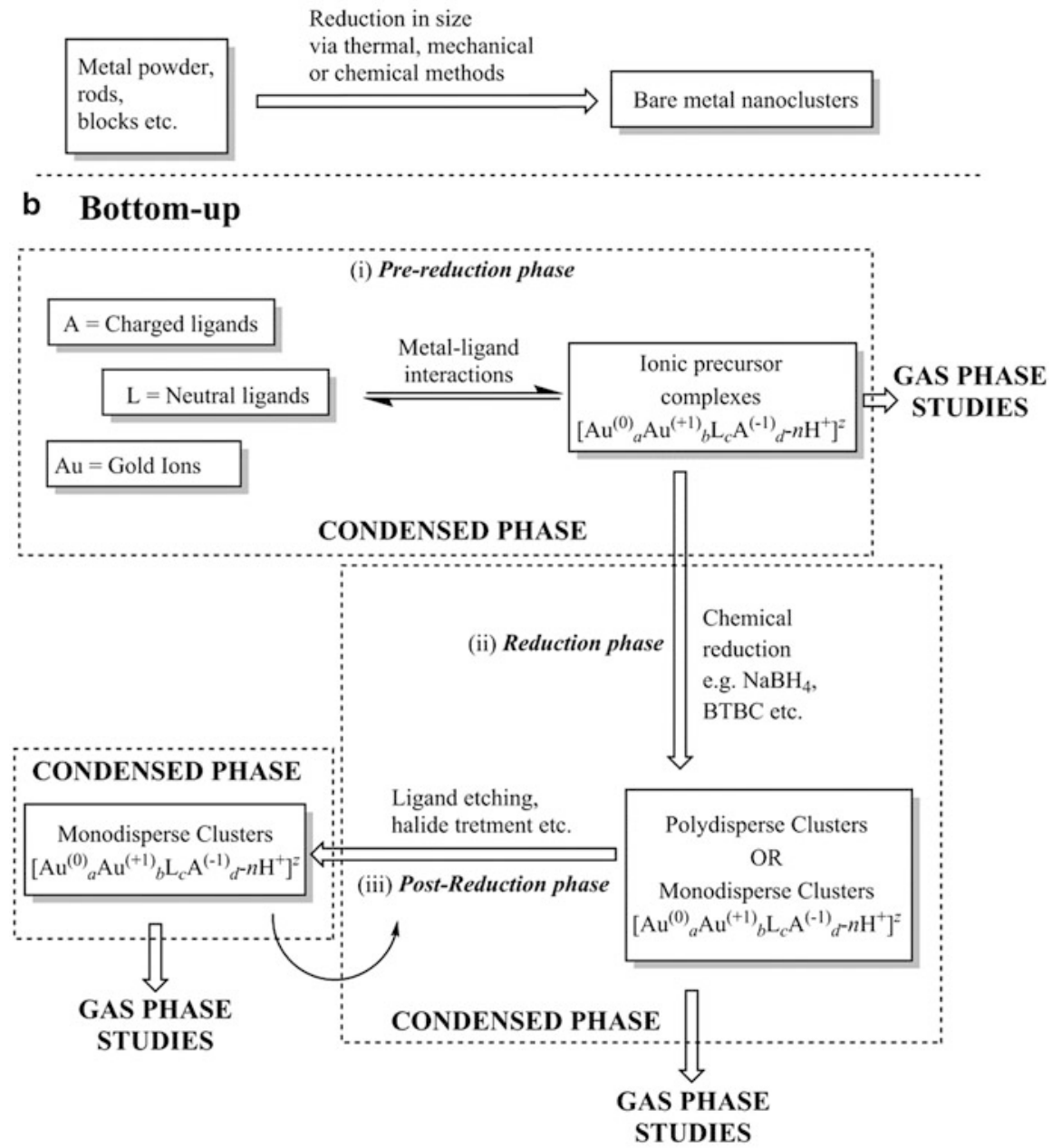

Fig. 3 The two general techniques used to synthesise nanoclusters are (a) the 'top-down' approach and (b) the 'bottom-up' approach

1. The 'top-down' approach utilises bulk material (metal powder, rods, blocks, etc.) which is broken down by physical methods to smaller architectures on the nanometre scale. Methods that have been applied to the synthesis of gold nanoclusters following the 'top-down' approach include lithographic techniques [62, 63], mechanical methods such as ball milling [64], thermal methods such as laser ablation vaporisation [65-67] and chemical methods such as ligand etching [68-70]. Issues concerning the top-down approach include difficulties with reproducibility, polydispersity and the need to require mechanical equipment and instrumentation which may add time and costs to the synthesis. 
De Heer has reviewed a range of top-down methods available for the production of gas-phase metal cluster ions [71]. Of these, the laser vaporisation cluster source, also known as the 'Smalley source', has been commonly used for the production of gas-phase clusters for over 30 years [72]. Indeed this method has been most widely used to generate bare gold cluster ions in the gas phase. Readers interested in the design and operational aspects of these laser vaporisation cluster source should refer to an excellent recent review by Duncan [72].

2. The 'bottom-up' approach involves chemical methods whereby a metal salt or complex, in the presence of an appropriate chelating ligand, is reduced to form ligand-protected metal nanoclusters. Reduction commonly occurs via treatment with a chemical reducing agent such as sodium borohydride, borane tertbutylamine complex and citrate [73]. The addition of chemical reducing agents to gold ions in solution provides a source of electrons whereby neutral gold atoms are formed. When the onset of reduction occurs in the presence of an appropriate chelating ligand, such as a phosphine or thiolate, the aggregation of neutral gold atoms to bulk material is perturbed by the properties of the ligand in a given environment. Size selectivity of a ligand is an inherent property that can be optimised experimentally by varying factors such as the temperature, stir rate, concentration, solvent, etc.

Gold cluster synthesis via the bottom-up method requires a deep understanding of the assembly processes, governed by the interactions of the atomic and molecular components, that leads to the formation of stable and monodisperse nanoclusters [74-77]. This can lead to the rational design and fine tuning of the AuNCs architecture. Although the bottom-up method is seen as the inverse method to the top-down approach, it may also be used in addition to top-down techniques [78] in particular via processes that involve ligand etching. There is a growing awareness that there are three phases associated with AuNC synthesis via the bottom-up method and that ESI-MS can be used to examine ionic species present during these phases (Fig. 3b):

1. Pre-reduction phase: To provide insight into the fundamental processes that govern the formation of nanoclusters it is important to establish the identity and relative abundance of ionic complexes that exist in solution before the initiation of chemical reduction. These complexes are the 'molecular building blocks' that can then interact to form particles of well-defined stoichiometry upon reduction. ESI-MS has been used to examine the identity and relative abundance of the cationic precursors that spontaneously assemble in solution prior to reduction.

2. Reduction phase: A key step in the synthesis of AuNCs in the condensed phase involves the use of chemical reducing agents. Reducing agents which are routinely used for AuNCs are sodium borohydride $\left(\mathrm{NaBH}_{4}\right)$, a fast reducing agent, and borane tert-butylamine complex (BTBC), a comparatively slow reducing agent. Subsequently, ESI-MS can be used to monitor the abundance and identity of AuNC ions present in solution over time from the onset of reduction. This provides a tool to monitor reactive cluster intermediates, 
potentially revealing the reaction mechanisms that result in the formation of the final product distribution of AuNCs.

3. Post-reduction phase: ESI-MS can be used to monitor gold cluster reactions after the exhaustion of chemical reducing agents. Processes such as ligand etching and exchange will govern the formation or transformation of clusters to reach the final thermodynamically stable product(s). These products can be further transformed via the addition of other reagents such as $\mathrm{HCl}$.

The bottom-up approach has been widely used to synthesise ligand-protected gold NCs. There are numerous reports which have examined a range of ligands, solvents, concentrations and many other experimental conditions. Here we solely focus on literature reports in which ESI-MS and MALDI-MS have been used as a key tool to monitor the formation and reactions of gold nanoclusters.

\subsection{Thiolate Ligands}

A great deal of attention has been invested into the formation of monodisperse thiolate-protected nanoclusters, and several reviews described their synthesis and properties [79-83]. In 1994, Brust [84] first reported the synthesis of less than $5 \mathrm{~nm}$-sized alkanethiolate-protected gold nanoclusters by using sodium borohydride as a reducing agent. It was noted that these nanoclusters should exhibit intriguing properties due to quantum confinement effects. Since then, the synthetic method of Brust has been refined and optimised by numerous researchers. Here we consider literature reports which have dealt with the three phases of nanocluster growth described in Fig. 3.

\subsubsection{Pre-reduction Phase}

Briñas et al. [85] used direct light scattering (DLS), UV-Vis and size exclusion chromatography (SEC) studies to monitor how the size of thiolate-protected gold nanoparticles is dependent on the $\mathrm{pH}$-induced size of the gold(I)-thiolate precursor complex formed upon addition of glutathione to an aqueous solution of $\mathrm{HAuCl}_{4}$. Lower $\mathrm{pH}$ levels resulted in the formation of larger gold(I)-thiolate precursor complexes, which in turn gave rise to larger thiolate-protected gold nanoparticles upon reduction with sodium borohydride. In contrast, higher $\mathrm{pH}$ levels resulted in the formation of smaller gold(I)-thiolate complexes which resulted in the formation of smaller thiolate-protected gold nanoclusters upon addition of $\mathrm{NaBH}_{4}$.

Simpson et al. [86] used a modified Brust method [84] to study the identity and structure of gold(I)-thiolate precursors formed upon mixing $\mathrm{N}$-(2-mercaptopropionyl)-glycine (tiopronin) and $\mathrm{HAuCl}_{4}$. MALDI-TOF-MS analysis revealed the sole presence of a tetramer $\left[\mathrm{Au}_{4}(\mathrm{Tio})_{4}+\mathrm{Na}_{x}-\mathrm{H}_{x-1}\right]^{+}(x=1-4)$. A cyclic structure was proposed for this tetramer (Fig. 4a) due to the absence of other cluster 
Fig. 4 Proposed structures for the gold(I)-thiolate precursor showing (a) a discrete tetrameric gold(I)thiolate and (b) a straight chain gold(I)-thiolate polymer

Fig. 5 MALDI-TOF-MS of AuNPs using the DCTB matrix operating at threshold laser fluence. Figure reproduced from [87]
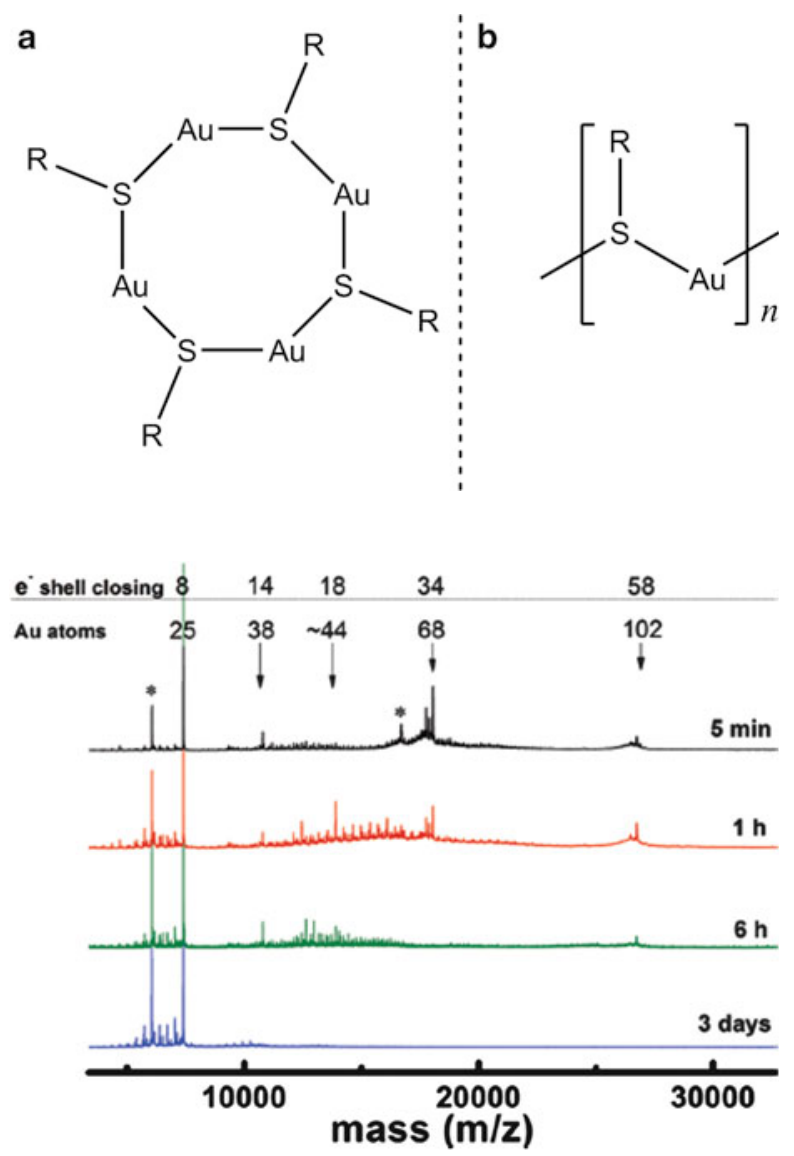

stoichiometries, which would otherwise indicate an open chain polymer structure (Fig. 4b).

\subsubsection{Reduction Phase}

Few reports have appeared on the use of MS to examine the evolution of thiolateprotected gold nanoclusters during the reduction phase. A rare example probed the size evolution to monodisperse $\mathrm{Au}_{25}\left(\mathrm{SCH}_{2} \mathrm{CH}_{2} \mathrm{Ph}\right)_{18}$ using MALDI-TOF-MS (Fig. 5) [87]. At approximately $5 \mathrm{~min}$ after the addition of sodium borohydride to a stirring solution of gold/phenylethanethiol (1:6) in THF, polydisperse ligandprotected AuNPs with the gold cores of $\mathrm{Au}_{25}, \mathrm{Au}_{38}, \mathrm{Au}_{44}, \mathrm{Au}_{68}$ and $\mathrm{Au}_{102}$ are observed. The $\mathrm{Au}_{68}$ ligand-protected cluster seems to act as an intermediate during the reduction phase, where its disappearance occurs between 1 and $6 \mathrm{~h}$. The $\mathrm{Au}_{102}$ ligand-protected cluster persists until at least $6 \mathrm{~h}$. 


\subsubsection{Post-reduction Phase}

Mass spectrometry has been used to monitor ligand exchange reactions of thiolateprotected gold nanoclusters. For example, Spivey et al. [88] used MALDI-TOF-MS to show that treatment of glutathione-protected nanoclusters with dodecanethiol $\left(\mathrm{SC}_{12} \mathrm{H}_{25}\right)$ results in the transformation to monodisperse $\mathrm{Au}_{38}\left(\mathrm{SC}_{12} \mathrm{H}_{25}\right)_{12}$. Bare $\mathrm{Au}_{38}$ clusters, formed via reduction of $\mathrm{Au}_{38}\left(\mathrm{SC}_{12} \mathrm{H}_{25}\right)_{12}$ by $\mathrm{H}_{2}$, were attached to $\mathrm{TiO}_{2}$ supports, and their role in catalysing $\mathrm{CO}$ oxidation was investigated.

Whetten et al. have used mass spectrometry to assign the number of ligands and gold atoms of synthesised thiolate-protected gold nanoclusters. For instance, they used ESI-MS to identify the various charge states of $\left[\mathrm{Au}_{144} \mathrm{Cl}_{60}\right]^{z}$. This cluster was synthesised from the well-known thiolate-protected cluster $\left[\mathrm{Au}_{144}(\mathrm{SR})_{60}\right]^{z}$ via ligand exchange with chloride [89]. They concluded that the $z=2$ and $4^{+}$charge states yielded a highly symmetric $\left(\mathrm{I}_{\mathrm{h}}\right)$ cluster. Mass spectrometry was also used in their study of the $\mathrm{Au}_{67}(\mathrm{SR})_{35}$ cluster via MALDI-TOF [90] as well as the study of $\left[\mathrm{Au}_{25}\left(\mathrm{SC}_{6} \mathrm{H}_{13}\right)_{18}\right]^{x}$ cluster via ESI-MS [91]. In this latter study, they concluded that geometric rather than electronic factors are responsible for the stability of $\left[\mathrm{Au}_{25}\left(\mathrm{SC}_{6} \mathrm{H}_{13}\right)_{18}\right]^{x}(x=-1,0,+1)$.

Recently, Jin et al. [92] used ESI-MS and UV-Vis spectroscopy to monitor the solution phase reactivity of monodisperse $\mathrm{Au}_{38}(\mathrm{PET})_{24},(\mathrm{PET}=$ phenylethanethiol $)$, with an excess of 4-tert-butylbenzenethiol (TBBT) and sampled at various time intervals, Fig. 6. The excess addition of the bulkier ligand TBBT ultimately results in the formation of monodisperse $\mathrm{Au}_{36}(\mathrm{TBBT})_{24}$.

Given the data in Fig. 6 the evolution of the thiol-induced $A_{36}(T B B T)_{24}$ from $\mathrm{Au}_{38}(\mathrm{PET})_{24}$ was divided into four stages (Fig. 7): (1) ligand exchange reactions of PET for TBBT occur, (2) ligand exchange reaction continues together with a structural distortion of the cluster core as observed by the optical spectra, (3) disproportionation reaction occurs as identified by ESI-MS whereby 2 equiv. of $\mathrm{Au}_{38}(\mathrm{TBBT})_{m}(\mathrm{PET})_{24-m}$ give $\mathrm{Au}_{36}(\mathrm{TBBT})_{m}(\mathrm{PET})_{24-m}$ and $\mathrm{Au}_{40}(\mathrm{TBBT})_{m+2}$ $(\mathrm{PET})_{24-m}$, and (4) size focusing occurs, resulting in the formation of monodisperse $\mathrm{Au}_{36}(\mathrm{TBBT})_{24}$.

\subsection{Phosphine Ligands}

Gold nanoclusters protected by phosphine ligands have been studied in the condensed phase since the pioneering work of Malatesta in the 1960s [93-97]. These early studies were motivated by the desire to develop models for cluster bonding and thus a key aim was the isolation of crystalline material suitable for X-ray diffraction studies [57, 98-108]. A significant achievement was the isolation and characterisation of a triphenylphosphine monolayer-protected clusters (MPCs) of monodisperse $\mathrm{Au}_{55}\left(\mathrm{PPh}_{3}\right)_{12} \mathrm{Cl}_{6}$ by Schmid [109-112]. In recent years ESI-MS has been used to monitor the role of bis(phosphino)alkane ligands of the type 

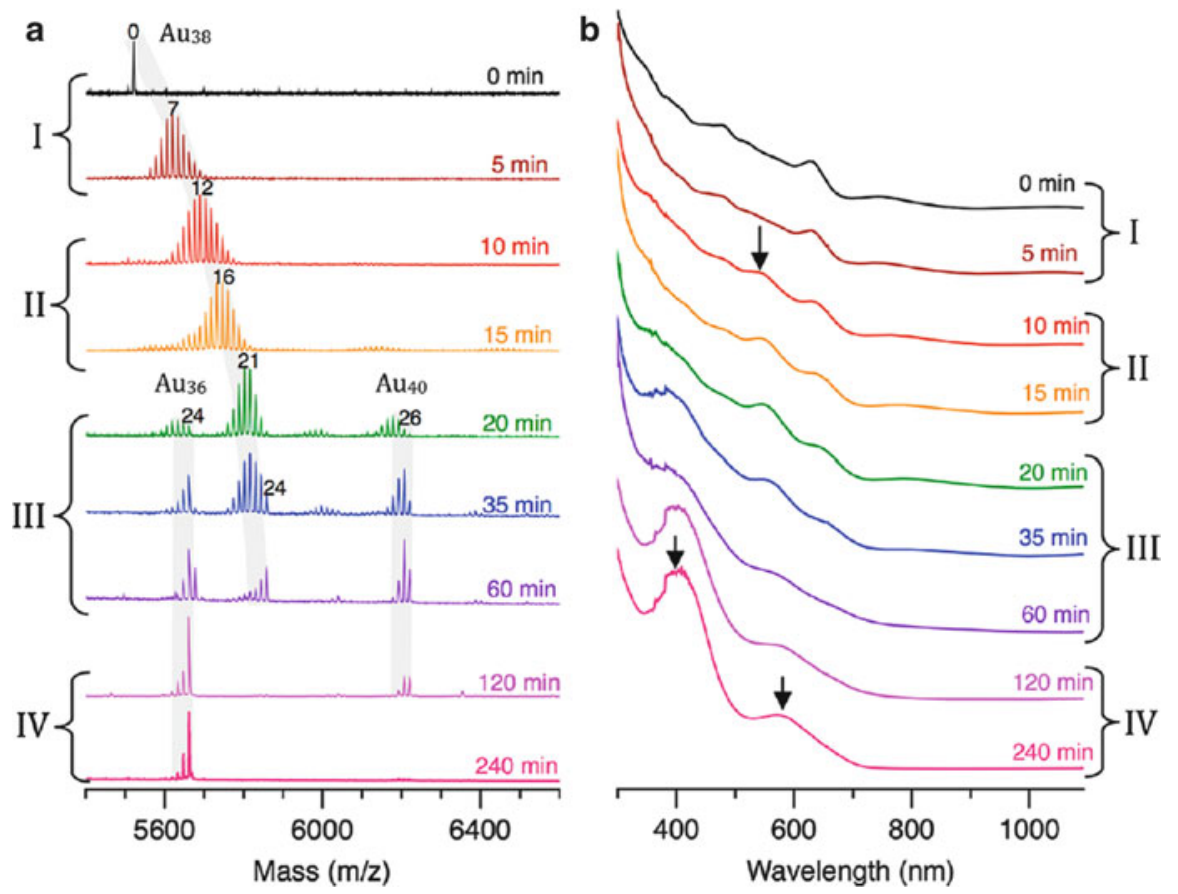

Fig. 6 (a) Time-dependent ESI-MS reaction of $\mathrm{Au}_{38}(\mathrm{PET})_{24}$ with excess TBBT. The doubly charged region is shown. The three grey shadows indicate three groups of peaks: (left) $\mathrm{Au}_{36}(\mathrm{TBBT})_{m}(\mathrm{PET})_{24-m},($ middle $) \mathrm{Au}_{38}(\mathrm{TBBT})_{m}(\mathrm{PET})_{24-m}$, and $($ right $) \mathrm{Au}_{40}(\mathrm{TBBT})_{m}(\mathrm{PET})_{24-m}$. The numbers on top of the mass peaks indicate the number of TBBT ligands $(m)$ exchanged onto the cluster; (b) corresponding UV-Vis spectra at different times taken parallel to the ESI-MS data. Figure reproduced from [92]

$\mathrm{Ph}_{2} \mathrm{P}-\left(\mathrm{CH}_{2}\right)_{n}-\mathrm{PPh}_{2}$, where $n=1-6$, in promoting the formation of 'size-selected' monodisperse clusters. Table 1 summarises the types of bis(phosphino)alkaneprotected gold clusters that have been observed by ESI-MS. From Table 1 it is evident that a variety of gold core nuclearities are observed, depending on the bisphosphine ligand used. This size selectivity correlates to the variation in the alkane chain of $\mathrm{Ph}_{2} \mathrm{P}-\left(\mathrm{CH}_{2}\right)_{n}-\mathrm{PPh}_{2}$, where $n=1-6$. In the next sections, literature reports which have dealt with the three phases of bisphosphine-protected nanoclusters growth are discussed.

\subsubsection{Pre-reduction Phase}

Colton et al. [143] were the first to use ESI-MS to monitor the ligand exchange reactions of $\mathrm{ClAuPPh}_{3}$ with various monodentate and bidentate phosphine ligands added at various concentrations. The aims of their study were to examine (1) the identity and abundance of gold(I) complexes that undergo ligand exchange and 


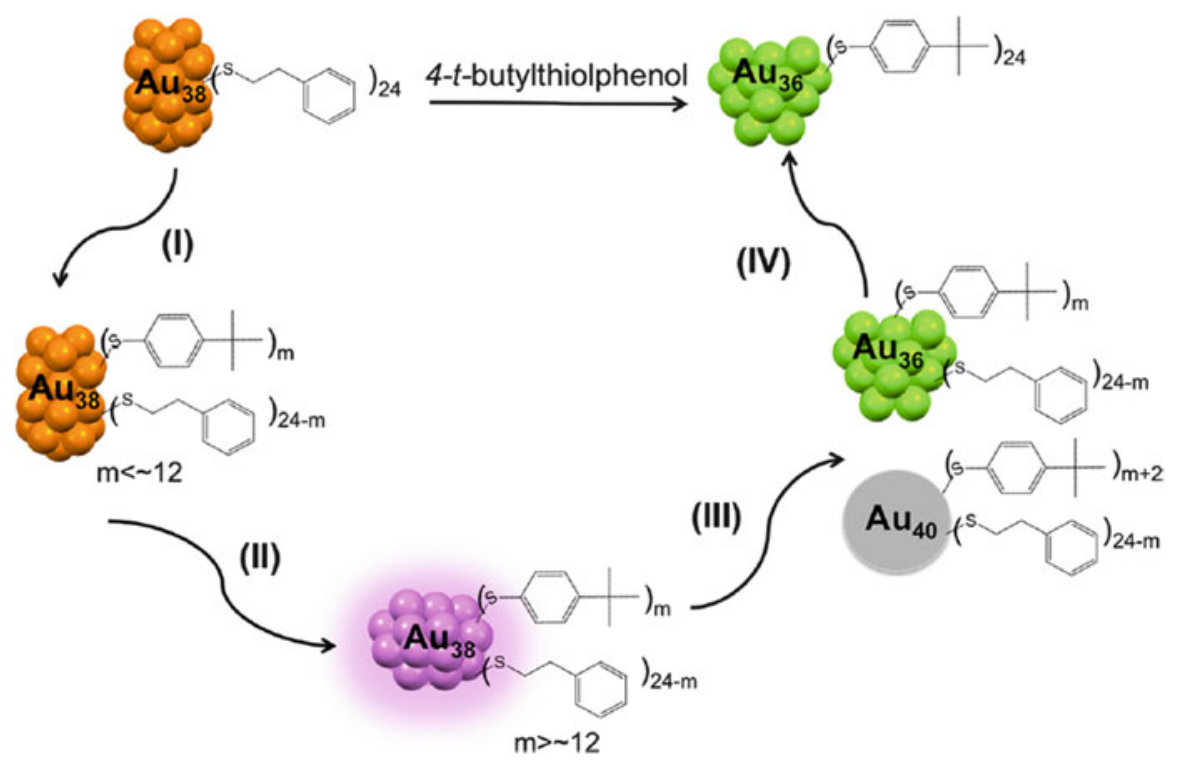

Fig. 7 'Reaction pathway for conversion of $\mathrm{Au}_{38}(\mathrm{PET})_{24}$ to $\mathrm{Au}_{36}(\mathrm{TBBT})_{24}$. Stage I, ligand exchange; Stage II, structure distortion; Stage III, disproportionation; Stage IV, size focusing'. Figure reproduced from [92]

Table 1 A comparison of the types of gold nanoclusters observed by ESI-MS which are formed via reduction of Au salts in the presence of bisphosphine ligand as a function of the ligand

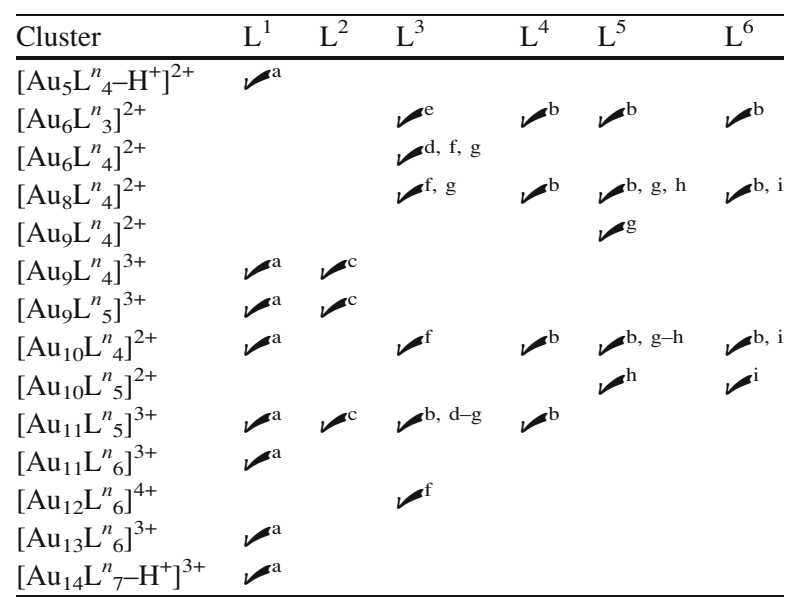

The letters a-i are used to denote the following references: (a) [113], (b) [114], (c) [58], (d) [115], (e) [116], (f) [117-139], (g) $[140],(\mathrm{h})[141]$ and (i) [142]. A $\varnothing$ indicates that the ion was observed (reported). A blank box indicates that the ion was not observed (not reported). $\mathrm{L}^{n}$ denotes the bisphosphine ligands, $\mathrm{Ph}_{2} \mathrm{P}-\left(\mathrm{CH}_{2}\right)_{n}-\mathrm{PPh}_{2}$, where $n=1-6$. Table reproduced from [113] 
Fig. 8 Representations of (a) singly charged mononuclear bis-ligated gold(I) complex $\left[\mathrm{AuL}_{2}\right]^{+}$ and (b) doubly charged dinuclear bis-ligated gold(I) complex $\left[\mathrm{Au}_{2} \mathrm{~L}_{2}\right]^{2+}$

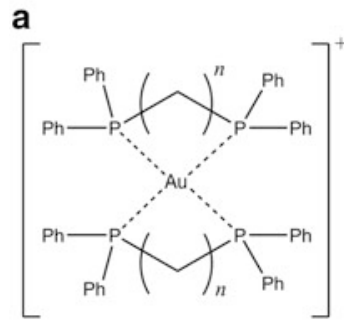

(2) the maximum number of ligands associated with gold(I) ions. For monodentate phosphines they observed the formation of $\left[\mathrm{Au}\left(\mathrm{PR}_{3}\right)_{n}\right]^{+}$, where $n=2$ and 3 but not 4. The studies provided evidence on the instability of a three coordinate monodentate phosphine complex, $\left[\mathrm{Au}\left(\mathrm{PPh}_{3}\right)_{3}\right]^{+}$consistent with previous solution phase NMR experiments [144, 145].

Subsequently Hudgens et al. [146] set out to systematically investigate the relationship between the types of AuNPs formed and the cationic ligand complexes of gold that exist in solution prior to treatment with the reducing agent. The series of bisphosphine ligands, $\mathrm{Ph}_{2} \mathrm{P}-\left(\mathrm{CH}_{2}\right)_{n}-\mathrm{PPh}_{2}$ where $n=1-6$, were proposed to form the mononuclear, bis-ligated complex shown in Fig. 8a. It was suggested that the ligand in the $\left[\mathrm{AuL}_{2}\right]^{+}$complex acts as a trap, protecting the bis-ligated gold(I) via the steric bulk of the ligand. This ultimately hinders the reduction and postreduction nucleation process as supported by previous studies [116]. The bridged dinuclear species, Fig. 8b, may be further stabilised by aurophilic interactions [147, 148].

Control of the pre-reduction phase is important in order to tailor the synthesis of AuNCs [113]. The undesirable $\left[\mathrm{Au}\left(\mathrm{PPh}_{3}\right)_{2}\right]^{+}$, known to be a precursor to colloid formation, could be minimised by the addition of 2 equiv. of the bis(diphenylphosphino)methane ligand. Reduction of the now enriched cationic precursors to nanocluster resulted in a polydisperse solution as monitored via ESI-MS and UVVis spectroscopy. Several of these clusters had not been previously described (Table 1).

In efforts to investigate how bidentate phosphine ligands control the "size selectivity' of gold NC formation, ESI-MS was used in a series of experiments to examine the role of ligand concentration relative to the gold salt concentration. The incremental addition of 1,6-bis(diphenylphosphino)hexane, $\left(\mathrm{L}^{6}\right)$, to a methanolic solution containing $10.0 \mathrm{mg}$ of $\mathrm{AuClPPh}_{3}$ was monitored via ESI-MS to observe the identity and abundance of cationic gold-ligand complexes that form prior to the addition of sodium borohydride [142].

The fractional total ion current of each 'pre-reduction' complex was plotted, Fig. 9, as a function of the various ratios of $\left[\mathrm{L}^{6}\right] /\left[\mathrm{PPh}_{3}\right]$, where $0 \leq\left[\mathrm{L}^{6}\right] /\left[\mathrm{PPh}_{3}\right]$ $\leq 16$. The aim was to monitor how the complexes formed during the "pre-reduction' phase determine the fate of the identity and abundance of AuNPs in solution. It was concluded that the ultimate formation of bisphosphine-protected clusters 


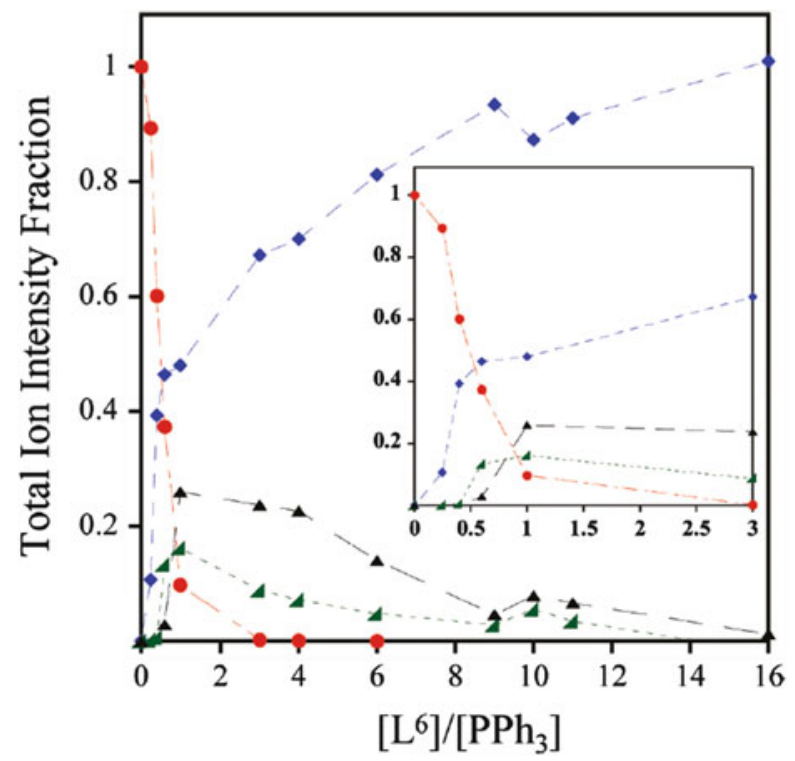

Fig. 9 Fractional total ion current measured via ESI-MS as a function of the ligand to $\mathrm{AuClPPh}_{3}$ ratio, $\left[\mathrm{L}^{6}\right] /\left[\mathrm{PPh}_{3}\right]$. Triphenylphosphine ligands are increasingly replaced on the metal complexes as $\mathrm{L}^{6}$ is added incrementally to a solution comprising $10.0 \mathrm{mg}$ of $\mathrm{AuClPPh}_{3}$ dissolved in chloroform/ methanol (50:50). The symbols are assigned as follows: red circles, $\left[\mathrm{Au}\left(\mathrm{PPh}_{3}\right)_{2}\right]^{+} ;$blue diamonds, $\left[\mathrm{Au}_{2} \mathrm{~L}_{2}^{6}\right]^{+}$; green wedges, $\left[\mathrm{Au}_{2} \mathrm{~L}_{2}^{6} \mathrm{Cl}\right]^{+}$; and black triangles, $\left[\mathrm{Au}_{2} \mathrm{~L}_{3}^{6} \mathrm{Cl}\right]^{+}$. The insert displays the fractional total ion current for $0 \leq\left[\mathrm{L}^{6}\right] /\left[\mathrm{PPh}_{3}\right] \leq 3$. Figure reproduced from [142]

observed via ESI-MS could be 'tuned' by the nature of the gold-ligand complex distribution prior to reduction. Figure 10 summarises the fractional product distribution of AuNPs as a function of $\left[\mathrm{L}^{6}\right] /\left[\mathrm{PPh}_{3}\right]$ and will be discussed in greater detail in Sect. 2.4.3.

\subsubsection{Reduction Phase}

In 2006 Wang et al. [149] used ESI-MS and UV-Vis spectroscopy to monitor the formation of AuNCs upon the slow reduction of $\mathrm{AuClPPh}_{3}$ in chloroform by the addition of 5 equiv. of BTBC. A range of $\mathrm{PPh}_{3}$-protected AuNC intermediates were observed by examining aliquots of the reaction at various time intervals. Their studies were extended to the reduction of $\mathrm{AuClPPh}_{3}$ in chloroform mixed with equimolar bisphosphine ligand $\mathrm{Ph}_{2} \mathrm{P}-\left(\mathrm{CH}_{2}\right)_{n}-\mathrm{PPh}_{2},=3-6$. It was concluded that the bidentate ligands showed exceptional size selectivity, Fig. 11, compared to the monodentate triphenylphosphine ligand. Monodisperse $\left[\mathrm{Au}_{11}\left(\mathrm{~L}^{n}\right)_{5}\right]^{3+}$ was selectively synthesised when $n=3$.

The formation of gold nanoclusters described initially by Wang et al. was later refined by Hudgens et al. [140], in which bisphosphine $\left(L^{3}\right)$-protected gold 


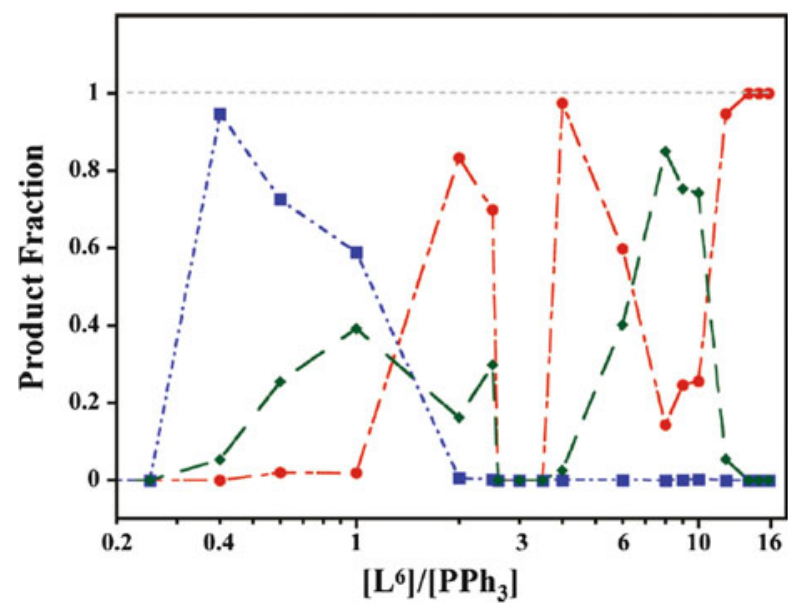

Fig. 10 Fractional product distribution as a function of $\left[\mathrm{L}^{6}\right] /\left[\mathrm{PPh}_{3}\right]$ as determined from fractional ion intensities measured with ESI-MS. The symbols are assigned as follows: red circles, $\left[\mathrm{Au}_{8} \mathrm{~L}_{4}^{6}\right]^{2+}$; blue squares, $\left[\mathrm{Au}_{9} \mathrm{~L}^{6}{ }_{4} \mathrm{Cl}\right]^{2+}$; and green diamonds, $\left[\mathrm{Au}_{10} \mathrm{~L}^{6}{ }_{x}\right]^{2+}(x=4$ and 5$)$. See [142] for more detail. Figure reproduced from [142]

nanoclusters were formed and the substitution of the solvent from neat chloroform to a (50:50) methanol/chloroform solution assisted in both the stabilisation of the clusters over time and the ESI ion current. They observed that using neat chloroform resulted in the decomposition of clusters over time and led to the formation of a red precipitate which was soluble in methanol. Additionally, when the synthesis was carried out in neat chloroform alone, the $\mathrm{Au}_{11}$ cluster was formed in relatively low abundance. In contrast, when the (50:50) methanol/chloroform solvent system was used, the $\left[\mathrm{Au}_{11}\left(\mathrm{~L}^{3}\right)_{5}\right]^{3+}$ was present in greater intensity and the additional clusters $\left[\mathrm{Au}_{6}\left(\mathrm{~L}^{3}\right)_{3}\right]^{3+}$ and $\left[\mathrm{Au}_{8}\left(\mathrm{~L}^{3}\right)_{4}\right]^{3+}$ were identified as minor components. This refined solvent system was also applied to a synthesis of $\mathrm{Et}_{2} \mathrm{P}\left(\mathrm{CH}_{2}\right)_{3} \mathrm{P}(\mathrm{Et})_{2^{-}}$ protected AuNCs [150] which were also studied via density functional theory (DFT) calculations.

The reaction mechanisms that govern the formation of gold nanoclusters protected by 1,3-bis(diphenylphosphino)propane were further elaborated by Hudgens et al. [117], who recorded ESI-MS at various time intervals prior to and after the addition of sodium borohydride.

Tsukuda et al. [151] have also shown that the dinuclear system $\mathrm{Au}_{2}(\mathrm{BINAP}) \mathrm{X}_{2}$, $\mathrm{X}=\mathrm{Cl}$ or $\mathrm{Br}$, can be treated with $\mathrm{NaBH}_{4}$ to form monodisperse undecagold clusters using either of the bidentate ligand $( \pm$ )-2,2'-bis(diphenylphosphino)$1,1^{\prime}$-binapthylene (BINAP), as revealed via ESI-MS, which gave the ions as $\left[\mathrm{Au}_{11}(\mathrm{BINAP})_{4} \mathrm{X}_{y}\right]^{z+}(\mathrm{X}=\mathrm{Cl}$ or Br; $y, z=1,2 ; 2,1)$, Fig. 12. 


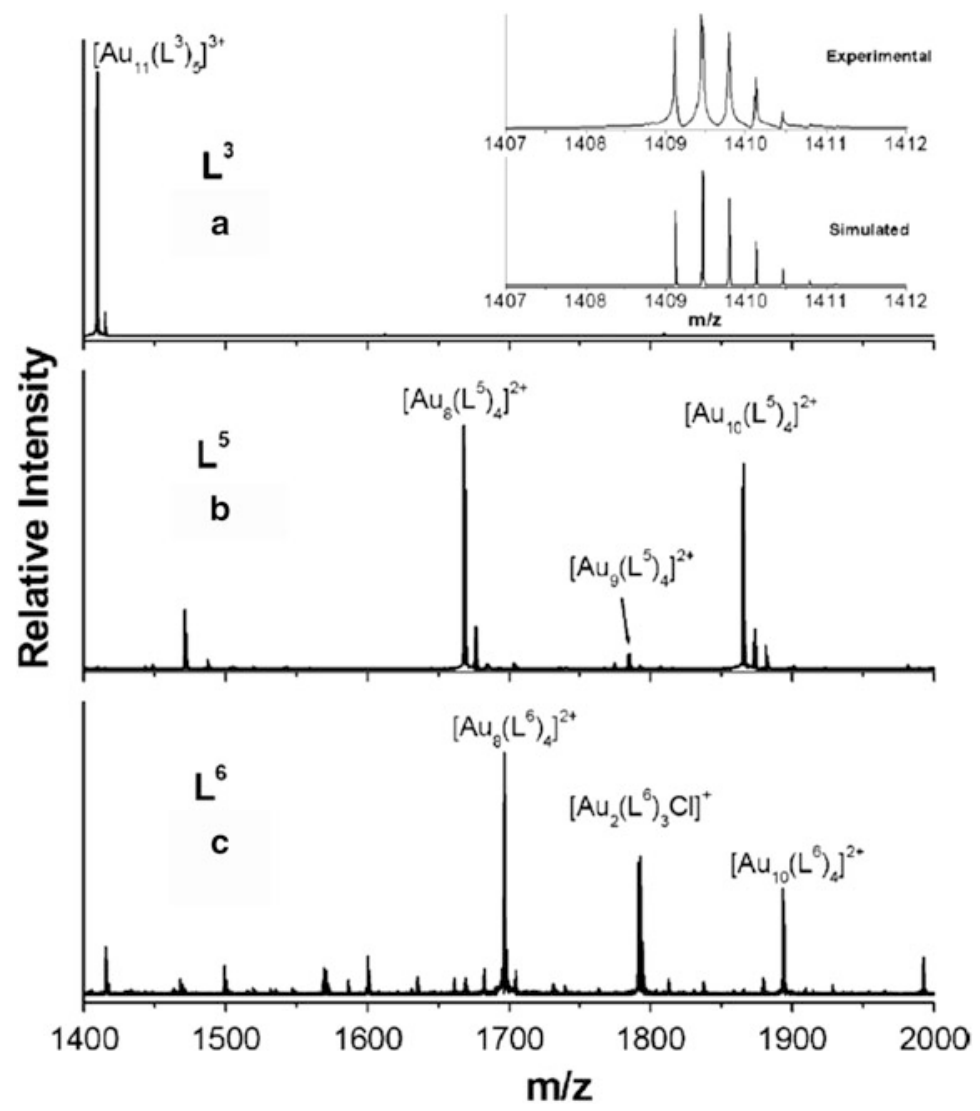

Fig. 11 High-resolution positive ion ESI-MS characterisation of Au clusters stabilised with the indicated diphosphine ligand, $\mathrm{L}^{n}$, where $\mathrm{L}=\mathrm{Ph}_{2} \mathrm{P}-\left(\mathrm{CH}_{2}\right)_{n}-\mathrm{PPh}_{2}$ : (a) $\mathrm{L}^{3}(n=3) ;(\mathbf{b}) \mathrm{L}^{5}(n=5)$; (c) $\mathrm{L}^{6}(n=6)$. The inset in (a) shows the isotopic pattern of the $\left[\mathrm{Au}_{11}\left(\mathrm{~L}^{3}\right)_{5}\right]^{3+}$ peak and the simulated isotopic pattern using the natural isotopic abundances of $\mathrm{Au}, \mathrm{P}, \mathrm{C}$ and H. Figure reproduced from [149]

\subsubsection{Post-reduction Phase}

Several studies have examined post-synthetic modification of gold nanoclusters [152-157]. Konishi et al. [58] have used ESI-MS to show that the polydisperse solution of gold nanoclusters formed upon reduction of the dinuclear complex $\mathrm{Au}_{2}$ (dppe) $\mathrm{Cl}_{2}$ by $\mathrm{NaBH}_{4}$ (Fig. 13a) transforms of the monodisperse cluster $\left[\mathrm{Au}_{13} \mathrm{~L}_{5} \mathrm{Cl}_{2}\right]^{3+}$ after treatment with $\mathrm{HCl}$ for $3 \mathrm{~h}$ (Fig. 13b).

ESI-MS is a valuable tool to monitor the reactions that occur after chemical reduction [142], which is known to be complete within hours after the addition sodium borohydride [158]. In Fig. 14, the initial distribution of $\left[\mathrm{Au}_{8} \mathrm{~L}_{4}^{6}\right]^{2+}$ remains persistent over at least 6 days after the addition of sodium borohydride. After 14 days, a new peak corresponding to $\left[\mathrm{Au}_{9} \mathrm{~L}^{6} \mathrm{Cl}\right]^{2+}$ is observed. 
Fig. 12 Positive ion ESI-MS of BINAPprotected AuNCs. The bottom panels show the experimental and simulated isotopic patterns for each of the main peaks.

Figure reproduced from [151]

Fig. 13 Positive ion ESI-MS spectra of (a) polydisperse gold nanoclusters protected by (dppe), (b) after treatment of the polydisperse cluster with $\mathrm{HCl}$ for $3 \mathrm{~h}$ and (c) post-purification of the monodisperse cluster.

Figure reproduced from [58]
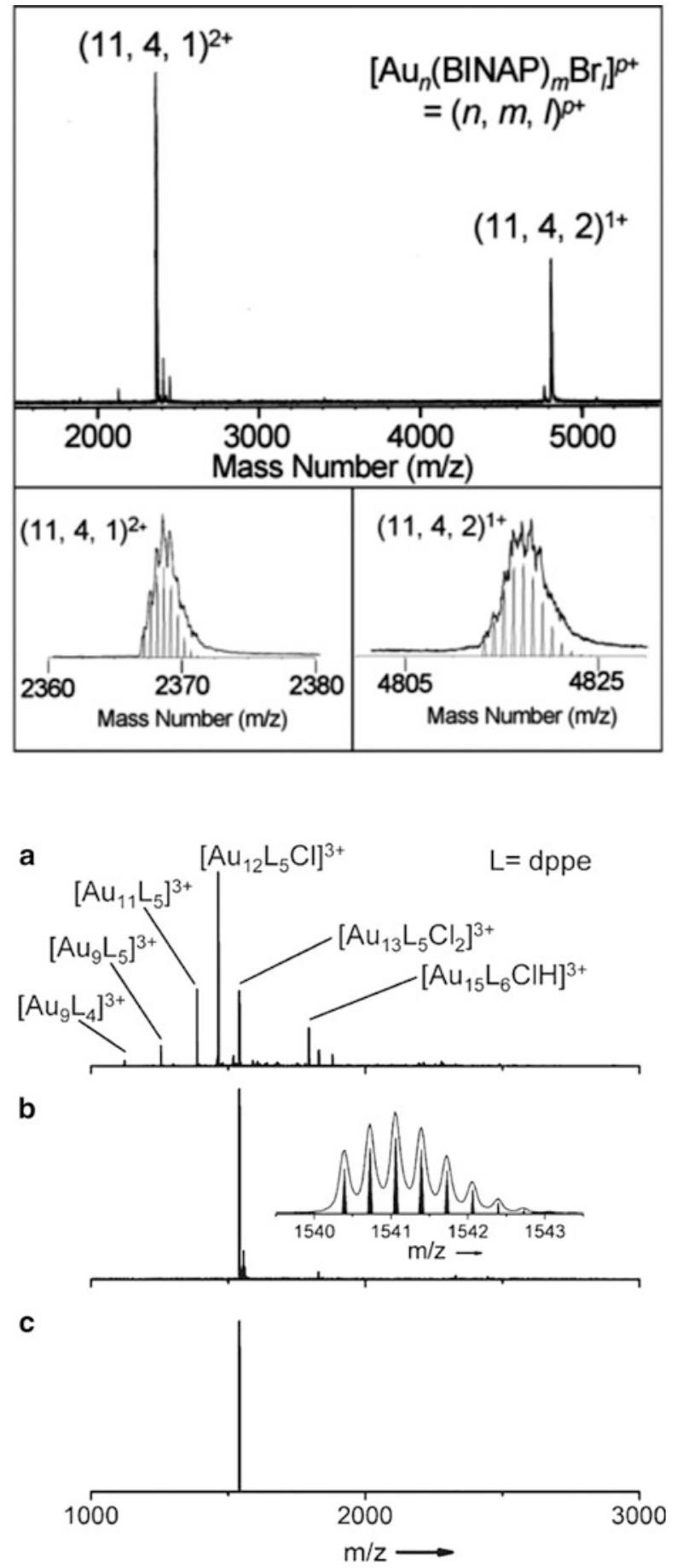


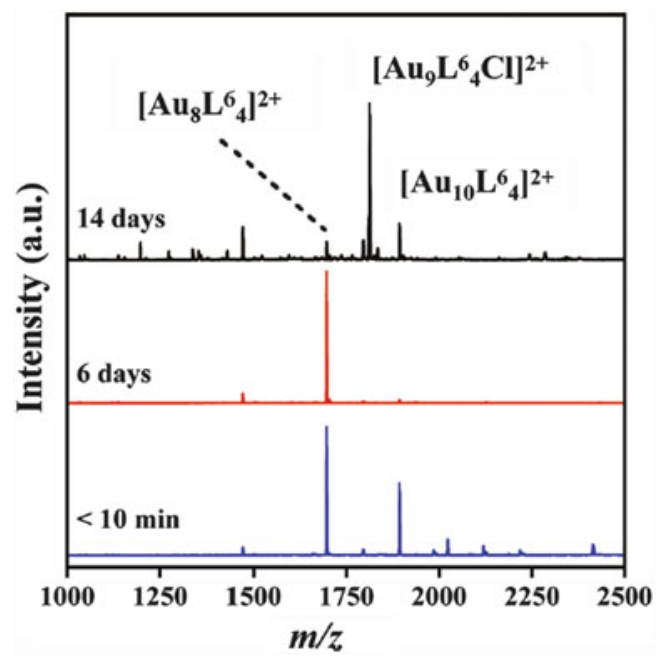

Fig. 14 Time resolved ESI-MS for nanocluster synthesis from solutions containing $\left[\mathrm{L}^{6}\right] /$ $\left[\mathrm{PPh}_{3}\right]=1$. The sequence shows that $\left[\mathrm{Au}_{9} \mathrm{~L}^{6}{ }_{4} \mathrm{Cl}\right]^{2+}$ cluster growth is preceded by the formation of monodisperse $\left[\mathrm{Au}_{8} \mathrm{~L}^{6}{ }_{4}\right]^{2+}$ clusters through degradation of larger clusters. Figure reproduced from [142]
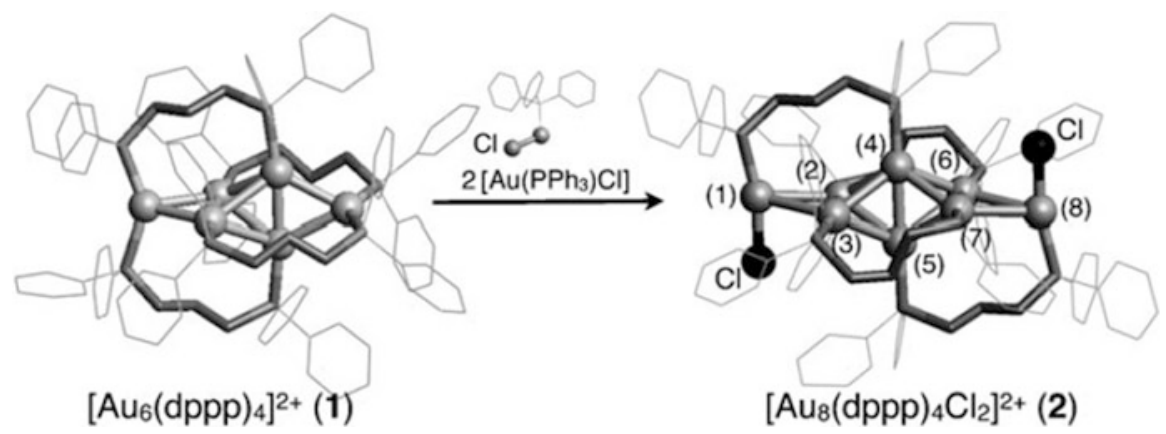

Fig. 15 X-ray crystal structures of the cations of $\left[\mathrm{Au}_{6}(\mathrm{dppp})_{4}\right]\left(\mathrm{NO}_{3}\right)_{2}(\mathbf{1})$ and $\left[\mathrm{Au}_{8}(\mathrm{dppp})_{4} \mathrm{Cl}_{2}\right]$ $\left(\mathrm{PF}_{6}\right)_{2}$ (2). dppp = 1,3-Bis(diphenylphosphino)propane. Hydrogen atoms omitted for clarity. Figure reproduced from [159]

Kamei et al. [159] used ESI-MS to monitor the reactions of two AuNCs $\left[\mathrm{Au}_{6}(\mathrm{dppp})_{4}\right]\left(\mathrm{NO}_{3}\right)_{2}\left((\mathbf{1})\right.$ in Fig. 15) [102] and $\left[\mathrm{Au}_{9}\left(\mathrm{PPh}_{3}\right)_{8}\right]\left(\mathrm{NO}_{3}\right)_{2}$ [160]. ESI-MS revealed that $\left[\mathrm{Au}_{6}(\mathrm{dppp})_{4}\right]^{2+}$ (Fig. 16a) transforms to monodisperse $\left[\mathrm{Au}_{8}(\mathrm{dppp})_{4} \mathrm{Cl}_{2}\right]^{2+}$ upon treatment with 20 equiv. of $\mathrm{ClAuPPh}_{3}$. The subsequent addition of an alcoholic solution of $\mathrm{NaPF}_{6}$ resulted in the precipitation of crude $\left[\mathrm{Au}_{8}(\mathrm{dppp})_{4} \mathrm{Cl}_{2}\right]\left(\mathrm{PF}_{6}\right)_{2}$ which was recrystallised in dichloromethane to yield crystals suitable for X-ray crystallography ((2) in Fig. 15). ESI-MS was also used to 

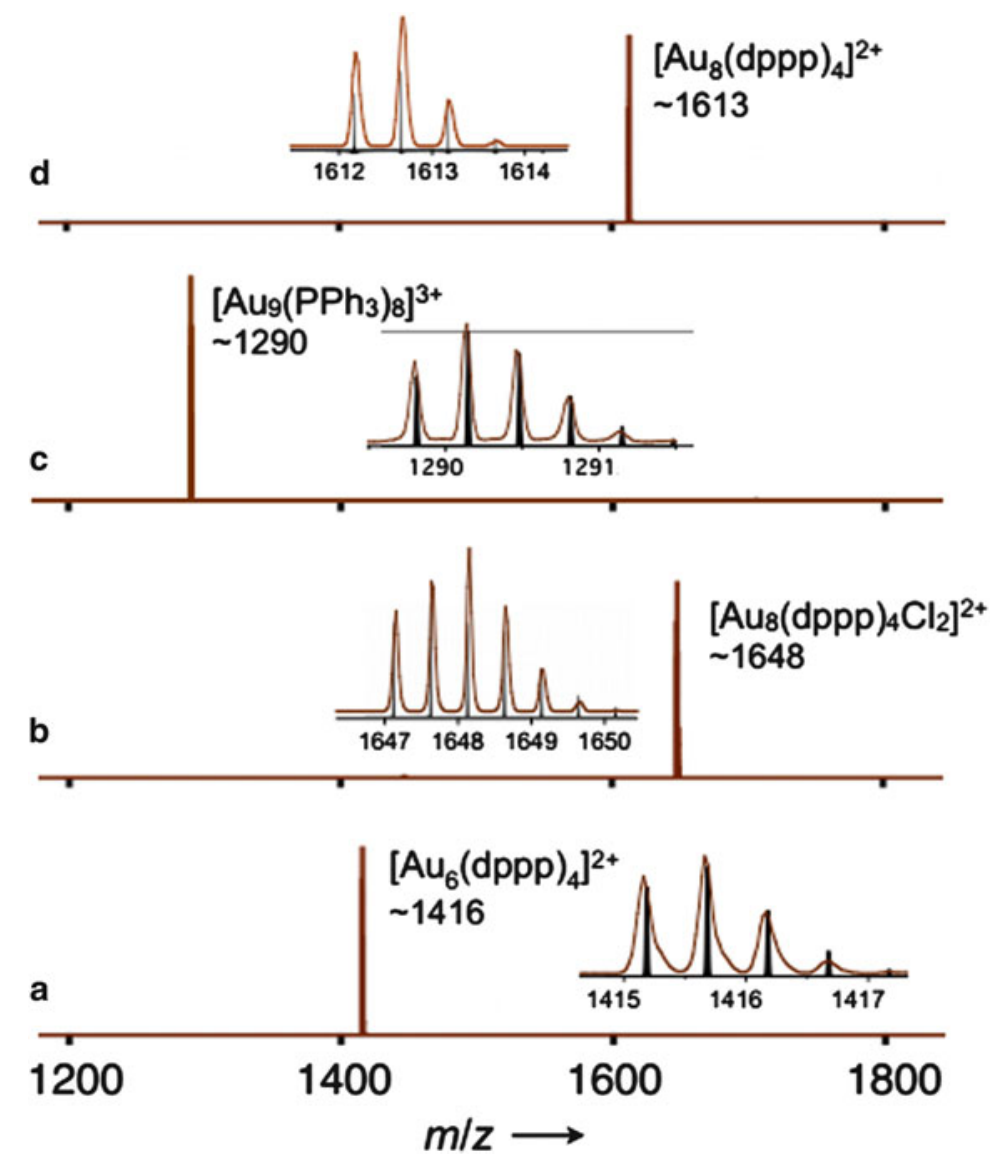

Fig. 16 ESI-MS of $(\mathbf{a})\left[\mathrm{Au}_{6}(\mathrm{dppp})_{4}\right]\left(\mathrm{NO}_{3}\right)_{2}$, (b) the product of reacting $\left[\mathrm{Au}_{6}(\mathrm{dppp})_{4}\right]\left(\mathrm{NO}_{3}\right)_{2}[102]$ in methanol with 2 molar equivalents of $\mathrm{AuClPPh}$ in chloroform, (c) $\left[\mathrm{Au}_{9}\left(\mathrm{PPh}_{3}\right)_{8}\right]\left(\mathrm{NO}_{3}\right)_{3}[160]$ and (d) the product of reacting $\left[\mathrm{Au}_{9}\left(\mathrm{PPh}_{3}\right)_{8}\right]\left(\mathrm{NO}_{3}\right)_{3}$ in dichloromethane with 6 equiv. of dppp also in dichloromethane. $\mathrm{dppp}=1,3$-bis(diphenylphosphino)propane. Figure reproduced from Supplementary Material of [159]

monitor the ligand etching of $\left[\mathrm{Au}_{9}\left(\mathrm{PPh}_{3}\right)_{8}\right]^{3+}$ (Fig. 16c) into monodisperse $\left[\mathrm{Au}_{8}(\mathrm{dppp})_{4}\right]^{2+}$ upon addition of 6 equiv. of dppp.

\subsection{MS-Based Fragmentation Methods for the Production of Gas-Phase Gold Cluster Ions}

Fragmentation of mass-selected gold cluster ions provides (1) structural information and (2) a gas-phase top-down approach to the 'synthesis' of new gold cluster 


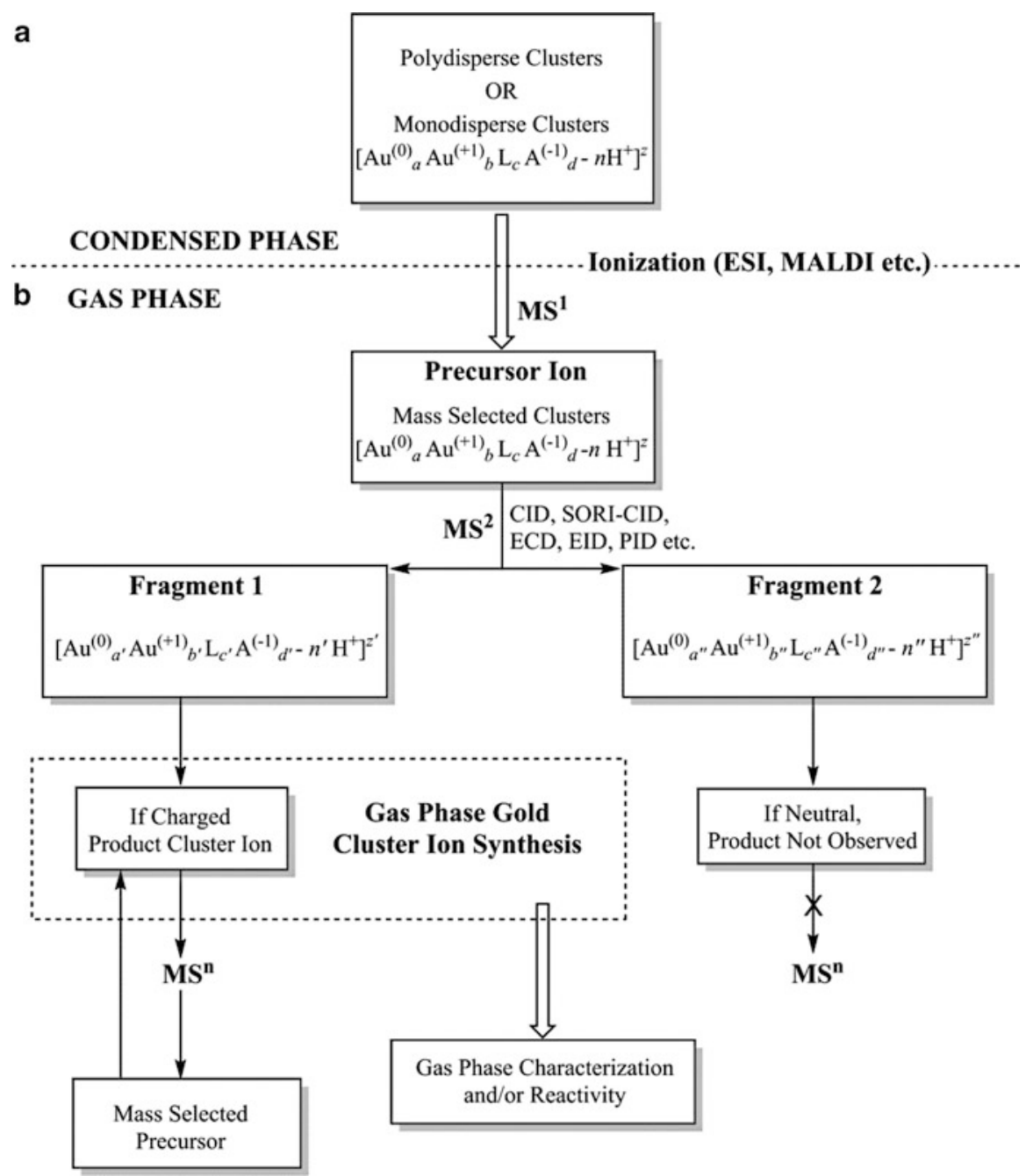

Fig. 17 Combination of solution phase synthesis, ESI and multistage mass spectrometry experiments for the gas-phase 'synthesis' of gold cluster ions: (a) condensed phase clusters transferred to the gas phase and (b) fragmentation (via CID, SORI-CID, ECD, EID, PID, etc.) produces new cluster ions

ions (Fig. 17), whose reactivity can be examined using instruments with multistage mass spectrometry $\left(\mathrm{MS}^{n}\right)$ capabilities. Several examples where this approach has been adopted are discussed later in Sect. 3.1.

As discussed further in Sect. 3.1, fragmentation of a gas-phase cluster ion can be induced in several ways. The subsequent fragmentation of the activated massselected precursor ion can occur via three general channels: 
Table 2 The general formula $\left[\mathrm{Au}^{(0)}{ }_{a} \mathrm{Au}^{(+1)}{ }_{b} \mathrm{~L}_{c} \mathrm{~A}^{(-1)}{ }_{d}-n \mathrm{H}^{+}\right]^{z}$ (Eq. (5)) can be tabulated and used to account for the fragmentation channels of a mass-selected gold cluster ion

\begin{tabular}{lllllll}
\hline & $a$ & $b$ & $c$ & $d$ & $n$ & $z$ \\
\hline Mass-selected precursor ion $\left[\mathrm{Au}^{(0)}{ }_{a} \mathrm{Au}^{(+1)}{ }_{b} \mathrm{~L}_{c} \mathrm{~A}^{(-1)}{ }_{d}-n \mathrm{H}^{+}\right]^{z}$ & $a$ & $b$ & $c$ & $d$ & $n$ & $z$ \\
Product ion $\left[\mathrm{Au}^{(0)}{ }_{a} \mathrm{Au}^{(+1)} \mathrm{L}_{c} \mathrm{~A}^{(-1)}{ }_{d}-n \mathrm{H}^{+}\right]^{z}$ & $a^{\prime}$ & $b^{\prime}$ & $c^{\prime}$ & $d^{\prime}$ & $n^{\prime}$ & $z^{\prime}$ \\
Loss from precursor to form product $\left[\mathrm{Au}^{(0)}{ }_{a} \mathrm{Au}^{(+1)}{ }_{b} \mathrm{~L}_{c} \mathrm{~A}^{(-1)}{ }_{d}-n \mathrm{H}^{+}\right]^{z}$ & $a^{\prime \prime}$ & $b^{\prime \prime}$ & $c^{\prime \prime}$ & $d^{\prime \prime}$ & $n^{\prime \prime}$ & $z^{\prime \prime}$ \\
\hline
\end{tabular}

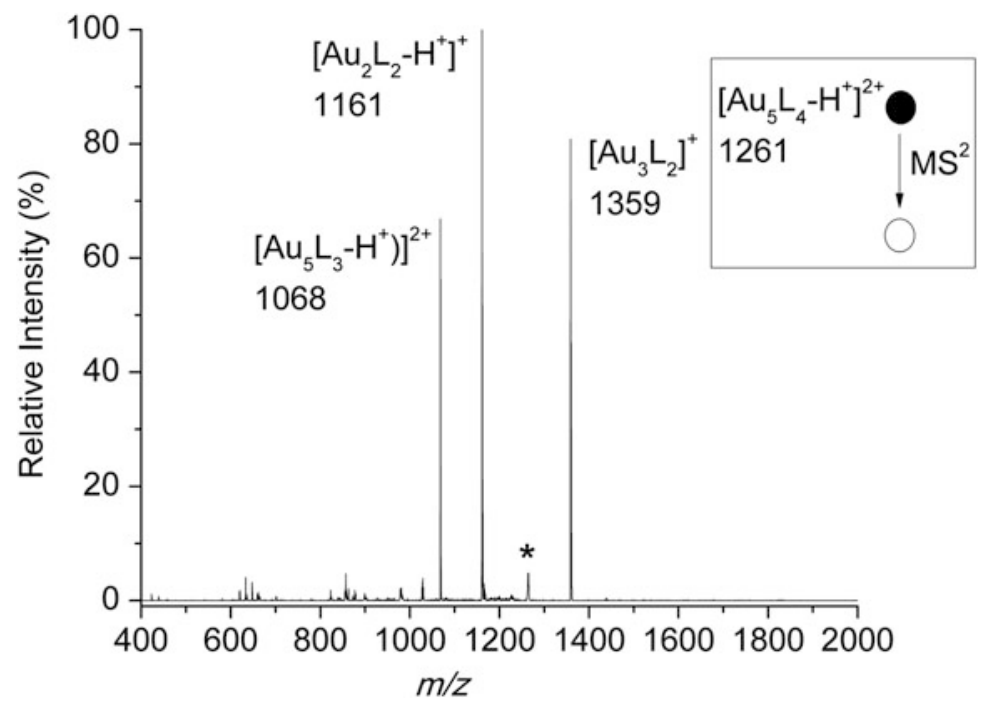

Fig. 18 Linear ion trap low-energy collision-induced dissociation of $\left[\mathrm{Au}_{5} \mathrm{~L}_{4}-\mathrm{H}^{+}\right]^{2+}$. The most intense peak in the cluster is represented by the $\mathrm{m} / \mathrm{z}$ value. Asterisk refers to the mass-selected precursor ion peak $\left[\mathrm{Au}_{5} \mathrm{~L}_{4}-\mathrm{H}^{+}\right]^{2+}$. Figure adapted from [113]

1. Ligand loss occurs where no dissociation of the gold cluster core remains inert.

2. Core fission occurs when the cluster core undergoes fragmentation. As a subset of core fission, the precursor ion can also split into complimentary ion pairs.

3. Ligand activation occurs when the protecting ligand fragments undergo fragmentation via loss of functional groups or rearrangement.

Table 2 summarises how precursor ion fragmentation can be accounted for using the general formula $\left[\mathrm{Au}^{(0)}{ }_{a} \mathrm{Au}^{(+1)}{ }_{b} \mathrm{~L}_{c} \mathrm{~A}^{(-1)}{ }_{d^{-}} n \mathrm{H}^{+}\right]^{z}$, (Eq. (5)), for gold cluster ions. For instance, the fragmentation of $\left[\mathrm{Au}_{5} \mathrm{~L}^{1}{ }_{4}-\mathrm{H}^{+}\right]^{2+}$, where $\mathrm{L}=\mathrm{dppm}$, has been studied [113] via collision-induced dissociation (CID) in a LTQ FT hybrid linear ion-trap mass spectrometer. Mass selection of $\left[\mathrm{Au}_{5} \mathrm{~L}_{4}{ }_{4}-\mathrm{H}^{+}\right]^{2+}$ and subsequent ion activation, Fig. 18, results in the mass-selected precursor, $\left[\mathrm{Au}_{5} \mathrm{~L}^{1}{ }_{4}-\mathrm{H}^{+}\right]^{2+}$ having two main fragmentation channels. A charge separation fragmenting into the complimentary ion pairs $\left[\mathrm{Au}_{3} \mathrm{~L}_{2}{ }_{2}\right]^{+}\left(\right.$Table $2, a^{\prime}=2, b^{\prime}=1, c^{\prime}=2, d^{\prime}=0, n^{\prime}=0$ ) 
and $\left[\mathrm{Au}_{2} \mathrm{~L}_{2}{ }_{2}-\mathrm{H}^{+}\right]^{+}\left(\right.$Table $\left.2, a^{\prime \prime}=0, b^{\prime \prime}=2, c^{\prime \prime}=2, d^{\prime \prime}=0, n^{\prime \prime}=1\right)$ and a ligand loss to generate $\left[\mathrm{Au}_{5} \mathrm{~L}_{3}{ }_{3}-\mathrm{H}^{+}\right]^{2+}$.

\subsection{Formation of Carbides, Hydroxides, Phosphides and Tellurides from Miscellaneous Top-Down Approaches}

Top-down approaches that utilise particle or photon-surface interactions have been used to 'synthesise' a range of clusters in which gold is combined with other elements. Most of these studies have only used MS to determine the cluster ion stoichiometries, and thus their structures remain unknown. Exceptions are Wang's photoelectron spectroscopy studies on gold cluster anions containing other elements, which are discussed further in Sect. 3.6.

Gold carbide clusters, $\mathrm{Au}_{x} \mathrm{C}_{y}{ }^{+}$, have been formed in several ways, including the reactions of 'hot' laser-desorbed gold cluster cations with ethene and alkanes [65], laser vaporisation of gold-coated carbon rods [161] and via impact of the $\mathrm{C}_{60}{ }^{-}$ anion at $\mathrm{keV}$ energies onto gold surfaces [162]. The latter approach produces both gold carbide cluster cations and anions. The structures of these gold carbide cluster ions have intrigued scientists and theoretical modelling has been employed to examine potential isomers [161-164]. Many of the isomers found consist of gold atoms coordinated to the end of carbon chains, and thus these do not possess gold-gold bonds.

Caesium ion bombardment at $\mathrm{keV}$ energies of gold surfaces prepared by vapour deposition of gold onto silver or glass substrates produces a wide range of anions containing a combination of different numbers of gold, oxygen or hydrogen [165]. The source of oxygen and hydrogen was assumed to be due to a surface layer of adsorbed $\mathrm{H}_{2} \mathrm{O}$ and $\mathrm{O}_{2}$ or their derived products. Anions with both even and odd electron counts were observed with nearly similar abundances for the oligomeric series $\mathrm{Au}_{x} \mathrm{O}_{2 x} \mathrm{H}_{y}{ }^{-}$and $\mathrm{Au}_{x} \mathrm{O}_{2 x+1} \mathrm{H}_{z}{ }^{-}$(where $x=2$ or 3). Although the structures of these clusters were not determined, the authors made analogies to the known structures of neutral gold fluorides.

Finally laser ablation of nanogold mixtures with either red phosphorus or tellurium has been used to produce a range of gold phosphide [166] and gold telluride [167] cluster ions. A rich set of gold phosphide cations and anions were identified including $\mathrm{AuP}_{n}{ }^{+}\left(n=1,2-88\right.$ (even numbers)); $\mathrm{Au}_{2} \mathrm{P}_{n}{ }^{+}(n=1-7$, 14-16, 21-51 (odd numbers)); $\mathrm{Au}_{3} \mathrm{P}_{n}^{+}(n=1-6,8,9,14) ; \mathrm{Au}_{4} \mathrm{P}_{n}^{+}(n=1-9$, 14-16); $\mathrm{Au}_{5} \mathrm{P}_{n}^{+}(n=1-6,14,16) ; \mathrm{Au}_{6} \mathrm{P}_{n}{ }^{+}(n=1-6) ; \mathrm{Au}_{7} \mathrm{P}_{n}{ }^{+}(n=1-7) ; \mathrm{Au}_{8} \mathrm{P}_{n}{ }^{+}$ $(n=1-6,8) ; \mathrm{Au}_{9} \mathrm{P}_{n}{ }^{+}(n=1-10) ; \mathrm{Au}_{10} \mathrm{P}_{n}{ }^{+}(n=1-8,15), \mathrm{Au}_{11} \mathrm{P}_{n}{ }^{+}(n=1-6)$ and $\mathrm{Au}_{12} \mathrm{P}_{n}{ }^{+}(n=1,2,4) ; \mathrm{AuP}_{n}{ }^{-}\left(n=4-6,8-26,30-36\right.$ (even numbers), 48); $\mathrm{Au}_{2} \mathrm{P}_{n}{ }^{-}$ $(n=2-5,8,11,13,15,17) ; \mathrm{Au}_{3} \mathrm{P}_{n}{ }^{-}(n=6-11,32) ; \mathrm{Au}_{4} \mathrm{P}_{n}{ }^{-}(n=1,2,4,6,10)$; 
$\mathrm{Au}_{6} \mathrm{P}_{n}{ }^{-}$; and $\mathrm{Au}_{7} \mathrm{P}_{n}{ }^{-}$. Several new $\mathrm{Au}_{m} \mathrm{Te}_{n}(m=1-11 ; n=1-4)$ clusters were identified.

\section{Tools for Determining Structures and Their Application to Gold Cluster Ions}

Ever since the development of soft ionisation methods such as FAB, ESI and MALDI, mass spectrometry has been applied to the analysis of gold cluster compounds. The primary concern has generally been the assignment of cluster formulae. For larger clusters where the stoichiometries of gold to ligand are unknown, or which are polydisperse mixtures, or mixtures containing different ligands, this can be challenging. Various approaches have been adopted to overcome these problems. For example, Maity et al. have used [168] 50:50 phenylacetylene and para-tolylacetylene mixtures to assign the stoichiometry of organogold clusters protected by phenylacetylene.

In this section we do not review all of the analytical applications of MS in gold cluster chemistry. Rather we highlight the types of tools that have been developed to study the structures of both bare and ligated cluster ions in the gas phase. Quantum chemical calculations are an essential adjunct to experimental techniques, which allow the gas-phase structures of many clusters to be obtained. A recent interesting review by Kappes et al. highlights the techniques used to date to determine the structures of bare gold clusters [169]. The experimental techniques discussed below include (1) fragmentation methods (identify atom connectivity), (2) ion mobility spectrometry (IMS) (identify the collision cross section), (3) infrared multiphoton dissociation (IRMPD) (identify IR absorption), (4) UV-Vis spectroscopy (identify the UV-Vis absorption spectra to investigate the clusters structure), (5) trapped ion electron diffraction (TIED) (identify molecular scattering) and (6) photoelectron spectroscopy (PES) (identify the electron binding energy).

\subsection{MS-Based Fragmentation Methods}

The most commonly used approach in mass spectrometry to gain structural information is the use of activation methods to induce fragmentation of a mass-selected precursor ion. Activation can occur, for example, via collision-induced dissociation (CID, discussed in Sect. 3.1.1), surface-induced dissociation (SID), laser-based activation methods such as photodissociation (PD, discussed in Sect. 3.1.1) and ion-electron interactions (discussed in Sect. 3.1.2). When tunable lasers are used, this allows the spectroscopy of AuNCs to be examined, and this is discussed further in Sects. 3.3 and 3.4 below. 


\subsubsection{Collision-Induced Dissociation and Photodissociation of Gold Cluster Ions in the Gas Phase}

\section{Bare Gold Cluster Cations and Anions}

Schweikhard's group has widely studied the fragmentation reactions of bare gold cluster anions and cations in a Penning ion trap using a range of activation techniques including CID [170-178], PD [176, 179-195] and electron-induced dissociation (EID) [196-201]. The latter studies are discussed in Sect. 3.1.2 below.

The collision of positively charged gold clusters, $\mathrm{Au}_{n}{ }^{+}(2 \leq n \leq 23$ atoms), with rare gases, results in dissociation via loss of a single gold atom, (Eq. (7), $z=+1$ ), or two gold atoms. The loss of two atoms occurs most probably through the emission of a dimer, (Eq. (8), $z=+1$ ), rather than by a sequential evaporation. The minimum kinetic energies of clusters required to induce dissociation exhibit a pronounced odd-even effect. Clusters with an even number of delocalised electrons are more stable than those with an odd number. This was observed for $\mathrm{Au}_{n}{ }^{+}$, $n \leq 15$. When $15 \leq n \leq 23$, monomer loss is the main fragmentation pathway suggesting that the binding energies of all cluster cations in this range lie above the dimer binding energy:

$$
\begin{aligned}
{\left[\mathrm{Au}_{n}\right]^{z} } & \rightarrow\left[\mathrm{Au}_{n-1}\right]^{z}+\mathrm{Au} \\
& \rightarrow\left[\mathrm{Au}_{n-2}\right]^{z}+\mathrm{Au}_{2} \\
{\left[\mathrm{Au}_{n}\right]^{z} } & \rightarrow\left[\mathrm{Au}_{n}\right]^{(z+1)}+\mathrm{e}^{-}
\end{aligned}
$$

Ervin's group have examined the fragmentation patterns and extracted the bond dissociation energies of small gold anionic clusters, $\mathrm{Au}_{n}{ }^{-}$, using the energyresolved threshold collision-induced dissociation $(n=2-7)$ as well as the timeresolved photodissociation lifetime $(n=6,7)$ techniques [176]. In both cases the main fragmentation channels are found to be loss of Au atom (Eq. (7), $z=-1$ ), which is favoured for odd electron anions (i.e. when $n=$ even) or $\mathrm{Au}_{2}$ (Eq. (8), $z=-1$ ), which dominates for even electron ions (i.e. when $n=$ odd). The dissociation energies extracted from the two techniques were in good agreement and show an even-odd alternation for the loss of an atom from gold cluster anions, $D_{0}\left(\mathrm{Au}_{n-1}^{-}-\mathrm{Au}\right)$. Finally, photoelectron loss (Eq. (9)) appears to be important for $\left[\mathrm{Au}_{6}\right]^{-}$and was inferred via depletion of the signal for the cluster anion. Table 3 summarises the fragmentation methods used and the key observations in the study of bare gold cluster ions.

\section{Ligated Gold Cluster Cations}

One of the first studies in which a ligated gold cluster cation was subjected to CID appears to be that of Wang et al. [202], who studied the gas-phase fragmentation of $\left[\mathrm{Au}_{20}\left(\mathrm{PPh}_{3}\right)_{8}\right]^{2+}$ under conditions of sustained off-resonance irradiation collisioninduced dissociation (SORI-CID) in an FT-ICR. Losses of $n \mathrm{PPh}_{3}$ ligands (where 
Gas Phase Formation, Structure and Reactivity of Gold Cluster Ions

Table 3 Summaries of studies on the fragmentation of bare gold cluster cations and anions

\begin{tabular}{|c|c|c|c|c|}
\hline $\mathrm{Au}_{n}{ }^{z}$ & $(n)$ & Method & Key observation(s) & References \\
\hline$\overline{\mathrm{Au}_{n}^{+}}$ & $2-23$ & CID & $\begin{array}{l}\text { CID for } n \leq 15 \text { results in dimer evapora- } \\
\text { tion. All larger clusters fragment via } \\
\text { monomer evaporation }\end{array}$ & {$[170]$} \\
\hline $\mathrm{Au}_{n}^{+}$ & $2-23$ & CID & $\begin{array}{l}\text { Study of binding energies for the dissoci- } \\
\text { ation of clusters. Even electron clusters } \\
\text { were found to be more stable than odd } \\
\text { electron clusters }\end{array}$ & {$[171]$} \\
\hline $\mathrm{Au}_{15}{ }^{2+}$ & 15 & CID & $\begin{array}{l}\text { Fragments into the complimentary ion } \\
\text { pairs } \mathrm{Au}_{3}^{+} \text {and } \mathrm{Au}_{11}^{+}\end{array}$ & {$[172]$} \\
\hline $\mathrm{Au}_{n}^{+}$ & $3-23$ & PD & Undergo dimer evaporation & [179] \\
\hline $\mathrm{Au}_{n}^{+}$ & 9,21 & $\mathrm{PD}$ & Dissociation energies determined & {$[180]$} \\
\hline $\mathrm{Au}_{n}^{2+}$ & 12 & CID & $\begin{array}{l}\text { Sequential dissociation was used to cir- } \\
\text { cumvent interference with singly } \\
\text { charged clusters. Fragmentation into } \\
\text { the complimentary ions pairs } \mathrm{Au}_{3}^{+} \text {and } \\
\mathrm{Au}_{9}{ }^{+} \text {was observed for } \mathrm{Au}_{12}{ }^{2+}\end{array}$ & {$[173]$} \\
\hline $\mathrm{Au}_{n}^{2+}$ & $7-35$ & CID & $\begin{array}{l}\text { Fission occurs for small clusters at } n=15 \\
\text { (Eq. }(8), z=+2) . \text { Larger clusters } \\
\text { undergo gold atom evaporation } \\
\text { (Eq. }(7), z=+2)\end{array}$ & {$[174]$} \\
\hline $\mathrm{Au}_{n}^{3+}$ & $19-35$ & CID & $\begin{array}{l}\text { Fission occurs for small clusters at } n=25 \\
\begin{array}{l}\text { (Eq. }(8), z=+3) \text { and larger clusters } \\
\text { exhibit gold atom evaporation (Eq. (7), } \\
z=+3)\end{array}\end{array}$ & [174] \\
\hline $\mathrm{Au}_{n}^{-}$ & $16-30$ & EID & $\begin{array}{l}\text { First observation of gold cluster dianions } \\
\quad n=20-30\end{array}$ & [196] \\
\hline $\mathrm{Au}_{n}^{-}$ & $12-28$ & EID & $\begin{array}{l}\text { Formation of dianions. Strong odd-even } \\
\text { effect observed }\end{array}$ & [197] \\
\hline $\mathrm{Au}_{n}{ }^{-}$ & $2-21$ & CID & Neutral monomer and dimer evaporation & [175] \\
\hline $\mathrm{Au}_{n}^{+}$ & $12-72$ & EID & $\begin{array}{l}\text { Odd-even effects. For larger clusters } \\
\text { magic numbers are observed }\end{array}$ & [198] \\
\hline $\mathrm{Au}_{n}{ }^{-}$ & 6,7 & PD & Determination of dissociation energies & [176] \\
\hline $\mathrm{Au}_{n}{ }^{-}$ & $2-7$ & CID & Determination of dissociation energies & [176] \\
\hline $\mathrm{Au}_{n}^{2+}$ & $7-35$ & CID & Odd-even effect disappears for $n<11$ & [177] \\
\hline $\mathrm{Au}_{n}^{3+}$ & $19-35$ & CID & $\begin{array}{l}\text { First studies for the CID of } \mathrm{Au}_{n}{ }^{3+} \text {. The } \\
\text { dissociation energy as a function of } \\
\text { cluster size is smaller than } \mathrm{Au}_{n}{ }^{2+} \text {. No } \\
\text { odd-even effects and no particularly } \\
\text { stable clusters were observed }\end{array}$ & {$[177]$} \\
\hline $\mathrm{Au}_{n}^{+}$ & $7-15$ & PD & $\begin{array}{l}\text { The energy dependence for monomer and } \\
\text { dimer evaporation has been calculated } \\
\text { for the size-selected clusters decay } \\
\text { pathway }\end{array}$ & [181] \\
\hline $\mathrm{Au}_{n}^{+}$ & $2-27$ & PD & $\begin{array}{l}\mathrm{Au}_{9}^{+} \text {shows anomalous behaviour to its } \\
\text { odd neighbours with less likelihood of } \\
\text { dimer evaporation. This is due to } \\
\text { electron shell closing at } n=8\end{array}$ & {$[182]$} \\
\hline $\mathrm{Au}_{n}^{+}$ & 14,16 & $\mathrm{PD}$ & Determination of dissociation energies & {$[183]$} \\
\hline
\end{tabular}


Table 3 (continued)

\begin{tabular}{|c|c|c|c|c|}
\hline $\mathrm{Au}_{n}{ }^{2}$ & $(n)$ & Method & Key observation(s) & References \\
\hline$\overline{\mathrm{Au}_{n}^{+}}$ & $14-24$ & PD & Determination of dissociation energies & [184] \\
\hline $\mathrm{Au}_{n}{ }^{-}$ & & EID & $\begin{array}{l}\text { Production of dianionic and trianionic } \\
\text { clusters }\end{array}$ & {$[199,200]$} \\
\hline $\mathrm{Au}_{n}{ }^{-}$ & 25 & EID & $\begin{array}{l}\text { Threshold for production of } \mathrm{Au}_{25}{ }^{2-} \text { is } \\
\text { determined }\end{array}$ & [201] \\
\hline $\mathrm{Au}_{n}^{-}$ & 7 & PD & $\begin{array}{l}\text { Photodissociation with a green laser } \\
\text { pointer shows decay into } \mathrm{Au}_{6}{ }^{-} \text {and } \\
\mathrm{Au}_{5}{ }^{-}\end{array}$ & [185] \\
\hline $\mathrm{Au}_{n}^{2-}$ & 29 & PD & Decay observed by PD & [185] \\
\hline $\mathrm{Au}_{n}^{+}$ & $9,11,13,15$ & PD & $\begin{array}{l}\text { Determination of dissociation energy via } \\
\text { dimer evaporation }\end{array}$ & [186] \\
\hline $\mathrm{Au}_{n}^{+}$ & $17-21$ & PD & $\begin{array}{l}\text { Excitation energies far above the clusters } \\
\text { dissociation thresholds have been used } \\
\text { to induce multisequential fragmenta- } \\
\text { tion by the evaporation of neutral } \\
\text { monomers }\end{array}$ & [187] \\
\hline $\mathrm{Au}_{n}{ }^{-}$ & $\begin{array}{l}11-40 \\
51-70\end{array}$ & $\begin{array}{r}\text { Low-energy } \\
\text { electrons }\end{array}$ & Production of dianions and trianions & [188] \\
\hline $\mathrm{Au}_{n}^{+}$ & $3-21$ & $\mathrm{PD}$ & $\begin{array}{l}\text { Fragmentation pathways monitored as a } \\
\text { function of cluster size. Monomer and } \\
\text { dimer evaporation }\end{array}$ & [189] \\
\hline $\mathrm{Au}_{n}^{+}$ & $5,8,12$ & PD & $\begin{array}{l}\text { Isomers can be distinguished by their dis- } \\
\text { tinct decay rates }\end{array}$ & [190] \\
\hline $\mathrm{Au}_{n}^{+}$ & 30 & PD & $\begin{array}{l}\text { The determination of relative dissociation } \\
\text { energies }\end{array}$ & [191] \\
\hline $\mathrm{Au}_{n}^{+}$ & $7-27$ & $\mathrm{PD}$ & $\begin{array}{l}\text { The monomer-dimer branching ratios as a } \\
\text { function of the excitation energy and } \\
\text { dissociation energy were determined }\end{array}$ & [192] \\
\hline $\mathrm{Au}_{n}^{2-}$ & 29 & PD & Dissociation products determined & [193] \\
\hline $\mathrm{Au}_{n}^{-}$ & 14,17 & PD & Study of decay rates for cluster anions & [194] \\
\hline $\mathrm{Au}_{n}^{2-}$ & $35,40,45,50$ & $\mathrm{PD}$ & $\begin{array}{l}\text { Photoexcited gold cluster dianions } \\
\text { resulted in neutral atom evaporation } \\
\text { (Eq. (7), } z=-2 \text { ) and electron emis- } \\
\text { sion (Eq. (9), } z=-2 \text { ) }\end{array}$ & [195] \\
\hline $\mathrm{Au}_{n}^{2-}$ & $21-31$ & CID & $\begin{array}{l}\text { Singly charged clusters have been } \\
\text { observed at low collision energy, } \\
\text { indicating the emission of one electron } \\
\text { Eq. (9) }\end{array}$ & [178] \\
\hline
\end{tabular}

$n=1-4)$ were observed, with no core fission occurring under these low-energy collision conditions. These results highlight the relative structural stability of the $\mathrm{Au}_{20}$ core, which was predicted from theoretical calculations to be tetrahedral [203].

The CID of bisphosphine-protected gold nanoclusters where the protecting ligand was $\mathrm{Ph}_{2} \mathrm{P}-\left(\mathrm{CH}_{2}\right)_{n}-\mathrm{PPh}_{2}(n=1-6)$ has been studied (Sect. 2.5 above). This 
Table 4 Types of reactions and their branching ratios (BR) observed in the ECD spectra of multiply charged dppm-capped gold nanoclusters

\begin{tabular}{lrll}
\hline Ion & BR (Eq. (10)) & BR (Eq. (11)) & BR (n) \\
\hline$\left[\mathrm{Au}_{2} \mathrm{~L}_{2}{ }_{2}\right]^{2+}$ & & & $100 \%$ \\
{$\left[\mathrm{Au}_{5} \mathrm{~L}_{4}^{1}-\mathrm{H}^{+}\right]^{2+}$} & & $100 \%$ & \\
{$\left[\mathrm{Au}_{9} \mathrm{~L}_{4}{ }_{4}\right]^{3+}$} & $89.0 \%$ & $6.9 \%$ & $4.1 \%$ \\
{$\left[\mathrm{Au}_{9} \mathrm{~L}_{5}{ }_{5}\right]^{3+}$} & $87.7 \%$ & $12.3 \%$ & \\
{$\left[\mathrm{Au}_{10} \mathrm{~L}_{4}^{1}\right]^{2+}$} & $100.0 \%$ & & \\
{$\left[\mathrm{Au}_{11} \mathrm{~L}_{4}^{1}\right]^{3+}$} & $100.0 \%$ & & \\
{$\left[\mathrm{Au}_{11} \mathrm{~L}_{5}{ }_{5}\right]^{3+}$} & $100.0 \%$ & & \\
{$\left[\mathrm{Au}_{11} \mathrm{~L}_{6}{ }_{6}\right]^{3+}$} & $41.6 \%$ & $58.4 \%$ & \\
{$\left[\mathrm{Au}_{13} \mathrm{~L}_{5}{ }_{5}\right]^{3+}$} & $100.0 \%$ & & \\
{$\left[\mathrm{Au}_{13} \mathrm{~L}_{6}^{1}\right]^{3+}$} & $99.3 \%$ & $0.7 \%$ & \\
{$\left[\mathrm{Au}_{14} \mathrm{~L}_{7}{ }_{7}-\mathrm{H}^{+}\right]^{3+}$} & & $100.0 \%$ & \\
\hline
\end{tabular}

No ionic fragments are observed for $\mathrm{Au}_{8}$ and $\mathrm{Au}_{6}$ clusters. Blank cells indicate that the channel was not observed

approach not only provides structural information but also allows for the synthesis of new metal clusters in the gas phase (Sect. 2.5).

\subsubsection{Electron Capture Dissociation and Electron-Induced Dissociation}

Multiply charged gold cluster ions present the opportunity to investigate fragmentation induced by one electron reduction. In solution the electron source for reduction of $\mathrm{Au}(\mathrm{I})$ to $\mathrm{Au}(0)$ originates from the chemical reducing agent (e.g. $\mathrm{NaBH}_{4}, \mathrm{BTBC}$ and other boranes). Additionally, the reducing environment persists after the initial formation of gold nanoclusters during the reduction phase. Mass selection of reactive intermediates of the general equation $\left[\mathrm{Au}^{(0)}{ }_{a} \mathrm{Au}^{(+1)}{ }_{b} \mathrm{~L}_{c}\right.$ $\left.\mathrm{A}^{(-1)}{ }_{d^{-}} n \mathrm{H}^{+}\right]^{z}$ where $z \geq 2$ could provide useful information regarding the electronically driven fragmentation processes that are required for the formation of subsequent clusters, whether they are poly- or monodispersed. Compared to the condensed phase, gas-phase single-electron electrochemical reactions of gold cluster ions are free of competing neutral radical $\mathrm{Au}(0)$ atoms and small clusters.

Three types of reactions were observed in the electron capture dissociation (ECD) studies of multiply charged dppm-protected gold clusters [113] (Table 4):

(1) charge reduction Eq. (10), (2) charge reduction and ligand loss Eq. (11) and

(3) charge reduction and ligand activation Eq. (12):

$$
\begin{gathered}
{\left[\mathrm{Au}_{x} \mathrm{~L}_{y}\right]^{n+}+\mathrm{e}^{-} \rightarrow\left[\mathrm{Au}_{x} \mathrm{~L}_{y}\right]^{(n-1)+\bullet}} \\
{\left[\mathrm{Au}_{x} \mathrm{~L}_{y}\right]^{n+}+\mathrm{e}^{-} \rightarrow\left[\mathrm{Au}_{x} \mathrm{~L}_{y-1}\right]^{(n-1)+\bullet}+\mathrm{L}} \\
{\left[\mathrm{Au}_{x} \mathrm{~L}_{y}\right]^{n+}+\mathrm{e}^{-} \rightarrow\left[\mathrm{Au}_{x} \mathrm{~L}_{y-1}\left(\mathrm{CH}_{2} \mathrm{PPh}_{2}\right)\right]^{(n-1)+}+\mathrm{Ph}_{2} \mathrm{P}^{\bullet}}
\end{gathered}
$$

Compared to the CID fragmentation studies, no core fission was observed, suggesting the preservation of aurophilic interactions in the reduced cluster cations. 
Bare gold cluster cations, $\mathrm{Au}_{n}{ }^{+}(n=12-72)$, generated via laser vaporisation using a Smalley-type source were mass selected and isolated in a Penning trap [198]. The mass-selected clusters were then bombarded with an electron beam (typically ca. $150 \mathrm{eV}$ for $1.2 \mathrm{~s}$ ) generated from a rhenium filament. Electron impact resulting in the dissociation and further ionisation of mass-selected gold clusters reveals that small gold clusters, $\mathrm{Au}_{n}{ }^{z+}(n \leq 30)$ where $z=1$ or 2 , exhibit an oddeven alternation in their abundance with preference to even electron clusters. For $\mathrm{Au}_{n}{ }^{+}, n$ is generally an odd number and for $\mathrm{Au}_{n}{ }^{2+} n$ is generally an even number.

\subsection{Ion Mobility}

The mobility of gas-phase ions through a gas and under the influence of an electric field is a useful property to exploit in order to develop techniques to separate nanoparticles and nanoclusters based on their size, shape and charge [204]. When coupled to mass spectrometry, termed IMS [205], it allows for accurate measurements of the particle mass and therefore its composition. The marriage of this technique with theoretical calculations has proven to be very powerful in determining the structures of gas-phase cluster ions [206]. The use of IMS is gaining grounds in the analysis of clusters. Weis has reviewed the use of IMS in fundamental studies of metal clusters, including gold clusters [207], and a chapter in this book, by A. Fielicke et al., highlights work done on bare AuNC ions. Here we briefly review IMS studies on bare AuNCs (Sect. 3.2.1) and ligated AuNCs (Sect. 3.2.2).

\subsubsection{Bare Gold Nanoclusters}

In early work, laser ablation coupled with IMS and density functional theory calculations was used to determine the structures of bare gold anions and cations, $\mathrm{Au}_{n}{ }^{-}$and $\mathrm{Au}_{n}{ }^{+}$( $n$ up to 13) [208, 209]. Cationic clusters were found to have planar structures for $n \leq 3-7$ and form $3 \mathrm{D}$ structures at $n \geq 8$. Anionic clusters on the other hand are planar for $n \leq 3-11$, for $n=12$ both a planar and a threedimensional structure seem to coexist, and for $n=13$, only a three-dimensional structure is observed (Fig. 19). Kappes also studied mixed silver-gold clusters $\mathrm{Ag}_{m} \mathrm{Au}_{n}{ }^{+}(m+n)<6$. Triangular, rhombus (or Y-shaped) and connected triangles (or trigonal bipyramid) were observed as the main structures for trimers, tetramers and pentamers, respectively.

\subsubsection{Ligated Gold Nanoclusters}

Ion mobility was also used to study ligated gold clusters. Lenggoro et al. [210] have reported the use of ES-DMA (electrospray-differential mobility analysis) to study AuNPs. This technique allows the segregation of the nanoclusters by size 


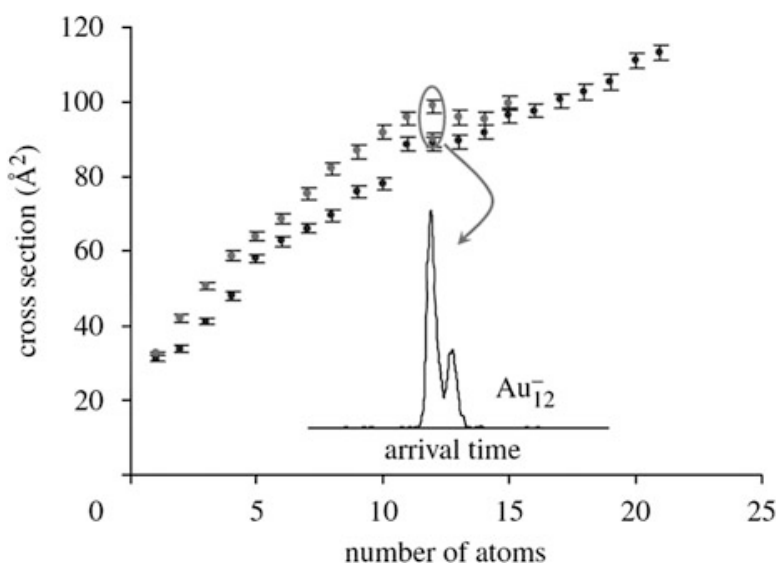

Fig. 19 IMS determined experimental cross section for gold cluster cations (black circles) $\mathrm{Au}_{n}{ }^{+}$ and anions (grey circles) $\mathrm{Au}_{n}{ }^{-}$at $300 \mathrm{~K}$. For the same $\mathrm{n}$ value, the anions clearly have a larger cross section. For $n=12$; a bimodal arrival time is observed indicating the presence of 2 isomers. Figure reproduced from [209]

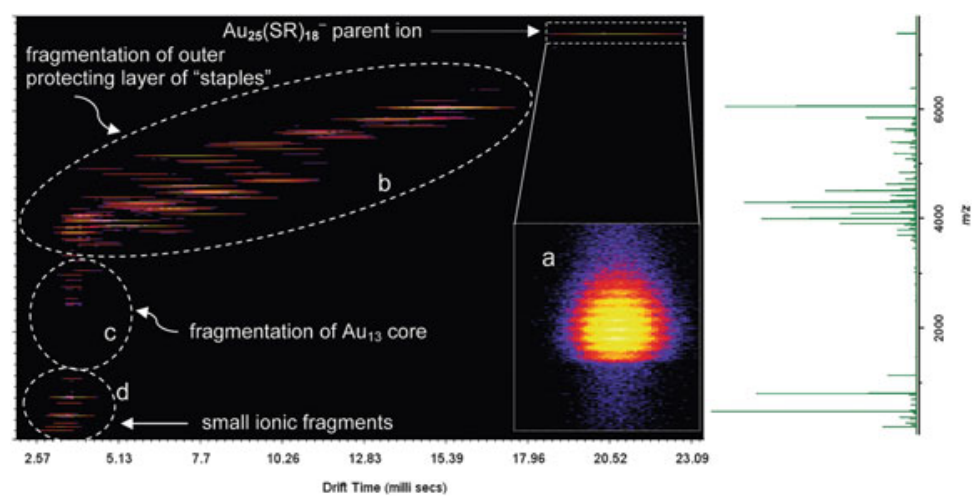

Fig. 20 IM-MS/MS driftscope plot showing $m / z$ ( $y$ axis) versus drift time ( $x$ axis) for the analysis of $\mathrm{Au}_{25}\left(\mathrm{SCH}_{2} \mathrm{CH}_{2} \mathrm{Ph}\right)_{18}$. Inset $a$ shows an expansion of the isotopic distribution of the parent ion, $\mathrm{Au}_{25}\left(\mathrm{SCH}_{2} \mathrm{CH}_{2} \mathrm{Ph}\right)_{18}{ }^{-}$. The CID of $\mathrm{Au}_{25}\left(\mathrm{SCH}_{2} \mathrm{CH}_{2} \mathrm{Ph}\right)_{18}$ results in the fragmentation of the [-SR-Au-SR-Au-SR-] staples as shown by the slant oval $b$. Fragmentation of the $\mathrm{Au}_{13}(\mathrm{SR})_{m}(\mathrm{~S})_{n}$ core is shown by the vertical oval $c$, and the small ionic fragments are shown by $d$. Figure reproduced from [216]

[211]. Zachariah et al. have studied gold nanorods [212], aggregation and kinetics of colloidal gold [211] and the conformation of bovine serum albumin on AuNPs [213]. Hackley et al. reported recently the use of a new hyphenated technique where ES-DMA was coupled to ICP-MS. They show that this technique can be used to segregate gold nanoparticles based on their size and their elemental composition $[214,215]$. ES-DMA and variants were also coupled directly to mass spectrometry (ESI-IMS) and used to decipher the structures of ligated gold nanoparticles. Dass 


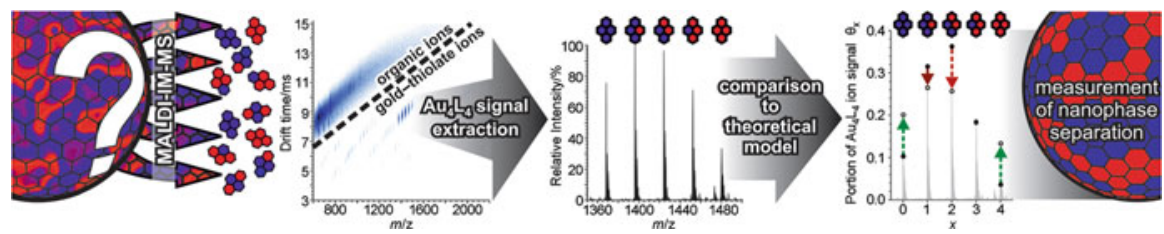

Fig. 21 Workflow for MALDI-IM-MS experiments conducted by Cliffel et al. on mixed-ligand AuNPs with unknown levels of nanophase separation. The MALDI process leads to the fragmentation and the gold-thiolate ions undergo gas-phase separation from organic ions via IM. The $\mathrm{Au}_{4} \mathrm{~L}_{4}$ ion species re-extracted from the data by software, and their abundances are compared to a theoretical model. Deviations indicate nanophase separation in the AuNP monolayer. Figure reproduced from [219]

et al. used ESI-IMS to study the structures of $\mathrm{Au}_{25}\left(\mathrm{SCH}_{2} \mathrm{CH}_{2} \mathrm{Ph}\right)_{18}$ and its fragments upon CID [216] (Fig. 20). As seen in Fig. 20, their results show that the $\mathrm{Au}_{25}$ exists in the gas phase as one structural isomer, with an $\mathrm{Au}_{13}$ as the core and six staples (-RS-Au-SR-Au-SR). In addition, the IMS results show formation of a series of eight bands that are related to the fragmentation of the outer protecting 'staples' shell, each containing an increasing number of $\mathrm{Au} l \mathrm{~S} m \mathrm{R} n$ products (Fig. 20). Fragments relating to the breakdown of the $\mathrm{Au}_{13}$ core can also be observed, along with other low-mass fragments.

McLean et al. used MALDI-IMS [217] for the analysis of low-mass Au-thiolate fragments derived from thiolate-protected AuNPs. Positive fragment ions generated were identified as identical to the gold-thiolate precursor complex, and hence, the authors postulate that a reversal of the reduction of the precursor complex has occurred due to the energy provided by the ionisation method (i.e. MALDI). On the other hand, negative fragment ions were found to be similar to capping structural motifs that are well established in the literature [218].

Cliffel et al. also used MALDI-IMS to study the mixed thiolate ligands on AuNPs and measured the phase segregation in the protecting monolayer. This is achieved when fragmentation of the Au-thiolate complex occurs during the MALDI process from the AuNP surface. These Au-thiolate separate via ion mobility in the gas phase from organic ions. $\mathrm{Au}_{4} \mathrm{~L}_{4}$ species were identified and then analysed. They claim this as a novel strategy for the analysis of nanophase separation on nanoparticles (Fig. 21) [217, 219].

\subsection{IR Spectroscopy}

Infrared (IR) spectroscopy is increasingly becoming a widely used technique aimed at determining gas-phase structures of metal clusters amongst others [220]. For instance, Armentrout et al. determined the structures of the dehydrogenated products of methane achieved by group 5 transition metals [221], and Asmis et al. have been determining the structures of transition-metal oxides [222, 223]. 
Table 5 Gas-phase IR spectroscopy of ligated neutral and anionic gold clusters. Experimentally observed absorption bands and structures are listed

\begin{tabular}{|c|c|c|c|c|}
\hline Gold cluster & $\begin{array}{l}\text { Absorption wave } \\
\text { number(s) }\left(\mathrm{cm}^{-1}\right)\end{array}$ & Ligand & Structure & References \\
\hline$\overline{\mathrm{Au}_{4}{ }^{0}}$ & 1,502 & $\mathrm{O}_{2}$ & 2D distorted Y-shaped & [226] \\
\hline $\mathrm{Au}_{7}{ }^{\mathrm{O}}$ & 1,063 & $\mathrm{O}_{2}$ & 2D centred hexagone & [226] \\
\hline $\mathrm{Au}_{9}{ }^{0}$ & 1,064 & $\mathrm{O}_{2}$ & 3D bicapped trigonal prism & [226] \\
\hline $\mathrm{Au}_{11}{ }^{0}$ & 1,058 & $\mathrm{O}_{2}$ & - & [226] \\
\hline $\mathrm{Au}_{21}{ }^{0}$ & 1,069 & $\mathrm{O}_{2}$ & - & [226] \\
\hline $\mathrm{Au}_{2}{ }^{0}$ & ca. 57 & $\mathrm{Kr}$ & - & [224] \\
\hline $\mathrm{Au}_{3}{ }^{0}$ & ca. 95 & $\mathrm{Kr}$ & Obtuse-angled isosceles triangle & [224] \\
\hline $\mathrm{Au}_{4}{ }^{0}$ & ca. 150 & $\mathrm{Kr}$ & 2D rhombus and Y-shaped & [224] \\
\hline $\mathrm{Au}_{7}{ }^{\mathrm{O}}$ & $165,186,201$ & $\mathrm{Kr}$ & 2D structure & [224] \\
\hline $\mathrm{Au}_{19}{ }^{0}$ & 149,167 & $\mathrm{Kr}$ & Truncated pyramid & [225] \\
\hline $\mathrm{Au}_{20}{ }^{0}$ & 148 & $\mathrm{Kr}$ & Tetrahedral & [225] \\
\hline $\mathrm{Au}_{4}{ }^{-}$ & ca. 1,060 & $\mathrm{O}_{2}$ & 2D distorted Y-shape & [232] \\
\hline $\mathrm{Au}_{6}^{-}$ & ca. 1,060 & $\mathrm{O}_{2}$ & $2 \mathrm{D} \mathrm{D}_{3 \mathrm{~h}}$ & [232] \\
\hline $\mathrm{Au}_{8}^{-}$ & $1,043,1,059,1,102$ & $\mathrm{O}_{2}$ & Planar edge-capped hexagon & [232] \\
\hline $\mathrm{Au}_{10}{ }^{-}$ & ca. 1,060 & $\mathrm{O}_{2}$ & $\begin{array}{l}\text { Planar - contains a } 7 \mathrm{Au} \\
\text { hexagonal motif }\end{array}$ & [232] \\
\hline $\mathrm{Au}_{x}{ }^{-}(x=12-20)$ & ca. 1,060 & $\mathrm{O}_{2}$ & - & [232] \\
\hline
\end{tabular}

Several gas-phase IR spectroscopic studies aimed at understanding the structures of small gold cluster anions, cations and neutrals were reported [224-232] and are the subject of another chapter in this book by A. Fielicke et al. Table 5 above is a summary of the absorption wave numbers observed for selected neutral and anionic gold clusters.

\subsection{UV-Vis Spectroscopy}

Gas-phase UV-Vis spectroscopic studies of gold clusters have been rarely reported. The first report on neutral and cationic clusters of the form $\mathrm{Au}_{n}(n=7,9,11,13)$ and $\mathrm{Au}_{n}{ }^{+}(n=6-13)$ appeared around 20 years ago [233]. The authors highlighted the odd-even alterations in the UV-Vis spectra; however, they concluded that little structural information could be extracted from these spectra. Thus, only $\mathrm{Au}_{13}$ was reported to be consistent with an icosahedral structure. Recently, the UV-Vis spectrum of the glutathione-protected gold cluster $\left[\mathrm{Au}_{25}(\mathrm{SG})_{18}-6 \mathrm{H}\right]^{7-}$ was reported [234]. Although no structural information was extracted, the authors have shown that the UV-Vis spectrum for this AuNC is similar in both the gas and solution phases. 

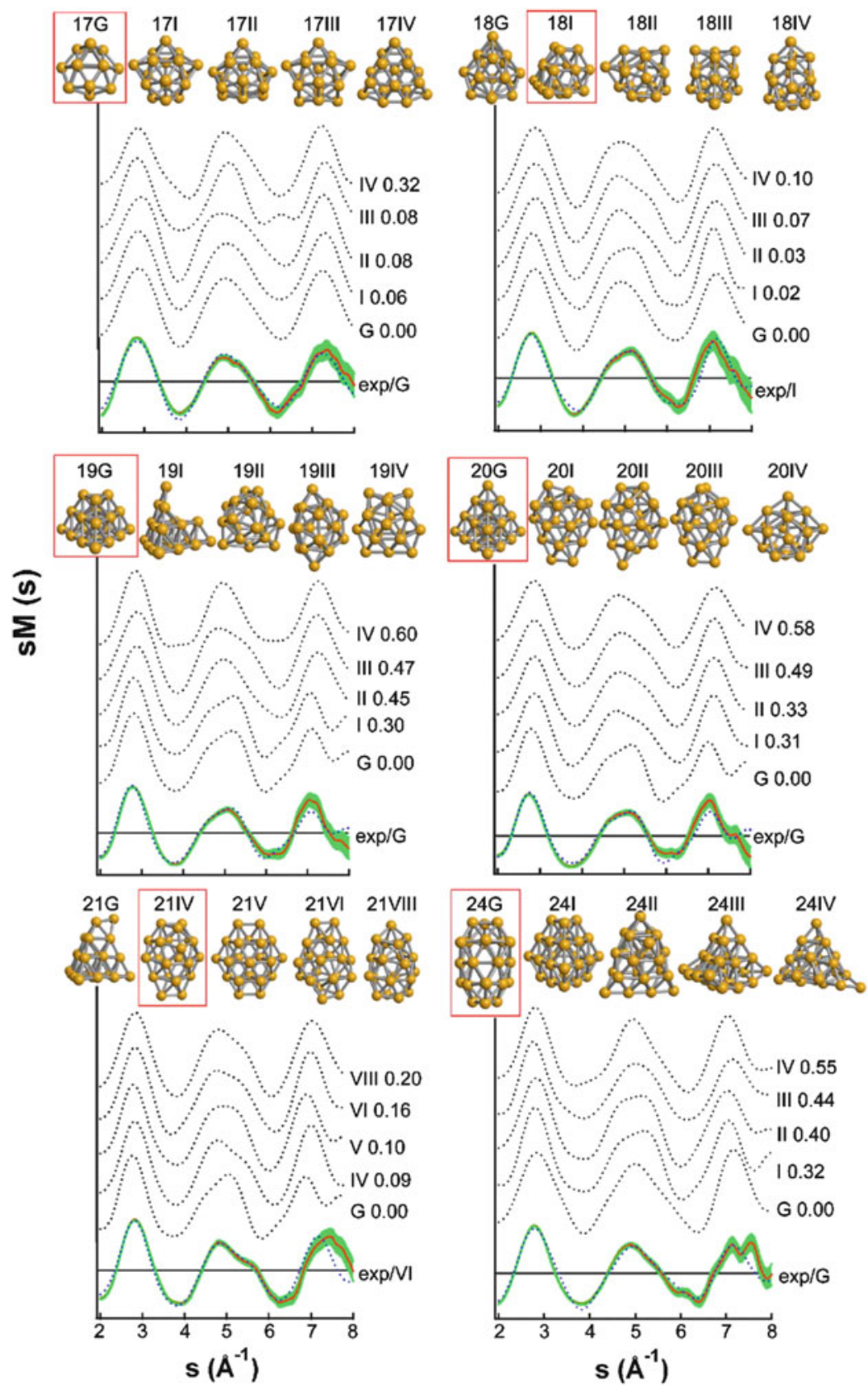

Fig. 22 Gas-phase electron diffraction of gold cluster anions. Calculated isomeric structures for $\mathrm{Au}_{n}{ }^{-}$ clusters with $11 \leq n \leq 16$ are shown at the top of each panel with their corresponding diffraction patterns $\left(s M(s)\right.$ vs $\left.s\left(\mathrm{~A}^{-1}\right)\right)$ depicted below (dotted curves). Experimental diffraction $s M(s)$ (solid curve, red) along with the best fit (dotted curve, blue) are shown at the bottom. The grey (online green) shading shows the data uncertainty $\pm \sigma$. The energy of the isomer relative to the ground state (GS) is shown on the right for each corresponding curve. The diffraction intensity has arbitrary units. The isomers that constitute the best fit are marked by a red frame in each panel. Figure reproduced from [236] 


\subsection{Trapped Ion Electron Diffraction}

TIED was also used in the structural determination of gold cluster ions. The analysis of the diffraction measurements is appropriate since it directly relates to the spatial arrangement of the scattering atoms. This technique however suffers from limitations due to, for example, the atomic scattering intensities which limit the lower end of detection and the inability to distinguish between isomers belonging to the same structural family.

Gold cluster anions were studied by Schooss and Kappes et al. [235] as well as by Parks et al. [236]. The work of Kappes et al. was recently reviewed [169]. Briefly, the structures of the anions $\mathrm{Au}_{n}{ }^{-}(n=11-20)$ have been determined by TIED and compared to theoretically calculated structures. The smallest cluster studied, $\mathrm{Au}_{11}{ }^{-}$, possessed a flat $\mathrm{C}_{\mathrm{s}}$ structure as was predicted by theory [237]. The structures of $\mathrm{Au}_{n}{ }^{-}(n=11,13)$ were reported to be in agreement with IMS studies (see before) and PES (Sect. 3.6). $\mathrm{Au}_{n}{ }^{-}(n=16-20)$ possess a cagelike structural motif, in agreement with previous PES studies. Parks et al.'s work on gold cluster anions $\mathrm{Au}_{n}{ }^{-} \quad(n=11-24)$ reported [236] structures that were also compared to DFT calculations. For $\mathrm{Au}_{n}{ }^{-}(n=11-12)$, structures were found that match those determined via IMS [209]. For $\mathrm{Au}_{13}{ }^{-}$, however, a mixture of isomers was reported, in disagreement with the previously mentioned TIED work. In addition the 3D structures reported for $\mathrm{Au}_{n}{ }^{-}(n=14,15)$ were in stark contrast to the previously mentioned TIED work. Structures for $\mathrm{Au}_{n}{ }^{-}(n=16-20)$ were in agreement with other TIED reports highlighting their cagelike structures (Fig. 22). $\mathrm{Au}_{21}{ }^{-}$and $\mathrm{Au}_{24}{ }^{-}$were reported to possess an elongated cage and a single-wall tube-like structure, respectively (Fig. 22).

Structures for gold cluster cations, $\mathrm{Au}_{11-20}{ }^{+}$, were also studied by TIED. The 3D structures of $\mathrm{Au}_{11-13}{ }^{+}$were found to be in close agreement to those reported by IMS. $\mathrm{Au}_{14-17^{+}}$were found to have layered structures, whereas a change in the structural motif to decorated cagelike structures is observed for $\mathrm{Au}_{18-20}{ }^{+}$with $\mathrm{Au}_{20}{ }^{+}$possessing 2 isomers.

In many cases, the minimum-energy structures obtained by calculations were not consistent with the experimental scattering function. It was rather calculated structures with higher energies that fitted the experimental data.

\subsection{Photoelectron Spectroscopy}

Another technique used in determining the structures of anionic clusters is PES. We should note that experiments conducted in the last century generated useful data, however failed to yield detailed structural information. In all cases, an odd-even oscillation in the values of the electron affinity was observed [233, 238]. Bare 
anionic gold clusters were widely studied in particular by Lai-Sheng Wang et al. who have recently reviewed their wide body of work (see [239] with references therein) and included some comparisons to other reports. Briefly, the structures of the anionic clusters $\mathrm{Au}_{n}{ }^{-}(n=3-15)$ were reported as 2D flat structures for $n \leq 12$ [240]. This was surprising since metal clusters are expected to form $3 \mathrm{D}$ structures in this size range. For $n=12$, a mixture of isomers (2D and 3D) has been reported, and hence this size represents the transition from 2D to 3D structures for gold cluster anions. In the case of $n=13-15,3 \mathrm{D}$ structures are expected. Mixtures of isomeric structures were identified for most of the cluster sizes for $n=7-15$.

Argon tagging and oxygen titration were used to shed more light on the structures of $\mathrm{Au}_{n}{ }^{-}$[241]. For instance, they were used to resolve the issue of isomeric $\mathrm{Au}_{10}{ }^{-}$where four distinct isomers were found to coexist and they were readily distinguished (Fig. 23). It should be noted that the formation of a superoxo was observed and confirmed via PES, upon adsorption of $\mathrm{O}_{2}$ onto gold cluster anions $\left(\mathrm{Au}_{n}{ }^{-}\right)$with an even number of gold atoms [242, 243]. In addition, substitution in $\mathrm{Au}_{n}{ }^{-}$by isoelectronic $\mathrm{Cu}$ or $\mathrm{Ag}$ was also used as another method that provide information on the various isomers [244].

Structures of the gold clusters, $\mathrm{Au}_{n}{ }^{-}$, in the range $n=16-19$ [245] were also reported (Fig. 24). The major isomers found for $n=16-18$ were dominated by hollow cage motifs, with the $\mathrm{Au}_{16}{ }^{-}$structure being the most interesting. This highly symmetrical cage structure ( $\mathrm{T}_{d}$ symmetry) shows, amongst others, a break from the odd-even trend observed for coinage metal cluster ions. $\mathrm{Au}_{19}{ }^{-}$structure was resolved and assigned as a single isomer with a pyramidal structure. A transition from cage structure to pyramidal is observed at $\mathrm{Au}_{18}{ }^{-}$.

A tetrahedral symmetric structure for $\mathrm{Au}_{20}{ }^{-}$was reported (Fig. 24) [203]. This highly symmetric cluster is special, possessing a large HUMO-LUMO gap of $1.77 \mathrm{eV}$ reminiscent of $\mathrm{C}_{60}{ }^{-}$. Excluding $\mathrm{Au}_{2}$ and $\mathrm{Au}_{6}$, this HUMO-LUMO gap is the largest amongst all known coinage metal clusters [238]. The high symmetry of this structure led several researchers to attempt the synthesis of ligand-protected golden pyramids with an $\mathrm{Au}_{20}$ core. For example, the isolation of the thiolatecapped $\mathrm{Au}_{20}\left(\mathrm{SCH}_{2} \mathrm{CH}_{2} \mathrm{Ph}\right)_{16}$ cluster has recently been reported [246].

The experimental vertical detachment energies and adiabatic detachment energies measured for $\mathrm{Au}_{n}{ }^{-}(n=2-20)$ gold cluster anions via PES are listed in Table 6.

Few experimental structures of the anions in the range $\mathrm{Au}_{n}{ }^{-} n=21-35$ have been proposed [247-249] to range from pyramidal to tubular to core-shell. $\mathrm{Au}_{21}{ }^{-}$ possesses a pyramidal structure, whereas $\mathrm{Au}_{22,23}{ }^{-}$were reported to have mixed isomers: pyramidal and fused planar. $\mathrm{Au}_{24}{ }^{-}$was found to be tubular and $\mathrm{Au}_{25}{ }^{-}$with a core-shell structure. This latter cluster is the smallest anionic gold cluster with an atom in the core. Larger clusters were reported to have low-symmetry core-shell structures. 
a

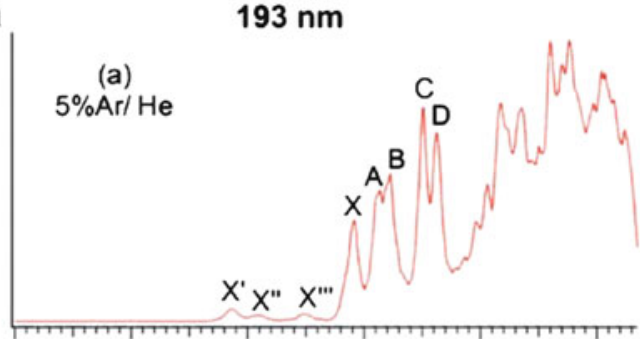

(b)

$0.1 \% \mathrm{O}_{2} / \mathrm{He}$

(c)

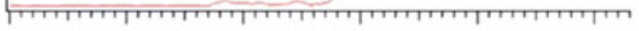

$$
0.5 \% \mathrm{O}_{2} / \mathrm{He}
$$

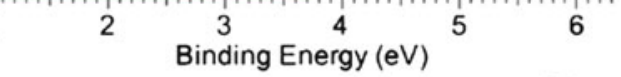

b

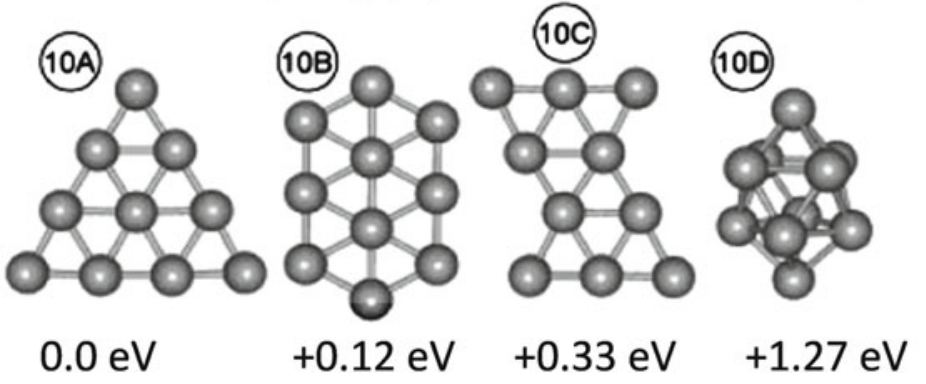

Fig. 23 (a) Comparison of the $193 \mathrm{~nm}$ and $266 \mathrm{~nm}$ PES spectra of $\mathrm{Au}_{10}{ }^{-}$produced using a 5\% $\mathrm{Ar}-\mathrm{He}(a)$ or pure $\mathrm{He}(d)$ as carrier gases with those using $0.1 \% \mathrm{O}_{2}-\mathrm{He}(b, e)$ and $0.5 \% \mathrm{O}_{2}-\mathrm{He}$ $(c, f)$ as carrier gases. Note that the weak features $\left(\mathrm{X}^{\prime}, \mathrm{X}^{\prime \prime}, \mathrm{X}^{\prime \prime \prime}\right)$ are titrated out with increasing $\mathrm{O}_{2}$ concentration. A-D are spectral features due to the $\mathrm{D}_{3 \mathrm{~h}}$ global minimum structure. (b) Calculated minimum-energy structures for $\mathrm{Au}_{10}{ }^{-}$(10A is the global minimum). Figures reproduced from (a) [240] and (b) [241] 
A. Zavras et al.

Fig. 24 Lowest-energy structures of the $\mathrm{Au}_{n}{ }^{-}$ clusters for $n=16-20$ as determined via DFT calculations.

Figure reproduced from [245]

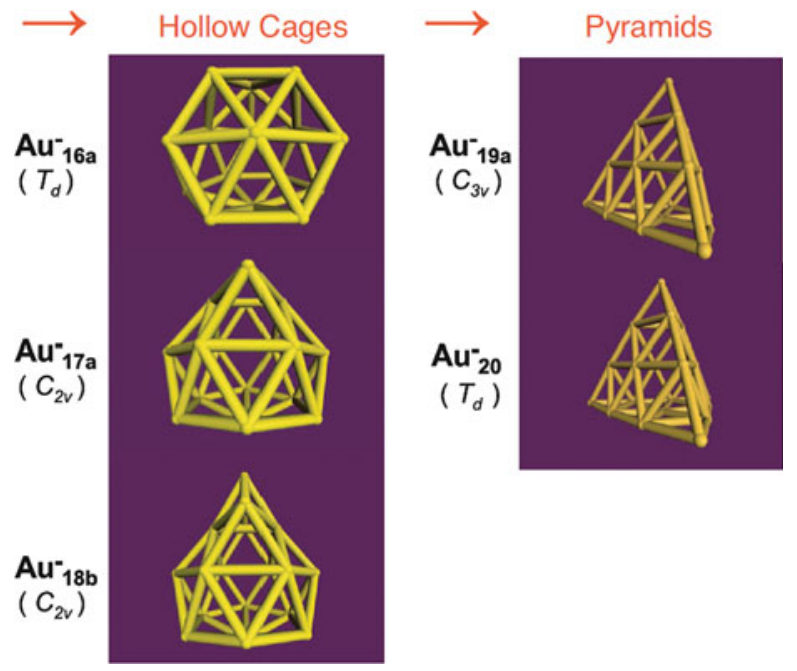

Table 6 Experimental vertical detachment energies (VDE) and adiabatic detachment energies (ADE) for $\mathrm{Au}_{n}{ }^{-}(n=2-20)$

\begin{tabular}{llll}
\hline Cluster $\mathrm{Au}_{n}{ }^{-}$ & Experimental VDE $(\mathrm{eV})$ & Experimental ADE $(\mathrm{eV})$ & References \\
\hline 2 & 2.01 & 1.92 & {$[240]$} \\
3 & 3.88 & 3.88 & {$[240]$} \\
4 & 2.75 & 2.70 & {$[240]$} \\
5 & 3.09 & 3.06 & {$[240]$} \\
6 & 2.13 & 2.06 & {$[240]$} \\
7 & 3.46 & 3.40 & {$[240]$} \\
8 & 2.79 & 2.73 & {$[240]$} \\
9 & 3.83 & 3.81 & {$[240]$} \\
10 & 3.91 & 3.89 & {$[240]$} \\
11 & 3.80 & 3.76 & {$[240]$} \\
12 & 3.06 & 3.03 & {$[240]$} \\
13 & 3.94 & 3.91 & {$[240]$} \\
14 & 3.00 & 2.94 & {$[240]$} \\
15 & 3.65 & - & {$[245]$} \\
16 & 4.03 & - & {$[245]$} \\
17 & 4.08 & - & {$[245]$} \\
18 & 3.32 & - & {$[245]$} \\
19 & 3.74 & - & {$[245]$} \\
20 & 2.751 & 2.745 & {$[203]$} \\
\hline
\end{tabular}


Table 7 Key gas-phase bond energies derived from guided ion beam studies of $\mathrm{Au}^{+}$reacting with substrates

\begin{tabular}{lllll}
\hline Substrate & Reaction products & $\begin{array}{l}\text { Bond energy } \\
\text { derived }\end{array}$ & $\begin{array}{l}\text { Bond energy eV } \\
\left(\mathrm{kJ} \mathrm{mol}^{-1}\right)\end{array}$ & References \\
\hline $\mathrm{H}_{2}\left(\mathrm{D}_{2}\right)$ & $\mathrm{AuH}^{+}\left(\mathrm{AuD}^{+}\right)+\mathrm{H}(\mathrm{D})$ & $\mathrm{Au}^{+}-\mathrm{H}$ & $2.13 \pm 0.11(206 \pm 11)^{\mathrm{a}}$ & {$[258]$} \\
$\mathrm{CH}_{4}$ & $\mathrm{AuH}^{+}+\mathrm{CH}_{3}$ & $\mathrm{Au}^{+}-\mathrm{H}$ & $1.94 \pm 0.08(187 \pm 8)^{\mathrm{b}}$ & {$[260]$} \\
$\mathrm{CH}_{4}$ & $\mathrm{AuCH}_{3}{ }^{+}+\mathrm{H}$ & $\mathrm{Au}^{+}-\mathrm{CH}_{3}$ & $1.91 \pm 0.13(184 \pm 13)$ & {$[260]$} \\
$\mathrm{CH}_{4}$ & $\mathrm{AuCH}_{2}^{+}+\mathrm{H}_{2}$ & $\mathrm{Au}^{+}-\mathrm{CH}_{2}$ & $3.75 \pm 0.05(362 \pm 5)$ & {$[260]$} \\
$\mathrm{O}_{2}$ & $\mathrm{AuO}^{+}+\mathrm{O}$ & $\mathrm{Au}^{+}-\mathrm{O}$ & $>0.42 \pm 0.20(>41 \pm 19)^{\mathrm{c}}$ & {$[259]$} \\
$\mathrm{N}_{2} \mathrm{O}$ & $\mathrm{AuO}^{+}+\mathrm{N}_{2}$ & $\mathrm{Au}^{+}-\mathrm{O}$ & $>0.55 \pm 0.07(>53 \pm 7)^{\mathrm{c}}$ & {$[259]$} \\
$\mathrm{N}_{2} \mathrm{O}$ & $\mathrm{AuN}_{2}^{+}+\mathrm{O}$ & $\mathrm{Au}^{+}-\mathrm{N}_{2}$ & $>0.30 \pm 0.04(>29 \pm 4)^{\mathrm{c}}$ & {$[259]$} \\
\hline
\end{tabular}

${ }^{a}$ Average from measurements of both $\mathrm{H}_{2}$ and $\mathrm{D}_{2}$, adjusted for the zero point energy difference

${ }^{\mathrm{b}}$ Lower limit of bond energy

${ }^{\mathrm{c}}$ Lower limit due to impulsive behaviour

\subsection{Thermochemistry}

There is a rich history on the use of mass spectrometry-based methods to measure the binding energies of substrates to metal ions and metal cluster ions using gas-phase ion-molecule reactions [31, 250-257].

Much of the earlier literature dealt with the thermochemistry associated with bare metal atomic cations [253]. Recent guided ion beam measurements from Armentrout et al. [258-260] have examined the reactions of $\mathrm{Au}^{+}$with $\mathrm{H}_{2}, \mathrm{D}_{2}$, $\mathrm{HD}, \mathrm{O}_{2}, \mathrm{~N}_{2} \mathrm{O}$ and $\mathrm{CH}_{4}$ and have provided important $\mathrm{Au}^{+}-\mathrm{X}$ bond energies, which are listed in Table 7.

Two key methods have been used to measure the binding energies of substrates to gold cluster ions: (1) equilibrium measurements, whereby an equilibrium between the cluster ion, $\mathrm{Au}_{n}^{+-}$, and the neutral, $\mathrm{L}$, at a known concentration and temperature is established (Eq. (13)). Measurement of the relative ion signals for the cluster ion, $\mathrm{Au}_{n}^{+/-}$, and its complex, $\mathrm{Au}_{n}(\mathrm{~L})^{+/-}$, combined with the known concentration of the neutral allows the equilibrium constant to be determined, from which the binding energy can be calculated. (2) Kinetic measurements, whereby the rate of reaction between the cluster ion, $\mathrm{Au}_{n}{ }^{+-}$, and the neutral, $\mathrm{L}$, at a known concentration and temperature is determined (Eq. (14)). The initially formed energised adduct undergoes collisional stabilisation with the bath gas, which is typically helium in ion-trapping instruments. Treatment of the kinetic data using theoretical approaches such as Rice-Ramsperger-Kassel-Marcus (RRKM) theory can allow the binding energy to be estimated:

$$
\mathrm{Au}_{n}^{+/-}+\mathrm{L} \rightleftharpoons \mathrm{Au}_{n}(\mathrm{~L})^{+/-}
$$




$$
\mathrm{Au}_{n}^{+/-}+\mathrm{L} \rightarrow\left[\mathrm{Au}_{n}(\mathrm{~L})^{+/-}\right]^{*} \stackrel{\mathrm{He}}{\rightarrow} \mathrm{Au}_{n}(\mathrm{~L})^{+/-}
$$

Table 8 lists the gas-phase binding energies of gold cluster ions towards a range of substrates $[261,262]$. The motivation of many of these studies was to provide a firm thermochemical understanding of key steps associated with possible catalytic cycles for the processing of substrates. Thus the reader is directed to related studies on ion-molecule reactions (Sect. 4.1) and catalytic cycles (Sect. 4.3).

An examination of the data in Table 8 reveals some interesting trends:

1. The thermochemistry associated with room temperature $\mathrm{CO}$ adsorption on isolated gold cluster cations exhibits a pronounced cluster size effect for the adsorption energies for the first $\mathrm{CO}$ molecule binding to the gold cluster ions. The binding energies decrease with increasing cluster size from $1.09 \mathrm{eV}$ for $n=6$ to less than $0.65 \mathrm{eV}$ or $n=26$. Exceptions were local maxima of between 0.73 and 0.75 , which were found for $n=30,31$, and 48, 49. The atom-by-atom variations were suggested to arise from different binding sites on the gold clusters, consistent with DFT calculations on the smallest cluster sizes $n=3-9$ and $n=20$.

2. Not surprisingly, the binding energies also depend on the nature of the substrate. Thus $\mathrm{CO}$ binds more strongly than $\mathrm{CH}_{4}$ to the gold cluster cations.

3. The magnitude of the cluster charge is important. Thus CO binds more strongly to the cluster cations than the cluster anions.

The combination of experiment and DFT calculations provides valuable insight into how binding energies change upon sequential addition of $\mathrm{CO}$ and how this influences the geometry of the gold cluster core. A case in point is the binding of $\mathrm{CO}$ to the homo and hetero, $\mathrm{M}$ gold and silver cluster cations, $\mathrm{M}_{5-{ }_{x}} \mathrm{M}_{x}^{\prime}{ }^{+}$(where $\mathrm{M}=\mathrm{Au}$ and $\mathrm{M}^{\prime}=\mathrm{Ag}$ ) [267]. At room temperature, $\mathrm{Au}_{5}{ }^{+}$rapidly absorbed four $\mathrm{CO}$ molecules, with absorption of a fifth $\mathrm{CO}$ only occurring at temperatures lower than $250 \mathrm{~K}$. This is consistent with the results of DFT calculations (Fig. 25), which reveal that the 'bow-tie' structure for the bare $\mathrm{Au}_{5}{ }^{+}$cluster can readily bind four $\mathrm{CO}$ molecules at each of the four corner atoms. Binding of a fifth $\mathrm{CO}$ requires the gold cluster core to undergo a rearrangement to a structure described as a 'side-capped tetrahedron'. Related structural transitions were determined for the mixed goldsilver clusters $\mathrm{Au}_{3} \mathrm{Ag}_{2}{ }^{+}, \mathrm{Au}_{2} \mathrm{Ag}_{3}{ }^{+}$and $\mathrm{AuAg}_{4}{ }^{+}$.

\section{Reactivity of Gold Cluster Ions}

The gas-phase reactions of gold cluster anions and cations with single and multiple neutral substrates have been widely studied over the past 2 decades. Much of this work has been inspired by Haruta's discovery of CO oxidation by gold clusters 
Gas Phase Formation, Structure and Reactivity of Gold Cluster Ions

Table 8 Gas-phase binding energies of substrates to gold cluster ions

\begin{tabular}{|c|c|c|c|c|}
\hline Au cluster ion & Substrate & Binding energy eV $\left(\mathrm{kJ} \mathrm{mol}^{-1}\right)$ & Method & Reference \\
\hline$\overline{\mathrm{Au}^{+}}$ & $\mathrm{CO}$ & $2.08 \pm 0.15(201 \pm 14)$ & $\bar{a}$ & {$[261,262]$} \\
\hline $\mathrm{Au}_{5}^{+}$ & $\mathrm{CO}$ & $1.03 \pm 0.1(99 \pm 10)$ & $\mathrm{c}$ & [263] \\
\hline $\mathrm{Au}_{5}^{+}$ & $\mathrm{CO}$ & $1.04 \pm 0.1(100 \pm 10)$ & $\mathrm{c}$ & [263] \\
\hline $\mathrm{Au}_{6}^{+}$ & $\mathrm{CO}$ & $1.09 \pm 0.1(105 \pm 10)$ & $\mathrm{c}$ & {$[263,264]$} \\
\hline $\mathrm{Au}_{7}^{+}$ & $\mathrm{CO}$ & $1.07 \pm 0.1(103 \pm 10)$ & $\mathrm{c}$ & [263] \\
\hline $\mathrm{Au}_{8}^{+}$ & $\mathrm{CO}$ & $0.89 \pm 0.1(86 \pm 10)$ & $\mathrm{c}$ & [263] \\
\hline $\mathrm{Au}_{9}^{+}$ & $\mathrm{CO}$ & $0.85 \pm 0.1(82 \pm 10)$ & $\mathrm{c}$ & [263] \\
\hline $\mathrm{Au}_{10}^{+}$ & $\mathrm{CO}$ & $0.90 \pm 0.1(87 \pm 10)$ & $\mathrm{c}$ & [263] \\
\hline $\mathrm{Au}_{11}^{+}$ & $\mathrm{CO}$ & $0.90 \pm 0.1(87 \pm 10)$ & $\mathrm{c}$ & [263] \\
\hline $\mathrm{Au}_{12}^{+}$ & $\mathrm{CO}$ & $0.87 \pm 0.1(84 \pm 10)$ & $\mathrm{c}$ & [263] \\
\hline $\mathrm{Au}_{13}^{+}$ & $\mathrm{CO}$ & $0.86 \pm 0.1(83 \pm 10)$ & $\mathrm{c}$ & [263] \\
\hline $\mathrm{Au}_{14}^{+}$ & $\mathrm{CO}$ & $0.86 \pm 0.1(83 \pm 10)$ & $\mathrm{c}$ & [263] \\
\hline $\mathrm{Au}_{15}^{+}$ & $\mathrm{CO}$ & $0.88 \pm 0.1(85 \pm 10)$ & $\mathrm{c}$ & [263] \\
\hline $\mathrm{Au}_{16}^{+}$ & $\mathrm{CO}$ & $0.86 \pm 0.1(83 \pm 10)$ & $\mathrm{c}$ & [263] \\
\hline $\mathrm{Au}_{17}^{+}$ & $\mathrm{CO}$ & $0.80 \pm 0.1(77 \pm 10)$ & $\mathrm{c}$ & [263] \\
\hline $\mathrm{Au}_{18}^{+}$ & $\mathrm{CO}$ & $0.85 \pm 0.1(82 \pm 10)$ & $\mathrm{c}$ & [263] \\
\hline $\mathrm{Au}_{19}^{+}$ & $\mathrm{CO}$ & $0.84 \pm 0.1(81 \pm 10)$ & $\mathrm{c}$ & [263] \\
\hline $\mathrm{Au}_{20}^{+}$ & $\mathrm{CO}$ & $0.78 \pm 0.1(75 \pm 10)$ & $\mathrm{c}$ & [263] \\
\hline $\mathrm{Au}_{21}^{+}$ & $\mathrm{CO}$ & $0.81 \pm 0.1(78 \pm 10)$ & $\mathrm{c}$ & [263] \\
\hline $\mathrm{Au}_{22}^{+}$ & $\mathrm{CO}$ & $0.71 \pm 0.1(69 \pm 10)$ & $\mathrm{c}$ & [263] \\
\hline $\mathrm{Au}_{23}{ }^{+}$ & $\mathrm{CO}$ & $0.66 \pm 0.1(64 \pm 10)$ & $\mathrm{c}$ & [263] \\
\hline $\mathrm{Au}_{24}^{+}$ & $\mathrm{CO}$ & $0.70 \pm 0.1(68 \pm 10)$ & $\mathrm{c}$ & [263] \\
\hline $\mathrm{Au}_{25}^{+}$ & $\mathrm{CO}$ & $0.70 \pm 0.1(68 \pm 10)$ & $\mathrm{c}$ & [263] \\
\hline $\mathrm{Au}_{26-29}{ }^{+}$ & $\mathrm{CO}$ & $<0.65(<63)$ & $\mathrm{c}$ & [263] \\
\hline $\mathrm{Au}_{30}^{+}$ & $\mathrm{CO}$ & $0.73 \pm 0.1(70 \pm 10)$ & $\mathrm{c}$ & [263] \\
\hline $\mathrm{Au}_{31}^{+}$ & $\mathrm{CO}$ & $0.75 \pm 0.1(72 \pm 10)$ & $\mathrm{c}$ & [263] \\
\hline $\mathrm{Au}_{32}^{+}$ & $\mathrm{CO}$ & $0.69 \pm 0.1(67 \pm 10)$ & $\mathrm{c}$ & [263] \\
\hline $\mathrm{Au}_{33-40}{ }^{+}$ & $\mathrm{CO}$ & $<0.65(<63)$ & $\mathrm{c}$ & [263] \\
\hline $\mathrm{Au}_{41}^{+}$ & $\mathrm{CO}$ & $0.65 \pm 0.1(63 \pm 10)$ & $\mathrm{c}$ & [263] \\
\hline $\mathrm{Au}_{42-47}^{+}$ & $\mathrm{CO}$ & $<0.65(<63)$ & $\mathrm{c}$ & [263] \\
\hline $\mathrm{Au}_{48}^{+}$ & $\mathrm{CO}$ & $0.74 \pm 0.1(71 \pm 10)$ & $\mathrm{c}$ & [263] \\
\hline $\mathrm{Au}_{49}^{+}$ & $\mathrm{CO}$ & $0.74 \pm 0.1(71 \pm 10)$ & $\mathrm{c}$ & [263] \\
\hline $\mathrm{Au}_{50-65}{ }^{+}$ & $\mathrm{CO}$ & $<0.65(<63)$ & $\mathrm{c}$ & [263] \\
\hline $\mathrm{Au}_{2}^{+}$ & $\mathrm{CH}_{4}$ & $0.65 \pm 0.03(63 \pm 3)$ & $\mathrm{d}, \mathrm{e}$ & [265] \\
\hline $\mathrm{Au}_{2}^{+}$ & $\mathrm{CH}_{4}$ & $0.91 \pm 0.04(88 \pm 4)$ & $d, f$ & [265] \\
\hline $\mathrm{Au}_{3}^{+}$ & $\mathrm{CH}_{4}$ & $0.40 \pm 0.06(39 \pm 6)$ & $\mathrm{d}, \mathrm{e}$ & [265] \\
\hline $\mathrm{Au}_{3}^{+}$ & $\mathrm{CH}_{4}$ & $0.72 \pm 0.07(69 \pm 7)$ & $d, f$ & [265] \\
\hline $\mathrm{Au}_{4}^{+}$ & $\mathrm{CH}_{4}$ & $0.36 \pm 0.04(35 \pm 4)$ & $\mathrm{d}, \mathrm{e}$ & [265] \\
\hline $\mathrm{Au}_{4}^{+}$ & $\mathrm{CH}_{4}$ & $0.64 \pm 0.04(62 \pm 4)$ & $d, f$ & {$[265]$} \\
\hline $\mathrm{Au}_{5}^{+}$ & $\mathrm{CH}_{4}$ & $0.32 \pm 0.09(31 \pm 9)$ & $\mathrm{d}, \mathrm{e}$ & [265] \\
\hline $\mathrm{Au}_{5}^{+}$ & $\mathrm{CH}_{4}$ & $0.57 \pm 0.09(55 \pm 9)$ & $d, f$ & [265] \\
\hline $\mathrm{Au}_{6}^{+}$ & $\mathrm{CH}_{4}$ & $0.20 \pm 0.02(19 \pm 2)$ & $\mathrm{d}, \mathrm{e}$ & [265] \\
\hline $\mathrm{Au}_{6}^{+}$ & $\mathrm{CH}_{4}$ & $0.41 \pm 0.03(40 \pm 3)$ & $\mathrm{d}, \mathrm{f}$ & [265] \\
\hline $\mathrm{Ag}_{2} \mathrm{Au}^{+}$ & $\mathrm{CO}$ & $0.81 \pm 0.1(78 \pm 10)$ & $\mathrm{d}$ & [266] \\
\hline $\mathrm{Ag}_{2} \mathrm{Au}(\mathrm{CO})^{+}$ & $\mathrm{CO}$ & $0.77 \pm 0.1(74 \pm 10)$ & $\mathrm{d}$ & [266] \\
\hline $\mathrm{Ag}_{2} \mathrm{Au}(\mathrm{CO})_{2}{ }^{+}$ & $\mathrm{CO}$ & $0.73 \pm 0.1(70 \pm 10)$ & $\mathrm{d}$ & [266] \\
\hline
\end{tabular}


Table 8 (continued)

\begin{tabular}{lllll}
\hline $\mathrm{Au}$ cluster ion & Substrate & Binding energy eV $\left(\mathrm{kJ} \mathrm{mol}^{-1}\right)$ & Method & Reference \\
\hline $\mathrm{AgAu}_{4}{ }^{+}$ & $\mathrm{CO}$ & $1.01 \pm 0.1(97 \pm 10)$ & $\mathrm{c}$ & {$[264]$} \\
$\mathrm{Ag}_{2} \mathrm{Au}_{3}{ }^{+}$ & $\mathrm{CO}$ & $0.78 \pm 0.1(75 \pm 10)$ & $\mathrm{c}$ & {$[264]$} \\
$\mathrm{Ag}_{3} \mathrm{Au}_{2}(\mathrm{CO})_{2}{ }^{+}$ & $\mathrm{CO}$ & $0.52 \pm 0.1(50 \pm 10)$ & $\mathrm{b}$ & {$[267]$} \\
$\mathrm{Ag}_{3} \mathrm{Au}_{2}(\mathrm{CO})_{3}{ }^{+}$ & $\mathrm{CO}$ & $0.47 \pm 0.1(45 \pm 10)$ & $\mathrm{b}$ & {$[267]$} \\
$\left.\mathrm{Ag}_{3} \mathrm{Au}_{2} \mathrm{CO}\right)_{4}{ }^{+}$ & $\mathrm{CO}$ & $0.33 \pm 0.1(32 \pm 10)$ & $\mathrm{b}$ & {$[267]$} \\
$\mathrm{Ag}_{4} \mathrm{Au}^{+}$ & $\mathrm{CO}$ & $0.77 \pm 0.1(74 \pm 10)$ & $\mathrm{b}$ & {$[267]$} \\
$\mathrm{Ag}_{4} \mathrm{Au}(\mathrm{CO})^{+}$ & $\mathrm{CO}$ & $0.73 \pm 0.1(70 \pm 10)$ & $\mathrm{b}$ & {$[267]$} \\
$\mathrm{Ag}_{4} \mathrm{Au}(\mathrm{CO})_{2}{ }^{+}$ & $\mathrm{CO}$ & $0.55 \pm 0.1(53 \pm 10)$ & $\mathrm{b}$ & {$[267]$} \\
$\mathrm{Ag}_{4} \mathrm{Au}(\mathrm{CO})_{3}{ }^{+}$ & $\mathrm{CO}$ & $0.05 \pm 0.1(5 \pm 10)$ & $\mathrm{b}$ & {$[267]$} \\
$\mathrm{Ag}_{4} \mathrm{Au}(\mathrm{CO})_{4}{ }^{+}$ & $\mathrm{CO}$ & $0.07 \pm 0.1(7 \pm 10)$ & $\mathrm{b}$ & {$[267]$} \\
$\mathrm{Ag}_{4} \mathrm{Au}(\mathrm{CO})_{5}{ }^{+}$ & $\mathrm{CO}$ & $0.07 \pm 0.1(7 \pm 10)$ & $\mathrm{b}$ & {$[267]$} \\
$\mathrm{AgAu}_{5}{ }^{+}$ & $\mathrm{CO}$ & $0.96 \pm 0.1(93 \pm 10)$ & $\mathrm{c}$ & {$[264]$} \\
$\mathrm{Ag}_{2} \mathrm{Au}_{4}{ }^{+}$ & $\mathrm{CO}$ & $0.92 \pm 0.1(89 \pm 10)$ & $\mathrm{c}$ & {$[264]$} \\
$\mathrm{Ag}_{3} \mathrm{Au}{ }_{3}^{+}$ & $\mathrm{CO}$ & $0.77 \pm 0.1(74 \pm 10)$ & $\mathrm{c}$ & {$[264]$} \\
$\mathrm{Au}_{2}{ }^{-}$ & $\mathrm{CO}$ & $0.18 \pm 0.02(17 \pm 2)$ & $\mathrm{d}, \mathrm{e}$ & {$[268]$} \\
$\mathrm{Au}_{2}{ }^{-}$ & $\mathrm{CO}$ & $0.38 \pm 0.04(37 \pm 4)$ & $\mathrm{d}, \mathrm{f}$ & {$[268]$} \\
$\mathrm{Au}_{3}{ }^{-}$ & $\mathrm{CO}$ & $0.28 \pm 0.04(27 \pm 4)$ & $\mathrm{d}, \mathrm{e}$ & {$[268]$} \\
$\mathrm{Au}_{3}{ }^{-}$ & $\mathrm{CO}$ & $0.46 \pm 0.05(44 \pm 5)$ & $\mathrm{d}, \mathrm{f}$ & {$[268]$} \\
$\mathrm{Au}_{3}(\mathrm{CO})^{-}$ & $\mathrm{CO}$ & $0.28 \pm 0.1(27 \pm 10)$ & $\mathrm{d}$ & {$[266]$} \\
$\mathrm{Au}_{2}{ }^{-}$ & $\mathrm{O}$ & $0.60 \pm 0.10(58 \pm 10)$ & $\mathrm{d}, \mathrm{e}$ & {$[268]$} \\
$\mathrm{Au}_{2}{ }^{-}$ & $\mathrm{O}$ & $0.93 \pm 0.10(90 \pm 10)$ & $\mathrm{d}, \mathrm{f}$ & {$[268]$} \\
$\mathrm{AgAu}^{-}$ & $\mathrm{O}$ & $1.10 \pm 0.15(106 \pm 14)$ & $\mathrm{d}, \mathrm{e}$ & {$[268]$} \\
$\mathrm{AgAu}^{-}$ & $\mathrm{O}$ & $1.59 \pm 0.20(153 \pm 19)$ & $\mathrm{d}, \mathrm{f}$ & {$[268]$} \\
\hline $\mathrm{Bra}^{-}$ & & &
\end{tabular}

${ }^{\mathrm{a}}$ Bracketing method

${ }^{\mathrm{b}}$ Equilibrium measurement

${ }^{\mathrm{c}}$ Radiative association

${ }^{\mathrm{d}}$ Kinetic measurement with RRKM modelling

${ }^{\mathrm{e}}$ Modelled with a tight TS

${ }^{\mathrm{f}}$ Modelled with a loose TS

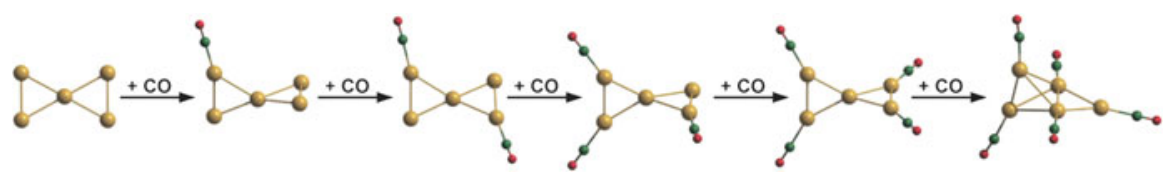

Fig. 25 DFT-calculated changes to the gold core structure upon sequential binding of $\mathrm{CO}$ to $\mathrm{Au}_{5}{ }^{+}$. Figure reproduced from [267]

(Eq. (3)). By examining the role of charge and cluster size, a considerable body of reactivity patterns has been accumulated. Reactions of bare gold cluster ions are discussed in Sect. 4.1 and those of ligated clusters in Sect. 4.2, while mixed metal clusters are discussed in Sect. 4.3. Finally complete catalytic cycles are described in Sect. 4.4. 
Table 9 Gas-phase products and rates constants for the reactions of gold dimers with neutral substrates

\begin{tabular}{|c|c|c|c|c|c|c|}
\hline Substrate & $\begin{array}{l}\mathrm{Au}_{2}{ }^{+} \\
\text {rate }^{\mathrm{a}}\end{array}$ & $\mathrm{Au}_{2}{ }^{+} \operatorname{Product}(\mathrm{s})$ & $\mathrm{Au}_{2}$ rate $^{\mathrm{b}}$ & $\mathrm{Au}_{2} \operatorname{product}(\mathrm{s})^{\mathrm{a}}$ & $\mathrm{Au}_{2}{ }^{-} \mathrm{rate}^{\mathrm{c}}$ & $\mathrm{Au}_{2}{ }^{-} \operatorname{product}(\mathrm{s})$ \\
\hline $\mathrm{O}_{2}$ & $\mathrm{NR}^{\mathrm{c}}$ & $\mathrm{NR}^{\mathrm{b}}$ & $\mathrm{NR}^{\mathrm{b}}$ & $\mathrm{NR}^{\mathrm{b}}$ & $83 \pm 8^{c}$ & $\mathrm{Au}_{2}(\mathrm{O})_{2}{ }^{-}$ \\
\hline $\mathrm{N}_{2} \mathrm{O}$ & $0.24^{\mathrm{d}}$ & $\mathrm{NO}^{+}+\mathrm{Au}_{2} \mathrm{~N}$ & $\mathrm{NR}^{\mathrm{b}}$ & $\mathrm{NR}^{\mathrm{b}}$ & NS & NS \\
\hline $\mathrm{N}_{2}$ & NS & NS & $\mathrm{NR}^{\mathrm{b}}$ & $\mathrm{NR}^{\mathrm{b}}$ & NS & NS \\
\hline $\mathrm{CH}_{4}$ & $2.9^{\mathrm{e}}$ & $\mathrm{Au}_{2} \mathrm{CH}_{4}^{+}$ & $\mathrm{NR}^{\mathrm{b}}$ & $\mathrm{NR}^{\mathrm{b}}$ & NS & NS \\
\hline $\mathrm{CO}$ & NR & NR & $2.6 \pm 0.9$ & $\mathrm{Au}_{2}(\mathrm{CO})$ & $5.1 \pm 1^{\mathrm{c}}$ & $\mathrm{Au}_{2}(\mathrm{CO})^{-}$ \\
\hline $\mathrm{NH}_{3}$ & $60^{\mathrm{b}}$ & $\mathrm{Au}\left(\mathrm{NH}_{3}\right)^{+}$ & $22 \pm 4$ & $\mathrm{Au}_{2}\left(\mathrm{NH}_{3}\right)$ & NS & NS \\
\hline $\mathrm{C}_{2} \mathrm{H}_{4}$ & NS & NS & $230 \pm 50$ & $\mathrm{Au}_{2}\left(\mathrm{C}_{2} \mathrm{H}_{4}\right)$ & NR & NR \\
\hline $\mathrm{H}_{2}$ & NS & $\mathrm{Au}_{2}\left(\mathrm{H}_{2}\right)_{3}{ }^{+\mathrm{f}}$ & $1.4 \pm 0.3$ & $\mathrm{Au}_{2}(\mathrm{H})_{2}$ & NS & NS \\
\hline
\end{tabular}

${ }^{a}$ Second order, rate constant with units of $10^{-11} \mathrm{~cm}^{3} \mathrm{~s}^{-1}$

${ }^{\mathrm{b}}$ Data collected in a fast-flow reactor at room temperature under thermalised conditions [270]. Termolecular rates reported units of $10^{-30} \mathrm{~cm}^{6} \mathrm{~s}^{-1}$

${ }^{\mathrm{c}}$ Data collected in a variable-temperature ion trap [268, 271]

${ }^{\mathrm{d}}$ Data collected in an ion trap [272]

${ }^{\mathrm{e}}$ Data collected in an ion trap at $300 \mathrm{~K}$ [265]

${ }^{\mathrm{f}}$ Data collected in an ion trap at $100 \mathrm{~K}$ [271]

$\mathrm{NR}=$ no reaction observed, which sets a limit on the bimolecular rate constants of less than $5 \times 10^{-15} \mathrm{~cm}^{3} \mathrm{~s}^{-1}$ at 6 Torr He

$N R$ no reaction, $N S$ not studied

\subsection{Reactions of Bare Gold Cluster Ions: Overview}

The total electron count on bare gold clusters can be manipulated in two ways:

1. Clusters of gold atoms which are neutral, cationic or anionic have different electron counts. Apart from the role of total electron count, the presence or absence of a charge influences the collisional rate constant. Thus the collisional rate constants of singly charged ions are substantially larger than those of analogous neutrals.

One of the first studies to have systematically examined the gas-phase reactions of a range of neutral substrates $\left(\mathrm{D}_{2}, \mathrm{CH}_{4}\right.$ and $\left.\mathrm{O}_{2}\right)$ with gold clusters $\mathrm{Au}_{n}$ $(n=2-25)$, in their cationic, neutral and anionic forms, revealed that the cluster charge and electron count can have a pronounced effect on their reactivities [269]. For the reactions with $\mathrm{D}_{2}$, the reactivity follows the order $\mathrm{Au}_{n}{ }^{+}$(reactive for $n=2-15)>\mathrm{Au}_{n}$ (only $n=3$ and 7 reactive) $>>\mathrm{Au}_{n}{ }^{-}$(nonreactive). For $\mathrm{O}_{2}$, the reactivity follows the order $\mathrm{Au}_{n}{ }^{-}$(clusters where $\mathrm{n}$ is even are reactive) $>>\mathrm{Au}_{n}{ }^{+}$(only $n=10$ reactive).

To further highlight the role of electron count and charge on reactivity, we have summarised from the literature, data for the reactions of the gold dimer cation, neutral and anion with a range of neutral substrates (Table 9).

2. Pioneering work by the groups of Cox and Ervin on the gas-phase reactivity of small gold clusters with substrates has shown that the addition or removal of single $\mathrm{Au}$ atom can have a profound effect on reactivity [273, 274]. Figure 26 shows that the relative reactivities of bare anionic gold clusters with both carbon 
Fig. 26 Literature data on the relative reactivity of gold cluster anions, $\mathrm{Au}_{n}{ }^{-}$, in the adsorption reaction of one $\mathrm{O}_{2}$ or one $\mathrm{CO}$ molecule, respectively, as a function of the cluster size $n$.

(a) Reactions of $\mathrm{Au}_{n}{ }^{-}$with $\mathrm{O}_{2}$ : (filled square) data from [274], (open triangle) data from [273], and (circle) data from [275]. For comparison, all data are normalised to the reactivity of $\mathrm{Au}_{6}{ }^{-}$. (b) Reactions of $\mathrm{Au}_{n}{ }^{-}$with CO: (filled square) data from [273] and (circle) data from [276]. Again, the data shown have been normalised to the reactivity of $\mathrm{Au}_{6}{ }^{-}$towards $\mathrm{O}_{2}$. Figure reproduced from [34]

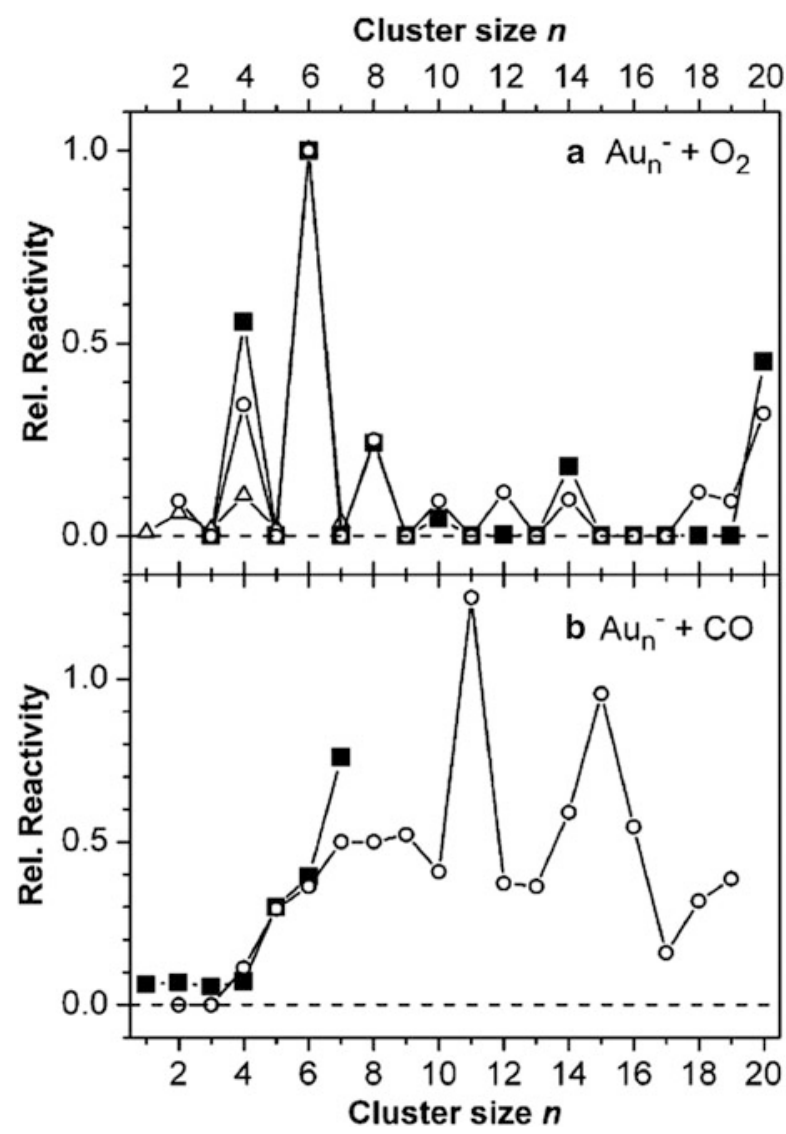

monoxide and oxygen are dependent on cluster size. It is evident that there is a 'saw' pattern for $\mathrm{O}_{2}$, whereby the clusters with even numbers of gold atoms and which have open-shell electronic structures are more reactive. It has been suggested that this effect arises from the interaction of the cluster's HOMO with the unpaired electron in the $\mathrm{O}_{2} \pi^{*}$ antibonding orbital. This interaction is attractive for the anionic clusters with an even number of gold atoms as they possess an odd number of electrons, and thus the HOMO contains an unpaired electron.

\subsubsection{Reactions of Bare Gold Cluster Ions with a Single Substrate}

Reactions with CO

The adsorption of $\mathrm{CO}$ to gold cluster cations and anions has been widely studied under a range of experimental conditions. The thermochemistry for binding of the 
Table 10 Bimolecular collision rates for the reactions of $\mathrm{Au}_{x}^{-} ; x \leq 7$ with $\mathrm{CO}$

\begin{tabular}{llll}
\hline Cluster & $k_{\exp }{ }^{\mathrm{a}}$ & $k_{\text {theor }}{ }^{\mathrm{b}}$ & Efficiency (\%) \\
\hline $\mathrm{Au}^{-}$ & 0.20 & 6.74 & 0.3 \\
$\mathrm{Au}_{2}{ }^{-}$ & 0.22 & 6.53 & 0.3 \\
$\mathrm{Au}_{3}{ }^{-}$ & 0.18 & 6.46 & 0.3 \\
$\mathrm{Au}_{4}{ }^{-}$ & 0.23 & 6.42 & 0.4 \\
$\mathrm{Au}_{5}{ }^{-}$ & 0.96 & 6.40 & 1.5 \\
$\mathrm{Au}_{6}{ }^{-}$ & 1.26 & 6.38 & 2.0 \\
$\mathrm{Au}_{7}{ }^{-}$ & 2.43 & 6.38 & 3.8 \\
\hline${ }^{\mathrm{a}} k_{\text {exp }}$ Experimental bimolecular rate constant \\
${ }^{\mathrm{b} C a l c u l a t e d}$ theoretical collision rate [277] \\
${ }^{\mathrm{c}} k_{\text {exp }} / k_{\text {theor }} \times 100$ \\
Table adapted from [273]
\end{tabular}

first $\mathrm{CO}$ was described in Sect. 3.7. Multiple $\mathrm{CO}$ adsorptions have been observed for gold cluster anions and cations (Eq. (15)):

$$
\mathrm{Au}_{x}^{-/+}+y \mathrm{CO} \rightarrow \mathrm{Au}_{n}(\mathrm{CO})_{y}^{-/+}
$$

Ervin and Lee studied the reactions of gold cluster anions $\left(\mathrm{Au}_{x}{ }^{-} ; x \leq 7\right)$ with $\mathrm{O}_{2}$ and $\mathrm{CO}$ in a flow tube reactor [273]. Unlike in the case of $\mathrm{O}_{2}$ (see below), no evenodd alteration of the reactivity was observed with $\mathrm{CO}$, and gold clusters $\mathrm{Au}_{x}{ }^{-}$with $x>4$ were more reactive than the smaller ones $(x \leq 4)$ (Table 10).

Wallace and Whetten have published several studies on the reaction of $\mathrm{CO}$ with size-selected gold clusters at room temperature [276, 278-280]. For instance, in a study aimed at understanding the size-dependent reactivity of $\mathrm{Au}_{x}{ }^{-}(x=4-19)$ [280], they concluded that initial products formed seem to correspond mainly to clusters with a gold electron shell filling at 8, 14, 18 and 20 electrons (i.e. $\mathrm{Au}_{5} \mathrm{CO}^{-}$, $\left.\mathrm{Au}_{11} \mathrm{CO}^{-}, \mathrm{Au}_{15} \mathrm{CO}^{-}, \mathrm{Au}_{15}(\mathrm{CO})_{2}{ }^{-}\right)$. When the concentration of $\mathrm{CO}$ is increased, cluster saturation is observed with 4-8 molecules of $\mathrm{CO}$ adsorbed (e.g. $\mathrm{Au}_{5}(\mathrm{CO})_{4}{ }^{-}$, $\left.\mathrm{Au}_{8}(\mathrm{CO})_{5}{ }^{-}, \mathrm{Au}_{9}(\mathrm{CO})_{6}{ }^{-}, \mathrm{Au}_{12}(\mathrm{CO})_{8}{ }^{-}\right)$. In another study, Whetten and Wallace reported that $\mathrm{Au}_{2}{ }^{-}$and $\mathrm{Au}_{3}{ }^{-}$were unreactive [276] at room temperature. This contradicted Ervin's results that these small clusters react with $\mathrm{CO}$, albeit slowly [273]. This was later explained when they reported that preadsorbed water on $\mathrm{Au}_{2}{ }^{-}$ and $\mathrm{Au}_{3}{ }^{-}$allowed the subsequent adsorption of the carbonyl and displacement of water [278].

The temperature-dependent reaction kinetics of the bare gold cluster anions $\mathrm{Au}_{x}{ }^{-}(x=1-3)$ to $\mathrm{CO}$ (and $\mathrm{O}_{2}$ discussed below) adsorption have been studied by Bernhardt et al. in a variable-temperature ion trap [268]. At room temperature $\mathrm{Au}_{x}{ }^{-}$ $(x=1-3)$ was found to be unreactive with $\mathrm{CO}$, as previously described by Whetten et al. [280]. For an ion-trap temperature of $250 \mathrm{~K}$, the gold clusters $\mathrm{Au}_{x}{ }^{-}(x=2,3)$ are able to adsorb only one molecule of CO. At $100 \mathrm{~K} \mathrm{Au}_{x}(\mathrm{CO})_{y}{ }^{-}(x, y=2,2 ; 3,2)$ are also detected, and $\mathrm{Au}^{-}$remains unreactive even at lower temperatures. Kinetic measurements reveal that $\mathrm{Au}_{2}(\mathrm{CO})^{-}$and $\mathrm{Au}_{2}(\mathrm{CO})_{2}{ }^{-}$reach an equilibrium when reaction times are extended. In contrast $\mathrm{Au}_{3}(\mathrm{CO})_{2}{ }^{-}$is almost the sole product of allowing $\mathrm{Au}_{3}(\mathrm{CO})^{-}$to react with $\mathrm{CO}$ (Eq. (15)) over extended reaction times. 
This binding can be reversible, as demonstrated by the fact that certain cluster ions are metastable, undergoing CO loss (Eq. (16)) [279]:

$$
\mathrm{Au}_{x}(\mathrm{CO})_{y}^{-/+} \rightarrow \mathrm{Au}_{x}(\mathrm{CO})_{y-z}^{-/+}+z \mathrm{CO}
$$

\section{Reactions with $\mathrm{O}_{2}$}

$\mathrm{O}_{2}$ is more selective in its reactions with gold cluster ions. Small gold cluster cations are essentially unreactive, while anions exhibit a pronounced odd-even effect for $x$ in adding $\mathrm{O}_{2}$ (Eq. (17)) [273, 275]. Cluster anions with an unpaired electron $(x=$ even) are highly reactive, and it has been suggested that these undergo electron transfer to form a superoxide anion bound to $\mathrm{Au}_{x}$ (see Sect. 3.6 and A. Fielicke et al.'s chapter in this book):

$$
\mathrm{Au}_{x}^{-}+\mathrm{O}_{2} \rightarrow \mathrm{Au}_{x}\left(\mathrm{O}_{2}\right)^{-}
$$

\section{Reactions with $\mathrm{N}_{2}$}

The reactions of $\mathrm{Au}_{x}^{+}\left(x=3\right.$ and 5) with $\mathrm{N}_{2}$ have been studied in a variabletemperature ion trap [281]. The addition of multiple $\mathrm{N}_{2}$ to $\mathrm{Au}_{x}{ }^{+}$is very sensitive to the temperature. At room temperature no $\mathrm{Au}_{x}\left(\mathrm{~N}_{2}\right)_{y}{ }^{+}$are observed. For $\mathrm{Au}_{3}{ }^{+}$the ions $\mathrm{Au}_{3}{ }^{+}$and $\mathrm{Au}_{3}\left(\mathrm{~N}_{2}\right)_{3}{ }^{+}$are observed at $200 \mathrm{~K}$, while at $100 \mathrm{~K}$ only $\mathrm{Au}_{3}\left(\mathrm{~N}_{2}\right)_{3}{ }^{+}$is found. In the case of $\mathrm{Au}_{5}{ }^{+}$both $\mathrm{Au}_{5}\left(\mathrm{~N}_{2}\right)_{3}{ }^{+}$and $\mathrm{Au}_{5}\left(\mathrm{~N}_{2}\right)_{4}{ }^{+}$are observed at $200 \mathrm{~K}$, and only the latter ion is observed at $100 \mathrm{~K}$. These nitrogen adducts facilitate absorption of $\mathrm{H}_{2}$ and $\mathrm{O}_{2}$, as discussed below.

\section{Reactions with $\mathrm{H}_{2}$}

Three studies of the reactions of gold cluster ions with hydrogen have been reported using different instruments, which highlight the role of reaction conditions (pressure and temperature). Cox's group used a fast-flow reactor to examine the reactions of gold cluster cations and anion with deuterium. They found that while small $(n<15)$ gold cations react readily with $\mathrm{D}_{2}$ via addition of $\mathrm{D}_{2}$, no reactions were observed for the anions [269]. Sugawara et al. have noted that in the lower-pressure regime of an FT-ICR mass spectrometer, no reaction occurs for gold cluster cations $\mathrm{Au}_{n}{ }^{+}(n=1-12)$ with $\mathrm{H}_{2}$ [67]. Under variable-temperature ion-trap conditions, where the hydrogen adducts can be collisionally cooled with the helium bath gas [271], $\mathrm{Au}_{x}{ }^{+}(x=2-7)$ exhibit interesting temperature-dependent reactivity patterns towards molecular hydrogen. At $300 \mathrm{~K}$, only $\mathrm{Au}_{5}{ }^{+}$adsorbs up to 3 molecules of $\mathrm{H}_{2}$. Lowering the temperature to $200 \mathrm{~K}$ results in a dramatic change of reactivity. Although $\mathrm{Au}_{2}{ }^{+}$remains unreactive, the other cluster cations adsorb the following numbers of hydrogen molecules: $\mathrm{Au}_{3}{ }^{+}$and $\mathrm{Au}_{4}{ }^{+}$up to three; $\mathrm{Au}_{5}{ }^{+}$and $\mathrm{Au}_{6}{ }^{+}$up to four; and $\mathrm{Au}_{7}{ }^{+}$up to two. Further lowering the temperature to $100 \mathrm{~K}$ leads to a 
Fig. 27 Cluster sizedependent hydrogen saturation at $T_{\mathrm{R}}=100 \mathrm{~K}$ and minimum-energy structures of the investigated cluster sizes. 'Corner' site atoms are indicated by filled circles. For the case of $\mathrm{Au}_{6}{ }^{+}$, the two lowest-energy isomers are displayed with the nontriangular incomplete hexagonal (ih) isomer being $0.19 \mathrm{eV}$ higher in energy than the triangular $(\mathrm{t})$ one. Figure reproduced from [271]

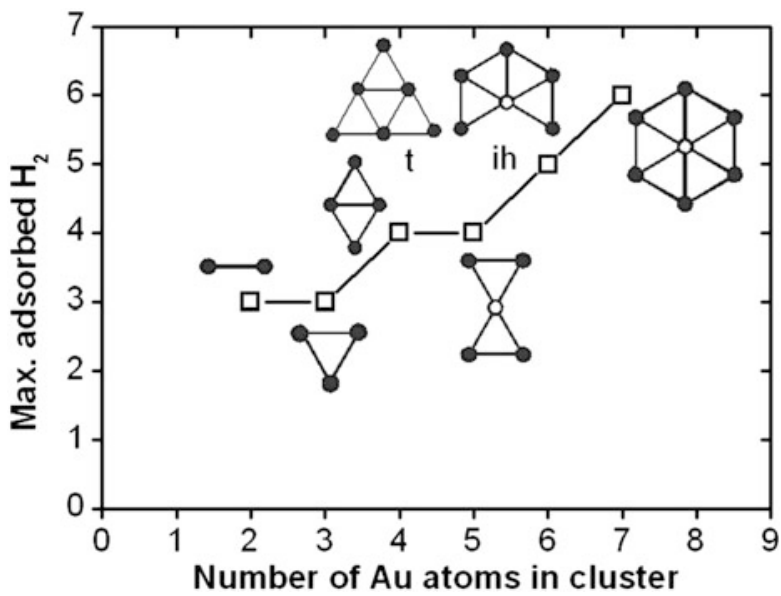

size-dependent hydrogen saturation, which nicely matches the numbers of corner sites available for the lowest-energy structures of the clusters as shown in Fig. 27.

\section{Reactions with $\mathrm{N}_{2} \mathrm{O}$}

The reactions of small gold cluster cation with $\mathrm{N}_{2} \mathrm{O}$ have been studied in an ion-trap mass spectrometer [272]. $\mathrm{Au}_{2}{ }^{+}$reacts with $\mathrm{N}_{2} \mathrm{O}$ to yield $\mathrm{NO}^{+}$as the major product (Eq. (18)). In contrast, $\mathrm{Au}_{3}{ }^{+}$reacts via adduct formation to give $\mathrm{Au}_{3} \mathrm{~N}_{2} \mathrm{O}^{+}$(Eq. (19)) and via $\mathrm{O}$ atom abstraction to yield $\mathrm{Au}_{3} \mathrm{O}^{+}$(Eq. (20)). The former channel operates for $\mathrm{Au}_{4}{ }^{+}$:

$$
\begin{gathered}
\mathrm{Au}_{2}^{+}+\mathrm{N}_{2} \mathrm{O} \rightarrow \mathrm{NO}^{+}+\mathrm{Au}_{2} \mathrm{~N} \\
\mathrm{Au}_{3}^{+}+\mathrm{N}_{2} \mathrm{O} \rightarrow \mathrm{Au}_{3} \mathrm{~N}_{2} \mathrm{O}^{+} \\
\mathrm{Au}_{3}^{+}+\mathrm{N}_{2} \mathrm{O} \rightarrow \mathrm{Au}_{3} \mathrm{O}^{+}+\mathrm{N}_{2}
\end{gathered}
$$

Reactions with $\mathrm{NH}_{3}$ and $\mathrm{CH}_{3} \mathrm{NH}_{2}$

Pronounced odd versus even electron effects have been observed in the reactions of gold cluster cations, $\mathrm{Au}_{x}{ }^{+}$, with ammonia and methylamine [282]. Slow association reactions are observed for $x=1$ and 3 (Eq. (21)), whereas Au atom displacement was observed for $x=2$ and 4 (Eq. (22)). The primary product for $x=4$ undergoes further cluster degradation via loss of $\mathrm{Au}_{2}$ (Eq. (23)):

$$
\mathrm{Au}_{x}^{+}+\mathrm{RNH}_{2} \rightarrow \mathrm{Au}_{x}\left(\mathrm{RNH}_{2}\right)^{+}
$$




$$
\begin{gathered}
\mathrm{Au}_{x}^{+}+\mathrm{RNH}_{2} \rightarrow \mathrm{Au}_{x-1}\left(\mathrm{RNH}_{2}\right)^{+}+\mathrm{Au} \\
\mathrm{Au}_{3}\left(\mathrm{RNH}_{2}\right)^{+}+\mathrm{RNH}_{2} \rightarrow \mathrm{Au}\left(\mathrm{RNH}_{2}\right)_{2}^{+}+\mathrm{Au}_{2}
\end{gathered}
$$

Reactions with the Sulphur Compounds $\mathrm{H}_{2} \mathrm{~S}$ and $\mathrm{CH}_{3} \mathrm{SSCH}_{3}$

Sugawara et al. examined the reactions of gold cluster cations $\mathrm{Au}_{n}{ }^{+}(n=1-12)$ with $\mathrm{H}_{2} \mathrm{~S}$ in an FT-ICR mass spectrometer [67]. Four types of primary reaction channels were observed: (1) adduct formation (Eq. (24)), a reaction that occurs for clusters where $n=9,11$ and 12; (2) HS abstraction (Eq. (25)), a reaction that only occurs for $n=2$; (3) sulphuration to yield $\mathrm{Au}_{n} \mathrm{~S}^{+}$(Eq. (26)), which occurs for $n=4-8$ and 10 and (4) Au displacement (Eq. (27)), a reaction that only occurs for $n=2 . \mathrm{Au}_{3}{ }^{+}$was unreactive towards $\mathrm{H}_{2} \mathrm{~S}$ and even $n$ cluster cations were found to be more reactive than adjacent odd $n$ clusters. Subsequent sulphuration reactions of $\mathrm{Au}_{n} \mathrm{~S}^{+}$proceeded to give $\mathrm{Au}_{n} \mathrm{~S}_{m}{ }^{+}$but stopped at $\mathrm{Au}_{n} \mathrm{~S}_{m+{ }_{x}} \mathrm{H}_{2}{ }^{+}$when $\mathrm{H}_{2}$ loss did not occur. The maximum number of sulphur atoms, $m$, observed in $\mathrm{Au}_{n} \mathrm{~S}_{m}{ }^{+}$increased with the cluster size up to $n=7$ and 8 (where $m=5$ ), while the sulphuration reaction stopped at early stages for $n>9$ :

$$
\begin{aligned}
\mathrm{Au}_{x}^{+}+\mathrm{H}_{2} \mathrm{~S} & \rightarrow \mathrm{Au}_{x}\left(\mathrm{SH}_{2}\right)^{+} \\
& \rightarrow \mathrm{Au}_{x}(\mathrm{SH})^{+}+\mathrm{H} \\
& \rightarrow \mathrm{Au}_{x} \mathrm{~S}^{+}+\mathrm{H}_{2} \\
& \rightarrow \mathrm{Au}_{x-1}\left(\mathrm{SH}_{2}\right)^{+}+\mathrm{Au}
\end{aligned}
$$

Using FT-ICR mass spectrometry, Höckendorf et al. have shown that small odd electron gold cluster anions $\mathrm{Au}_{x}{ }^{-}(x=2$ and 4) react with dimethyldisulphide via S-S (Eq. (28)) and S-C bond activation (Eq. (29)) [283]. $\mathrm{Au}_{2}{ }^{-}$also reacts via displacement of a gold atom (Eq. (30)) or anion (Eq. (31)):

$$
\begin{aligned}
\mathrm{Au}_{x}^{-}+\mathrm{CH}_{3} \mathrm{SSCH}_{3} & \rightarrow \mathrm{Au}_{x}\left(\mathrm{SCH}_{3}\right)^{-} \\
& \rightarrow \mathrm{Au}_{x}\left(\mathrm{SSCH}_{3}\right)^{-} \\
& \rightarrow \mathrm{Au}_{x-1}\left(\mathrm{CH}_{3} \mathrm{SSCH}_{3}\right)^{-}+\mathrm{Au} \\
& \rightarrow \mathrm{Au}^{-}+\mathrm{Au}_{x-1}\left(\mathrm{CH}_{3} \mathrm{SSCH}_{3}\right)
\end{aligned}
$$

Reactions with $\mathrm{H}_{2}$ and $\mathrm{CH}_{4}$

The co-adsorption of hydrogen and methane on small bare cationic gold clusters $\mathrm{Au}_{x}{ }^{+}(x=3,5)$ has been proposed to occur on the same adsorption site of the gold cluster (i.e. the same gold atom) [284], termed permissive co-adsorption. For these experiments Bernhardt et al. used a variable-temperature ion trap. For short reaction times, at $300 \mathrm{~K}, \mathrm{Au}_{3} \mathrm{CH}_{4}{ }^{+}$is observed as a single product. Increasing the reaction time to 1 and $2 \mathrm{~s}$ results in formation of $\mathrm{Au}_{3}\left(\mathrm{CH}_{4}\right)_{2}\left(\mathrm{H}_{2}\right)_{2}{ }^{+}$. When the ion-trap temperature is reduced to $200 \mathrm{~K}$, the formation of the $\mathrm{CH}_{4}$ and $\mathrm{H}_{2}$ adsorption 
with the $\mathrm{Au}_{3}{ }^{+}$cluster is accelerated. At a reaction time as short as $0.1 \mathrm{~s}$, minute amounts of $\mathrm{Au}_{3}\left(\mathrm{CH}_{4}\right)_{2}\left(\mathrm{H}_{2}\right)_{2}{ }^{+}$are observed, and the dominant peaks correspond to $\mathrm{Au}_{3}\left(\mathrm{CH}_{4}\right)_{x}\left(\mathrm{H}_{2}\right)_{y}{ }^{+},(x, y=3,0 ; 3,3)$. At reaction times greater than $0.5 \mathrm{~s}$, the only product observed is $\mathrm{Au}_{3}\left(\mathrm{CH}_{4}\right)_{3}\left(\mathrm{H}_{2}\right)_{3}{ }^{+}$.

Mass-selected $\mathrm{Au}_{5}{ }^{+}$stored in an ion trap under similar conditions reacts in a similar way to $\mathrm{Au}_{3}{ }^{+}$. At an ion-trap temperature of $300 \mathrm{~K}$ and a reaction time of $0.1 \mathrm{~s}$, only one $\mathrm{CH}_{4}$ molecule is adsorbed. Increasing the reaction time from 0.5 to $2 \mathrm{~s}$ results in the addition of a second adsorbate being $\mathrm{H}_{2}$ to give $\mathrm{Au}_{5}\left(\mathrm{CH}_{4}\right)\left(\mathrm{H}_{2}\right)^{+}$. Reducing the temperature to $200 \mathrm{~K}$ enhances the reactivity of the cluster considerably. At $0.1 \mathrm{~s} \mathrm{Au}_{5}\left(\mathrm{CH}_{4}\right)_{2}{ }^{+}$is the dominant peak. Increasing the reaction time to $0.5 \mathrm{~s}$ shows $\mathrm{Au}_{5}\left(\mathrm{CH}_{4}\right)_{3}\left(\mathrm{H}_{2}\right)^{+}$as the dominant peak with $\mathrm{Au}_{5}\left(\mathrm{CH}_{4}\right)_{2}\left(\mathrm{H}_{2}\right)^{+}$and $\mathrm{Au}_{5}\left(\mathrm{CH}_{4}\right)_{3}\left(\mathrm{H}_{2}\right)_{4}{ }^{+}$. Further increasing the reaction time from 0.5 up to $2 \mathrm{~s}$ results in mainly $\mathrm{Au}_{5}\left(\mathrm{CH}_{4}\right)_{4}\left(\mathrm{H}_{2}\right)_{4}{ }^{+}$.

\section{Reactions with $\mathrm{H}_{2}$ and $\mathrm{CH}_{3} \mathrm{CH}=\mathrm{CH}_{2}$}

The mass-selected bare gold cluster cations, $\mathrm{Au}_{3}{ }^{+}$and $\mathrm{Au}_{5}{ }^{+}$, were reacted with propylene $\left(\mathrm{CH}_{3} \mathrm{CH}=\mathrm{CH}_{2}\right)$ comparable to the reactions discussed above, however replacing $\mathrm{CH}_{4}$ with $\mathrm{CH}_{3} \mathrm{CH}=\mathrm{CH}_{2}$. Both clusters appear to immediately react with $\mathrm{CH}_{3} \mathrm{CH}=\mathrm{CH}_{2}$. At a reaction time of $0.1 \mathrm{~s}$ and an ion-trap temperature of either $300 \mathrm{~K}$ or $200 \mathrm{~K}$, the main peak is solely $\mathrm{Au}_{3}\left(\mathrm{CH}_{3} \mathrm{CH}=\mathrm{CH}_{2}\right)_{3}{ }^{+}$for the mass-selected trimer. In comparison, the $\mathrm{Au}_{5}{ }^{+}$cluster at $300 \mathrm{~K}$ forms predominantly $\mathrm{Au}_{5}\left(\mathrm{CH}_{3} \mathrm{CH}=\mathrm{CH}_{2}\right)_{4}{ }^{+}$and at $200 \mathrm{~K} \mathrm{Au}{ }_{5}\left(\mathrm{CH}_{3} \mathrm{CH}=\mathrm{CH}_{2}\right)_{3}{ }^{+}$is the predominant peak observed. In contrast to $\mathrm{CH}_{4}$, only trace amounts of $\mathrm{CH}_{3} \mathrm{CH}=\mathrm{CH}_{2}$ are required to react with and completely saturate the gold clusters which then also inhibit the co-adsorption of molecular $\mathrm{H}_{2}$.

\section{Reactions with $\mathrm{CH}_{3} \mathrm{X}$}

Koszinowski et al. showed that the reaction of $\mathrm{Au}_{2}{ }^{+}$with methyl halides could be used to 'synthesise' the gold carbene, $\mathrm{Au}_{2} \mathrm{CH}_{2}{ }^{+}$, in the gas phase (Eq. (32)) [282]:

$$
\mathrm{Au}_{2}^{+}+\mathrm{CH}_{3} \mathrm{X} \rightarrow \mathrm{Au}_{2} \mathrm{CH}_{2}^{+}+\mathrm{HX}
$$

Lang and Bernhardt studied bare gold cluster cation $\mathrm{Au}_{3}{ }^{+}$and $\mathrm{Au}_{5}{ }^{+}$reaction with $\mathrm{CHCl}_{3}$ and $\mathrm{H}_{2} \mathrm{O}$ [285]. With the ion trap at room temperature $(300 \mathrm{~K})$, it was found that the reactions of $\mathrm{Au}_{x}{ }^{+}(x=3,5)$ proceeded quickly. For the trimer, the number of adsorbate molecules of $\mathrm{CHCl}_{3}$ and $\mathrm{H}_{2} \mathrm{O}$ never exceeds the number of gold atoms. The distribution of the adsorbate molecules also suggests that there is an equilibrium constraint to direct the reaction channels. The $\mathrm{Au}_{5}{ }^{+}$cluster exhibits an $\mathrm{X}$-shaped, $\mathrm{D}_{2 \mathrm{~h}}$ symmetry, with 4 equiv. gold corner atoms around the central gold atoms. Hence, the number of adsorbate molecules does not exceed 4 . The reaction behaviour is comparable to $\mathrm{Au}_{3}{ }^{+}$. 
In a similar method to that described above, the reactions of the bare gold cluster cations $\mathrm{Au}_{x}{ }^{+}(x=1-3,5,7)$ with $\mathrm{CH}_{3} \mathrm{Br}$ have been investigated [286]. Adsorbates of molecular methyl bromide were observed for each of the gold clusters. When the mass-selected cluster was held in the ion trap for longer reaction times, the products of methyl elimination would successively increase to also produce $\mathrm{Au}_{x}\left(\mathrm{CH}_{3} \mathrm{Br}\right)_{y}(\mathrm{Br})_{z}^{+}$.

\section{Reactions with Other Neutral Substrates}

Höckendorf found that small gold cluster anions $\mathrm{Au}_{x}{ }^{-}(x=2-4)$ were unreactive to a wide range of substrates (methanol, acetonitrile, acetaldehyde, acetone, dimethyl sulphide, methyl mercaptan, benzene, ethynylbenzene and difluoroacetic acid) in an FT-ICR mass spectrometer [283]. The only reactive substrates were dimethyldisulphide (discussed above) and trifluoroacetic acid, which reacts via adduct formation for $x=2$ and 4 (Eq. (33)) and via $\mathrm{Au}$ displacement for $x=2$ (Eq. (34)). $\mathrm{Au}^{-}$was unreactive towards $\mathrm{CF}_{3} \mathrm{CO}_{2} \mathrm{H}$ :

$$
\begin{aligned}
\mathrm{Au}_{x}^{-}+\mathrm{CF}_{3} \mathrm{CO}_{2} \mathrm{H} & \rightarrow \mathrm{Au}_{x}\left(\mathrm{CF}_{3} \mathrm{CO}_{2} \mathrm{H}\right)^{-} \\
& \rightarrow \mathrm{Au}_{x-1}\left(\mathrm{CF}_{3} \mathrm{CO}_{2} \mathrm{H}\right)^{-}+\mathrm{Au}
\end{aligned}
$$

\subsubsection{Reactions of Bare Gold Cluster Ions with More than One Substrate: 'Cooperative Effects'}

Reactions with $\mathrm{CO}$ and $\mathrm{O}_{2}$

The bare gold cluster anions $\mathrm{Au}_{2}{ }^{-}$and $\mathrm{Au}_{3}{ }^{-}$, are able to form co-adsorption complexes, $\mathrm{Au}_{a}{ }^{-}(\mathrm{CO})_{b}(\mathrm{O})_{c}(a=2,3 ; b=1 ; c=1,2)$, when exposed to small partial pressure of $\mathrm{CO}$ and $\mathrm{O}_{2}$ in a temperature-controlled ion trap at cryogenic temperatures [287]. This type of cluster complex has been proposed theoretically to be a key intermediate in a catalytic CO oxidation cycle [288].

\section{Reactions with $\mathrm{H}_{2}$ and $\mathrm{O}_{2}$}

Lang et al. have used a variable-temperature ion trap to examine the $\mathrm{H}_{2} / \mathrm{O}_{2}$ co-adsorption behaviour of cationic gold clusters $\mathrm{Au}_{x}{ }^{+}(x=2-7)$ at $100 \mathrm{~K}$ [271]. They found a striking odd-even alternation reactivity. For the even $x$ cluster sizes $(x=2,4,6)$, cooperative co-adsorption of only one oxygen molecule was observed, with $\mathrm{Au}_{2} \mathrm{H}_{4} \mathrm{O}_{2}{ }^{+}, \mathrm{Au}_{4} \mathrm{H}_{6} \mathrm{O}_{2}{ }^{+}$and $\mathrm{Au}_{6} \mathrm{H}_{6} \mathrm{O}_{2}{ }^{+}$being observed. No co-adsorption of multiple $\mathrm{O}_{2}$ molecules occurs, even at higher $\mathrm{O}_{2}$ pressures and extended reaction times. For the odd $x$ cluster sizes $(x=3,5,7)$ no measurable co-adsorption of $\mathrm{O}_{2}$ occurred. The lack of reactivity of $\mathrm{Au}_{x}{ }^{+}(x=$ odd $)$ can be explained via a valence electron structure model in which the spin-paired valence 
electron structure of $\mathrm{Au}_{x}^{+}$hampers the interaction of the gold cluster valence electrons with the unpaired electrons of the $2 \pi_{\mathrm{g}}{ }^{*}$ antibonding $\mathrm{O}_{2}$ orbitals. As the temperature of the ion trap is raised the types of product ions observed for $\mathrm{Au}_{4}{ }^{+}$and $\mathrm{Au}_{6}{ }^{+}$change. At $300 \mathrm{~K}, \mathrm{Au}_{4} \mathrm{H}_{2} \mathrm{O}^{+}$and $\mathrm{Au}_{6} \mathrm{H}_{4} \mathrm{O}^{+}$are observed, which signifies that the oxygen has been activated. Detailed DFT calculations were carried out on the co-adsorption of $\mathrm{H}_{2}$ and $\mathrm{O}_{2}$ and their chemical activation on the $\mathrm{Au}_{4}{ }^{+}$and $\mathrm{Au}_{6}{ }^{+}$ clusters. These suggest a mechanisms for dissociation of $\mathrm{O}_{2}$ involving the adsorption at adjacent sites to give $\left[(\mathrm{Au})_{\mathrm{x}-2} \mathrm{Au}\left(\mathrm{H}_{2}\right) \mathrm{Au}\left(\mathrm{O}_{2}\right)\right]^{+}$structures, which can then undergo intermolecular hydrogen atom transfer to form $\left[(\mathrm{Au})_{x-2} \mathrm{Au}(\mathrm{H}) \mathrm{Au}\left(\mathrm{O}_{2} \mathrm{H}\right)\right]^{+}$ intermediates possessing the mixed hydride, hydroperoxide sites, which in turn can eliminate water to form a gold oxide site.

\section{Reactions with $\mathrm{N}_{2} / \mathrm{H}_{2}$ and $\mathrm{N}_{2} / \mathrm{O}_{2}$}

The reactions of $\mathrm{Au}_{x}{ }^{+}\left(x=3\right.$ and 5) with mixtures of $\mathrm{N}_{2}$ and $\mathrm{H}_{2}$ and $\mathrm{N}_{2}$ and $\mathrm{O}_{2}$ have been studied in a variable-temperature ion trap [281]. As noted above, at low temperatures $(100$ and $200 \mathrm{~K})$ in the presence of pure $\mathrm{N}_{2}$, both $\mathrm{Au}_{3}{ }^{+}$and $\mathrm{Au}_{5}{ }^{+}$both give $\mathrm{Au}_{x}\left(\mathrm{~N}_{2}\right)_{y}{ }^{+}$. In pure $\mathrm{H}_{2}, \mathrm{Au}_{3}{ }^{+}$and $\mathrm{Au}_{5}{ }^{+}$both give $\mathrm{Au}_{x}\left(\mathrm{H}_{2}\right)_{y}{ }^{+}$. In contrast, no reactions are observed between $\mathrm{Au}_{x}{ }^{+}$and $\mathrm{O}_{2}$. At $100 \mathrm{~K}$, mixtures of $\mathrm{N}_{2}$ and $\mathrm{H}_{2}$ react with $\mathrm{Au}_{3}{ }^{+}$to yield $\mathrm{Au}_{3}\left(\mathrm{H}_{2}\right)_{2}\left(\mathrm{~N}_{2}\right)^{+}, \mathrm{Au}_{3}\left(\mathrm{H}_{2}\right)\left(\mathrm{N}_{2}\right)_{2}{ }^{+}$and $\mathrm{Au}_{3}\left(\mathrm{~N}_{2}\right)_{3}{ }^{+} . \mathrm{Au}_{5}\left(\mathrm{H}_{2}\right)_{3}\left(\mathrm{~N}_{2}\right)^{+}, \mathrm{Au}_{5}\left(\mathrm{H}_{2}\right)_{2}\left(\mathrm{~N}_{2}\right)_{2}{ }^{+}$ and $\mathrm{Au}_{5}\left(\mathrm{H}_{2}\right)\left(\mathrm{N}_{2}\right)_{3}{ }^{+}$are observed under the same conditions. The authors suggested that these reactions involve competitive co-adsorption. $\mathrm{Au}_{3}{ }^{+}$and $\mathrm{Au}_{5}{ }^{+}$co-adsorb $\mathrm{N}_{2}$ and $\mathrm{O}_{2}$ at $100 \mathrm{~K}$, at longer reactions times and with low concentrations of $\mathrm{N}_{2}$ to, respectively, give: $\mathrm{Au}_{3}\left(\mathrm{~N}_{2}\right)_{3}{ }^{+}, \mathrm{Au}_{3}\left(\mathrm{~N}_{2}\right)_{2}\left(\mathrm{O}_{2}\right)^{+}, \mathrm{Au}_{3}\left(\mathrm{~N}_{2}\right)\left(\mathrm{O}_{2}\right)_{2}{ }^{+}$and $\mathrm{Au}_{3}\left(\mathrm{O}_{2}\right)_{3}{ }^{+}$; $\mathrm{Au}_{5}\left(\mathrm{~N}_{2}\right)_{3}{ }^{+}, \mathrm{Au}_{5}\left(\mathrm{~N}_{2}\right)_{2}\left(\mathrm{O}_{2}\right)^{+}, \mathrm{Au}_{5}\left(\mathrm{~N}_{2}\right)\left(\mathrm{O}_{2}\right)_{2}{ }^{+}$and $\mathrm{Au}_{5}\left(\mathrm{O}_{2}\right)_{3}{ }^{+}$; as well as $\mathrm{Au}_{5}\left(\mathrm{~N}_{2}\right)_{4}{ }^{+}$, $\mathrm{Au}_{5}\left(\mathrm{~N}_{2}\right)_{2}\left(\mathrm{O}_{2}\right)_{2}{ }^{+}, \mathrm{Au}_{5}\left(\mathrm{~N}_{2}\right)\left(\mathrm{O}_{2}\right)_{3}{ }^{+}$and $\mathrm{Au}_{5}\left(\mathrm{O}_{2}\right)_{4}{ }^{+}$. Both cooperative and competitive co-adsorption appears to operate for $\mathrm{N}_{2} / \mathrm{O}_{2}$ mixtures.

\section{Reactions with $\mathrm{CH}_{4}$ and $\mathrm{O}_{2}$}

Lang and Bernhardt studied the reactions of $\mathrm{Au}_{x}{ }^{+}(x=2-4)$ with $\mathrm{CH}_{4}$ and $\mathrm{O}_{2}$ in a variable ion trap [289]. Upon reaction with $\mathrm{CH}_{4}$ only, these clusters appear to adsorb a $\mathrm{CH}_{4}$ molecule initially to form $\mathrm{Au}_{x}\left(\mathrm{CH}_{4}\right)^{+}$. Interestingly, at $300 \mathrm{~K}$ and upon reaction with another molecule of $\mathrm{CH}_{4}, \mathrm{Au}_{2}{ }^{+}$forms $\mathrm{Au}_{2}\left(\mathrm{C}_{2} \mathrm{H}_{4}\right)^{+}$indicating dehydrogenation of $\mathrm{CH}_{4}$, shown in this study to be catalytic. Larger $\mathrm{Au}_{x}{ }^{+}$clusters studied adsorb more $\mathrm{CH}_{4}$. To study the possibility of methane oxidation, the reaction of $\mathrm{CH}_{4}$ and $\mathrm{O}_{2}$ on the gold dimer cation $\mathrm{Au}_{2}{ }^{+}$was also examined at $210 \mathrm{~K}$. Two peaks corresponding to $\mathrm{Au}_{2}\left(\mathrm{CH}_{4}\right) \mathrm{O}_{2}{ }^{+}$and $\mathrm{Au}_{2}\left(\mathrm{C}_{3} \mathrm{H}_{8} \mathrm{O}_{2}\right)^{+}$were detected in the mass spectrum. The latter ion corresponds to a dehydrogenated product and was tentatively assigned as $\mathrm{Au}_{2}\left(\mathrm{CH}_{2} \mathrm{O}\right)_{2}\left(\mathrm{CH}_{4}\right)^{+}$(i.e. formation of formaldehyde) or a further oxidation product $\mathrm{Au}_{2}\left(\mathrm{CO}_{2}\right)\left(\mathrm{CH}_{4}\right)_{2}{ }^{+}$. 


\section{Reactions with $\mathrm{CO}$ and Benzene}

Adsorption complexes of the form $\mathrm{Au}_{x}\left(\mathrm{C}_{6} \mathrm{H}_{6}\right)_{y}(\mathrm{CO})_{z}{ }^{+}(n=3,5)$ were generated from reactions with benzene and with a mixture of benzene and carbon monoxide with $\mathrm{Au}_{x}{ }^{+}(x=3,5)$ [290]. Benzene was shown to react with all $\mathrm{Au}_{x}{ }^{+}$clusters exhibiting size-dependent coverage, and co-adsorption of benzene and $\mathrm{CO}$ was also achieved for both clusters.

\section{Reactions with $\mathrm{CH}_{3} \mathrm{X}$ and Water}

Adsorption complexes of the form $\mathrm{Au}_{x}\left(\mathrm{H}_{2} \mathrm{O}\right)_{y}\left(\mathrm{CHCl}_{3}\right)_{z}{ }^{+}(x=3,5)$ were generated from reactions with each of water and chloroform, as well as a mixture of the two reagents [285]. The reactions of chloroform with $\mathrm{Au}_{x}^{+}(x=3,5)$ were found to proceed quickly at room temperature where one molecule of $\mathrm{CHCl}_{3}$ adsorbs at each corner of the cluster hindering the adsorption of $\mathrm{H}_{2} \mathrm{O}$. Reducing the partial pressure of chloroform in the ion trap resulted in distinct co-adsorption complexes of both $\mathrm{H}_{2} \mathrm{O}$ and $\mathrm{CHCl}_{3}$ on the bare gold cluster cations.

\subsection{Ligated Gold Cluster Ions}

Gas phase chemistry on ligand-protected gold clusters has been recently employed [291] to resolve a controversy regarding the catalysis of the Sonogashira coupling reaction by gold nanoparticles as an alternative to the widely used palladium catalyst. Multistage mass spectrometry experiments using an ion trap mass spectrometer together with DFT calculations were used to show that the mononuclear $\mathrm{Au}(\mathrm{I})$ complex ligated with two bis-phosphinoalkane ligands (L), cannot induce the oxidative addition of iodobenzene, a crucial step in the Sonogashira coupling. In contrast, the trinuclear cluster, $\left[\mathrm{Au}_{3} \mathrm{~L}\right]^{+}$, was found to activate the $\mathrm{C}-\mathrm{I}$ bond. Another key finding from this work is that the linker size, $n$, of the bisphosphinoalkane ligand, $\mathrm{Ph}_{2} \mathrm{P}\left(\mathrm{CH}_{2}\right)_{n} \mathrm{PPh}_{2}(\mathrm{~L})$, tunes the rate of the reaction of the cluster with iodobenzene. As the linker size of the ligand (L) increases, the rate of the reaction increases (Fig. 28).

There is growing interest in the role of dinuclear gold species in catalysis [292]. In many cases ligated gold clusters are directly related to well-known reactive intermediates via the isolobal analogy [118, 119, 293, 294]. For example, Scheme 1 shows two gold analogues 2 [295] and $\mathbf{3}$ [296] of $\mathrm{H}_{3}{ }^{+}, \mathbf{1}$ [297, 298], first reported by Sir JJ Thomson and now recognised as playing a key role in interstellar chemistry. In the next sections we discuss the chemistry of ligated gold clusters and, where appropriate, use the isolobal analogy to highlight their relationship to known reactive intermediates in organic chemistry. The gas phase is an ideal environment to study the bimolecular and unimolecular reactivity of such species, and we discuss reports on gold hydrides, gold oxides and gem-diaurated ions. 
a

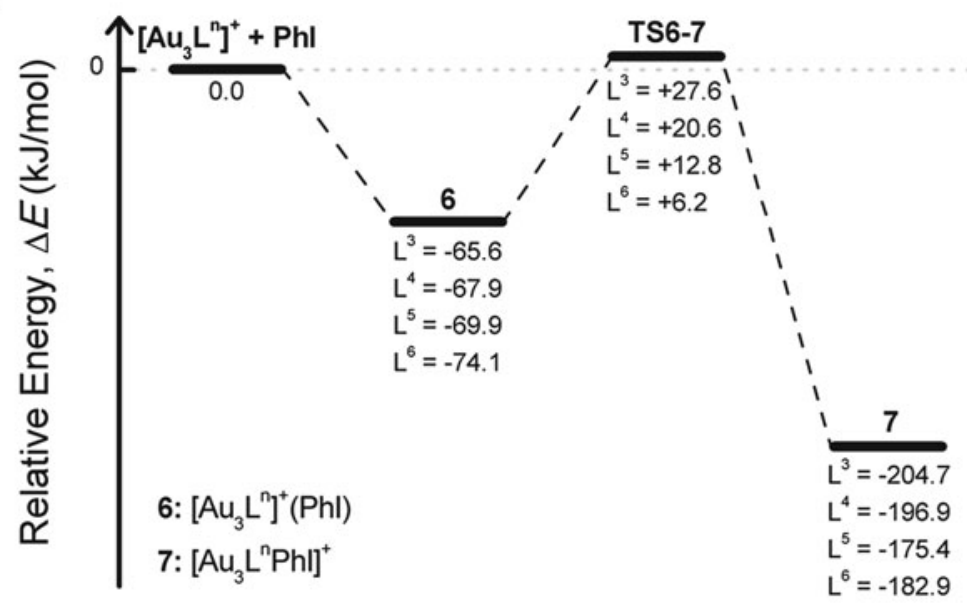

b

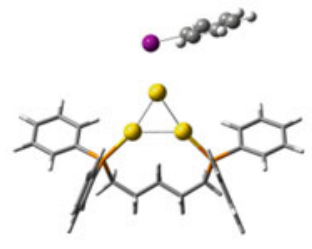

6

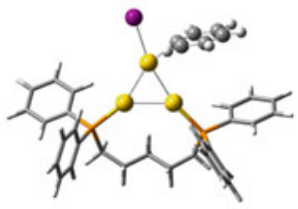

TS6-7

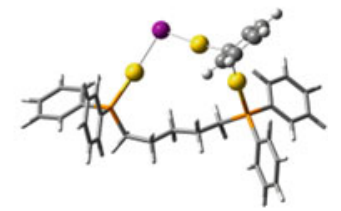

7

Fig. 28 (a) DFT-calculated energy diagrams (M06/SDD6-31G(d,p)//B3LYP/SDD6-31G(d,p) level of theory) for ion-molecule reactions of iodobenzene with $\left[\mathrm{Au}_{3} \mathrm{~L}_{n}\right]^{+}\left(\mathrm{L}=\mathrm{Ph}_{2} \mathrm{P}\left(\mathrm{CH}_{2}\right)_{n} \mathrm{PPh}_{2}\right.$; $n=3-6$ ); (b) key species for reaction of $\left[\mathrm{Au}_{3} \mathrm{~L}_{5}\right]^{+}$. Figure reproduced from [291]

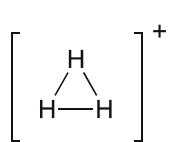

1

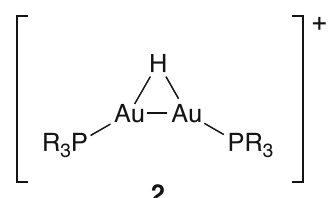

2

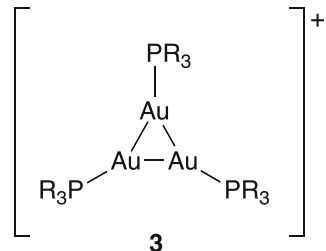

3

Scheme 1 Isolobal analogy illustrated for $\mathrm{H}_{3}{ }^{+}$

\subsubsection{Gold Hydride Cluster Ions}

Gold hydrides have been implicated as reactive intermediates in the transformation of organic substrates, but few have been isolated and structurally characterised [299]. While the bare coinage metal hydrides $\mathrm{M}_{2} \mathrm{H}^{+}$(where $\mathrm{M}=\mathrm{Cu}$ and $\mathrm{Ag}$ ) have been formed via CID of suitable precursors such as amino acids [300, 301], $\mathrm{Au}_{2} \mathrm{H}^{+}$ has not yet be reported. The phosphine-ligated gold hydrides, $\left(\mathrm{R}_{3} \mathrm{PAu}\right)\left(\mathrm{R}_{3}^{\prime} \mathrm{PAu}\right) \mathrm{H}^{+}$ (where $\mathrm{R}=\mathrm{R}^{\prime}=\mathrm{Ph} ; \mathrm{R}=\mathrm{R}^{\prime}=\mathrm{Me} ; \mathrm{R}=\mathrm{Me}$ and $\mathrm{R}^{\prime}=\mathrm{Ph}$ ) 2, can be prepared in the gas 
Fig. 29 B3LYP/LanL2D6$31 \mathrm{G}(\mathrm{d})$-calculated potential energy diagram for the competing fragmentation reactions of the model system $\left(\mathrm{H}_{3} \mathrm{PAu}\right)_{2} \mathrm{H}^{+}$. Figure reproduced from [295]

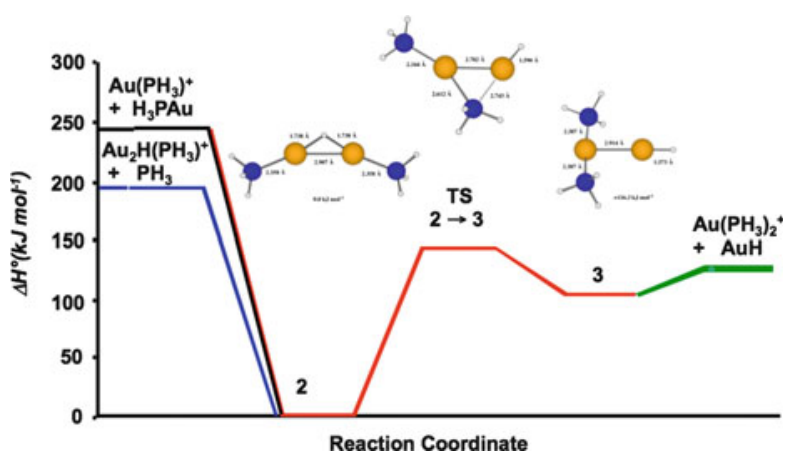

phase via CID of the deprotonated amino acid $N, N$-dimethylglycine (DMG) cluster ions $\left(\mathrm{R}_{3} \mathrm{PAu}\right)\left(\mathrm{R}_{3}^{\prime} \mathrm{PAu}\right)(\mathrm{DMG}-\mathrm{H})^{+}$, which are formed via electrospray ionisation of a mixture of the two gold phosphine chlorides, $\mathrm{R}_{3} \mathrm{PAuCl}(\mathrm{R}=\mathrm{Ph}$ and $\mathrm{Me})$, silver nitrate and the amino acid $N, N$-dimethylglycine (DMG). For the homodimeric precursor ions, four fragment channels are observed and include formation of the ligated dinuclear gold hydride (Eq. (35)); formation of the bis-ligated gold cation, $\left(\mathrm{R}_{3} \mathrm{P}\right)_{2} \mathrm{Au}^{+}$(Eq. (36)); loss of the neutral ligated monogold hydride (Eq. (37)); and formation of the monoligated gold cation, $\left(\mathrm{R}_{3} \mathrm{P}\right) \mathrm{Au}^{+}$(Eq. (38)). In all cases formation of $\mathbf{2}$ is the dominant reaction:

$$
\begin{aligned}
& {\left[\left(\mathrm{Me}_{2} \mathrm{NCH}_{2} \mathrm{CO}_{2}\right)+2 \mathrm{AuPR}_{3}\right]^{+} } \\
\rightarrow & \left(\mathrm{R}_{3} \mathrm{PAu}\right)_{2} \mathrm{H}^{+}+\left[\mathrm{H}_{7}, \mathrm{C}_{4}, \mathrm{~N}, \mathrm{O}_{2}\right] \\
\rightarrow & \left(\mathrm{R}_{3} \mathrm{P}\right)_{2} \mathrm{Au}^{+}+\mathrm{Me}_{2} \mathrm{NCH}_{2} \mathrm{CO}_{2} \mathrm{Au} \\
\rightarrow & {\left[\left(\mathrm{Me}_{2} \mathrm{NCH}_{2} \mathrm{CO}_{2}\right)+\mathrm{AuPR}_{3}-\mathrm{H}\right]^{+}+\mathrm{R}_{3} \mathrm{PAuH} } \\
\rightarrow & \mathrm{R}_{3} \mathrm{PAu}^{+}+\mathrm{Me}_{2} \mathrm{NCH}_{2} \mathrm{CO}_{2} \mathrm{AuPR}_{3}
\end{aligned}
$$

Unlike the bare silver hydride, $\mathrm{Ag}_{2} \mathrm{H}^{+}$, which reacts with a range of substrates [300, 302], 2 is unreactive towards a range of neutral reagents including $\mathrm{H}_{2} \mathrm{O}$, $\mathrm{MeOH}$, 2-propanol, acetonitrile, pyridine, allyl iodide, $\mathrm{O}_{2}, \mathrm{~N}_{2} \mathrm{O}$, nitromethane and DMSO. Low-energy CID of 2 proceeds via loss of AuH (Eq. (39)), rather than loss of $\mathrm{R}_{3} \mathrm{P}$ (Eq. (40)) or direct cluster fragmentation (Eq. (41)). The observed reactivity is accounted for by the DFT-calculated potential energy diagram of the model system $\left(\mathrm{H}_{3} \mathrm{PAu}\right)_{2} \mathrm{H}^{+}$shown in Fig. 29. Thus both the barrier for isomerisation of 2 to $3\left(140.8 \mathrm{~kJ} \mathrm{~mol}^{-1}\right)$ and the final reaction endothermicity for loss of $\mathrm{AuH}$ (126.1 $\mathrm{kJ} \mathrm{mol}^{-1}$ ) are lower than the energy required for loss of $\mathrm{H}_{3} \mathrm{P}$ (Eq. (40), $\left.194.9 \mathrm{~kJ} \mathrm{~mol}^{-1}\right)$ or formation of $\left(\mathrm{R}_{3} \mathrm{P}\right) \mathrm{Au}^{+}$(Eq. (41), $\left.244.8 \mathrm{~kJ} \mathrm{~mol}^{-1}\right)$ :

$$
\begin{aligned}
\left(\mathrm{R}_{3} \mathrm{PAu}\right)_{2} \mathrm{H}^{+} & \rightarrow\left(\mathrm{R}_{3} \mathrm{P}\right)_{2} \mathrm{Au}^{+}+\mathrm{AuH} \\
& \rightarrow\left(\mathrm{R}_{3} \mathrm{P}\right) \mathrm{Au}_{2} \mathrm{H}^{+}+\mathrm{R}_{3} \mathrm{P} \\
& \rightarrow\left(\mathrm{R}_{3} \mathrm{P}\right) \mathrm{Au}^{+}+\left(\mathrm{R}_{3} \mathrm{P}\right) \mathrm{AuH}
\end{aligned}
$$


Sugawara et al. have probed gold hydride clusters formation upon laser ablation of a gold rod in a $\mathrm{H}_{2} / \mathrm{He}$ mixture [67]. The hydride cluster cations $\mathrm{Au}_{n} \mathrm{H}_{m}{ }^{+}$were produced for $n=1-7$, while bare $\mathrm{Au}_{n}{ }^{+}$clusters were the main products for $n \geq 8$. The authors suggested that the border between $n=7$ and 8 hints to the formation of planar gold hydrides as the structure of bare $\mathrm{Au}_{n}{ }^{+}$changes from planar for $n=7$ to three-dimensional for $n=8$. Finally, the stoichiometries of the gold hydride cluster cations $\mathrm{Au}_{n} \mathrm{H}_{m}{ }^{+}$favour combinations of $\mathrm{n}$ and $\mathrm{m}$ that yield even electron clusters. Thus the main gold hydride clusters formed were $\mathrm{Au}_{2} \mathrm{H}_{5}{ }^{+}, \mathrm{Au}_{3} \mathrm{H}_{6}{ }^{+}, \mathrm{Au}_{5} \mathrm{H}_{6}{ }^{+}$, $\mathrm{Au}_{6} \mathrm{H}_{5}{ }^{+}$and $\mathrm{Au}_{7} \mathrm{H}_{4}{ }^{+}$.

\subsubsection{Gold Hydroxide Cluster Ions}

Wallace et al. [303] have studied the reactions of gold cluster anions with oxygen under humid conditions in a near-atmospheric-pressure flow reactor. In the absence of oxygen and at near room temperature, abundant gold hydroxide cluster anions, $\mathrm{Au}_{x} \mathrm{OH}^{-}(x=2-6)$, are observed. When oxygen is added, adsorption occurs to yield, $\mathrm{Au}_{x} \mathrm{OH}\left(\mathrm{O}_{2}\right)^{-}$. An even/odd size effect is observed for $\mathrm{Au}_{x} \mathrm{OH}^{-}$which is different to the bare gold cluster anion $\mathrm{Au}_{x}{ }^{-}$reactions with $\mathrm{O}_{2}$. Thus the binding of an $\mathrm{OH}$ group enhances the reactivity towards molecular oxygen on odd-sized anionic gold clusters but lowers the reactivity on even-sized ones.

\subsubsection{Gold Oxide Cluster Ions}

Castleman's group has widely studied the reactions of gold oxide cluster ions in the gas phase, and much of that work has been reviewed [304]. This work has been inspired by Haruta's discovery of CO oxidation by gold clusters (Eq. (3)). Indeed the focus of all of the bimolecular work has been on developing an understanding of how charge and cluster stoichiometry influence the reactions of gold oxide cluster ions, $\mathrm{Au}_{x} \mathrm{O}_{y}{ }^{-/+}$, with $\mathrm{CO}$. For the anions, there are three types of reactions that can occur [305-309]: association (Eq. (42)), replacement (Eq. (43)) and oxidation of CO (Eq. (44)). Which of these reactions occur depends on both $x$ and $y$ :

$$
\begin{aligned}
\mathrm{Au}_{x} \mathrm{O}_{y}^{-}+\mathrm{CO} & \rightarrow \mathrm{Au}_{x} \mathrm{O}_{y}(\mathrm{CO})^{-} \\
& \rightarrow \mathrm{Au}_{x} \mathrm{O}_{y-2}(\mathrm{CO})^{-}+\mathrm{O}_{2} \\
& \rightarrow \mathrm{Au}_{x} \mathrm{O}_{y-1}^{-}+\mathrm{CO}_{2}
\end{aligned}
$$

Detailed DFT calculations and molecular dynamics calculations were carried out on several systems to help rationalise the experimental observations. The results of DFT calculations on $\mathrm{Au}_{2} \mathrm{O}_{y}{ }^{-}$and $\mathrm{Au}_{3} \mathrm{O}_{y}{ }^{-}(y=1-5)$, which are shown in Fig. 30, reveal that there are three types of oxygen centres in these cluster anions: peripheral $\mathrm{O}$ atoms (e.g. $\mathrm{Au}_{2} \mathrm{O}^{-}$), bridging $\mathrm{O}$ atoms (e.g. $\mathrm{Au}_{2} \mathrm{O}_{2}{ }^{-}$) and molecular $\mathrm{O}_{2}$ (e.g. $\mathrm{Au}_{3} \mathrm{O}^{-}$). Experimentally it was found that association (Eq. (42)) occurs for 


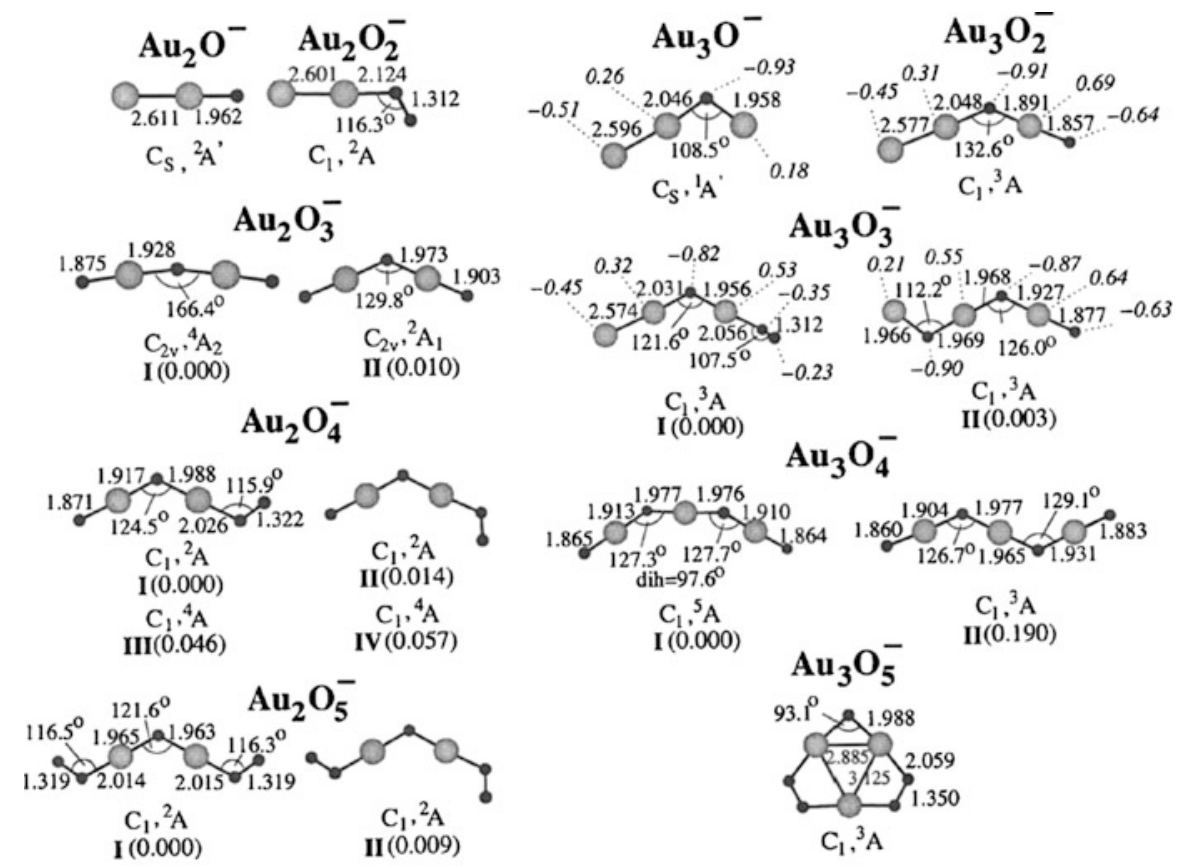

Fig. 30 Lowest-energy structures of $\mathrm{Au}_{2} \mathrm{O}_{y}{ }^{-}$and $\mathrm{Au}_{3} \mathrm{O}_{y}{ }^{-}(y=1-5)$. All structures fall within an energy range of $0.2 \mathrm{eV}$. The energy differences in $\mathrm{eV}$ with respect to the most stable structure are given in round brackets. Labels of the symmetry group and the ground electronic state are also given. Bond distances are in $\AA$. Figure reproduced from reference [307]

$\mathrm{Au}_{3} \mathrm{O}^{-}$, replacement occurs for $\mathrm{Au}_{3} \mathrm{O}_{3}{ }^{-}$(Eq. (43)) and oxidation (Eq. (44)) occurs for $\mathrm{Au}_{2} \mathrm{O}^{-}, \mathrm{Au}_{2} \mathrm{O}_{3}{ }^{-}$and $\mathrm{Au}_{2} \mathrm{O}_{4}{ }^{-}$. Theoretical results suggest that oxidation reactions mainly occur at the peripheral $\mathrm{O}$ atoms [309].

Gold oxide cluster cations react with $\mathrm{CO}$ via four types of reactions that also depend on both $x$ and $y$ [306, 310,311]: association (Eq. (45)), replacement (Eq. (46)), oxidation of CO (Eq. (47)) and cluster fragmentation (Eq. (48)). Clusters with one oxygen promoted oxidation (Eq. (47)), with $\mathrm{Au}_{3} \mathrm{O}^{+}$reacting more rapidly than $\mathrm{Au}_{2} \mathrm{O}^{+}$[311]. Clusters with larger numbers of oxygen favoured adsorption of $\mathrm{CO}$ and loss of $\mathrm{O}_{2}$ (Eqs. (45) and (46)), while $\mathrm{Au}_{2} \mathrm{O}_{3}{ }^{+}, \mathrm{Au}_{3} \mathrm{O}_{3}{ }^{+}, \mathrm{Au}_{4} \mathrm{O}_{2}{ }^{+}$and $\mathrm{Au}_{4} \mathrm{O}_{3}{ }^{+}$ all underwent some cluster fragmentation (Eq. (48)):

$$
\begin{aligned}
\mathrm{Au}_{x} \mathrm{O}_{y}^{+}+\mathrm{CO} & \rightarrow \mathrm{Au}_{x} \mathrm{O}_{y}(\mathrm{CO})^{+} \\
& \rightarrow \mathrm{Au}_{x} \mathrm{O}_{y-2}(\mathrm{CO})^{+} \\
& \rightarrow \mathrm{Au}_{x} \mathrm{O}_{y-1}^{+}+\mathrm{CO}_{2} \\
& \rightarrow \mathrm{Au}_{x-1} \mathrm{O}_{y-2}(\mathrm{CO})^{+}+\mathrm{AuO}_{2}
\end{aligned}
$$

A combination of experiments and theory provided detailed insights into how the charge state of gold oxide cluster ions influences the mechanism of oxidation of $\mathrm{CO}$ 


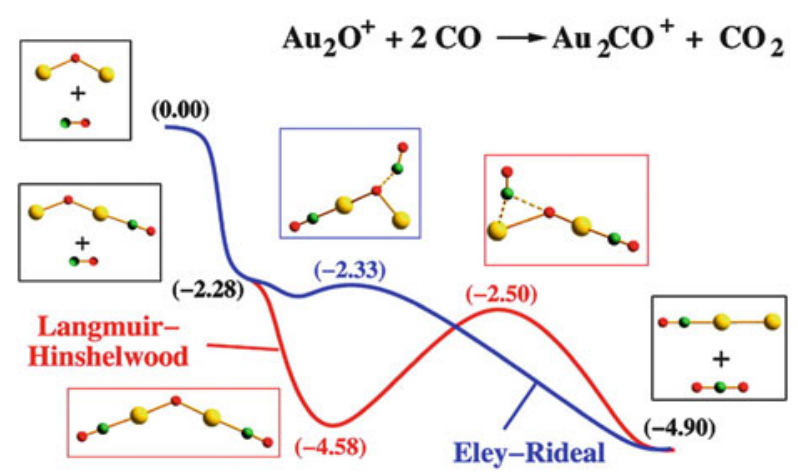

Fig. 31 Energy profiles for the reaction of $\mathrm{CO}$ with $\mathrm{Au}_{2} \mathrm{O}^{+}$. All energies are given in electron volts (eV) relative to the energy of the reactant at $0 \mathrm{~K}$. Shown are ER-type (blue) and LH-type (red) mechanisms. For the ER-like mechanism, a barrier of $0.2 \mathrm{eV}$ and an excess energy of $2.5 \mathrm{eV}$ have been calculated for the rate-determining step. For the LH-like mechanism, the calculated barrier and excess energy are 2.08 and $4.58 \mathrm{eV}$, respectively. Figure reproduced from [306]

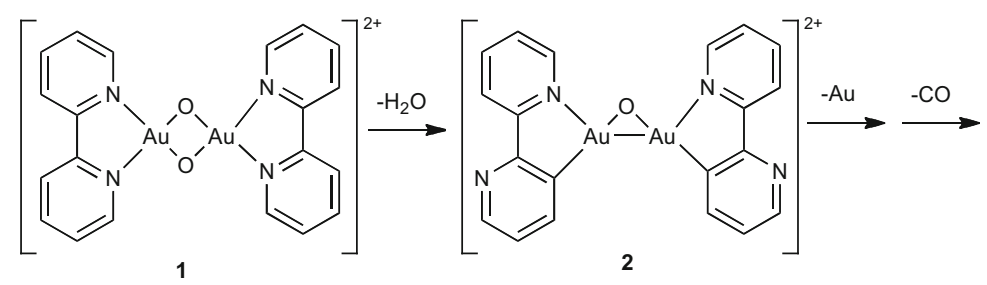

Scheme 2 Loss of $\mathrm{H}_{2} \mathrm{O}$ from dinuclear gold(III) oxo cluster coordinated by 2,2'-bipyridyl ligands

[306]. $\mathrm{Au}_{2} \mathrm{O}^{-}$reacts with one molecule of $\mathrm{CO}$ to yield $\mathrm{Au}_{2}{ }^{-}$. Theoretical calculations reveal that the $\mathrm{CO}$ directly attacks the $\mathrm{O}$ atom of the cluster. Thus $\mathrm{CO}$ oxidation of $\mathrm{CO}$ by $\mathrm{Au}_{2} \mathrm{O}^{-}$proceeds via an Eley-Rideal (ER)-type mechanism rather than attacks at $\mathrm{Au}$ via a Langmuir-Hinshelwood ( $\mathrm{LH}$ )-type mechanism. In contrast, $\mathrm{Au}_{2} \mathrm{O}^{+}$requires adsorption of two molecules of $\mathrm{CO}$ for oxidation to proceed. The DFT calculations highlight that both ER- and LH-type mechanisms can operate (Fig. 31).

Tyo et al. have reported on the gas-phase fragmentation reactions of dinuclear gold(III) oxo clusters possessing a rhombic $\mathrm{Au}_{2} \mathrm{O}_{2}$ core and 2,2'-bipyridyl ligands with substituents in the 6-position (bipyR) [312]. The clusters were synthesised as hexafluorophosphate salts in solution and were transferred to the gas phase via ESI-MS to yield the free dications $\left[(\right.$ bipyR $) \mathrm{Au}(\mu-\mathrm{O})_{2} \mathrm{Au}(\text { bipyR) }]^{2+}$. A noteworthy aspect of this report is the use of condensed phase IR spectroscopy, gas-phase IRMPD and DFT calculations to provide evidence that isomerisation of the substituted complexes does not occur in the gas phase. CID of this series of complexes revealed a significant effect of substitution. The parent, un-substituted complex, 1, fragments via loss of $\mathrm{H}_{2} \mathrm{O}$, presumably forming the organometallic ion 2, (Scheme 2) via a rollover cyclometalation reaction [313]. This ion subsequently undergoes loss of $\mathrm{Au}$ and $\mathrm{CO}$ (Scheme 2). 


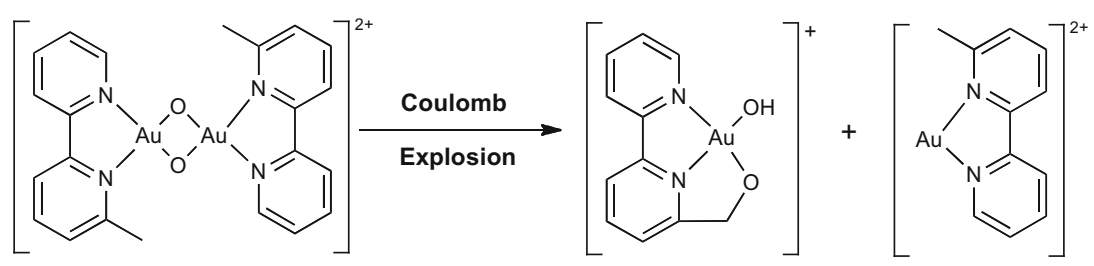

Scheme 3 Coloumb explosion pathway for dinuclear gold(III) oxo cluster coordinated by 6-substituted 2,2'-bipyridyl ligands
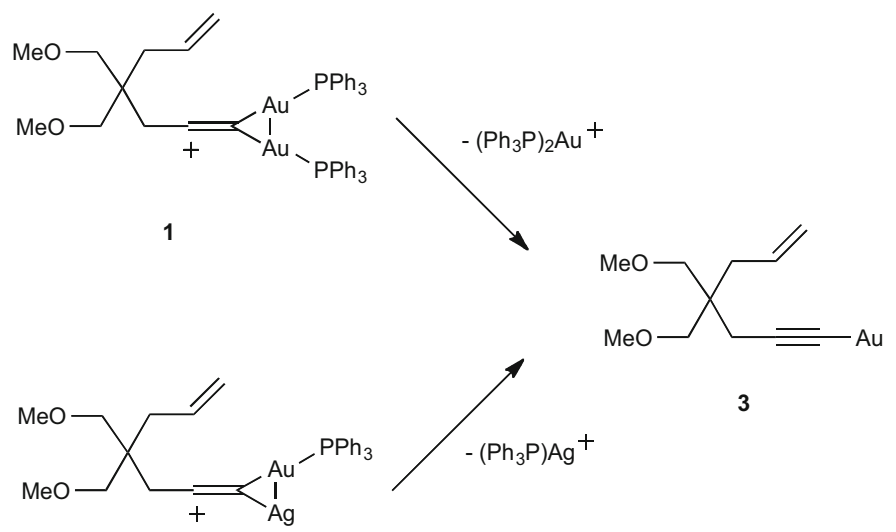

3

2

Scheme 4 Gas-phase fragmentation of homo (1) and hetero (2) dinuclear acetylides [315]

In contrast, all complexes with alkyl substituents in the 6-position of the ligands undergo Coulomb explosion to produce two monocationic fragments, as illustrated for the methyl derivative in Scheme 3. The difference in behaviour was rationalised by the combined effects of steric strain introduced to the central $\mathrm{Au}_{2} \mathrm{O}_{2}$ core by the substituents on the bipyridine ligand and the presence of oxidisable $\mathrm{C}-\mathrm{H}$ bonds in the substituents.

\subsubsection{Gem-Diaurated Cluster Ions}

There has been considerable interest in the possibility of cooperation of two gold centres in catalytic reaction pathways, which has been termed 'dual gold catalysis' [314]. A key question is whether the two gold centres are remote from each other or whether they directly interact via aurophilic interactions. Two studies have appeared in which mass spectrometry experiments and DFT calculations have been carried out to locate the site(s) of the $\mathrm{Au}$ atoms. In the first, Simonneau et al. demonstrated that gold acetylides formed the homo (1), and hetero (2) dinuclear systems, in Scheme 4 under ESI-MS conditions and when subjected to $\mathrm{CID}$, these fragmented via loss of either $\left(\mathrm{Ph}_{3} \mathrm{P}\right)_{2} \mathrm{Au}^{+}$or $\left(\mathrm{Ph}_{3} \mathrm{P}\right) \mathrm{Ag}^{+}$[315]. On the 


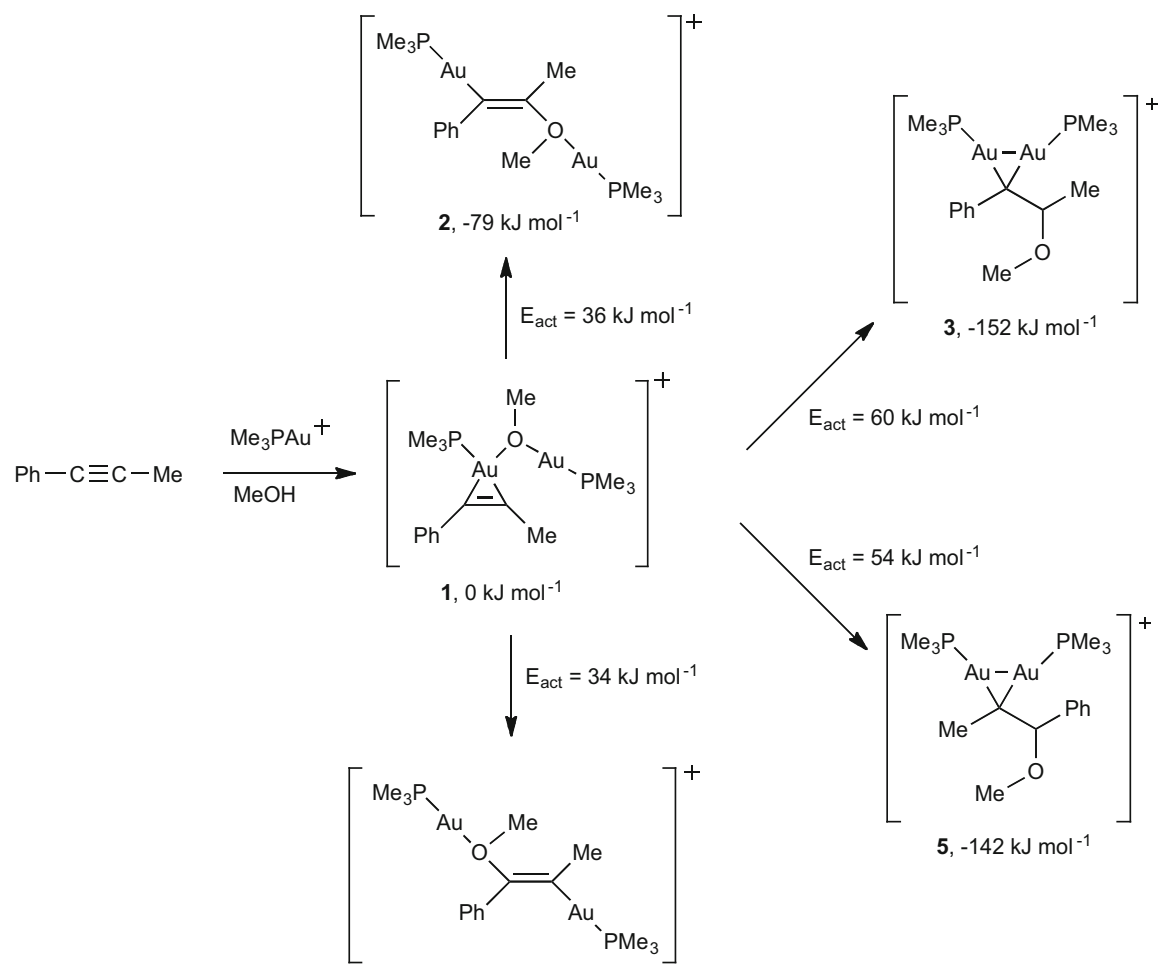

4, $-61 \mathrm{~kJ} \mathrm{~mol}^{-1}$

Scheme 5 DFT-calculated potential mechanism for gold-gold cooperation in the addition of methanol to an internal alkyne, 1-phenylpropyne [316]

basis of DFT calculations, the neutral product (2) was assigned as terminal acetylide with no intramolecular interaction between the $\mathrm{Au}$ and alkene site. Presumably these fragmentation reactions involve phosphine ligand migration prior to fragmentation in an analogous fashion to $\left(\mathrm{H}_{3} \mathrm{PAu}\right)_{2} \mathrm{H}^{+}$(Fig. 29).

Roithová et al. have reported an interesting example of gold-gold cooperation in the addition of methanol to an internal alkyne, 1-phenylpropyne [316]. Using a combination of electrospray ionisation, isotope-labelling experiments and gas-phase IR spectroscopy, they were able to find evidence for the formation of the gem-diaurated intermediates 3 and 5. Based on DFT calculations, the authors proposed a possible mechanism for the formation of these gem-diaurated intermediates, which is shown in Scheme 5.

\subsection{Gold-Containing Bimetallic Cluster Ions}

The synergistic or cooperative effects of bimetallic clusters containing gold atom (s) and other metal atoms towards substrates have been demonstrated in several studies. To model the Degussa process of formation of HCN, Schwarz's group have employed 
FT-ICR MS to investigate metal cluster ion-mediated bond coupling reaction between $\mathrm{CH}_{4}$ and $\mathrm{NH}_{3}$ [317]. While $\mathrm{Pt}$ is a known catalyst for this reaction, $\mathrm{Pt}_{n}{ }^{+}$clusters $(n \geq 2)$ do not induce the $\mathrm{C}-\mathrm{N}$ coupling step and the $\mathrm{Au}_{n}{ }^{+}$clusters do not activate the $\mathrm{C}-\mathrm{H}$ bond $(n \geq 2)$. In contrast, the mixed metal cluster $\mathrm{PtAu}^{+}$was successful since it combines the reactivity of both metals needed for each step (Eqs. (49) and (50)). Deuterium labelling confirmed that $\mathrm{N}-\mathrm{H}$ bond activation occurs in the second step:

$$
\begin{gathered}
\mathrm{PtAu}^{+}+\mathrm{CH}_{4} \rightarrow \mathrm{PtAuCH}_{2}^{+}+\mathrm{H}_{2} \\
\mathrm{PtAuCH}_{2}^{+}+\mathrm{NH}_{2} \rightarrow\left[\mathrm{PtAuCH}_{3} \mathrm{~N}\right]^{+}+\mathrm{H}_{2}
\end{gathered}
$$

In a follow-up study, the $\mathrm{C}-\mathrm{N}$ coupling of methane and $\mathrm{NH}_{3}$ was examined for larger bimetallic platinum-gold cluster cations [282]. Unlike the heterodimer, PtAuCH${ }_{2}{ }^{+}$, which undergoes $\mathrm{C}-\mathrm{N}$ bond coupling, $\mathrm{Pt}_{2} \mathrm{AuCH}_{2}{ }^{+}$reacts with $\mathrm{NH}_{3}$ via carbide formation (Eq. (51)), as does $\mathrm{PtAu}_{2} \mathrm{CH}_{2}{ }^{+}$(Eq. (52)), which also undergoes $\mathrm{Au}$ atom displacement (Eq. (53)). The reactivity of the bare bimetallic platinum-gold cluster cations towards ammonia and methylamine was also examined. The reactivity was found to depend on the nature of both the metal cluster and the amine. For example, $\mathrm{PtAu}^{+}$reacts with $\mathrm{NH}_{3}$ via displacement of $\mathrm{Au}$ (Eq. (54)), while for methylamine three channels are observed: hydride abstraction (Eq. (55)), dehydrogenation (Eq. (56)) and double dehydrogenation (Eq. (57)):

$$
\begin{aligned}
\mathrm{Pt}_{2} \mathrm{AuCH}_{2}^{+}+\mathrm{NH}_{3} & \rightarrow \mathrm{Pt}_{2} \mathrm{AuC}\left(\mathrm{NH}_{3}\right)^{+}+\mathrm{H}_{2} \\
\mathrm{PtAu}_{2} \mathrm{CH}_{2}^{+}+\mathrm{NH}_{3} & \rightarrow \mathrm{PtAu}_{2} \mathrm{C}\left(\mathrm{NH}_{3}\right)^{+}+\mathrm{H}_{2} \\
& \rightarrow\left[\mathrm{PtAuCH}_{5} \mathrm{~N}\right]^{+}+\mathrm{Au} \\
\mathrm{PtAu}^{+}+\mathrm{NH}_{3} & \rightarrow \mathrm{Pt}\left(\mathrm{NH}_{3}\right)^{+}+\mathrm{Au} \\
\mathrm{PtAu}^{+}+\mathrm{CH}_{3} \mathrm{NH}_{2} & \rightarrow \mathrm{CH}_{2}=\mathrm{NH}_{2}^{+}+\mathrm{PtAuH} \\
& \rightarrow\left[\mathrm{PtAuCH}_{3}\right]^{+}+\mathrm{H}_{2} \\
& \rightarrow\left[\mathrm{PtAuCHN}^{+}+2 \mathrm{H}_{2}\right.
\end{aligned}
$$

The reactivity of bimetallic $\mathrm{Pt}_{x} \mathrm{Au}_{y}{ }^{+}$clusters $(x+y \leq 4)$ towards $\mathrm{O}_{2}$ and $\mathrm{CH}_{4}$ highlights the role of cluster composition in controlling the preferred reaction channel(s) [318]. While platinum-rich clusters behave similarly to $\mathrm{Pt}_{x}{ }^{+}$clusters, gold-rich clusters like their pure gold counterparts are inert. For the oxygen substrate, platinum-only and platinum-rich clusters react via cluster decomposition, as illustrated for the trimer clusters in Eqs. (58)-(62). When methane is used as a substrate, pure and platinum-rich clusters react via dehydrogenation (Eq. (63)). Indeed, this reaction only occurs for $y=1$ and $x \geq 1$. The carbene $\mathrm{Pt}_{x} \mathrm{Au}_{y} \mathrm{CH}_{2}{ }^{+}$ mainly loses $\mathrm{H}_{2}$ upon CID (Eq. (64)) and undergoes dehydrogenation in reactions with a second molecule of methane (Eq. (65)):

$$
\begin{aligned}
\mathrm{Pt}_{3}^{+}+\mathrm{O}_{2} & \rightarrow \mathrm{Pt}_{2}^{+}+\mathrm{PtO}_{2} \\
& \rightarrow \mathrm{Pt}_{2} \mathrm{O}^{+}+\mathrm{PtO}
\end{aligned}
$$




$$
\begin{gathered}
\rightarrow \mathrm{Pt}_{2} \mathrm{O}_{2}^{+}+\mathrm{Pt} \\
\mathrm{Pt}_{2} \mathrm{Au}^{+}+\mathrm{O}_{2} \rightarrow \mathrm{PtAu}^{+}+\mathrm{PtO}_{2} \\
\mathrm{PtAu}_{2}^{+}+\mathrm{O}_{2} \rightarrow \mathrm{NO} \mathrm{REACTION} \mathrm{Pt}_{x} \mathrm{Au}_{y}^{+}+\mathrm{CH}_{4} \rightarrow \mathrm{Pt}_{x} \mathrm{Au}_{y} \mathrm{CH}_{2}^{+}+\mathrm{H}_{2} \\
\mathrm{PtAuCH}_{2}^{+} \rightarrow \mathrm{PtAuC}^{+}+\mathrm{H}_{2} \\
\mathrm{PtAuCH}_{2}^{+}+\mathrm{CH}_{4} \rightarrow \mathrm{PtAuC}_{2} \mathrm{H}_{4}^{+}+\mathrm{H}_{2}
\end{gathered}
$$

At the higher pressures of an ion-trap mass spectrometer, Lang et al. have examined the reactions of $\mathrm{PdAu}_{2}{ }^{+}, \mathrm{Pd}_{2} \mathrm{Au}^{+}$and $\mathrm{Pd}_{2} \mathrm{Au}_{2}{ }^{+}$with $\mathrm{CD}_{4}$ [319]. All ions react to sequentially add $\mathrm{CD}_{4}$. The palladium-rich trimer, $\mathrm{Pd}_{2} \mathrm{Au}^{+}$, also undergoes loss of two $\mathrm{D}_{2}$ upon addition of the second $\mathrm{CD}_{4}$ (Eq. (66)). Deuterated ethene is liberated upon addition of a third molecule of $\mathrm{CD}_{4}$, thereby closing a catalytic cycle, which is related to that observed for $\mathrm{Au}_{2}{ }^{+}$which is discussed in detail in Sect. 4.4:

$$
\mathrm{Pd}_{2} \mathrm{Au}\left(\mathrm{CD}_{4}\right)^{+}+\mathrm{CD}_{4} \rightarrow \mathrm{Pd}_{2} \mathrm{Au}\left(\mathrm{C}_{2} \mathrm{D}_{4}\right)^{+}+2 \mathrm{D}_{2}
$$

To model the requirements of co-adsorption of both $\mathrm{CO}$ and water in the watergas shift reactions (Eq. (67)), Fleischer et al. have used a combination of ion-trap mass spectrometry experiments and DFT calculations to compare the reactions of water, $\mathrm{CO}$ and their mixtures with the pure and mixed silver-gold trimer cations, $\mathrm{Au}_{3}{ }^{+}, \mathrm{Ag}_{3}{ }^{+}$and $\mathrm{Ag}_{2} \mathrm{Au}^{+}$[320]. Figure 32 clearly highlights that cluster composition plays a key role in the outcomes of these reactions. $\mathrm{Au}_{3}{ }^{+}$rapidly reacts via sequential addition of three $\mathrm{CO}$ (Fig. 32a) or water molecules (Fig. 32d), while $\mathrm{Ag}_{3}{ }^{+}$and $\mathrm{Ag}_{2} \mathrm{Au}^{+}$mainly add a single $\mathrm{CO}$ (Fig. 32b, c) or water molecule (Fig. 32e, f). The cooperative effect becomes apparent when the reactions of all three trimers with a mixture of water and carbon monoxide are compared. $\mathrm{Au}_{3}{ }^{+}$preferentially adsorbs three $\mathrm{CO}$ molecules (Fig. 32g) while $\mathrm{Ag}_{3}{ }^{+}$adsorbs up to two water molecules (Fig. 32i). This is consistent with the high affinity of gold cluster cations for $\mathrm{CO}$ discussed in Sect. 3.7. In contrast, the replacement of two gold atoms by silver in $\mathrm{Ag}_{2} \mathrm{Au}^{+}$frees up sites for the adsorption of $\mathrm{H}_{2} \mathrm{O}$ since the co-adsorption complexes $\mathrm{Ag}_{2} \mathrm{Au}(\mathrm{CO})\left(\mathrm{H}_{2} \mathrm{O}\right)^{+}$and $\mathrm{Ag}_{2} \mathrm{Au}(\mathrm{CO})\left(\mathrm{H}_{2} \mathrm{O}\right)_{2}{ }^{+}$are observed (Fig. 32h). Detailed kinetic modelling of the experimental data reveals that the process of co-adsorption involves the initial adsorption of CO (Eq. (68)) followed by sequential adsorption of water (Eqs. (69) and (70)). DFT calculations on possible isomers of the co-adsorption complexes $\mathrm{Ag}_{2} \mathrm{Au}(\mathrm{CO})\left(\mathrm{H}_{2} \mathrm{O}\right)^{+}$and $\mathrm{Ag}_{2} \mathrm{Au}(\mathrm{CO})\left(\mathrm{H}_{2} \mathrm{O}\right)_{2}{ }^{+}$ uncovered 3 and 3 isomers, respectively, all lying within around $0.2 \mathrm{eV}$ $\left(\approx 2 \mathrm{~kJ} \mathrm{~mol}^{-1}\right)$ :

$$
\begin{gathered}
\mathrm{H}_{2} \mathrm{O}+\mathrm{CO} \rightarrow \mathrm{CO}_{2}+\mathrm{H}_{2} \\
\mathrm{Ag}_{2} \mathrm{Au}^{+}+\mathrm{CO} \rightarrow \mathrm{Ag}_{2} \mathrm{Au}(\mathrm{CO})^{+}
\end{gathered}
$$


A. Zavras et al.

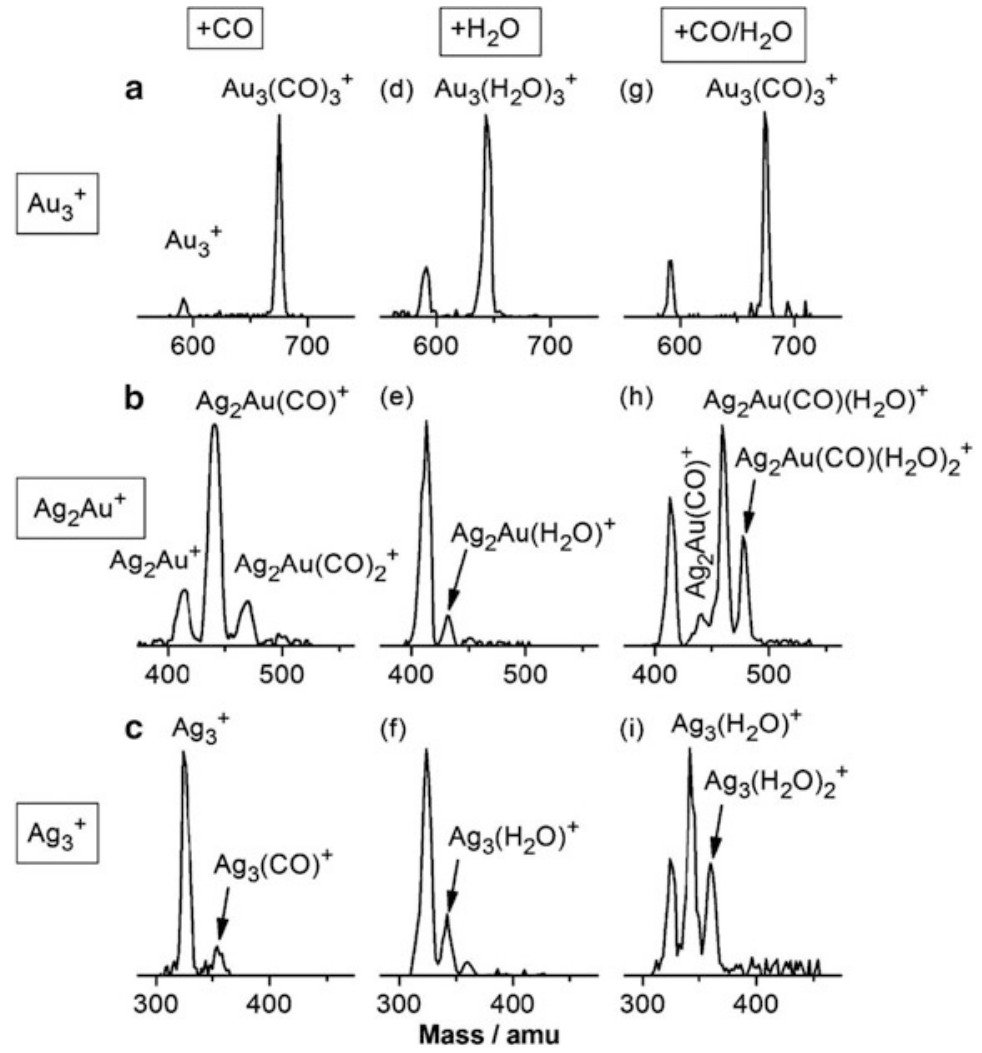

Fig. 32 Ionic products formed after the reaction of $\mathrm{Au}_{3}{ }^{+}(a, d, g), \mathrm{Ag}_{2} \mathrm{Au}^{+}(b, e, h) \operatorname{and~}_{\mathrm{Ag}_{3}}{ }^{+}(c, f$, $i)$ with $\mathrm{CO}(a-c)$ and $\mathrm{H}_{2} \mathrm{O}(d-f)$ at $300 \mathrm{~K}(p(\mathrm{He})=1 \mathrm{~Pa} ; p(\mathrm{CO})=0.02 \mathrm{~Pa}$, except in $(b) p$ $\left.(\mathrm{CO})=0.22 \mathrm{~Pa} ; p\left(\mathrm{H}_{2} \mathrm{O}\right)=0.003 \mathrm{~Pa}\right)$. The spectra in the right column display product ion mass distributions obtained when both reactive molecules $\mathrm{CO}$ and $\mathrm{H}_{2} \mathrm{O}$ were present in the ion trap $(p$ $\left.(\mathrm{CO})=0.04 \mathrm{~Pa}, p\left(\mathrm{H}_{2} \mathrm{O}\right)=0.004,300 \mathrm{~K}\right)$ for $\mathrm{Au}_{3}{ }^{+}(g), \mathrm{Ag}_{2} \mathrm{Au}^{+}(h)$ and $\left.\mathrm{Ag}_{3}{ }^{+} i\right)$. All the spectra were obtained after a reaction time of $500 \mathrm{~ms}$. Figure reproduced from [320]

$$
\begin{aligned}
\mathrm{Ag}_{2} \mathrm{Au}(\mathrm{CO})^{+}+\mathrm{H}_{2} \mathrm{O} & \rightarrow \mathrm{Ag}_{2} \mathrm{Au}(\mathrm{CO})\left(\mathrm{H}_{2} \mathrm{O}\right)^{+} \\
\mathrm{Ag}_{2} \mathrm{Au}(\mathrm{CO})\left(\mathrm{H}_{2} \mathrm{O}\right)^{+}+\mathrm{H}_{2} \mathrm{O} & \rightarrow \mathrm{Ag}_{2} \mathrm{Au}(\mathrm{CO})\left(\mathrm{H}_{2} \mathrm{O}\right)_{2}^{+}
\end{aligned}
$$

\subsection{Catalysis by Gold Cluster Ions}

Trapping mass spectrometers are uniquely suited to study complete catalytic cycles [44]. In 1981, Kappes and Staley reported groundbreaking research on the first examples of transition-metal-catalysed reactions in the gas phase using an ICR mass spectrometer [321]. A key reaction they studied was the oxidation of $\mathrm{CO}$ (Eq. (71)), which is exothermic $\left(\Delta H^{\circ}=-107 \mathrm{kcal} \mathrm{mol}^{-1}\right)$ but does not occur at room temperature in the absence of a catalyst. They described a simple two-step catalytic cycle for the oxidation of $\mathrm{CO}$ catalysed by the atomic iron cation 
Scheme $6 \mathrm{Fe}^{+}$-catalysed oxidation of $\mathrm{CO}$ [321]. Step 1 is oxygen atom abstraction; step 2 is oxygen atom transfer

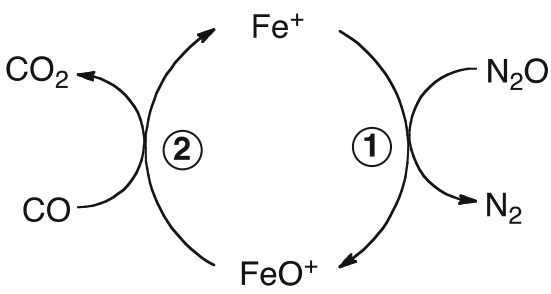

(Scheme 6). In the first step, $\mathrm{Fe}^{+}$reacted with $\mathrm{N}_{2} \mathrm{O}$ by oxygen atom transfer to yield $\mathrm{FeO}^{+}$, which transferred an oxygen atom to $\mathrm{CO}$ in the second step to yield neutral $\mathrm{CO}_{2}$ and regenerate the atomic $\mathrm{Fe}^{+}$catalyst. The exploration of gas-phase transition-metal catalytic cycles has continued in the intervening 4 decades and been reviewed on several occasions [28, 29, 287, 322, 323]. Here we focus on complete gas-phase catalytic cycles that are catalysed by gold nanoclusters. Readers are also directed to Sect. 4 for data relevant for potential catalytic cycles whose final step (s) has not yet been realised.

$$
\mathrm{CO}+\mathrm{N}_{2} \mathrm{O} \rightarrow \mathrm{CO}_{2}+\mathrm{N}_{2}
$$

Bernhardt's group has used a variable-temperature ion trap to examine related oxidation of $\mathrm{CO}$ by $\mathrm{N}_{2} \mathrm{O}$ occurring on the coinage metal cluster cations $\mathrm{Au}_{3}{ }^{+}$ (at $300 \mathrm{~K}$ ) and $\mathrm{Ag}_{3}{ }^{+}$(at 230 and $250 \mathrm{~K}$ ) [287]. They studied the reactions of $\mathrm{Au}_{3}{ }^{+}$ and $\mathrm{Ag}_{3}{ }^{+}$with $\mathrm{N}_{2} \mathrm{O}$ only, $\mathrm{CO}$ only and with both $\mathrm{N}_{2} \mathrm{O}$ and $\mathrm{CO}$ in the ion trap. Both $\mathrm{Au}_{3}{ }^{+}$and $\mathrm{Ag}_{3}{ }^{+}$react with $\mathrm{N}_{2} \mathrm{O}$ via a series of oxygen atom abstraction reactions (Eq. (72), with $n=1-3)$. Additional products formulated as $\mathrm{M}_{3} \mathrm{O}_{n}\left(\mathrm{~N}_{2} \mathrm{O}_{2}\right)_{m}{ }^{+}$were observed (where $n=1-3$ for $m=1$ for $\mathrm{M}=\mathrm{Ag}$ and $\mathrm{Au} ; n=2$ and 3 for $m=2$ for $\mathrm{M}=\mathrm{Ag} ; n=2$ for $m=2$ for $\mathrm{M}=\mathrm{Au})$. When only $\mathrm{CO}$ was in the ion trap, $\mathrm{Au}_{3}{ }^{+}$reacted to exclusively give $\mathrm{Au}_{3}(\mathrm{CO})_{3}{ }^{+}$(Eq. (73), with $n=3$ ) while $\mathrm{Ag}_{3}{ }^{+}$gave a combination of $\mathrm{Ag}_{3}(\mathrm{CO})^{+}$and $\mathrm{Ag}_{3}(\mathrm{CO})_{2}{ }^{+}$(Eq. (73), with $n=1$ and 2). When both $\mathrm{N}_{2} \mathrm{O}$ and $\mathrm{CO}$ were in the ion trap two main products were observed for $\mathrm{Au}_{3}{ }^{+}: \mathrm{Au}_{3}(\mathrm{CO})_{3}{ }^{+}$and $\mathrm{Au}_{3}\left(\mathrm{CO}_{2}\right)_{3}{ }^{+}$. The observation of the latter product suggests that oxidation of all each oxygen atom in the oxide $\mathrm{Au}_{3} \mathrm{O}_{3}{ }^{+}$reacted with one $\mathrm{CO}$ molecule to produce $\mathrm{CO}_{2}$ that remained bound to the cluster (Eq. (74)). While the authors did not examine the CID reactions of the product $\mathrm{Au}_{3}\left(\mathrm{CO}_{2}\right)_{3}{ }^{+}$, if this were to undergo losses of three molecules of $\mathrm{CO}_{2}$ (Eq. (75)), then this would formally close a catalytic cycle for the oxidation of $\mathrm{CO}$ (Eq. (71)). Finally, oxidation of $\mathrm{CO}$ when $\mathrm{N}_{2} \mathrm{O}$ was present in the trap proceeded via a different process for $\mathrm{Ag}_{3}{ }^{+}$, which is shown in Eq. (76):

$$
\begin{gathered}
\mathrm{M}_{3}^{+}+n \mathrm{~N}_{2} \mathrm{O} \rightarrow \mathrm{M}_{3} \mathrm{O}_{3}^{+}+n \mathrm{~N}_{2} \\
\mathrm{M}_{3}^{+}+n \mathrm{CO} \rightarrow \mathrm{M}_{3}(\mathrm{CO})_{n}^{+} \\
\mathrm{Au}_{3} \mathrm{O}_{3}^{+}+3 \mathrm{CO} \rightarrow \mathrm{Au}_{3}\left(\mathrm{CO}_{2}\right)_{3}^{+}
\end{gathered}
$$


Scheme $7 \quad \mathrm{Au}_{2}{ }^{-}$-catalysed oxidation of CO [287, 321]. Step 1 is oxygen addition; step 2 is $\mathrm{CO}$ addition; step 3 is oxygen atom transfer

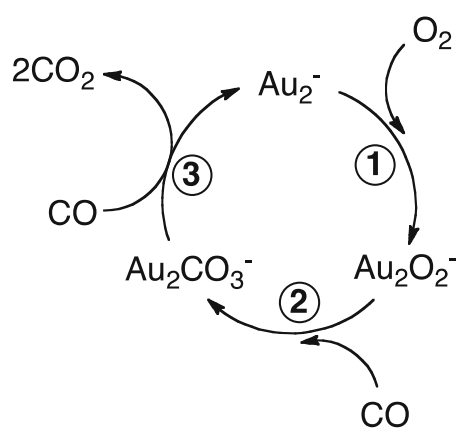

Bernhardt's group has used the same experimental set-up to study the related oxidation of $\mathrm{CO}$ (Eq. (77)) by $\mathrm{O}_{2}$ catalysed by the gold dimer anion $\mathrm{Au}_{2}{ }^{-}$over a temperature range of 100-300 K (Scheme 7) [324, 325]. DFT calculations were used to examine key intermediates associated with this cycle [288, 325]. The first step of the cycle involves adsorption of $\mathrm{O}_{2}$ onto $\mathrm{Au}_{2}{ }^{-}$, with the resultant complex stabilised by further collisions with the helium bath gas. DFT calculations predict that $\mathrm{Au}_{2} \mathrm{O}_{2}{ }^{-}$ consists of dioxygen bound molecularly to $\mathrm{Au}_{2}{ }^{-}$, with partial electron transfer to the adsorbed $\mathrm{O}_{2}$ molecule resulting in a 'superoxo-like' species (cf. Sect. 3.4). In step $2, \mathrm{Au}_{2} \mathrm{O}_{2}{ }^{-}$reacts with $\mathrm{CO}$ to yield the metastable complex $\mathrm{Au}_{2} \mathrm{CO}_{3}{ }^{-}$, which was not observed at room temperature but could be detected at lower temperatures $(100 \mathrm{~K})$. DFT calculations of potential isomers of ' $\mathrm{Au}_{2} \mathrm{CO}_{3}{ }^{-}$, revealed the digold-carbonate species of connectivity $\left[\mathrm{Au}-\mathrm{Au}-\mathrm{OCO}_{2}\right]^{-}$to be the most stable species, although a second structural isomer was found and suggested to be relevant to the catalytic process. The final step of the cycle in which $\mathrm{Au}_{2} \mathrm{CO}_{3}{ }^{-}$reacts with $\mathrm{CO}$ resulted in the liberation of two molecules of $\mathrm{CO}_{2}$ and the regeneration of $\mathrm{Au}_{2}{ }^{-}$, thus closing a three-step catalytic cycle for the oxidation of $\mathrm{CO}$ to $\mathrm{CO}_{2}$ with $\mathrm{O}_{2}$ as the terminal oxidant (Scheme 7). Related work by other groups on the reactions of gold clusters with $\mathrm{O}_{2}$ and $\mathrm{CO}$ was highlighted in previous sections.

$$
2 \mathrm{CO}+\mathrm{O}_{2} \rightarrow 2 \mathrm{CO}_{2}
$$

Two competing, temperature-dependent catalytic cycles for the oxidation of methane by $\mathrm{O}_{2}$ catalysed by $\mathrm{Au}_{2}{ }^{+}$have been described (Scheme 8) [326, 327]. Variable-temperature ion-trap mass spectrometry experiments were carried out in which the partial pressures of $\mathrm{CH}_{4}$ and $\mathrm{O}_{2}$ were varied and product distributions at different temperature were examined. In combination with these detailed experiments, kinetic modelling of the product ion abundances was used to establish the order of the individual steps of each of the catalytic cycles, and DFT calculations were used to shed light on possible mechanisms. Reversible absorption of methane onto $\mathrm{Au}_{2}{ }^{+}$(step 1 of Scheme 8) represents the key first step and provides the shared entry point into both catalytic cycles, which also share the same next step involving 
Scheme 8 Competing catalytic cycles for oxidation of methane catalysed by $\mathrm{Au}_{2}^{+}$: Cycle 1 involves dehydrocoupling of methane to yield ethane (Eq. (78)) [326, 327]; Cycle 2 involves oxidation of methane to formaldehyde (Eq. (79)) [327]

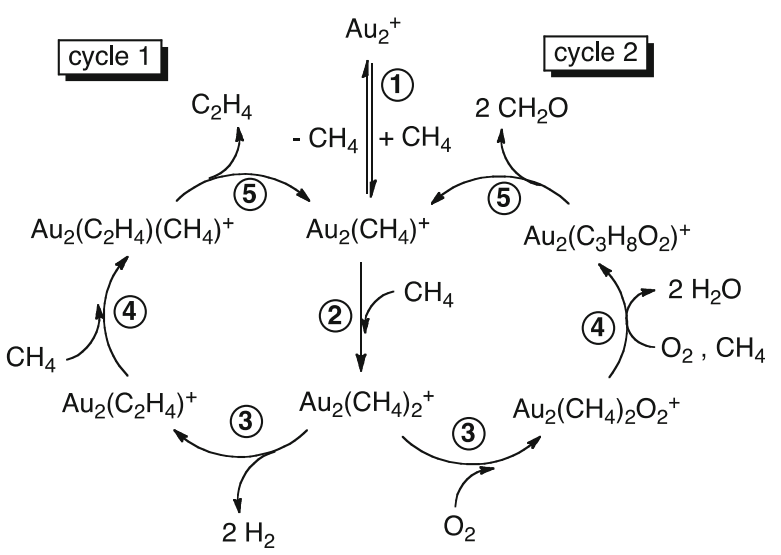

reaction with a second molecule of methane (step 2 of Scheme 8). The subsequent reactions of $\mathrm{Au}_{2}\left(\mathrm{CH}_{4}\right)_{2}{ }^{+}$represent the branch points for the competing cycles.

Either in the absence of $\mathrm{O}_{2}$ or at higher temperatures that disfavour the adsorption of $\mathrm{O}_{2}$, cycle 1 proceeds via elimination of $\mathrm{H}_{2}$ (step 3) [326, 327]. Desorption of ethene from $\mathrm{Au}_{2}\left(\mathrm{C}_{2} \mathrm{H}_{4}\right)^{+}$does not occur spontaneously, but rather is triggered by reaction with a third molecule of methane (step 5), which closes catalytic cycle 1 via the regeneration of $\mathrm{Au}_{2}\left(\mathrm{CH}_{4}\right)^{+}$. This cycle corresponds to the dehydrocoupling of two molecules of methane to form ethene (Eq. (78)). By studying the relative abundances of the various product ions as a function of temperature, information was gleaned on the relative barriers associated with key steps. Thus the barrier for dehydrogenation (step 3) can only be surmounted at $250 \mathrm{~K}$ and above, while loss of ethene from $\mathrm{Au}_{2}\left(\mathrm{C}_{2} \mathrm{H}_{4}\right)\left(\mathrm{CH}_{4}\right)^{+}$only occurs at temperatures above $270 \mathrm{~K}$. At the lowest temperature studied $(200 \mathrm{~K})$, a minor product formulated as $\mathrm{Au}_{2}\left(\mathrm{C}_{4} \mathrm{H}_{12}\right)^{+}$was observed, while the ion $\mathrm{Au}\left(\mathrm{C}_{2} \mathrm{H}_{4}\right)\left(\mathrm{CH}_{4}\right)^{+}$, which corresponds to loss of an $\mathrm{Au}$ atom from $\mathrm{Au}_{2}\left(\mathrm{C}_{2} \mathrm{H}_{4}\right)$ $\left(\mathrm{CH}_{4}\right)^{+}$, appears at $250 \mathrm{~K}$. The DFT calculations reveal that the mechanistic sequence for dehydrogenation of $\mathrm{Au}_{2}\left(\mathrm{CH}_{4}\right)_{2}{ }^{+}$involves stepwise losses of $\mathrm{H}_{2}$ and involves 11 intermediates and 9 transition states. The first loss of $\mathrm{H}_{2}$ gives rise to the organometallic cluster ion, $\left(\mathrm{CH}_{3} \mathrm{Au}\right)_{2}{ }^{+}$as a key intermediate. A related catalytic cycle was recently reported for the reaction of mixed metal cluster $\mathrm{Pd}_{2} \mathrm{Au}^{+}$with $\mathrm{CD}_{4}$ [319]:

$$
2 \mathrm{CH}_{4} \rightarrow \mathrm{CH}_{2}=\mathrm{CH}_{2}+2 \mathrm{H}_{2}
$$

Cycle 2, which corresponds to the oxidation of methane to formaldehyde (Eq. (79)), dominates at $210 \mathrm{~K}$, while cycle 2 becomes competitive at $240 \mathrm{~K}$ and then dominates at temperatures of $250 \mathrm{~K}$ and above [327]. The cooperative action of multiple substrate and oxidant molecules is vital for the successful progress of cycle 2. Only $\mathrm{Au}_{2}\left(\mathrm{CH}_{4}\right)_{2}{ }^{+}$can react with a molecule of $\mathrm{O}_{2}$ to form $\mathrm{Au}_{2}\left(\mathrm{CH}_{4}\right)_{2} \mathrm{O}_{2}{ }^{+}$ (step 3), which reacts with a third molecule methane and a second molecule of $\mathrm{O}_{2}$ to form $\mathrm{Au}_{2}\left(\mathrm{C}_{3} \mathrm{H}_{8} \mathrm{O}_{2}\right)^{+}$and 2 equiv. of water (step 4) [327]. The final step involves loss of two molecules of formaldehyde from $\mathrm{Au}_{2}\left(\mathrm{C}_{3} \mathrm{H}_{8} \mathrm{O}_{2}\right)^{+}$to regenerate the catalyst $\mathrm{Au}_{2}\left(\mathrm{CH}_{4}\right)^{+}$. A multistep process for oxidation of both adsorbed methane molecules 
to formaldehyde was predicted via DFT calculations. Each formaldehyde is formed at a different end of the gold dimer, and they are formed in the following related steps: oxygen absorbs at a gold site to form a peroxo intermediate, $\left(\mathrm{CH}_{4}\right) \mathrm{Au}-\mathrm{Au}$ $(\mathrm{O}-\mathrm{O})\left(\mathrm{CH}_{4}\right)^{+}$, which then abstracts a hydrogen atom to yield an organogoldhydroperoxide intermediate, $\left(\mathrm{CH}_{4}\right) \mathrm{Au}-\mathrm{Au}(\mathrm{O}-\mathrm{OH})\left(\mathrm{CH}_{3}\right)^{+}$, which then loses water to form a oxo-gold-carbene, $\left(\mathrm{CH}_{4}\right) \mathrm{Au}-\mathrm{Au}(\mathrm{O})\left(\mathrm{CH}_{2}\right)^{+}$, that can then rearrange to the $\mathrm{O}$ bound formaldehyde complex, $\left(\mathrm{CH}_{4}\right) \mathrm{Au}-\mathrm{Au}\left(\mathrm{OCH}_{2}\right)^{+}$. The final step involves absorption of the third methane molecule onto the bisformaldehyde complex, $\left(\mathrm{CH}_{2} \mathrm{O}\right) \mathrm{Au}-\mathrm{Au}\left(\mathrm{OCH}_{2}\right)^{+}$, which acts as a trigger to release both formaldehydes:

$$
2 \mathrm{CH}_{4}+2 \mathrm{O}_{2} \rightarrow 2 \mathrm{CH}_{2} \mathrm{O}+2 \mathrm{H}_{2} \mathrm{O}
$$

\section{From the Gas Phase to Materials}

Mass spectrometry-based studies offer exciting opportunities to direct the synthesis of new materials, as dramatically highlighted by the discovery and subsequent isolation of bulk fullerenes. Initial studies using a cluster beam source coupled to a mass spectrometer led to the discovery of the magic number of $C_{60}$ [328]. Subsequently Kroto et al. proposed the Buckminsterfullerene structure [329]. These exciting results inspired other researchers to devise synthetic strategies aimed at isolating samples of $\mathrm{C}_{60}$ in order to structurally characterise them, but it was not until 5 years later that bulk samples became available [330].

Within the context of AuNCs, mass spectrometry has had an impact in the generation of materials in two main ways: (1) the use of MS to 'direct' the synthesis of gold NCs and (2) the use of MS as a preparative tool to mass select gold NCs and soft land them onto surfaces. Both of these approaches are briefly described below.

\subsection{MS-Directed Synthesis of Gold Clusters}

As noted in Sect. 2, mass spectrometry has been used to monitor the growth and processing of gold clusters. In several cases, MS had been used to direct the synthesis and isolation of bulk material of the gold cluster for subsequent structure and property studies. Recent cases include work from the group of Konishi et al. [58, 59]. For example, the isolation of $\left[\mathrm{Au}_{11}\left(\mathrm{Ph}_{2} \mathrm{P}\left(\mathrm{CH}_{2}\right)_{2} \mathrm{PPh}_{2}\right)_{6}\right]^{3+}$ [59], as the $\mathrm{SbF}_{6}{ }^{-}$salt, was found to be composed of an $\mathrm{Au}_{9}$ core with two gold atoms located at the exo position. In brief, the gold complex $\left[\mathrm{Au}_{2}\left(\mathrm{Ph}_{2} \mathrm{P}\left(\mathrm{CH}_{2}\right)_{2} \mathrm{PPh}_{2}\right)\right] \mathrm{Cl}_{2}[331,332](200 \mu \mathrm{mol})$ in $75 \mathrm{~mL}$ ethanol was treated with a $5 \mathrm{~mL}$ ethanolic solution of sodium borohydride $(400 \mu \mathrm{mol})$. After $1 \mathrm{~h}$ of stirring crude material was precipitated using excess $\mathrm{NaSbF}_{6}$. ESI-MS analysis of the crude precipitate revealed monodispersed $\left[\mathrm{Au}_{11}\left(\mathrm{Ph}_{2} \mathrm{P}\left(\mathrm{CH}_{2}\right)_{2} \mathrm{PPh}_{2}\right)_{6}\right]^{3+}$, $m / z=1519$. The isolation of crystalline material suitable for structural studies by X-ray crystallography was prompted by ESI-MS analysis of the crude material and crystals successfully grown from ethanol/dichloromethane. 


\subsection{MS-Selected Deposition of Gold Cluster Ions}

Preparative mass spectrometry, whereby a species is ionised, mass selected and collected as a bulk sample for subsequent use, has a history dating back to the use of calutrons during World War II for separation and isolation of ${ }^{235} \mathrm{U}$ [333]. The low-energy collisions of ions with surfaces have been comprehensively reviewed and, depending on the conditions used, can be exploited for the deposition of massselected clusters onto surfaces [334]. This is an active area of research since it holds great promise for the modification of surfaces and the synthesis of novel structures. Soft landing (SL) experiments allow intact, mass-selected clusters to be applied to surfaces. The ability to control the size, density and in some cases the morphology of the deposited particles allows unprecedented flexibility in the creation of new types of nanostructures and as such holds considerable promise in the development of new catalysts. This dynamic field has been reviewed [335], including a consideration of the types of instruments that have been developed, which are essentially all 'homebuilt' [334]. The challenges of characterising the resultant surface covered nanoclusters have also been discussed [336].

As noted by Johnson et al., mass spectrometry offers several unique capabilities for deposition experiments, including (1) multiple ways of forming gas-phase ions such as laser ablation and ESI of intact clusters; (2) the ability to mass select ions from a complex mixture - this allows deposition of a monodisperse cluster from a polydisperse mixture; and (3) since ions are used, it is possible to focus and pattern the ion beam, thereby controlling the landing process. The surface onto which the clusters are deposited can also be varied to examine how the support influences the reactivity of the landed cluster.

The next two sections consider the role of the surface on the structure and properties of surface landed gold nanoclusters and the reactions of surface landed gold nanoclusters with substrates.

\subsubsection{Determining the Role of Surface on the Structure and Properties of Surface Landed Gold Nanoclusters}

Table 11 highlights the range of different surfaces that have been used in soft landing of mass-selected gold NC ions, which include: graphite, highly ordered pyrolytic graphite (HOPG); silica and alumina; titania; $\mathrm{TiO}_{2}(110)$; and $\mathrm{MgO}$. Some key questions that have been addressed when assessing the outcomes of these experiments include: Have the AuNCs remained intact, or have they fragmented [345, 346] Are the AuNCs mobile [341] Has agglomeration (or sintering) occurred [337, 341] What happens to the charge [345, 346] Has the shape of the cluster changed [341] What role do surface defects play on the structure, reactivity and properties of soft landed AuNCs [348] In order to address the questions, techniques have been developed to examine the structure and properties of surface landed AuNCs. Interested readers in the details of these techniques are directed to key reviews [334-336, 359]. Table 11 also highlights some of the key findings for the growing literature of soft landed AuNPs. 
Table 11 Summary of key literature on the soft landing of AuNC ions onto surfaces

\begin{tabular}{|c|c|c|c|}
\hline AuNC ion & Surface & Key findings & References \\
\hline$\overline{\mathrm{Au}^{+}}$ & $\begin{array}{c}\text { Amorphous } \\
\text { carbon }\end{array}$ & $\begin{array}{l}\text { An example of 'bottom-up synthesis' via ion } \\
\text { beam deposition, which requires } \\
\text { agglomeration. The ion beam energy } \\
\text { plays a key role in the resultant cluster } \\
\text { size }\end{array}$ & [337] \\
\hline $\mathrm{Au}_{x}^{+}(x=5,7$ & $\begin{array}{l}\text { Amorphous } \\
\text { carbon }\end{array}$ & $\begin{array}{l}\text { No significant fragmentation or agglomera- } \\
\text { tion of the clusters was observed }\end{array}$ & [338] \\
\hline $\mathrm{Au}_{250}{ }^{+}$ & Graphite & $\begin{array}{l}\text { Clusters move on the surface but do not } \\
\text { always agglomerate when then touch }\end{array}$ & [339] \\
\hline $\mathrm{Au}_{x}^{+}$ & $\mathrm{Au}(111)$ & $\begin{array}{l}\text { Neither diffusion nor coalescence of the SL } \\
\text { AuNCs was detected }\end{array}$ & {$[340]$} \\
\hline $\mathrm{Au}_{x}^{+}(x=1-8)$ & $\mathrm{TiO}_{2}(110)$ & $\begin{array}{l}\mathrm{Au}^{+} \text {undergoes sintering. For } x=2-8, \mathrm{SL} \\
\mathrm{Au}_{x} \text { are not mobile and do not sinter. The } \\
\mathrm{SL} \text { clusters adopt a different shape to the } \\
\text { gas phase due to charge transfer from the } \\
\text { surface and ligation by the surface }\end{array}$ & {$[341]$} \\
\hline $\mathrm{Au}_{x}^{+}(x=2-10)$ & $\begin{array}{l}\mathrm{SiO}_{2} / \mathrm{Si}(111) \text { and } \\
\mathrm{Al}_{2} \mathrm{O}_{3} / \mathrm{SiO}_{2} / \\
\mathrm{Si}(111)\end{array}$ & $\begin{array}{l}\text { 2D SL AuNCs undergo a structural change } \\
\text { on the surface from vertical into hori- } \\
\text { zontal orientations. The horizontal clus- } \\
\text { ters can then undergo diffusion and } \\
\text { agglomeration }\end{array}$ & {$[342]$} \\
\hline $\begin{array}{l}\mathrm{Au}_{330 \pm 17^{+}} \text {and } \\
\mathrm{Au}_{10000} \pm 500^{+}\end{array}$ & $\begin{array}{l}\text { Amorphous } \\
\text { carbon }\end{array}$ & $\begin{array}{c}\text { The role of temperature and cluster size on } \\
\text { agglomeration were studied. At higher } \\
\text { temperatures smaller clusters are more } \\
\text { mobile and agglomerate more rapidly }\end{array}$ & [343] \\
\hline $\mathrm{Au}_{x}^{+}$ & Graphite & $\begin{array}{l}\text { The role of background pressure of } \\
\text { agglomeration of NCs was examined }\end{array}$ & [344] \\
\hline $\mathrm{Au}_{11} \mathrm{~L}_{5}^{3+\mathrm{a}}$ & $\mathrm{SAMs}^{\mathrm{a}}$ & $\begin{array}{l}\text { The cluster remains intact, but the SAM } \\
\text { used influences the charge state of } \\
\mathrm{Au}_{11} \mathrm{~L}_{5}{ }^{n+}: \text { FSAM: } n=3 \text {; COOH-SAM } \\
n=2 \text {, HSAM: } n=1\end{array}$ & {$[345]$} \\
\hline $\mathrm{Au}_{11} \mathrm{~L}_{5}{ }^{3+\mathrm{a}}$ & SAMs $^{\mathrm{a}}$ & $\begin{array}{l}\text { The charge state of soft landed } \mathrm{Au}_{11} \mathrm{~L}_{5}{ }^{\mathrm{n}+} \text { is } \\
\text { influenced by both the } \mathrm{SAM} \text { and the } \\
\text { surface coverage. At higher coverages, } \\
\text { pronounced reduction is observed }\end{array}$ & [346] \\
\hline $\mathrm{Au}_{x}^{+}$ & Silica & $\begin{array}{l}\text { Photoelectron spectroscopy was used to } \\
\text { examine how the valence electronic } \\
\text { states changes as a function of cluster } \\
\text { size }\end{array}$ & {$[347]$} \\
\hline $\begin{array}{l}\mathrm{Au}_{4}^{+}, \mathrm{Au}_{8}^{+} \text {and } \\
\qquad \mathrm{Au}_{3} \mathrm{Sr}^{+}\end{array}$ & $\operatorname{MgO}(100)$ & $\begin{array}{l}\text { A review focussing on the role of oxide } \\
\text { support defects, cluster size dependence, } \\
\text { cluster structural fluxionality and impu- } \\
\text { rity doping on the catalytic properties of } \\
\text { size-selected metal clusters on surfaces }\end{array}$ & [348] \\
\hline $\mathrm{Au}_{x}^{+}(1<x \leq 20)$ & $\operatorname{MgO}(100)$ & $\begin{array}{l}\text { Low-temperature oxidation of } \mathrm{CO} \text { was } \\
\text { studied as a function of cluster size. } \mathrm{Au}_{8} \\
\text { was found to be the smallest catalytically } \\
\text { active cluster }\end{array}$ & [349] \\
\hline
\end{tabular}


Table 11 (continued)

\begin{tabular}{|c|c|c|c|}
\hline AuNC ion & Surface & Key findings & References \\
\hline $\mathrm{Au}_{x}^{+}(1<x \leq 20)$ & $\mathrm{MgO}(100)$ & $\begin{array}{l}\text { Low-temperature oxidation of } \mathrm{CO} \text { was } \\
\text { studied. } \mathrm{SL} \mathrm{NCs} \mathrm{of} \mathrm{Au}_{x}, \mathrm{Pt}_{x}, \mathrm{Pd}_{x} \text { and } \mathrm{Rh}_{x} \\
\text { were compared. } \mathrm{Rh}_{20} \text { showed the highest } \\
\text { reactivity }\end{array}$ & {$[350]$} \\
\hline $\begin{array}{c}\mathrm{Au}_{x}^{+}(x=1,2 \\
3,4,7)\end{array}$ & $\mathrm{TiO}_{2}(110)$ & $\begin{array}{l}\mathrm{Au}_{7} \mathrm{NCs} \text { are }>50 \text { times more reactive in } \\
\text { catalysing } \mathrm{CO} \text { oxidation than samples } \\
\text { prepared by } \mathrm{Au} \text { or } \mathrm{Au}_{2} \text { deposition. }{ }^{18} \mathrm{O}_{2} \\
\text { and mass spectrometry were used to } \\
\text { analyse desorbed } \mathrm{C}^{16} \mathrm{O}, \mathrm{C}^{18} \mathrm{O} \text { and } \\
{ }^{16} \mathrm{OC}^{18} \mathrm{O} \text {. A lack of } \mathrm{C}^{18} \mathrm{O} \text { formation } \\
\text { highlights that } \mathrm{CO} \text { does not decompose } \\
\text { on the AuNCs }\end{array}$ & [351] \\
\hline $\mathrm{Au}_{8}^{+}$ & $\operatorname{MgO}(100)$ & $\begin{array}{l}\text { Oxide support defects play a key role in } \\
\text { enhancing cluster reactivity for the oxi- } \\
\text { dation of } \mathrm{CO}\end{array}$ & {$[352]$} \\
\hline $\mathrm{Au}_{17}{ }^{+}$ & Graphite & $\begin{array}{l}\text { Sub-monolayer films of size-selected } \mathrm{Au} \\
\text { clusters present binding sites to stabilise } \\
\text { individual protein molecules and com- } \\
\text { plexes for single-molecule } \\
\text { measurements }\end{array}$ & {$[353]$} \\
\hline $\mathrm{Au}_{x}^{+}(x=2-10)$ & $\begin{array}{l}\text { Sputter-damaged } \\
\text { HOPG }\end{array}$ & $\begin{array}{l}\text { Oxidation of the SL AuNCs by atomic oxy- } \\
\text { gen was studied as a function of cluster } \\
\text { size. The resultant oxides were allowed } \\
\text { to react with CO. Only } \mathrm{Au}_{8} \text { shows sig- } \\
\text { nificant reactivity }\end{array}$ & [354] \\
\hline $\mathrm{Au}_{x}^{+}(x=2-10)$ & Silica & $\begin{array}{l}\text { An additional } \mathrm{Au} \text { atom can significantly } \\
\text { change the oxidation of } \mathrm{SL} A \mathrm{AuNs} \text { by } \\
\text { atomic oxygen. } \mathrm{Au}_{5} \text { and } \mathrm{Au}_{7} \text { are resistant } \\
\text { to oxidation }\end{array}$ & {$[355]$} \\
\hline $\mathrm{Au}_{x}^{+}(x=5-8)$ & Silica & $\begin{array}{l}\text { SL AuNCs were first treated with either } \\
\text { water or } \mathrm{NaOH} \text {, and their oxidation by } \\
\text { atomic oxygen was then studied } \\
\text { Water has no effect, while oxidation resis- } \\
\text { tant } \mathrm{Au}_{5} \text { and } \mathrm{Au}_{7} \text { become more reactive } \\
\text { towards oxidation upon treatment with } \\
\mathrm{NaOH}\end{array}$ & {$[356]$} \\
\hline $\mathrm{Au}_{x}^{+}(x=6-10)$ & $\begin{array}{r}\text { Amorphous } \\
\text { alumina }\end{array}$ & $\begin{array}{l}\text { SL AuNCs catalyse the epoxidation of } \\
\text { propene. The highest selectivity for } \\
\text { epoxide formation over acrolein forma- } \\
\text { tion was found for gas mixtures involv- } \\
\text { ing oxygen and water, thereby } \\
\text { circumventing the use of hydrogen }\end{array}$ & [357] \\
\hline $\mathrm{Au}_{20}{ }^{+}$ & $\operatorname{MgO}(100)$ & $\begin{array}{l}\text { The role of the thickness and stoichiometry } \\
\text { of the } \mathrm{MgO} \text { films on the catalytic activity } \\
\text { of } \mathrm{SL} \mathrm{Au}_{20} \text { towards } \mathrm{CO} \text { oxidation was } \\
\text { examined. Theoretical calculations were } \\
\text { used to probe the mechanism of } \mathrm{CO} \\
\text { oxidation }\end{array}$ & {$[358]$} \\
\hline
\end{tabular}

${ }^{\mathrm{a}} \mathrm{L}=$ 1,3-bis(diphenylphosphino)propane, different self-assembled monolayers on gold (SAMs) were used: $1 H, 1 H, 2 H, 2 H$-perfluorodecanethiol (FSAM); 16-mercaptohexadecanoic acid (COOHSAM); 1-dodecanethiol (HSAM)

This table is adapted from [334] 


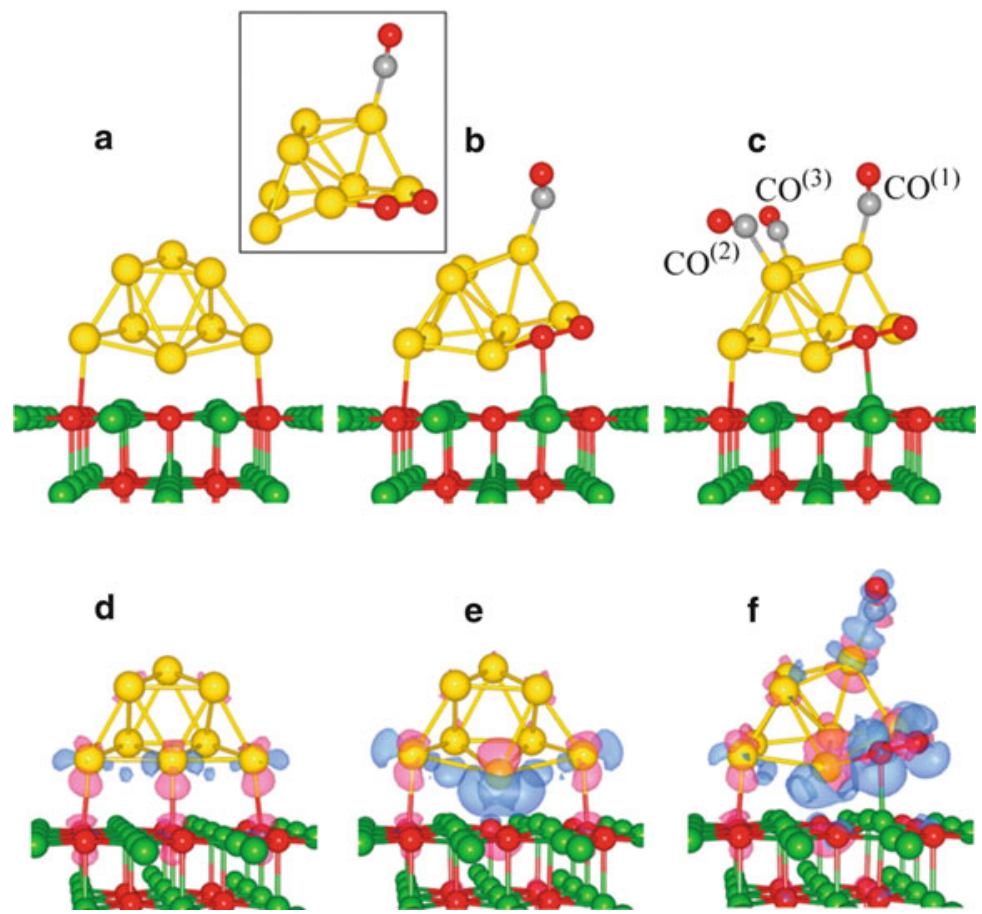

Fig. 33 Optimised structures of $(A)$ bare $\mathrm{Au}_{8}$ cluster (yellow spheres) adsorbed on an $F$ centre of a $\mathrm{MgO}(001)$ surface (O atoms are in red and $\mathrm{Mg}$ atoms in green); $(B)$ a surface-supported gold octamer with $\mathrm{O}_{2}$ adsorbed at the interface between the $\mathrm{Au}_{8}$ cluster and the magnesia surface and a $\mathrm{CO}$ molecule adsorbed on the top triangular facet (the $\mathrm{C}$ atom is depicted in grey). The inset between $(A)$ and $(B)$ shows a local-energy-minimum structure of the free $\mathrm{Au}_{8}$ cluster in the threedimensional (3D) isomeric form with co-adsorbed $\mathrm{O}_{2}$ and $\mathrm{CO}$ molecules. $(C) \mathrm{Au}_{8}$ on the magnesia surface $[\mathrm{MgO}(\mathrm{FC})]$ with three $\mathrm{CO}$ molecules adsorbed on the top facet of the cluster and an $\mathrm{O}_{2}$ molecule preadsorbed at the interface between the cluster and the magnesia surface. Isosurfaces of charge differences $(\delta \rho)$ are as follows: $(D) \mathrm{Au}_{8}$ cluster adsorbed on defect-free $\mathrm{MgO} ;(E) \mathrm{Au}_{8}$ cluster anchored to a surface $F$ centre of $\mathrm{MgO} ;(F)$ same as $(E)$ but with $\mathrm{O}_{2}$ and $\mathrm{CO}$ molecules adsorbed on the gold cluster. Pink isosurfaces represent $\delta \rho<0$ (depletion) and blue ones correspond to $\delta \rho>0$ (excess). Figure reproduced from reference [352]

\subsubsection{Reactions of Surface Landed Gold Nanoclusters}

Given Haruta's discovery that gold clusters can catalyse the oxidation of CO (Eq. (3)), it is not surprising that several studies have examined how surface landed gold nanoclusters react with mixtures of $\mathrm{CO}$ and $\mathrm{O}_{2}$ as well as other substrates. Table 11 highlighted key findings of these studies, while earlier work has been previously reviewed [348]. Here we briefly discuss two important studies that use a combination of experiments and theoretical calculations to shed light on how surface defects and impurities can influence reactivity. 
Yoon et al. have shown that F-centre surface defects in the $\mathrm{MgO}$ support play a key role in the enhanced catalytic activity of SL $\mathrm{Au}_{8}$ clusters towards the oxidation of $\mathrm{CO}$ [352]. Temperature-programmed desorption using mass spectrometry detection of $\mathrm{CO}_{2}$ showed a higher yield of $\mathrm{CO}_{2}$ at low temperature $(140 \mathrm{~K})$ for $\mathrm{Au}_{8}$ clusters supported on defect-rich $\mathrm{MgO}$ substrates compared to defect-poor surfaces. In situ IR spectroscopy of $\mathrm{CO}$ molecules bound to the $\mathrm{Au}_{8} \mathrm{NC}$ on the defect-rich $\mathrm{MgO}$ surface showed a redshift of the $\mathrm{CO}$ band, suggesting electron back-donation from the cluster to the $\mathrm{CO}$ antibonding orbitals. Figure 33 shows the results of detailed DFT calculations on the structures of the AuNCs and their reaction intermediates for $\mathrm{CO}$ oxidation. Figure $33 \mathrm{a}-\mathrm{c}$ shows the changes to the $\mathrm{Au}_{8} \mathrm{NC}$ upon co-adsorbed $\mathrm{O}_{2}$ and $\mathrm{CO}$ molecules. The change in electron density on the $\mathrm{Au}_{8}$ NC, shown in Fig. 33d-e, highlights that the surface defect plays a key role in transferring electron density to the cluster.

Lee et al. have explored how the catalytic activity and selectivity of $\mathrm{Au}_{6-10}$ clusters towards the epoxidation of propene is influenced by adding either hydrogen or water [357]. In the absence of these additives, propene is oxidised, but the selectivity is poor as the major product is acrolein (formed in a 2:1 ratio). This selectivity improves, with a ratio for formation of acrolein/propene oxide of up to 1:2 for $\mathrm{H}_{2}$ as an additive and 1:14 for water. DFT calculations were used to identify key reaction intermediates and reaction pathways. These calculations highlight that (1) the high catalyst activity arose from the formation of propene oxide metallacycles and (2) the key role of the $\mathrm{H}_{2}$ and $\mathrm{H}_{2} \mathrm{O}$ additives is to maintain a hydroxy-terminated alumina surface, which is critical to the enhanced selectivity.

\section{Conclusions}

Over the past 2 decades mass spectrometry-based methods have played important roles in the analysis of AuNCs and in defining the structures, properties and reactivities of AuNCs in the gas phase. An emerging role for mass spectrometry is its use in the synthesis of bulk materials. A common theme from fundamental gas-phase studies is that the spectroscopy, stability and reactivity of charged AuNCs often exhibit properties which depend on whether there are even or odd number metal atoms. The study of homogeneous and heterogeneous catalysts based on gold has highlighted the need for continued research to better define and understand the role of AuNCs. The mass spectrometric-based methods described in this chapter are likely to play an important role in developing that understanding.

Research on gold cluster ions continues unabated. Since this chapter was submitted several new studies have appeared that are relevant to the following sections:

Section 2: ESI-MS has been used to characterize histidine stabilized AuNCs [360] and the novel $\mathrm{Au}_{22}\left(\mathrm{~L}^{8}\right)_{6}$ nanocluster (where $\mathrm{L}^{8}=1,8$-bis-(diphenyl-phosphino) octane) [361]. Ligand exchange reactions of the $\mathrm{Au}_{25}(2-\mathrm{PET})_{18}$ nanocluster (where 2-PET=2phenylethylthiolate) have been examined using MALDI-TOF-MS [362]. The role of 
the ligand (1,3-bis(dicyclohexylphosphino)propane versus 1,3-bis(diphenylphosphino)propane) in the growth of AuNCs and their fragmentation reactions have been examined via ESI-MS and CID [363]. ESI-MS was used to assign the novel AuNCs $\mathrm{Au}_{10}\left(\mathrm{HSPh}-p \mathrm{NH}_{2}\right)_{10}$ (where $\mathrm{HSPh}-p \mathrm{NH}_{2}=4$-aminothiophenol) by the formation of charged adducts such as $\left[\mathrm{Au}_{10}\left(\mathrm{HSPh}-p \mathrm{NH}_{2}\right)_{10}+\mathrm{H}^{+}\right]^{+}$[364] and $\mathrm{Au}_{30}$ (tert-thiol) ${ }_{18}$ (tert-thiol=tert-butanethiol and 1-adamantanethiol) [365] which also used MALDI-MS. Laser ablation has been used to synthesize gold carbides [366] and gold arsenides [367]. MALDI of lysozyme-Au adducts produces the following bare gas phase $\mathrm{AuNC}$ cations: $\mathrm{Au}_{18}{ }^{+}, \mathrm{Au}_{25}{ }^{+}, \mathrm{Au}_{38}{ }^{+}$, and $\mathrm{Au}_{102}{ }^{+}$. Bare alloy clusters of the type $\mathrm{Au}_{24} \mathrm{Pd}^{+}$are formed for mixtures of gold and palladium lysozyme adducts [368].

Section 3: A recent photoelectron spectroscopy and theoretical study on $\mathrm{Au}_{n}{ }^{-}$ ( $n=36,37,38$ ) found that the most stable structures of $\mathrm{Au}_{36}{ }^{-}$to $\mathrm{Au}_{38}{ }^{-}$exhibit core-shell type structures all with a highly robust tetrahedral four-atom core. [369]

Section 4: Other gem aurated acetylides have been studied (cf. Scheme 5) [370]. $\mathrm{Au}_{2}{ }^{+}$has been shown to be a superior catalyst compared to $\mathrm{Pd}_{2}{ }^{+}$in the dehydrocoupling of methane (Scheme 8) [371].

Section 5: ESI-MS has been used to characterize $\mathrm{Ph}_{3} \mathrm{P}$ protected Au nanoclusters on a range of surfaces [372].

Acknowledgements We thank the ARC for generously funding our work on coinage metals.

\section{References}

1. Castleman AW, Jena P (2006) Clusters: a bridge between disciplines. Proc Natl Acad Sci 103(28):10552-10553. doi:10.1073/pnas.0601783103

2. Castleman AW, Jena P (2006) Clusters: a bridge across the disciplines of environment, materials science, and biology. Proc Natl Acad Sci 103(28):10554-10559. doi:10.1073/ pnas.0601780103

3. Jena P, Castleman AW (2006) Clusters: a bridge across the disciplines of physics and chemistry. Proc Natl Acad Sci 103(28):10560-10569. doi:10.1073/pnas.0601782103

4. Evans DG, Mingos DMP (1985) Molecular orbital analysis of the bonding in penta- and hepta-nuclear gold tertiary phosphine clusters. J Organomet Chem 295(3):389-400

5. Mingos DMP (1983) Polyhedral skeletal electron pair approach. A generalised principle for condensed polyhedra. J Chem Soc Chem Commun 12:706-708

6. Mingos DMP (1984) Polyhedral skeletal electron pair approach. Acc Chem Res 17(9): 311-319

7. Mingos DMP (1984) Gold cluster compounds - are they metals in miniature? Gold Bull 17(1):5-12

8. Mingos DMP (1996) Gold - a flexible friend in cluster chemistry. J Chem Soc Dalton Trans 5:561-566

9. Mingos DMP, Slee T, Zhenyang L (1990) Bonding models for ligated and bare clusters. Chem Rev 90(2):383-402

10. Mingos DMP (2014) Structural and bonding issues in clusters and nano-clusters. Struct Bond. doi:10.1007/430_2014_141 
11. Bond GC, Sermon PA, Webb G, Buchanan DA, Wells PB (1973) Hydrogenation over supported gold catalysts. J Chem Soc Chem Commun 13:444b-445b

12. Hutchings GJ (1985) Vapor phase hydrochlorination of acetylene: correlation of catalytic activity of supported metal chloride catalysts. J Catal 96(1):292-295

13. Haruta M, Yamada N, Kobayashi T, Iijima S (1989) Gold catalysts prepared by coprecipitation for low-temperature oxidation of hydrogen and of carbon monoxide. J Catal 115(2):301-309. doi:10.1016/0021-9517(89)90034-1

14. Haruta M (2005) Catalysis: gold rush. Nature 437(7062):1098-1099

15. Hutchings GJ (2005) Catalysis by gold. Catal Today 100(1-2):55-61

16. Bond GC, Louis CD, Thompson DTD (2006) Catalysis by gold. Catalytic science series: v. 6. Imperial College Press, London

17. Crabtree RH (2011) Resolving heterogeneity problems and impurity artifacts in operationally homogeneous transition metal catalysts. Chem Rev 112(3):1536-1554. doi:10.1021/ cr2002905

18. Oliver-Meseguer J, Cabrero-Antonino JR, Domínguez I, Leyva-Pérez A, Corma A (2012) Small gold clusters formed in solution give reaction turnover numbers of 107 at room temperature. Science 338(6113):1452-1455

19. Hashmi ASK (2012) Sub-nanosized gold catalysts. Science 338(6113):1434

20. Johnston RL (2002) Atomic and molecular clusters. Master's series in physics and astronomy. Taylor and Francis, London

21. Boyle R (1661) The sceptical chymist: or Chymico-physical doubts \& paradoxes, touching the spagyrist's principles commonly call'd hypostatical, as they are wont to be propos'd and defended by the generality of alchymists. Whereunto is praemis'd part of another discourse relating to the same subject. London, Printed by J. Cadwell for J. Crooke, 1661

22. Todd JFJ (1991) Recommendations for nomenclature and symbolism for mass spectroscopy (including an appendix of terms used in vacuum technology). Pure App Chem 63:1541. doi:10.1351/pac199163101541

23. Alonso JA (2005) Structure and properties of atomic nanoclusters. Imperial College Press, London

24. Murray KK, Boyd RK, Eberlin MN, Langley GJ, Li L, Naito Y (2013) Definitions of terms relating to mass spectrometry (IUPAC Recommendations 2013). Pure Appl Chem ASAP 85(7):1515-1609

25. Eleanor C (2012) Atom cluster. McGraw-Hill. Available via EBSCOhost. https://ezp.lib. unimelb.edu.au/login?url=https://search.ebscohost.com/login.aspx?direct $=$ true $\& \mathrm{db}=\mathrm{edsasc} \&$ $\mathrm{AN}=$ edsasc.059850\&scope $=$ site

26. Kreibig U, Vollmer M (1995) Optical properties of metal clusters. Springer series in materials science: 25. Springer, Berlin

27. Ott LS, Finke RG (2007) Transition-metal nanocluster stabilization for catalysis: a critical review of ranking methods and putative stabilizers. Coord Chem Rev 251(9-10):1075-1100

28. O'Hair RAJ, Khairallah GN (2004) Gas phase ion chemistry of transition metal clusters: production, reactivity, and catalysis. J Clust Sci 15(3):331-363

29. Böhme DK, Schwarz H (2005) Gas-phase catalysis by atomic and cluster metal ions: the ultimate single-site catalysts. Angew Chem Int Ed 44(16):2336-2354

30. Ervin KM (2001) Metal-ligand interactions: gas-phase transition metal cluster carbonyls. Int Rev Phys Chem 20(2):127-164

31. Armentrout PB (2001) Reactions and thermochemistry of small transition metal cluster ions. Ann Rev Phys Chem 52:423-461

32. Parent DC, Anderson SL (1992) Chemistry of metal and semimetal cluster ions. Chem Rev 92(7):1541-1565

33. Harkness KM, Cliffel DE, McLean JA (2010) Characterization of thiolate-protected gold nanoparticles by mass spectrometry. Analyst 135(5):868-874. doi:10.1039/b922291j

34. Bernhardt TM (2005) Gas-phase kinetics and catalytic reactions of small silver and gold clusters. Int J Mass Spectrom 243(1):1-29 
35. Spectrometry ASfM (1995) What is mass spectrometry? Am Soc Mass Spectrom. http:// www.asms.org

36. Henderson W, McIndoe JS (2005) Mass spectrometry of inorganic, coordination and organometallic compounds: tools - techniques - tips. Inorganic chemistry. Chichester, Wiley, Hoboken

37. McLuckey SA, Wells JM (2001) Mass analysis at the advent of the 21st century. Chem Rev 101(2):571-606

38. Farrar JM, Saunders WH (1988) Techniques for the study of ion-molecule reactions, vol 20. Wiley, New York, NY

39. Freiser BS (1996) Gas-phase metal ion chemistry. J Mass Spectrom 31(7):703-715

40. Asamoto B (ed) (1991) FT-ICR/MS: analytical applications of fourier transform ion cyclotron resonance mass spectrometry. vol Copyright (C) 2013 American Chemical Society (ACS). All Rights Reserved. VCH

41. Hammad LA, Gerdes G, Chen P (2005) Electrospray ionization tandem mass spectrometric determination of ligand binding energies in platinum(II) complexes. Organometallics 24(8): 1907-1913. doi:10.1021/om0491793

42. Schoen E, Zhang X, Zhou Z, Chisholm MH, Chen P (2004) Gas-phase and solution-phase polymerization of epoxides by $\mathrm{cr}($ salen) complexes: evidence for a dinuclear cationic mechanism. Inorg Chem 43(23):7278-7280. doi:10.1021/ic049120o

43. Damrauer R (2004) Organometallic chemistry in the flowing afterglow: a review. Organometallics 23(7):1462-1479. doi:10.1021/om030591c

44. O'Hair RAJ (2006) The 3D quadrupole ion trap mass spectrometer as a complete chemical laboratory for fundamental gas-phase studies of metal mediated chemistry. Chem Commun (Cambridge) 14:1469-1481. doi:10.1039/b516348j

45. De Haeck J, Veldeman N, Claes P, Janssens E, Andersson M, Lievens P (2011) Carbon monoxide adsorption on silver doped gold clusters. J Phys Chem A 115(11):2103-2109

46. Xie Y, Dong F, Bernstein ER (2011) Experimental and theory studies of the oxidation reaction of neutral gold carbonyl clusters in the gas phase. Catal Today 177(1):64-71

47. Knickelbein MB (1999) Reactions of transition metal clusters with small molecules. Ann Rev Phys Chem 50:79-155

48. Yin S, Bernstein ER (2012) Gas phase chemistry of neutral metal clusters: distribution, reactivity and catalysis. Int J Mass Spectrom 321-322:49-65

49. Colaianni L, Kung SC, Taggart D, De Giorgio V, Greaves J, Cioffil N, Penner RM (2009) Gold nanowires: deposition, characterization and application to the mass spectrometry detection of low-molecular weight analytes. In: Trani 2009. 3rd International workshop on advances in sensors and interfaces, IWASI, train, Italy, pp 20-24

50. McLean JA, Stumpo KA, Russel DH (2005) Size-selected (2-10 nm) gold nanoparticles for matrix assisted laser desorption ionization of peptides. J Am Chem Soc 127(15):5304-5305

51. Huang Y-F, Chang H-T (2007) Analysis of adenosine triphosphate and glutathione through gold nanoparticles assisted laser desorption/ionization mass spectrometry. Anal Chem 79 (13):4852-4859. doi:10.1021/ac070023x

52. Wu HP, Su CL, Chang HC, Tseng WL (2007) Sample-first preparation: a method for surfaceassisted laser desorption/ionization time-of-flight mass spectrometry analysis of cyclic oligosaccharides. Anal Chem 79(16):6215-6221

53. Su C-L, Tseng W-L (2007) Gold nanoparticles as assisted matrix for determining neutral small carbohydrates through laser desorption/ionization time-of-flight mass spectrometry. Anal Chem 79(4):1626-1633. doi:10.1021/ac061747w

54. Bruce MI, Liddell MJ (1987) Applications of fast-atom-bombardment mass spectrometry (FAB MS) to organometallic and coordination chemistry. Appl Organomet Chem 1(3): 191-226. doi:10.1002/aoc.590010302

55. Boyle PD, Johnson BJ, Alexander BD, Casalnuovo JA, Gannon PR, Johnson SM, Larka EA, Mueting AM, Pignolet LH (1987) Characterization of large cationic transition-metal-gold clusters by fast atom bombardment mass spectroscopy (FABMS). New rhenium-gold and 
platinum-gold clusters: $\left[\mathrm{Au}_{4} \mathrm{Re}(\mathrm{H})_{4}\left[\mathrm{P}(\mathrm{p}-\mathrm{tol})_{3}\right]_{2}\left(\mathrm{PPh}_{3}\right)_{4}\right]^{+},\left[\mathrm{Au}_{2} \mathrm{Re}_{2}(\mathrm{H})_{6}\left(\mathrm{PPh}_{3}\right)_{6}\right]^{+}$, and $\left[\mathrm{Au}_{6} \mathrm{Pt}\right.$ $\left.\left(\mathrm{PPh}_{3}\right)_{7}\right]^{2+}$. Inorg Chem 26(9):1346-1350. doi:10.1021/ic00256a002

56. Chisholm DM, Scott McIndoe J (2008) Charged ligands for catalyst immobilisation and analysis. Dalton Trans 30:3933-3945. doi:10.1039/B800371H

57. Van der Velden JWA, Bour JJ, Vollenbroek FA, Beurskens PT, Smits JMM (1979) Synthesis of a new pentanuclear gold cluster by metal evaporation. Preparation and X-ray structure determination of [tris $\{$ bis(diphenylphosphino)methane $\}]$ [bis(diphenylphosphino)methanido] pentagold dinitrate. J Chem Soc Chem Commun 24:1162-1163. doi:10.1039/c39790001162

58. Shichibu Y, Konishi K (2010) HCL-induced nuclearity convergence in diphosphineprotected ultrasmall gold clusters: a novel synthetic route to "Magic-Number" $\mathrm{Au}_{13}$ clusters. Small 6(11):1216-1220

59. Shichibu Y, Kamei Y, Konishi K (2012) Unique [core+two] structure and optical property of a dodeca-ligated undecagold cluster: critical contribution of the exo gold atoms to the electronic structure. Chem Commun 48(61):7559-7561

60. Heaven MW, Dass A, White PS, Holt KM, Murray RW (2008) Crystal structure of the gold nanoparticle $\left[\mathrm{N}\left(\mathrm{C}_{8} \mathrm{H}_{17}\right)_{4}\right]\left[\mathrm{Au}_{25}\left(\mathrm{SCH}_{2} \mathrm{CH}_{2} \mathrm{Ph}\right)_{18}\right]$. J Am Chem Soc 130(12):3754-3755. doi:10.1021/ja800561b

61. Zeng C, Qian H, Li T, Li G, Rosi NL, Yoon B, Barnett RN, Whetten RL, Landman U, Jin R (2012) Total structure and electronic properties of the gold nanocrystal $\mathrm{Au}_{36}(\mathrm{SR})_{24}$. Angew Chem Int Ed 51(52):13114-13118. doi:10.1002/anie.201207098

62. Liu J, Lee T, Janes DB, Walsh BL, Melloch MR, Woodall JM, Reifenberger R, Andres RP (2000) Guided self-assembly of Au nanocluster arrays electronically coupled to semiconductor device layers. Appl Phys Lett 77(3):373-375

63. Kadossov E, Cabrini S, Burghaus U (2010) Adsorption kinetics and dynamics of CO on silica supported Au nanoclusters - utilizing physical vapor deposition and electron beam lithography. J Mol Catal A Chem 321(1-2):101-109. doi:10.1016/j.molcata.2010.02.009

64. Ishida T, Kinoshita N, Okatsu H, Akita T, Takei T, Haruta M (2008) Influence of the support and the size of gold clusters on catalytic activity for glucose oxidation. Angew Chem Int Ed 47(48):9265-9268

65. Gibson JK (1998) Laser ablation and gas-phase reactions of small gold cluster ions, $\mathrm{Au}^{+} \mathrm{n}$ $(1 \leq \mathrm{n} \leq 7)$. J Vac Sci Technol A Vac Surfaces Films 16(2):653-659

66. Hu CW, Kasuya A, Wawro A, Horiguchi N, Czajka R, Nishina Y, Saito Y, Fujita H (1996) Gold clusters deposited on highly oriented pyrolytic graphite by pulse laser ablation and liquid metal ion source. Mater Sci Eng A 217-218:103-107

67. Sugawara KI, Sobott F, Vakhtin AB (2003) Reactions of gold cluster cations $\mathrm{Au}_{\mathrm{n}}{ }^{+}(\mathrm{n}=1-12)$ with $\mathrm{H}_{2} \mathrm{~S}$ and $\mathrm{H}_{2}$. J Chem Phys 118(17):7808-7816

68. Guo W, Yuan J, Wang E (2012) Organic-soluble fluorescent $\mathrm{Au}_{8}$ clusters generated from heterophase ligand-exchange induced etching of gold nanoparticles and their electrochemiluminescence. Chem Commun 48(25):3076-3078

69. Zhou R, Shi M, Chen X, Wang M, Chen H (2009) Atomically monodispersed and fluorescent sub-nanometer gold clusters created by biomolecule-assisted etching of nanometer-sized gold particles and rods. Chem Eur J 15(19):4944-4951. doi:10.1002/chem.200802743

70. Duan H, Nie S (2007) Etching colloidal gold nanocrystals with hyperbranched and multivalent polymers: a new route to fluorescent and water-soluble atomic clusters. J Am Chem Soc 129(9):2412-2413. doi:10.1021/ja067727t

71. De Heer WA (1993) The physics of simple metal clusters: experimental aspects and simple models. Rev Mod Phys 65(3):611-676

72. Duncan MA (2012) Invited Review Article: Laser vaporization cluster sources. Rev Sci Instrum 83(4):041101

73. Turkevich J, Stevenson PC, Hillier J (1951) A study of the nucleation and growth processes in the synthesis of colloidal gold. Discuss Faraday Soc 11:55-75

74. Rao CNR, Kulkarni GU, Thomas PJ, Edwards PP (2000) Metal nanoparticles and their assemblies. Chem Soc Rev 29(1):27-35 
75. Wilcoxon JP, Abrams BL (2006) Synthesis, structure and properties of metal nanoclusters. Chem Soc Rev 35(11):1162-1194. doi:10.1039/B517312B

76. Guo S, Wang E (2011) Noble metal nanomaterials: controllable synthesis and application in fuel cells and analytical sensors. Nano Today 6(3):240-264

77. Lu Y, Chen W (2012) Sub-nanometre sized metal clusters: from synthetic challenges to the unique property discoveries. Chem Soc Rev 41(9):3594-3623. doi:10.1039/C2CS15325D

78. Ayela C, Lalo H, Kuhn A (2013) Introducing a well-ordered volume porosity in 3-dimensional gold microcantilevers. Appl Phys Lett 102(5)

79. Daniel M-C, Astruc D (2003) Gold nanoparticles: assembly, supramolecular chemistry, quantum-size-related properties, and applications toward biology, catalysis, and nanotechnology. Chem Rev 104(1):293-346. doi:10.1021/cr030698+

80. Zhao P, Li N, Astruc D (2013) State of the art in gold nanoparticle synthesis. Coord Chem Rev 257(3-4):638-665. doi:10.1016/j.ccr.2012.09.002

81. Pei Y, Zeng XC (2012) Investigating the structural evolution of thiolate protected gold clusters from first-principles. Nanoscale 4(14):4054-4072. doi:10.1039/c2nr30685a

82. Jiang D-E (2010) Understanding and predicting thiolated gold nanoclusters from first principles. Wuli Huaxue Xuebao 26(4):999-1016

83. Jin R (2010) Quantum sized, thiolate-protected gold nanoclusters. Nanoscale 2(3):343-362. doi:10.1039/b9nr00160c

84. Brust M, Walker M, Bethell D, Schiffrin DJ, Whyman R (1994) Synthesis of thiol-derivatised gold nanoparticles in a two-phase Liquid-Liquid system. J Chem Soc Chem Commun 7: 801-802. doi:10.1039/C39940000801

85. Briñas RP, Hu M, Qian L, Lymar ES, Hainfeld JF (2008) Gold nanoparticle size controlled by polymeric $\mathrm{Au}(\mathrm{I})$ thiolate precursor size. J Am Chem Soc 130(3):975-982

86. Simpson CA, Farrow CL, Tian P, Billinge SJL, Huffman BJ, Harkness KM, Cliffel DE (2010) Tiopronin gold nanoparticle precursor forms aurophilic ring tetramer. Inorg Chem 49 (23):10858-10866. doi:10.1021/ic101146e

87. Dharmaratne AC, Krick T, Dass A (2009) Nanocluster size evolution studied by mass spectrometry in room temperature $\mathrm{Au}_{25}(\mathrm{SR})_{18}$ synthesis. J Am Chem Soc 131(38): 13604-13605. doi:10.1021/ja906087a

88. Gaur S, Miller JT, Stellwagen D, Sanampudi A, Kumar CSSR, Spivey JJ (2012) Synthesis, characterization, and testing of supported $\mathrm{Au}$ catalysts prepared from atomically-tailored $\mathrm{Au}_{38}\left(\mathrm{SC}_{12} \mathrm{H}_{25}\right)_{24}$ clusters. Phys Chem Chem Phys 14(5):1627-1634. doi:10.1039/ C1CP22438G

89. Tlahuice-Flores A, Black DM, Bach SBH, Jose-Yacaman M, Whetten RL (2013) Structure \& bonding of the gold-subhalide cluster $\mathrm{I}_{-} \mathrm{Au}_{144} \mathrm{C}_{160}[\mathrm{z}]$. Phys Chem Chem Phys 15(44): 19191-19195. doi:10.1039/c3cp53902d

90. Nimmala PR, Yoon B, Whetten RL, Landman U, Dass A (2013) $\mathrm{Au}_{67}(\mathrm{SR})_{35}$ nanomolecules: characteristic size-specific optical, electrochemical, structural properties and first-principles theoretical analysis. J Phys Chem A 117(2):504-517. doi:10.1021/jp311491v

91. Negishi Y, Chaki NK, Shichibu Y, Whetten RL, Tsukuda T (2007) Origin of magic stability of thiolated gold clusters: a case study on $\mathrm{Au}_{25}\left(\mathrm{SC}_{6} \mathrm{H}_{13}\right)_{18}$. J Am Chem Soc 129(37): 11322-11323. doi:10.1021/ja073580+

92. Zeng C, Liu C, Pei Y, Jin R (2013) Thiol ligand-induced transformation of Au38(SC2H4Ph) 24 to Au36(SPh-t-Bu)24. ACS Nano 7(7):6138-6145. doi:10.1021/nn401971g

93. Malatesta L, Naldini L, Simonetta G, Cariati F (1966) Triphenylphosphine-gold(0)/gold(I) compounds. Coord Chem Rev 1(1-2):255-262. doi:10.1016/S0010-8545(00)80179-4

94. Naldini L, Cariati F, Simonetta G, Malatesta L (1966) Gold-tertiary phosphine derivatives with intermetallic bonds. Chem Commun 18:647-648. doi:10.1039/c19660000647

95. Cariati F, Naldini L, Simonetta G, Malatesta L (1967) Ethyldiphenylphosphine-gold derivatives with intermetallic bonds. Inorg Chim Acta 1(1):24-26. doi:10.1016/S0020-1693(00) 93133-5 
96. Cariati F, Naldini L, Simonetta G, Malatesta L (1967) Clusters of gold compounds with 1,2-bis(diphenylphosphino)ethane. Inorg Chim Acta 1(2):315-318. doi:10.1016/S0020-1693 (00)93194-3

97. McPartlin M, Malatesta L, Mason R (1969) Cluster complexes of gold(0)-gold(I). J Chem Soc D 7:334. doi:10.1039/c29690000334

98. Abu-Salah OM, Al-Ohaly ARA, Knobler CB (1985) Preparation, identification, and X-ray structure of a novel pentanuclear gold-copper cluster complex. J Chem Soc Chem Commun (21):1502-1503. doi:10.1039/c39850001502

99. Briant CE, Hall KP, Mingos DMP (1982) Unusual degradation reaction of icosahedral cluster compounds of gold with chelating diphosphanes and the $\mathrm{X}$-ray structure of di[bis(diphenylphosphino)methanido]digold(I), $\left[\mathrm{Au}\left(\mathrm{Ph}_{2} \mathrm{P}\right)_{2} \mathrm{CH}\right]_{2}$. J Organomet Chem 229(1):C5-C8. doi:10.1016/S0022-328X(00)89123-8

100. Briant CE, Theobald BRC, White JW, Bell LK, Mingos DMP, Welch AJ (1981) Synthesis and $\mathrm{x}$-ray structural characterization of the centered icosahedral gold cluster compound $\left[\mathrm{Au}_{13}\left(\mathrm{PMe}_{2} \mathrm{Ph}\right)_{10} \mathrm{Cl}_{2}\right]\left(\mathrm{PF}_{6}\right)_{3}$; the realization of a theoretical prediction. J Chem Soc Chem Commun 5:201-202. doi:10.1039/c39810000201

101. van der Velden JWA, Bour JJ, Bosman WP, Noordik JH (1983) Reactions of cationic gold clusters with Lewis bases. Preparation and X-ray structure investigation of $\left[\mathrm{Au}_{8}\left(\mathrm{PPh}_{3}\right)_{7}\right]$ $\left(\mathrm{NO}_{3}\right) 2.2 \mathrm{CH}_{2} \mathrm{Cl}_{2}$ and $\mathrm{Au}_{6}\left(\mathrm{PPh}_{3}\right)_{4}\left[\mathrm{Co}(\mathrm{CO})_{4}\right]_{2}$. Inorg Chem 22(13):1913-1918. doi:10.1021/ ic $00155 \mathrm{a} 018$

102. van der Velden JWA, Bour JJ, Steggerda JJ, Beurskens PT, Roseboom M, Noordik JH (1982) Gold clusters. Tetrakis[1,3-bis(diphenylphosphino)propane]hexagold dinitrate: preparation, X-ray analysis, and gold-197 Moessbauer and phosphorus-31\{proton\} NMR spectra. Inorg Chem 21(12):4321-4324. doi:10.1021/ic00142a041

103. van der Velden JWA, Vollenbroek FA, Bour JJ, Beurskens PT, Smits JMM, Bosman WP (1981) Gold clusters containing bidentate phosphine ligands. Preparation and X-ray structure investigation of $\left[\mathrm{Au}_{5}(\mathrm{dppmH})_{3}(\mathrm{dppm})\right]\left(\mathrm{NO}_{3}\right)_{2}$ and $\left[\mathrm{Au}_{13}(\mathrm{dppmH})_{6}\right]\left(\mathrm{NO}_{3}\right)_{\mathrm{n}}$. Recl Trav Chim Pays Bas 100(4):148-152

104. Demartin F, Manassero M, Naldini L, Ruggeri R, Sansoni M (1981) Synthesis and X-ray characterization of an iodine-bridged tetranuclear gold cluster, di- $\mu$-iodo-tetrakis(triphenylphosphine)-tetrahedro-tetragold. J Chem Soc Chem Commun 5:222-223. doi:10.1039/ c39810000222

105. Cooper MK, Dennis GR, Henrick K, McPartlin M (1980) A new type of gold cluster compound. The syntheses and $\mathrm{x}$-ray structure analysis of pentakis(tricyclohexylphosphine) tris(thiocyanato)enneagold, $\left[\mathrm{Au}_{9}\left\{\mathrm{P}\left(\mathrm{C}_{6} \mathrm{H}_{11}\right)_{3}\right\}_{5}(\mathrm{SCN})_{3}\right]$, and bis $\{$ tri(cyclohexyl)phosphineto $\}$ gold(I) hexafluorophosphate, $\left[\mathrm{Au}\left\{\mathrm{P}\left(\mathrm{C}_{6} \mathrm{H}_{11}\right)_{3}\right\}_{2}\right]\left[\mathrm{PF}_{6}\right]$. Inorg Chim Acta 45(4):L151-L152. doi:10.1016/S0020-1693(00)80129-2

106. Vollenbroek FA, Bosman WP, Bour JJ, Noordik JH, Beurskens PT (1979) Reactions of goldphosphine cluster compounds. Preparation and X-ray structure determination of octakis (triphenylphosphine)octagold bis(hexafluorophosphate). J Chem Soc Chem Commun 9: 387-388. doi:10.1039/c39790000387

107. Manassero M, Naldini L, Sansoni M (1979) A new class of gold cluster compounds. Synthesis and $\mathrm{X}$-ray structure of the octakis(triphenylphosphinegold) dializarinsulfonate, $\left[\mathrm{Au}_{8}\left(\mathrm{PPh}_{3}\right)_{8}\right](\mathrm{aliz})_{2}$. J Chem Soc Chem Commun 9:385-386. doi:10.1039/c39790000385

108. Bellon PL, Cariati F, Manassero M, Naldini L, Sansoni M (1971) Novel gold clusters. Preparation, properties, and X-ray structure determination of salts of octakis

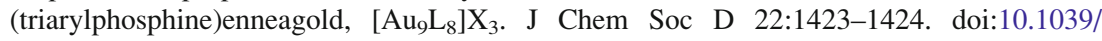
c29710001423

109. Feld H, Leute A, Rading D, Benninghoven A, Schmid G (1990) Formation of very large gold superclusters (clusters of clusters) as secondary ions up to $\left(\mathrm{Au}_{13}\right)_{55}$ by SIMS. J Am Chem Soc 112(22):8166-8167. doi:10.1021/ja00178a051 
110. Van SMPJ, Brom HB, De JLJ, Schmid G (1986) Physical properties of metal cluster compounds II: d.c.-conductivity of the high-nuclearity gold cluster compound $\mathrm{Au}_{55}\left(\mathrm{PPh}_{3}\right)_{12} \mathrm{C}_{16}$. Solid State Commun 60(4):319-322. doi:10.1016/0038-1098(86)90741-6

111. Schmid G (1982) Complex transition metal compounds. EP66287A2

112. Schmid G, Pfeil R, Boese R, Brandermann F, Meyer S, Calis GHM, Van der Velden JWA (1981) $\mathrm{Au}_{55}\left[\mathrm{P}\left(\mathrm{C}_{6} \mathrm{H}_{5}\right)_{3}\right]_{12} \mathrm{Cl}_{6}$ - a gold cluster of unusual size. Chem Ber 114(11):3634-3642

113. Zavras A, Khairallah GN, O'Hair RAJ (2013) Bis(diphenylphosphino)methane ligated gold cluster cations: synthesis and gas-phase unimolecular reactivity. Int J Mass Spectrom 354-355:242-248. doi:10.1016/j.ijms.2013.05.034

114. Robinson PSD, Nguyen TL, Lioe H, O'Hair RAJ, Khairallah GN (2012) Synthesis and gas-phase uni- and bi-molecular reactivity of bisphosphine ligated gold clusters, $\left[\mathrm{Au}_{\mathrm{x}} \mathrm{Ly}\right]_{\mathrm{n}}{ }^{+}$. Int J Mass Spectrom 330-332:109-117

115. Pettibone JM, Hudgens JW (2011) Gold cluster formation with phosphine ligands: etching as a size-selective synthetic pathway for small clusters? ACS Nano 5(4):2989-3002

116. Bergeron DE, Coskuner O, Hudgens JW, Gonzalez CA (2008) Ligand exchange reactions in the formation of diphosphine-protected gold clusters. J Phys Chem C 112(33):12808-12814

117. Hudgens JW, Pettibone JM, Senftle TP, Bratton RN (2011) Reaction mechanism governing formation of 1,3-bis(diphenylphosphino)propane-protected gold nanoclusters. Inorg Chem 50(20):10178-10189. doi:10.1021/ic2018506

118. Evans DG, Mingos DMP (1982) Molecular orbital analysis of the bonding in low nuclearity gold and platinum tertiary phosphine complexes and the development of isolobal analogies for the M(PR3) fragment. J Organomet Chem 232(2):171-191. doi:10.1016/S0022-328X(00) 87645-7

119. Hoffmann R (1982) Building bridges between inorganic and organic chemistry (nobel lecture). Angew Chem Int Ed Engl 21(10):711-724. doi:10.1002/anie.198207113

120. Pan QJ, Zhou X, Guo YR, Fu HG, Zhang HX (2009) Inorg Chem 48:2844-2854

121. King RB (1986) Inorg Chim Acta 116:109-117

122. Schwerdtfeger P, Hermann HL, Schmidbaur H (2003) Inorg Chem 42:1334-1342

123. Mingos DMP (1982) Philos Trans R Soc A 308:75-83

124. Lo CTF, Karan K, Davis BR (2007) Ind Eng Chem Res 46:5478-5484

125. Brown HC, Mead EJ, Shoaf CJ (1956) J Am Chem Soc 78:3616-3620

126. Majimel J, Bacinello D, Durand E, Vallee F, Treguer-Delapierre M (2008) Langmuir 24: 4289-4294

127. Elian M, Chen MML, Mingos DMP, Hoffmann R (1976) Inorg Chem 15:1148-1155

128. Mingos DMP, Slee T, Lin ZY (1990) Chem Rev 90:383-402

129. Mingos DMP (1976) J Chem Soc Dalton Trans 1163-1169

130. Mingos DMP (1984) Polyhedron 3:1289-1297

131. Mingos DMP (1996) J Chem Soc Dalton Trans 561-566

132. Pyykkö P (2004) Angew Chem Int Ed 43:4412-4456

133. Shafai G, Hong S, Bertino MF, Rahman TS (2009) J Phys Chem C 113:12072-12078

134. Vollenbroek FA, Bour JJ, Vandervelden JWA (1980) Recl Trav Chim Pays Bas 99:137-141

135. Van Der Linden JGM, Paulissen MLH, Schmitz JEJ (1983) J Am Chem Soc 105:1903-1907

136. Cheetham GMT, Harding MM, Haggitt JL, Mingos DMP, Powell HR (1993) J. Chem Soc D Chem Commun 1000-1001

137. Laguna A, Laguna M, Gimeno MC, Jones PG (1992) Organometallics 11:2759-2760

138. Wang BS, Hou H, Yoder LM, Muckerman JT, Fockenberg C (2003) J Phys Chem A 107: $11414-11426$

139. Hong S, Shafai G, Bertino M, Rahman TS (2011) J Phys Chem C 115:14478-14487

140. Bergeron DE, Hudgens JW (2007) Ligand dissociation and core fission from diphosphineprotected gold clusters. J Phys Chem C 111(23):8195-8201

141. Pettibone JM, Hudgens JW (2012) Reaction network governing diphosphine-protected gold nanocluster formation from nascent cationic platforms. Phys Chem Chem Phys 14 (12):4142-4154 
142. Pettibone JM, Hudgens JW (2010) Synthetic approach for tunable, size-selective formation of monodisperse, diphosphine-protected gold nanoclusters. J Phys Chem Lett 1(17):2536-2540

143. Colton R, Harrison KL, Mah YA, Traeger JC (1995) Cationic phosphine complexes of gold (I): an electrospray mass spectrometric study. Inorg Chim Acta 231(1-2):65-71

144. Muetterties EL, Alegranti CW (1970) Solution structure of coinage metal-phosphine complexes. J Am Chem Soc 92(13):4114-4115. doi:10.1021/ja00716a052

145. Mays MJ, Vergnano PA (1979) Structure and bonding in gold(I) compounds. Part 4. A phosphorus-31 nuclear magnetic study of the structure of some gold(I) phosphine complexes in solution. J Chem Soc Dalton Trans 6:1112-1115. doi:10.1039/DT9790001112

146. Pettibone JM, Hudgens JW (2012) Predictive gold nanocluster formation controlled by metal-ligand complexes. Small 8(5):715-725

147. Pyykkö P (1997) Strong closed-shell interactions in inorganic chemistry. Chem Rev 97(3): 597-636. doi:10.1021/cr940396v

148. Pyykkö P, Mendizabal F (1998) Theory of d 10 - d 10 closed-shell attraction. III. Rings. Inorg Chem 37(12):3018-3025

149. Bertino MF, Sun ZM, Zhang R, Wang LS (2006) Facile syntheses of monodisperse ultrasmall Au clusters. J Phys Chem B 110(43):21416-21418

150. Golightly JS, Gao L, Castleman AW Jr, Bergeron DE, Hudgens JW, Magyar RJ, Gonzalez CA (2007) Impact of swapping ethyl for phenyl groups on diphosphine-protected undecagold. J Phys Chem C 111(40):14625-14627

151. Yanagimoto Y, Negishi Y, Fujihara H, Tsukuda T (2006) Chiroptical activity of BINAPstabilized undecagold clusters. J Phys Chem B 110(24):11611-11614

152. Brown LO, Hutchison JE (1999) Controlled growth of gold nanoparticles during ligand exchange [14]. J Am Chem Soc 121(4):882-883

153. Schaaff TG, Whetten RL (1999) Controlled etching of Au:SR cluster compounds. J Phys Chem B 103(44):9394-9396

154. Maye MM, Zheng W, Leibowitz FL, Ly NK, Zhong CJ (2000) Heating-induced evolution of thiolate-encapsulated gold nanoparticles: a strategy for size and shape manipulations. Langmuir 16(2):490-497

155. Shichibu Y, Negishi Y, Tsunoyama H, Kanehara M, Teranishi T, Tsukuda T (2007) Extremely high stability of glutathionate-protected $\mathrm{Au}_{25}$ clusters against core etching. Small 3(5):835-839

156. Toikkanen O, Ruiz V, Rönnholm G, Kalkkinen N, Liljeroth P, Quinn BM (2008) Synthesis and stability of monolayer-protected $\mathrm{Au}_{38}$ clusters. J Am Chem Soc 130(33):11049-11055

157. Kanehara M, Sakurai JI, Sugimura H, Teranishi T (2009) Room-temperature size evolution of thiol-protected gold nanoparticles assisted by proton acids and halogen anions. J Am Chem Soc 131(5):1630-1631

158. Davis RE, Gottbrath JA (1962) Boron hydrides. V. Methanolysis of sodium borohydride. J Am Chem Soc 84(6):895-898

159. Kamei Y, Shichibu Y, Konishi K (2011) Generation of small gold clusters with unique geometries through cluster-to-cluster transformations: octanuclear clusters with edge-sharing gold tetrahedron motifs. Angew Chem Int Ed 50(32):7442-7445

160. Wen F, Englert U, Gutrath B, Simon U (2008) Crystal structure, electrochemical and optical properties of $\left[\mathrm{Au}_{9}\left(\mathrm{PPh}_{3}\right)_{8}\right]\left(\mathrm{NO}_{3}\right)_{3}$. Eur J Inorg Chem 1:106-111

161. Ticknor BW, Bandyopadhyay B, Duncan MA (2008) Photodissociation of noble metal-doped carbon clusters. J Phys Chem A 112(48):12355-12366

162. Cohen Y, Bernshtein V, Armon E, Bekkerman A, Kolodney E (2011) Formation and emission of gold and silver carbide cluster ions in a single $\mathrm{C}_{60}$-surface impact at $\mathrm{keV}$ energies: Experiment and calculations. J Chem Phys 134(12):124701

163. Pyykko P, Patzschke M, Suurpere J (2003) Calculated structures of $[\mathrm{Au}=\mathrm{C}=\mathrm{Au}]^{2+}$ and related systems. Chem Phys Lett 381(1,2):45-52. doi:10.1016/j.cplett.2003.09.045 
164. Li D-Z, Li S-D (2011) A density functional investigation on $\mathrm{C}_{2} \mathrm{Au}_{\mathrm{n}}{ }^{+}(\mathrm{n}=1,3,5)$ and $\mathrm{C}_{2} \mathrm{Aun}$ ( $\mathrm{n}=2$, 4, 6): from gold terminals, gold bridges, to gold triangles. J Cluster Sci 22(3): 331-341. doi:10.1007/s10876-011-0383-5

165. Bolbach G, Main DE, Standing KG, Westmore JB (1995) Structures of gas phase oligomeric gold-oxygen-hydrogen negative ions formed by cesium ion bombardment of vapordeposited gold surfaces. Inorg Chem 34(1):247-253. doi:10.1021/ic00105a040

166. Panyala NR, Pena-Mendez EM, Havel J (2012) Laser ablation synthesis of new gold phosphides using red phosphorus and nanogold as precursors. Laser desorption ionisation time-of-flight mass spectrometry. Rapid Commun Mass Spectrom 26(9):1100-1108. doi:10. 1002/rcm.6207

167. Svihlova K, Prokes L, Skacelova D, Pena-Mendez EM, Havel J (2013) Laser ablation synthesis of new gold tellurides using tellurium and nanogold as precursors. Laser desorption ionisation time-of-flight mass spectrometry. Rapid Commun Mass Spectrom 27(14): 1600-1606. doi:10.1002/rcm.6613

168. Maity P, Tsunoyama H, Yamauchi M, Xie S, Tsukuda T (2011) Organogold clusters protected by phenylacetylene. J Am Chem Soc 133(50):20123-20125

169. Schooss D, Weis P, Hampe O, Kappes MM (2010) Determining the size-dependent structure of ligand-free gold-cluster ions. Philos Trans Royal Soc A Math Phys Eng Sci 368(1915): 1211-1243

170. Becker S, Dietrich G, Hasse HU, Klisch N, Kluge HJ, Kreisle D, Krückeberg S, Lindinger M, Lützenkirchen K, Schweikhard L, Weidele H, Ziegler J (1994) Fragmentation pattern of gold clusters collided with xenon atoms. Comput Mater Sci 2(3-4):633-637. doi:10.1016/09270256(94)90099-X

171. Becker S, Dietrich G, Hasse HU, Klisch N, Kluge HJ, Kreisle D, Krueckeberg S, Lindinger M, Luetzenkirchen K et al (1994) Fragmentation of gold clusters stored in a Penning trap. Rapid Commun Mass Spectrom 8(5):401-402. doi:10.1002/rcm.1290080512

172. Schweikhard L, Beiersdorfer P, Bell W, Dietrich G, Krueckeberg S, Luetzenkirchen K, Obst B, Ziegler J (1996) Production and investigation of multiply charged metal clusters in a Penning trap. Hyperfine Interact 99(1-3):97-104. doi:10.1007/BF02274913

173. Schweikhard L, Dietrich G, Kruckeberg S, Lutzenkirchen K, Walther C, Ziegler J (1997) Collision induced dissociation of doubly charged stored metal cluster ions. Rapid Commun Mass Spectrom 11(14):1592-1595. doi:10.1002/(SICI)1097-0231(199709)11:14<1592:: AID-RCM996>3.0.CO;2-1

174. Ziegler J, Dietrich G, Kruckeberg S, Lutzenkirchen K, Schweikhard L, Walther C (1998) Dissociation pathways of doubly and triply charged gold clusters. Hyperfine Interact 115 (1-4):171-179. doi:10.1023/A:1012661008519

175. Weidele H, Vogel M, Herlert A, Kruckeberg S, Lievens P, Silverans RE, Walther C, Schweikhard L (1999) Decay pathways of stored metal-cluster anions after collisional activation. Eur Phys J D 9(1-4):173-177. doi:10.1007/s100530050421

176. Spasov VA, Shi Y, Ervin KM (2000) Time-resolved photodissociation and threshold collision-induced dissociation of anionic gold clusters. Chem Phys 262(1):75-91. doi:10. 1016/S0301-0104(00)00165-8

177. Ziegler J, Dietrich G, Kruckeberg S, Lutzenkirchen K, Schweikhard L, Walther C (2000) Multicollision-induced dissociation of multiply charged gold clusters, $\mathrm{Au}_{\mathrm{n}}{ }^{2+}, \mathrm{n}=7-35$, and $\mathrm{Au}_{\mathrm{n}}{ }^{3+}, \mathrm{n}=19-35$. Int J Mass Spectrom 202(1-3):47-54

178. Herlert A, Schweikhard L (2012) Electron binding energies from collisional activation of metal-cluster dianions. Appl Phys B Lasers Opt 107(4):1131-1143. doi:10.1007/s00340-0114792-9

179. Walther C, Becker S, Dietrich G, Kluge HJ, Lindlinger M, Luetzenkirchen K, Schweikhard L, Ziegler J (1996) Photofragmentation of metal clusters stored in a penning trap. Z Phys D At Mol Clusters 38(1):51-58. doi:10.1007/s004600050063

180. Lindinger M, Dasgupta K, Dietrich G, Kruckeberg S, Kuznetsov S, Lutzenkirchen K, Schweikhard L, Walther C, Ziegler J (1997) Time resolved photofragmentation of $\mathrm{Au}_{\mathrm{n}}{ }^{+}$ 
and $\mathrm{Ag}_{\mathrm{n}}{ }^{+}$clusters $(\mathrm{n}=9,21)$. Z Phys D At Mol Clusters 40(1-4):347-350. doi:10.1007/ s004600050225

181. Vogel M, Hansen K, Herlert A, Schweikhard L (2001) Energy dependence of the decay pathways of optically excited small gold clusters. Appl Phys B Lasers Opt 73(4):411-416. doi: $10.1007 / \mathrm{s} 003400100719$

182. Vogel M, Hansen K, Herlert A, Schweikhard L (2001) Decay pathways of small gold clusters. The competition between monomer and dimer evaporation. Eur Phys J D 16(1-3):73-76. doi:10.1007/s100530170063

183. Vogel M, Hansen K, Herlert A, Schweikhard L (2001) Determination of dissociation energies by use of energy-dependent decay pathway branching ratios. Chem Phys Lett 346(1,2): 117-122. doi:10.1016/S0009-2614(01)00935-6

184. Vogel M, Hansen K, Herlert A, Schweikhard L (2001) Model-free determination of dissociation energies of polyatomic systems. Phys Rev Lett 87(1):013401/013401-013401/013404. doi:10.1103/PhysRevLett.87.013401

185. Herlert A, Schweikhard L, Vogel M (2002) Photoinduced dissociation of anionic and electron detachment of dianionic gold clusters by use of a laser pointer. Int J Mass Spectrom 213(2/3): 157-161. doi:10.1016/S1387-3806(01)00529-2

186. Vogel M, Hansen K, Herlert A, Schweikhard L (2002) Dimer dissociation energies of small odd-size clusters $\mathrm{Au}_{\mathrm{n}}{ }^{+}$. Eur Phys J D 21(2):163-166. doi:10.1140/epjd/e2002-00190-3

187. Vogel M, Hansen K, Herlert A, Schweikhard L (2002) Multisequential photofragmentation of size-selected gold cluster ions. Phys Rev A At Mol Opt Phys 66(3):033201/033201-033201/ 033209. doi:10.1103/PhysRevA.66.033201

188. Herlert A, Schweikhard L (2003) Production of dianionic and trianionic noble metal clusters in a Penning trap. Int J Mass Spectrom 229(1-2):19-25. doi:10.1016/S1387-3806(03)00251-3

189. Vogel M, Herlert A, Schweikhard L (2003) Photodissociation of small group-11 metal cluster ions: fragmentation pathways and photoabsorption cross sections. J Am Soc Mass Spectrom 14(6):614-621. doi:10.1016/S1044-0305(03)00203-4

190. Vogel M, Hansen K, Schweikhard L (2004) Signature of cluster isomers in time-resolved photodissociation experiments. Int J Mass Spectrom 233(1-3):117-123. doi:10.1016/j.ijms. 2003.12.027

191. Schweikhard L, Hansen K, Herlert A, Herraiz LMD, Vogel M (2005) Photodissociation of stored metal clusters. Eur Phys J D 36(2):179-185. doi:10.1140/epjd/e2005-00264-8

192. Hansen K, Herlert A, Schweikhard L, Vogel M (2006) Dissociation energies of gold clusters $\mathrm{AuN}^{+}, \mathrm{N}=7-7$. Phys Rev A At Mol Opt Phys 73(6):063202/063201-063202/063214. doi:10. 1103/PhysRevA.73.063202

193. Herlert A, Schweikhard L (2006) First observation of delayed electron emission from dianionic metal clusters. Int J Mass Spectrom 252(2):151-156. doi:10.1016/j.ijms.2006.01. 051

194. Herlert A, Schweikhard L (2006) Delayed neutral-atom evaporation of photoexcited anionic gold clusters. Int J Mass Spectrom 249(250):215-221. doi:10.1016/j.ijms.2005.12.027

195. Herlert A, Schweikhard L (2012) Two-electron emission after photoexcitation of metalcluster dianions. New J Phys 14(May):055015/055011-055015/055024. doi:10.1088/13672630/14/5/055015

196. Herlert A, Kruckeberg S, Schweikhard L, Vogel M, Walther C (1999) First observation of doubly charged negative gold cluster ions. Phys Scr T T80B (IX International Conference on the Physics of Highly Charged Ions, 1998):200-202. doi:10.1238/Physica.Topical. 080a00200

197. Schweikhard L, Herlert A, Kruckeberg S, Vogel M, Walther C (1999) Electronic effects in the production of small dianionic gold clusters by electron attachment on to stored $\mathrm{Au}_{\mathrm{n}}{ }^{-}$, $\mathrm{n}=12-28$. Philos Mag B 79(9):1343-1352

198. Herlert A, Kruckeberg S, Schweikhard L, Vogel M, Walther C (2000) Electron impact ionization/dissociation of size selected gold cluster cations. J Electron Spectrosc Relat Phenom 106(2-3):179-186. doi:10.1016/S0368-2048(99)00075-4 
199. Yannouleas C, Landman U, Herlert A, Schweikhard L (2001) Trianionic gold clusters. Eur Phys J D 16(1-3):81-85. doi:10.1007/s100530170065

200. Yannouleas C, Landman U, Herlert A, Schweikhard L (2001) Multiply charged metal cluster anions. Phys Rev Lett 86(14):2996-2999. doi:10.1103/PhysRevLett.86.2996

201. Herlert A, Jertz R, Alonso OJ, Gonzalez MAJ, Schweikhard L (2002) The influence of the trapping potential on the attachment of a second electron to stored metal cluster and fullerene anions. Int J Mass Spectrom 218(3):217-225. doi:10.1016/S1387-3806(02)00723-6

202. Zhang HF, Stender M, Zhang R, Wang C, Li J, Wang LS (2004) Toward the solution synthesis of the tetrahedral $\mathrm{Au}_{20}$ cluster. J Phys Chem B 108(33):12259-12263

203. Li J, Li X, Zhai HJ, Wang LS (2003) Au $\mathrm{Au}_{20}$ : a tetrahedral cluster. Science 299(5608):864-867

204. Pease LF III, Elliott JT, Tsai D-H, Zachariah MR, Tarlov MJ (2008) Determination of protein aggregation with differential mobility analysis: application to IgG antibody. Biotechnol Bioeng 101(6):1214-1222. doi:10.1002/bit.22017

205. Eiceman GA, Karpas Z (2010) Ion mobility spectrometry. 2nd ed. Taylor and Francis, Boca, Florida

206. Lapthorn C, Pullen F, Chowdhry BZ (2013) Ion mobility spectrometry-mass spectrometry (IMS-MS) of small molecules: separating and assigning structures to ions. Mass Spectrom Rev 32(1):43-71. doi:10.1002/mas.21349

207. Weis P (2005) Structure determination of gaseous metal and semi-metal cluster ions by ion mobility spectrometry. Int J Mass Spectrom 245(1-3):1-13. doi:10.1016/j.ijms.2005.06.005

208. Gilb S, Weis P, Furche F, Alhrichs R, Kappes MM (2002) Structures of small gold cluster cations $\left(\mathrm{Au}_{\mathrm{n}}{ }^{+}, \mathrm{n}<14\right)$ : ion mobility measurements versus density functional calculations. J Chem Phys 116(10):4094-4101

209. Furche F, Ahlrichs R, Weis P, Jacob C, Gilb S, Bierweiler T, Kappes MM (2002) The structures of small gold cluster anions as determined by a combination of ion mobility measurements and density functional calculations. J Chem Phys 117(15):6982-6990

210. Lenggoro IW, Xia B, Okuyama K, De la Mora JF (2002) Sizing of colloidal nanoparticles by electrospray and differential mobility analyzer methods. Langmuir 18(12):4584-4591

211. Tsai DH, Pease LF 3rd, Zangmeister RA, Tarlov MJ, Zachariah MR (2009) Aggregation kinetics of colloidal particles measured by gas-phase differential mobility analysis. Langmuir 25(1):140-146. doi:10.1021/la703164j

212. Li M, You R, Mulholland GW, Zachariah MR (2013) Evaluating the mobility of nanorods in electric fields. Aerosol Sci Technol 47(10):1101-1107. doi:10.1080.02786826.2013.819565

213. Tsai D-H, Del RFW, Keene AM, Tyner KM, MacCuspie RI, Cho TJ, Zachariah MR, Hackley VA (2011) Adsorption and conformation of serum albumin protein on gold nanoparticles investigated using dimensional measurements and in situ spectroscopic methods. Langmuir 27(6):2464-2477. doi:10.1021/la104124d

214. Elzey S, Tsai DH, Yu LL, Winchester MR, Kelley ME, Hackley VA (2013) Real-time size discrimination and elemental analysis of gold nanoparticles using ES-DMA coupled to ICP-MS. Anal Bioanal Chem 405(7):2279-2288. doi:10.1007/s00216-012-6617-z

215. Tsai D-H, Cho TJ, Elzey SR, Gigault JC, Hackley VA (2013) Quantitative analysis of dendron-conjugated cisplatin-complexed gold nanoparticles using scanning particle mobility mass spectrometry. Nanoscale 5(12):5390-5395. doi:10.1039/c3nr00543g

216. Angel LA, Majors LT, Dharmaratne AC, Dass A (2010) Ion mobility mass spectrometry of $\mathrm{Au}_{25}\left(\mathrm{SCH}_{2} \mathrm{CH}_{2} \mathrm{Ph}\right)_{18}$ nanoclusters. ACS Nano 4(8):4691-4700

217. Harkness KM, Fenn LS, Cliffel DE, McLean JA (2010) Surface fragmentation of complexes from thiolate protected gold nanoparticles by ion mobility-mass spectrometry. Anal Chem (Washington, DC, U S) 82(7):3061-3066. doi:10.1021/ac100251d

218. Jadzinsky PD, Calero G, Ackerson CJ, Bushnell DA, Kornberg RD (2007) Structure of a thiol monolayer-protected gold nanoparticle at $1.1 \AA$ resolution. Science (Washington, DC, U S) 318(5849):430-433. doi:10.1126/science.1148624

219. Harkness KM, Balinski A, McLean JA, Cliffel DE (2011) Nanoscale phase segregation of mixed thiolates on gold nanoparticles. Angew Chem Int Ed 50(45):10554-10559 
220. Asmis KR, Fielicke A, von Helden G, Meijer G (2007) Chapter 8: Vibrational spectroscopy of gas-phase clusters and complexes. Chem Phys of Solid Surfaces, pp 327-375

221. Lapoutre VJF, Redlich B, van der Meer AFG, Oomens J, Bakker JM, Sweeney A, Mookherjee A, Armentrout PB (2013) Structures of the dehydrogenation products of methane activation by $5 \mathrm{~d}$ transition metal cations. J Phys Chem A 117(20):4115-4126. doi:10.1021/ jp400305k

222. Asmis KR, Wende T, Bruemmer M, Gause O, Santambrogio G, Stanca-Kaposta EC, Doebler J, Niedziela A, Sauer J (2012) Structural variability in transition metal oxide clusters: gas phase vibrational spectroscopy of V3O6-8+. Phys Chem Chem Phys 14(26):9377-9388. doi: $10.1039 / \mathrm{c} 2 \mathrm{cp} 40245 \mathrm{a}$

223. Asmis KR (2012) Structure characterization of metal oxide clusters by vibrational spectroscopy: possibilities and prospects. Phys Chem Chem Phys 14(26):9270-9281. doi:10.1039/ c2cp40762k

224. Ghiringhelli LM, Gruene P, Lyon JT, Rayner DM, Meijer G, Fielicke A, Scheffler M (2013) Not so loosely bound rare gas atoms: finite-temperature vibrational fingerprints of neutral gold-cluster complexes. New J Phys 15(8):083003. doi:10.1088/1367-2630/15/8/083003

225. Gruene P, Rayner DM, Redlich B, van der Meer AFG, Lyon JT, Meijer G, Fielicke A (2008) Structures of neutral $\mathrm{Au}_{7}, \mathrm{Au}_{19}$, and $\mathrm{Au}_{20}$ clusters in the gas phase. Science (Washington, DC, U S) 321(5889):674-676. doi:10.1126/science.1161166

226. Woodham AP, Meijer G, Fielicke A (2013) Charge separation promoted activation of molecular oxygen by neutral gold clusters. J Am Chem Soc 135(5):1727-1730. doi:10. $1021 / \mathrm{ja} 312223 \mathrm{t}$

227. Fielicke A, Von HG, Meijer G, Pedersen DB, Simard B, Rayner DM (2005) Gold cluster carbonyls: saturated adsorption of $\mathrm{CO}$ on gold cluster cations, vibrational spectroscopy, and implications for their structures. J Am Chem Soc 127(23):8416-8423. doi:10.1021/ ja0509230

228. Donald WA, O'Hair RAJ (2012) Shapeshifting: ligation by 1,4-cyclohexadiene induces a structural change in $\mathrm{Ag}^{5+}$. Dalton Trans 41(11):3185-3193. doi:10.1039/c2dt11876a

229. Manard MJ, Kemper PR, Bowers MT (2005) Probing the structure of gas-phase metallic clusters via ligation energetics: sequential addition of $\mathrm{C}_{2} \mathrm{H}_{4}$ to $\mathrm{Ag}_{\mathrm{m}}{ }^{+}(\mathrm{m}=3-7)$. $\mathrm{J}$ Am Chem Soc 127(28):9994-9995. doi:10.1021/ja052251j

230. Rousseau R, Dietrich G, Kruckeberg S, Lutzenkirchen K, Marx D, Schweikhard L, Walther C (1998) Probing cluster structures with sensor molecules: methanol adsorbed onto gold clusters. Chem Phys Lett 295(1,2):41-46. doi:10.1016/S0009-2614(98)00926-9

231. Fielicke A, von Helden G, Meijer G, Simard B, Rayner DM (2005) Direct observation of size dependent activation of NO on gold clusters. Phys Chem Chem Phys 7(23):3906-3909. doi:10.1039/b511710k

232. Woodham AP, Meijer G, Fielicke A (2012) Activation of molecular oxygen by anionic gold clusters. Angew Chem Int Ed 51(18):4444-4447

233. Collings BA, Athanassenas K, Lacombe D, Rayner DM, Hackett PA (1994) Optical absorption spectra of $\mathrm{Au}_{7}, \mathrm{Au}_{9}, \mathrm{Au}_{11}$, and $\mathrm{Au}_{13}$, and their cations: gold clusters with 6, 7, 8, 9, 10, 11, 12, and 13 s-electrons. J Chem Phys 101(5):3506-3513. doi:10.1063.1.4675.5

234. Hamouda R, Bellina B, Bertorelle F, Compagnon I, Antoine R, Broyer M, Rayane D, Dugourd P (2010) Electron emission of gas-phase $\left[\mathrm{Au}_{25}(\mathrm{SG}) 18-6 \mathrm{H}\right]_{7}-$ gold cluster and its action spectroscopy. J Phys Chem Lett 1(21):3189-3194. doi:10.1021/jz101287m

235. Schooss D, Weis P, Hampe O, Kappes MM (2010) Determining the size-dependent structure of ligand-free gold-cluster ions. Philos Trans R Soc A 368(1915):1211-1243. doi:10.1098/ rsta.2009.0269

236. Xing X, Yoon B, Landman U, Parks JH (2006) Structural evolution of Au nanoclusters: from planar to cage to tubular motifs. Phys Rev B Condens Matter Mater Phys 74(16):165423/ 165421-165423/165426. doi:10.1103/PhysRevB.74.165423

237. Johansson MP, Lechtken A, Schooss D, Kappes MM, Furche F (2008) 2D-3D transition of gold cluster anions resolved. Phys Rev A At Mol Opt Phys 77(5):058202 
238. Taylor KJ, Pettiette-Hall CL, Cheshnovsky O, Smalley RE (1992) Ultraviolet photoelectron spectra of coinage metal clusters. J Chem Phys 96(4):3319-3329

239. Wang LM, Wang LS (2012) Probing the electronic properties and structural evolution of anionic gold clusters in the gas phase. Nanoscale 4(14):4038-4053

240. Häkkinen H, Yoon B, Landman U, Li X, Zhai HJ, Wang LS (2003) On the electronic and atomic structures of small $\mathrm{AuN}-(\mathrm{N}=4-14)$ clusters: a photoelectron spectroscopy and density-functional study. J Phys Chem A 107(32):6168-6175

241. Huang W, Wang LS (2009) Au10: isomerism and structure-dependent $\mathrm{O}_{2}$ reactivity. Phys Chem Chem Phys 11(15):2663-2667. doi:10.1039/b823159a

242. Stolcic D, Fischer M, Gantefoer G, Kim YD, Sun Q, Jena P (2003) Direct observation of key reaction intermediates on gold clusters. J Am Chem Soc 125(10):2848-2849. doi:10.1021/ ja0293406

243. Huang W, Zhai HJ, Wang LS (2010) Probing the interactions of $\mathrm{O}_{2}$ with small gold cluster anions $\left(\mathrm{Au}_{\mathrm{n}}{ }^{-}, \mathrm{n}=1-7\right)$ : chemisorption vs physisorption. J Am Chem Soc 132(12): 4344-4351

244. Pal R, Wang L-M, Huang W, Wang L-S, Zeng XC (2011) Structure evolution of gold cluster anions between the planar and cage structures by isoelectronic substitution: $\mathrm{Au}_{\mathrm{n}}-$ $(\mathrm{n}=13-15)$ and $\mathrm{MAu}_{\mathrm{n}}-(\mathrm{n}=12-14 ; \mathrm{M}=\mathrm{Ag}, \mathrm{Cu})$. J Chem Phys 134(5):054306. 10.1063.1.35334.3

245. Bulusu S, Li X, Wang LS, Zeng XC (2006) Evidence of hollow golden cages. Proc Natl Acad Sci U S A 103(22):8326-8330

246. Zhu M, Qian H, Jin R (2009) Thiolate-protected $\mathrm{Au}_{20}$ clusters with a large energy gap of 2.1 eV. J Am Chem Soc 131(21):7220-7221. doi:10.1021/ja902208h

247. Bulusu S, Li X, Wang LS, Zeng XC (2007) Structural transitions from pyramidal to fused planar to tubular to core/shell compact in gold clusters: $\mathrm{Au}_{\mathrm{n}}{ }^{-}(\mathrm{n}=21-25)$. J Phys Chem C 111(11):4190-4198

248. Ji M, Gu X, Li X, Gong X, Li J, Wang L-S (2005) Experimental and theoretical investigation of the electronic and geometrical structures of the $\mathrm{Au}_{32}$ cluster. Angew Chem Int $\mathrm{Ed}$ 44(43): 7119-7123. doi:10.1002/anie.200502795

249. Gu X, Bulusu S, Li X, Zeng XC, Li J, Gong XG, Wang LS (2007) $\mathrm{Au}_{34}$ : a fluxional core-shell cluster. J Phys Chem C 111(23):8228-8232

250. Kebarle P (1992) Ion molecule equilibria, how and why. J Am Soc Mass Spectrom 3(1):1-9. doi:10.1016/1044-0305(92)85012-9

251. Kebarle $P$ (2000) Gas phase ion thermochemistry based on ion-equilibria from the ionosphere to the reactive centers of enzymes. Int J Mass Spectrom 200(1-3):313-330. doi:10.1016/ S1387-3806(00)00326-2

252. Peschke M, Blades AT, Kebarle P (2001) Determination of sequential metal ion-ligand binding energies by gas phase equilibria and theoretical calculations: application of results to biochemical processes. Adv Met Semicond Clusters 5 (Metal Ion Solvation and MetalLigand Interactions):77-119

253. Armentrout PB (2003) Guided ion beam studies of transition metal-ligand thermochemistry. Int J Mass Spectrom 227(3):289-302

254. Armentrout PB (2003) Threshold collision-induced dissociations for the determination of accurate gas-phase binding energies and reaction barriers. Top Curr Chem (Modern Mass Spectrometry) 225:233-262. doi:10.1007/b10468

255. Rodgers MT (2004) Armentrout PB gas phase coordination chemistry. Elsevier, Oxford, UK, pp 141-158, 141 plate. doi:10.1016/B0-08-043748-6/01119-1

256. Armentrout PB (2003) The thermochemistry of adsorbates on transition metal cluster ions: relationship to bulk-phase properties. Eur J Mass Spectrom 9(6):531-538. doi:10.1255/ejms.585

257. Armentrout PB (2010) Reactivity and thermochemistry of transition metal cluster cations. Elsevier, Amsterdam, Netherland, pp 269-297. doi:10.1016/B978-0-444-53440-8.00006-9

258. Li F, Hinton CS, Citir M, Liu F, Armentrout PB (2011) Guided ion beam and theoretical study of the reactions of $\mathrm{Au}^{+}$with $\mathrm{H}_{2}, \mathrm{D}_{2}$, and HD. J Chem Phys 134(2):024310 
259. Li FX, Gorham K, Armentrout PB (2010) Oxidation of atomic gold ions: thermochemistry for the activation of $\mathrm{O}_{2}$ and $\mathrm{N}_{2} \mathrm{O}$ by $\mathrm{Au}^{+}(1 \mathrm{~S}$ 0and 3D). J Phys Chem A 114(42):11043-11052

260. Li FX, Armentrout PB (2006) Activation of methane by gold cations: guided ion beam and theoretical studies. J Chem Phys 125(13):188114

261. Schwarz H (2003) Relativistic effects in gas-phase ion chemistry: an experimentalist's view. Angew Chem Int Ed 42(37):4442-4454

262. Schroeder D, Schwarz H, Hrusak J, Pyykkoe P (1998) Cationic gold(I) complexes of xenon and of ligands containing the donor atoms oxygen, nitrogen, phosphorus, and sulfur. Inorg Chem 37(4):624-632. doi:10.1021/IC970986M

263. Neumaier M, Weigend F, Hampe O, Kappes MM (2005) Binding energies of CO on gold cluster cations $\mathrm{Au}_{\mathrm{n}}{ }^{+}(\mathrm{n}=1-65)$ : a radiative association kinetics study. J Chem Phys 122(10): 104702

264. Neumaier M, Weigend F, Hampe O, Kappes MM (2006) Reactions of mixed silver-gold cluster cations AgmAu $n+(m+n=4,5,6)$ with $C O$ : Radiative association kinetics and density functional theory computations. J Chem Phys 125(10):104308

265. Lang SM, Bernhardt TM, Barnett RN, Landman U (2010) Size-dependent binding energies of methane to small gold clusters. ChemPhysChem 11(7):1570-1577

266. Popolan DM, Nössler M, Mitrić R, Bernhardt TM, Bonačić-Koutecký V (2011) Tuning cluster reactivity by charge state and composition: experimental and theoretical investigation of CO binding energies to Ag nAu m +/- $(n+m=3)$. J Phys Chem A 115(6):951-959

267. Popolan DM, Nößler M, Mitrić R, Bernhardt TM, Bonaić-Koutecký V (2010) Composition dependent adsorption of multiple $\mathrm{CO}$ molecules on binary silver-gold clusters $\mathrm{Ag}_{\mathrm{n}} \mathrm{Au}_{\mathrm{m}}{ }^{+}$ $(n+m=5)$ : theory and experiment. Phys Chem Chem Phys 12(28):7865-7873

268. Bernhardt TM, Hagen J, Lang SM, Popolan DM, Socaciu-Siebert LD, Wöste L (2009) Binding energies of $\mathrm{O}_{2}$ and $\mathrm{CO}$ to small gold, silver, and binary silver-gold cluster anions from temperature dependent reaction kinetics measurements. J Phys Chem A 113(12):2724-2733

269. Cox DM, Brickman R, Creegan K, Kaldor A (1991) Gold clusters: reactions and deuterium uptake. Z Phys D At Mol Clusters 19(1-4):353-355. doi:10.1007/BF01448327

270. Lian L, Hackett PA, Rayner DM (1993) Relativistic effects in reactions of the coinage metal dimers in the gas phase. J Chem Phys 99(4):2583-2590. doi:10.1063.1.4652.1

271. Lang SM, Bernhardt TM, Barnett RN, Yoon B, Landman U (2009) Hydrogen-promoted oxygen activation by free gold cluster cations. J Am Chem Soc 131(25):8939-8951. doi:10. 1021/ja9022368

272. Dietrich G, Luetzenkirchen K, Becker S, Hasse HU, Kluge HJ, Lindinger M, Schweikhard L, Ziegler J, Kuznetsov S (1994) $\mathrm{Au}_{\mathrm{n}}{ }^{+}$-induced decomposition of $\mathrm{N}_{2} \mathrm{O}$. Ber Bunsen Ges 98(12): 1608-1612

273. Lee TH, Ervin KM (1994) Reactions of copper group cluster anions with oxygen and carbon monoxide. J Phys Chem 98(40):10023-10031

274. Cox DM, Brickman RO, Creegan K, Kaldor A (1991) Studies of the chemical properties of size selected metal clusters: kinetics and saturation. Mater Res Soc Symp Proc (Clusters Cluster-Assem Mater) 206:43-48

275. Salisbury BE, Wallace WT, Whetten RL (2000) Low-temperature activation of molecular oxygen by gold clusters: a stoichiometric process correlated to electron affinity. Chem Phys 262(1):131-141. doi:10.1016/S0301-0104(00)00272-X

276. Wallace WT, Whetten RL (2002) Coadsorption of $\mathrm{CO}$ and $\mathrm{O}_{2}$ on selected gold clusters: evidence for efficient room-temperature $\mathrm{CO}_{2}$ generation. $\mathrm{J}$ Am Chem Soc 124(25): 7499-7505. doi:10.1021/ja0175439

277. Su T, Chesnavich WJ (1982) Parametrization of the ion-polar molecule collision rate constant by trajectory calculations. J Chem Phys 76(10):5183-5185. doi:10.1063.1.4428.8

278. Wallace WT, Wyrwas RB, Leavitt AJ, Whetten RL (2005) Adsorption of carbon monoxide on smaller gold-cluster anions in an atmospheric-pressure flow-reactor: temperature and humidity dependence. Phys Chem Chem Phys 7(5):930-937. doi:10.1039/b500398a 
279. Wallace WT, Whetten RL (2001) Metastability of gold-carbonyl cluster complexes, AuN(CO)M. Eur Phys J D 16(1-3):123-126. doi:10.1007/s100530170075

280. Wallace WT, Whetten RL (2000) Carbon monoxide adsorption on selected gold clusters. Highly size-dependent activity and saturation compositions. J Phys Chem B 104(47): 10964-10968. doi:10.1021/jp002889b

281. Lang SM, Bernhardt TM (2009) Cooperative and competitive coadsorption of $\mathrm{H}_{2}, \mathrm{O}_{2}$, and $\mathrm{N}_{2}$ on $\operatorname{Au}_{\mathrm{x}}{ }^{+}(\mathrm{x}=3,5)$. J Chem Phys 131(2):024310/024311-024310/024318. doi:10.1063.1.31683.6

282. Koszinowski K, Schroeder D, Schwarz H (2004) C-N coupling of methane and ammonia by bimetallic platinum-gold cluster cations. Organometallics 23(5):1132-1139. doi:10.1021/ om0306675

283. Höckendorf RF, Cao Y, Beyer MK (2010) Gas-phase ion chemistry of small gold cluster anions. Organometallics 29(13):3001-3006. doi:10.1021/om100228y

284. Lang SM, Bernhardt TM (2009) Reactions of small gold cluster cations with propylene, methane, and hydrogen: permissive and competitive coadsorption effects. Eur Phys J D 52 (1-3):139-142. doi:10.1140/epjd/e2009-00070-4

285. Lang SM, Bernhardt TM (2009) Reactions of free gold cluster cations with $\mathrm{H}_{2} \mathrm{O}, \mathrm{CH}_{3} \mathrm{Cl}$, and mixtures thereof. Int J Mass Spectrom 286(1):39-41. doi:10.1016/j.ijms.2009.06.005

286. Popolan DM, Bernhardt TM (2011) Interaction of gold and silver cluster cations with CH3Br: thermal and photoinduced reaction pathways. Eur Phys J D 63(2):251-254. doi:10.1140/epjd/ e2010-10588-9

287. Popolan DM, Bernhardt TM (2011) Communication: CO oxidation by silver and gold cluster cations: identification of different active oxygen species. J Chem Phys 134(9):091102/ 091101-091102/091103

288. Haekkinen H, Landman U (2001) Gas-phase catalytic oxidation of $\mathrm{CO}$ by $\mathrm{Au}_{2}$. J Am Chem Soc 123(39):9704-9705. doi:10.1021/ja0165180

289. Lang SM, Bernhardt TM (2011) Methane activation and partial oxidation on free gold and palladium clusters: mechanistic insights into cooperative and highly selective cluster catalysis. Faraday Discuss 152(Gold):337-351. doi:10.1039/c1fd00025j

290. Popolan DM, Bernhardt TM (2009) Formation and femtosecond photodissociation of $\mathrm{Ag}_{\mathrm{n}}{ }^{+}$ and $\mathrm{Au}_{\mathrm{n}}{ }^{+}$complexes with benzene and carbon monoxide. Chem Phys Lett 470(1-3):44-48

291. Robinson PSD, Khairallah GN, da Silva G, Lioe H, O'Hair RAJ (2012) Gold Mediated C-I Bond Activation of Iodobenzene Angew Chem Int Ed 51:3812-3817

292. Gõmez-Suárez A, Nolan SP (2012) Dinuclear gold catalysis: are two gold centers better than one? Angew Chem Int Ed 51(33):8156-8159

293. Raubenheimer HG, Schmidbaur H (2012) Gold chemistry guided by the isolobality concept. Organometallics 31(7):2507-2522

294. Hoffmann R (1982) Building bridges between inorganic and organic chemistry. Prix Nobel 173-205

295. Khairallah GN, O'Hair RAJ, Bruce MI (2006) Gas-phase synthesis and reactivity of binuclear gold hydride cations, $\left(\mathrm{R}_{3} \mathrm{PAu}\right) 2 \mathrm{H}^{+}(\mathrm{R}=\mathrm{Me}$ and $\mathrm{Ph})$. Dalton Trans 30:3699-3707

296. Robilotto TJ, Bacsa J, Gray TG, Sadighi JP (2012) Synthesis of a trigold monocation: an isolobal analogue of $\left[\mathrm{H}_{3}\right]^{+}$. Angew Chem Int Ed 51(48):12077-12080

297. Thomson JJ (1913) Bakerian lecture: rays of positive electricity. Proc Royal Soc Lond Ser A 89(607):1-20. doi:10.1098/rspa.1913.0057

298. Herbst E, Moller S, Oka T, Watson JKG (eds) (2000) Astronomy, physics and chemistry of $\mathrm{H}_{3}{ }^{+}$. In: Papers of a Discussion Meeting held 9-10 February 2000. Philos Trans R Soc London Ser A 358(1774)]. vol Copyright (C) 2013 American Chemical Society (ACS). All Rights Reserved Royal Society

299. Hashmi ASK (2010) Homogeneous gold catalysis beyond assumptions and proposalscharacterized intermediates. Angew Chem Int Ed 49(31):5232-5241

300. Khairallah GN, O'Hair RAJ (2005) Gas phase synthesis and reactivity of $\mathrm{Ag}_{\mathrm{n}}{ }^{+}$and $\mathrm{Ag}_{\mathrm{n}-1} \mathrm{H}^{+}$ cluster cations. Dalton Trans 16:2702-2712 
301. Blagojevic V, Samad SN, Banu L, Thomas MC, Blanksby SJ, Bohme DK (2011) Mass spectrometric study of the dissociation of Group XI metal complexes with fatty acids and glycerolipids: $\mathrm{Ag}_{2} \mathrm{H}^{+}$and $\mathrm{Cu}_{2} \mathrm{H}^{+}$ion formation in the presence of a double bond. Int $\mathrm{J}$ Mass Spectrom 299(2-3):125-130

302. Khairallah GN, O'Hair RAJ (2005) Gas-phase synthesis of $\left[\mathrm{Ag}_{4} \mathrm{H}\right]^{+}$and its mediation of the C-C coupling of allyl bromide. Angew Chem Int Ed 44(5):728-731. doi:10.1002/anie. 200461328

303. Wallace WT, Wyrwas RB, Whetten RL, Mitric R, Bonacic-Koutecky V (2003) Oxygen adsorption on hydrated gold cluster anions: experiment and theory. J Am Chem Soc 125(27): 8408-8414. doi:10.1021/ja034905z

304. Johnson GE, Mitric R, Bonacic-Koutecky V, Castleman AW (2009) Clusters as model systems for investigating nanoscale oxidation catalysis. Chem Phys Lett 475(1-3):1-9. doi:10.1016/j.cplett.2009.04.003

305. Kimble ML, Castleman AW Jr, Mitric R, Buergel C, Bonacic-Koutecky V (2004) Reactivity of atomic gold anions toward oxygen and the oxidation of CO: experiment and theory. J Am Chem Soc 126(8):2526-2535. doi:10.1021/ja030544b

306. Buergel C, Reilly NM, Johnson GE, Mitric R, Kimble ML, Castleman AW Jr, BonacicKoutecky V (2008) Influence of charge state on the mechanism of CO oxidation on gold clusters. J Am Chem Soc 130(5):1694-1698. doi:10.1021/ja0768542

307. Kimble ML, Moore NA, Johnson GE, Castleman AW Jr, Burgel C, Mitric R, BonacicKoutecky V (2006) Joint experimental and theoretical investigations of the reactivity of $\mathrm{Au}_{2} \mathrm{O}_{\mathrm{n}}{ }^{-}$and $\mathrm{Au}_{3} \mathrm{O}_{\mathrm{n}}{ }^{-}(\mathrm{n}=1-5)$ with carbon monoxide. J Chem Phys 125(20):204311/ 204311-204311/204314. doi:10.1063.1.23710.2

308. Kimble ML, Castleman AW, Buergel C, Bonacic-Koutecky V (2006) Interactions of CO with $\mathrm{Au}_{\mathrm{n}} \mathrm{O}_{\mathrm{m}}{ }^{-}(\mathrm{n} \geq 4)$. Int J Mass Spectrom 254(3):163-167. doi:10.1016/j.ijms.2006.05.015

309. Kimble ML, Moore NA, Castleman AW Jr, Buergel C, Mitric R, Bonacic-Koutecky V (2007) Reactivity of anionic gold oxide clusters towards CO: experiment and theory. Eur Phys J D 43 (1-3):205-208. doi:10.1140/epjd/e2007-00119-4

310. Kimble ML, Castleman AW (2004) Gas-phase studies of $\mathrm{Au}_{n} \mathrm{O}_{\mathrm{m}}{ }^{+}$interacting with carbon monoxide. Int J Mass Spectrom 233(1-3):99-101. doi:10.1016/j.ijms.2003.11.018

311. Johnson GE, Reilly NM, Tyo EC, Castleman AW (2008) Gas-phase reactivity of gold oxide cluster cations with CO. J Phys Chem C 112(26):9730-9736. doi:10.1021/jp801514d

312. Tyo EC, Castleman AW Jr, Schröder D, Milko P, Roithova J, Ortega JM, Cinellu MA, Cocco F, Minghetti G (2009) Large effect of a small substitution: competition of dehydration with charge retention and coulomb explosion in gaseous $\left[(\right.$ bipyR $) \mathrm{Au}(\mu-\mathrm{O}) 2 \mathrm{Au}(\text { bipyR) }]^{2+}$ dications. J Am Chem Soc 131(36):13009-13019

313. Butschke B, Schwarz H (2012) "Rollover" cyclometalation - early history, recent developments, mechanistic insights and application aspects. Chem Sci 3(2):308-326. doi:10.1039/ c1sc00651g

314. Hansmann MM, Rudolph M, Rominger F, Hashmi ASK (2013) Mechanistic switch in dual gold catalysis of diynes: $\mathrm{C}\left(\mathrm{sp}^{3}\right)-\mathrm{H}$ activation through bifurcation-vinylidene versus carbene pathways. Angew Chem Int Ed 52(9):2593-2598. doi:10.1002/anie.201208777

315. Simonneau A, Jaroschik F, Lesage D, Karanik M, Guillot R, Malacria M, Tabet J-C, Goddard J-P, Fensterbank L, Gandon V, Gimbert Y (2011) Tracking gold acetylides in gold(i)-catalyzed cycloisomerization reactions of enynes. Chem Sci 2(12):2417-2422. doi:10.1039/C1SC00478F

316. Roithová J, Janková Š, Jašíková L, Váňa J, Hybelbauerová S (2012) Gold-gold cooperation in the addition of methanol to alkynes. Angew Chem Int Ed 51(33):8378-8382. doi:10.1002/ anie. 201204003

317. Koszinowski K, Schroeder D, Schwarz H (2003) Probing cooperative effects in bimetallic clusters: indications of $\mathrm{C}-\mathrm{N}$ coupling of $\mathrm{CH}_{4}$ and $\mathrm{NH}_{3}$ mediated by the cluster ion $\mathrm{PtAu}^{+}$in the gas phase. J Am Chem Soc 125(13):3676-3677. doi:10.1021/ja029791q 
318. Koszinowski K, Schroder D, Schwarz H (2003) Additivity effects in the reactivities of bimetallic cluster ions $\mathrm{Pt}_{\mathrm{m}} \mathrm{Au}_{\mathrm{n}}{ }^{+}$. ChemPhysChem 4(11):1233-1237

319. Lang SM, Frank A, Bernhardt TM (2013) Composition and size dependent methane dehydrogenation on binary gold-palladium clusters. Int J Mass Spectrom 354-355:365-371. doi:10. 1016/j.ijms.2013.07.014

320. Fleischer I, Popolan DM, Krstić M, Bonačic-Koutecky V, Bernhardt TM (2013) Composition dependent selectivity in the coadsorption of $\mathrm{H}_{2} \mathrm{O}$ and $\mathrm{CO}$ on pure and binary silver-gold clusters. Chem Phys Lett 565:74-79

321. Kappes MM, Staley RH (1981) Gas-phase oxidation catalysis by transition-metal cations. J Am Chem Soc 103(5):1286-1287. doi:10.1021/ja00395a080

322. Schlangen M, Schwarz H (2012) Effects of ligands, cluster size, and charge state in gas-phase catalysis: a happy marriage of experimental and computational studies. Catal Lett 142(11): $1265-1278$

323. Waters T, O'Hair RAJ (2005) Contribution to "The Encyclopedia of Mass Spectrometry". In: Gross ML, Caprioli R (eds in Chief) Fundamentals of and applications to organic (and organometallic) compounds, vol 4. Metal ion complexes: formation and reactivity, topic: "Organometallic Catalysis in the Gas Phase", Chap 6. (Nibbering, N.M.M. Ed. ISBN: 0-08-043846-6), Elsevier, Amsterdam

324. Hagen J, Socaciu LD, Elijazyfer M, Heiz U, Bernhardt TM, Woeste L (2002) Coadsorption of $\mathrm{CO}$ and $\mathrm{O}_{2}$ on small free gold cluster anions at cryogenic temperatures: model complexes for catalytic CO oxidation. Phys Chem Chem Phys 4(10):1707-1709. doi:10.1039/b201236g

325. Socaciu LD, Hagen J, Bernhardt TM, Woste L, Heiz U, Hakkinen H, Landman U (2003) Catalytic $\mathrm{CO}$ oxidation by free $\mathrm{Au}_{2}$ : experiment and theory. J Am Chem Soc 125(34): $10437-10445$

326. Lang SM, Bernhardt TM, Barnett RN, Landman U (2010) Methane activation and catalytic ethylene formation on free $\mathrm{Au}_{2}^{+}$. Angew Chem Int Ed 49(5):980-983. doi:10.1002/anie. 200905643

327. Lang SM, Bernhardt TM, Barnett RN, Landman U (2011) Temperature-tunable selective methane catalysis on $\mathrm{Au}_{2}{ }^{+}$: from cryogenic partial oxidation yielding formaldehyde to cold ethylene production. J Phys Chem C 115(14):6788-6795. doi:10.1021/jp200160r

328. Rohlfing EA, Cox DM, Kaldor A (1984) Production and characterization of supersonic carbon cluster beams. J Chem Phys 81(7):3322-3330. doi:10.1063.1.4479.4

329. Kroto HW, Heath JR, O'Brien SC, Curl RF, Smalley RE (1985) $\mathrm{C}_{60}$ : buckminsterfullerene. Nature (London) 318(6042):162-163. doi:10.1038.3181.2.0

330. Kraetschmer W, Lamb LD, Fostiropoulos K, Huffman DR (1990) Solid C 60 : a new form of carbon. Nature (London) 347(6291):354-358. doi:10.1038.3473.4.0

331. Bates PA, Waters JM (1985) The crystal and molecular structure of dichloro-1,2-bis (diphenylphosphino)ethanedigold(I). Inorg Chim Acta 98(2):125-129

332. Brandys MC, Jennings MC, Puddephatt RJ (2000) Luminescent gold(i) macrocycles with diphosphine and 4,4'-bipyridyl ligands. J Chem Soc Dalton Trans 24:4601-4606

333. Parkins WE (2005) The uranium bomb, the calutron, and the space-charge problem. Phys Today 58(5):45-51. doi:10.1063.1.19957.7

334. Cyriac J, Pradeep T, Kang H, Souda R, Cooks RG (2012) Low-energy ionic collisions at molecular solids. Chem Rev (Washington, DC, US) 112(10):5356-5411. doi:10.1021/ cr200384k

335. Johnson GE, Hu Q, Laskin J (2011) Soft landing of complex molecules on surfaces. Ann Rev Anal Chem 83-104

336. Baer DR, Engelhard MH, Johnson GE, Laskin J, Lai J, Mueller K, Munusamy P, Thevuthasan S, Wang H, Washton N, Elder A, Baisch BL, Karakoti A, Kuchibhatla SVNT, Moon D (2013) Surface characterization of nanomaterials and nanoparticles: important needs and challenging opportunities. J Vac Sci Technol A 31(5):050820/050821-050820/050834. doi:10.1116.1.48184.3 
337. Thune E, Carpene E, Sauthoff K, Seibt M, Reinke P (2005) Gold nanoclusters on amorphous carbon synthesized by ion-beam deposition. J Appl Phys 98(3):034304/034301-034304/ 034309. doi:10.1063.1.19859.7

338. DiCenzo SB, Berry SD, Hartford EH Jr (1988) Photoelectron spectroscopy of single-size Au clusters collected on a substrate. Phys Rev B 38(12):8465-8468

339. Perez A, Melinon P, Dupuis V, Jensen P, Prevel B, Tuaillon J, Bardotti L, Martet C, Treilleux M, Broyer M, Pellarin M, Vaille JL, Palpant B, Lerme J (1997) Cluster assembled materials: a novel class of nanostructured solids with original structures and properties. J Phys D Appl Phys 30(5):709-721. doi:10.1088/0022-3727/30/5/003

340. Bardotti L, Prevel B, Melinon P, Perez A, Hou Q, Hou M (2000) Deposition of AuN clusters on $\mathrm{Au}(111)$ surfaces. II. Experimental results and comparison with simulations. Phys Rev B Condens Matter Mater Phys 62(4):2835-2842

341. Tong X, Benz L, Kemper P, Metiu H, Bowers MT, Buratto SK (2005) Intact size-selected Aun clusters on $\mathrm{a} \mathrm{TiO}_{2}(110)-(1 \mu \mathrm{e} 1)$ surface at room temperature. J Am Chem Soc 127(39): 13516-13518. doi:10.1021/ja052778w

342. Vajda S, Winans RE, Elam JW, Lee B, Pellin MJ, Seifert S, Tikhonov GY, Tomczyk NA (2006) Supported gold clusters and cluster-based nanomaterials: characterization, stability and growth studies by in situ GISAXS under vacuum conditions and in the presence of hydrogen. Top Catal 39(3-4):161-166. doi:10.1007/s11244-006-0052-3

343. DiVece M, Young NP, Li Z, Chen Y, Palmer RE (2006) Co-deposition of atomic clusters of different size and composition. Small 2(11):1270-1272. doi:10.1002/smll.200600065

344. Bardotti L, Tournus F, Melinon P, Pellarin M, Broyer M (2011) Mass-selected clusters deposited on graphite. Spontaneous organization controlled by cluster surface reaction. Phys Rev B Condens Matter Mater Phys 83(3):035425/035421-035425/035428. doi:10. 1103/PhysRevB.83.035425

345. Johnson GE, Priest T, Laskin J (2012) Charge retention by gold clusters on surfaces prepared using soft landing of mass selected ions. ACS Nano 6(1):573-582. doi:10.1021/nn2039565

346. Johnson GE, Priest T, Laskin J (2012) Coverage-dependent charge reduction of cationic gold clusters on surfaces prepared using soft landing of mass-selected ions. J Phys Chem C 116 (47):24977-24986

347. Cox DM, Eberhardt W, Fayet P, Fu Z, Kessler B, Sherwood RD, Sondericker D, Kaldor A (1991) Electronic structure of deposited monosized metal-clusters. Z Phys D At Mol Clusters 20(1-4):385-386. doi:10.1007/BF01544017

348. Heiz U, Bullock EL (2004) Fundamental aspects of catalysis on supported metal clusters. J Mater Chem 14(4):564-577. doi:10.1039/b313560h

349. Sanchez A, Abbet S, Heiz U, Schneider WD, Häkkinen H, Barnett RN, Landman U (1999) When gold is not noble: nanoscale gold catalysts. J Phys Chem A 103(48):9573-9578

350. Heiz U, Sanchez A, Abbet S, Schneider WD (2000) Tuning the oxidation of carbon monoxide using nanoassembled model catalysts. Chem Phys 262(1):189-200. doi:10.1016/S0301-0104 (00)00268-8

351. Lee S, Fan C, Wu T, Anderson SL (2004) CO oxidation on Aun/ $/ \mathrm{TiO}_{2}$ catalysts produced by size-selected cluster deposition. J Am Chem Soc 126(18):5682-5683. doi:10.1021/ja049436v

352. Yoon B, Haekkinen H, Landman U, Woerz AS, Antonietti J-M, Abbet S, Judai K, Heiz U (2005) Charging effects on bonding and catalyzed oxidation of $\mathrm{CO}$ on $\mathrm{Au}_{8}$ clusters on $\mathrm{MgO}$. Science (Washington, DC, U S) 307(5708):403-407. doi:10.1126/science.1104168

353. Leung C, Xirouchaki C, Berovic N, Palmer RE (2004) Immobilization of protein molecules by size-selected metal clusters on surfaces. Adv Mater (Weinheim, Ger) 16(3):223-226. doi:10.1002/adma.200305756

354. Lim DC, Dietsche R, Bubek M, Ketterer T, Ganteför G, Kim YD (2007) Chemistry of massselected Au clusters deposited on sputter-damaged HOPG surfaces: the unique properties of $\mathrm{Au}_{8}$ clusters. Chem Phys Lett 439(4-6):364-368

355. Lim DC, Dietsche R, Bubek M, Gantefor G, Kim YD (2006) Oxidation and reduction of mass-selected Au clusters on $\mathrm{SiO}_{2} / \mathrm{Si}$. ChemPhysChem 7(9):1909-1911 
356. Lim DC, Dietsche R, Ganteför G, Kim YD (2008) Chemical properties of size-selected Au clusters treated under ambient conditions. Chem Phys Lett 457(4-6):391-395

357. Lee S, Molina LM, Lopez M, Alonso JA, Hammer B, Lee B, Seifert S, Winans RE, Elam JW, Pellin MJ, Vajda S (2009) Selective propene epoxidation on immobilized $\mathrm{Au}_{6-10}$ clusters: the effect of hydrogen and water on activity and selectivity. Angew Chem Int Ed 48(8): 1467-1471. doi:10.1002/anie.200804154, S1467/1461-S1467/1462

358. Harding C, Habibpour V, Kunz S, Farnbacher AN-S, Heiz U, Yoon B, Landman U (2009) Control and manipulation of gold nanocatalysis: effects of metal oxide support thickness and composition. J Am Chem Soc 131(2):538-548. doi:10.1021/ja804893b

359. Binns C (2001) Nanoclusters deposited on surfaces. Surf Sci Rep 44(1-2):1-49. doi:10.1016/ S0167-5729(01)00015-2

360. Zhang Y, Hu Q, Paau MC, Xie S, Gao P, Wan C, Choi MMF (2013) Probing histidinestabilized gold nanoclusters product by high-performance liquid chromatography and mass spectrometry. J Phys Chem C 117(36):18697-18708

361. Chen J, Zhang Q-F, Bonaccorso TA, Williard PG, Wang L-S (2014) Controlling gold nanoclusters by diphosphine ligands. J Am Chem Soc 136(1):92-95

362. Knoppe S, Buergi T (2013) The fate of Au25(SR)18 clusters upon ligand exchange with binaphthyl-dithiol: interstaple binding vs. decomposition. Phys Chem Chem Phys 15(38): $15816-15820$

363. Johnson GE, Priest T, Laskin J (2013) Synthesis and characterization of gold clusters ligated with 1,3-bis(dicyclohexylphosphino)propane. ChemPlusChem 78(9):1033-1039

364. Lavenn C, Albrieux F, Tuel A, Demessence A (2014) Synthesis, characterization and optical properties of an amino-functionalized gold thiolate cluster: $\mathrm{Au}_{10}\left(\mathrm{SPh}-p \mathrm{NH}_{2}\right)_{10}$. J Colloid Interface Sci 418:234

365. Crasto D, Dass A (2014) Green gold: $\mathrm{Au}_{30}\left(\mathrm{~S}-t-\mathrm{C}_{4} \mathrm{H}_{9}\right)_{18}$. J Phys Chem C 117(42): 22094-22097

366. Havel J, Pena-Mendez EM, Amato F, Panyala NR, Bursikova V (2014) Laser ablation synthesis of new gold carbides. From gold-diamond nano-composite as a precursor to golddoped diamonds. Time-of-flight mass spectrometric study. Rapid Commun Mass Spectrom 28(3):297-304

367. Prokes L, Pena-Mendez EM, Conde JE, Panyala NR, Alberti M, Havel J (2014) Laser ablation synthesis of new gold arsenides using nano-gold and arsenic as precursors. Laser desorption ionisation time-of-flight mass spectrometry and spectrophotometry. Rapid Commun Mass Spectrom 28(6):577-586

368. Baksi A, Pradeep T (2013) Noble metal alloy clusters in the gas phase derived from protein templates: unusual recognition of palladium by gold. Nanoscale 5(24):12245-12254

369. Shao N, Huang W, Mei W, Wang L-S, Wu Q, Zeng XC (2014) Structural evolution of medium-sized gold clusters $\mathrm{Au}_{n}{ }^{-}(n=36,37,38)$ : appearance of bulk-like FCC fragment. J Phys Chem C. doi:10.1021/jp500582t

370. Jasikova L, Roithova J (2013) Interaction of gold acetylides with Gold(I) or Silver(I) cations. Organometallics 32(23):7025-7033

371. Lang SM, Frank A, Bernhardt TM (2013) Comparison of methane activation and catalytic ethylene formation on free gold and palladium dimer cations: product binding determines the catalytic turnover. Cat Sci Tech 3(11):2926-2933

372. Pettibone JM, Osborn WA, Rykaczewski K, Talin AA, Bonevich JE, Hudgens JW, Allendorf MD (2013) Surface mediated assembly of small, metastable gold nanoclusters. Nanoscale 5(14):6558-6566 


\section{University Library}

\section{- $\mathrm{M}$ IIN E R VA A gateway to Melbourne's research publications}

Minerva Access is the Institutional Repository of The University of Melbourne

Author/s:

Zavras, A;Khairallah, GN;O'Hair, RAJ

Title:

Gas Phase Formation, Structure and Reactivity of Gold Cluster lons

Date:

2014-01-01

Citation:

Zavras, A., Khairallah, G. N. \& O'Hair, R. A. J. (2014). Gas Phase Formation, Structure and Reactivity of Gold Cluster lons. Mingos, DMP (Ed.). GOLD CLUSTERS, COLLOIDS AND NANOPARTICLES II, (1), 162, pp.139-+. SPRINGER.

Persistent Link:

http://hdl.handle.net/11343/52435 